

\section{DISCLAIMER}

This report was prepared as an account of work sponsored by an agency of the United States Government. Neither the United States Government nor any agency Thereof, nor any of their employees, makes any warranty, express or implied, or assumes any legal liability or responsibility for the accuracy, completeness, or usefulness of any information, apparatus, product, or process disclosed, or represents that its use would not infringe privately owned rights. Reference herein to any specific commercial product, process, or service by trade name, trademark, manufacturer, or otherwise does not necessarily constitute or imply its endorsement, recommendation, or favoring by the United States Government or any agency thereof. The views and opinions of authors expressed herein do not necessarily state or reflect those of the United States Government or any agency thereof. 


\section{DISCLAIMER}

Portions of this document may be illegible in electronic image products. Images are produced from the best available original document. 
Available from:

National Technical Information Service (NTIS)

U.S. Department of Commerce

5285 Port Royal Road

Springfield, Virginia 22161

$\begin{array}{lll}\text { Price: } & \text { Printed copy: } & \$ 10.75 \\ & \text { Microfiche: } & \$ 3.00\end{array}$

For sale by the Superintendent of Documents, U.S. Government Printing Office

Washington, D.C. 20402

Stock Number 061-000-00133-6 


\title{
National Program Plan for Research and Development in Solar Heating and Cooling for Building, Agricultural, and Industrial Applications
}

\author{
August 1978

\section{U.S. DEPARTMENT OF ENERGY} \\ Assistant Secretary for Conservation \\ and Solar Applications \\ Washington, D.C. 20545
}

$95^{54^{17^{5}}}$

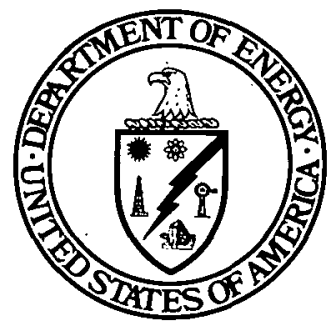

This repon was prepared as an account of work sponsored by the United States Covemment. Neither the

United States nor the United States Department of

Energy, nor any of their employees, nor any of their

Encers,

cony wers, subcontroctors, or the

and express or implied, or assumes any legal

Viability or responsibitity for the accuracy, completeness

or usefulness of any information, apparatus, product or
process disclosed, or represents that jis use would not

infringe privately owned rights. 


\section{FOREWORD}

This report on the Department of Energy (DOE) National Program Plan for Research and Development in Solar Heating and Cooling is a revision and update of an interim report prepared and published by the Research and Development Branch of the Division of Solar Energy of the Energy Research and Development Administration (ERDA).

The interim report (ERDA 76-144, November 1976), based on a draft provided by the Solar Energy Group of the Los Alamos Scientific Laboratory, was the result of a thorough assessment of the status of solar heating and cooling technology. The report described the Federal research and development program for solar heating and cooling, including those activities to be funded in whole or in part by the Federal Covernment. The program plan was compatible with, but more detailed than, ERDA's National Plan for Solar Heating and Cooling (ERDA 76-6).

The interim report was circulated widely for review and comment. The American Society for Heating, Refrigeration, and Air Conditioning Engineers (ASHRAE), the American Society of Mechanical Engineers (ASME), and the Solar Energy Industry Association (SEIA) established special groups to prepare detailed reviews. The present document includes revisions based on an integration of comments from these professional organizations.

In the year since the interim report was released, work has begun on many of the tasks identified. The status of these activities is indicated in this revision. This document also provides an expanded discussion of agricultural and industrial process applications and the specific tasks required for their development.

This R\&D program plan will be updated periodically as results from current research, development, and demonstration projects, both Federally and privately supported, become available.

Frederick H. Morse, Chief

Solar Heating and Cooling

Research and Development Branch,

Department of Energy 
THIS PAGE

\section{WAS INTENTIONALLY \\ LEFT BLANK}




\section{ACKNOWLEDGEMENTS}

The development and production of this Plan was a considerable undertaking which involved many organizations and individuals whose valuable assistance is herein acknowledged.

The interim report (ERDA 76-144) which preceded this document was drafted by the Solar Energy Group of Los Alamos Scientific Laboratory. Dr. J. D. Balcomb and Dr. J. E. Perry, Jr. organized meetings with representatives from industry, universities, and the Government, and developed the building applications portion of the plan into paths, tasks, and milestones. Their work was reviewed by representatives of several other DOE laboratories-Argonne National Laboratory, Brookhaven National Laboratory, and Sandia Laboratory. ERDA Division of Solar Energy Program managers, Dr. J. W. Leech, Dr. S. L. Sargent, and Mr. L. Taylor, supervised this review process, and Dr. S. Schweitzer integrated the comments into a draft interim report. Dr. P. G. Patil of Systems Consultants, Inc. (SCI) worked with ERDA program managers and laboratory representatives to ensure consistency throughout the draft report.

The Interim Report was reviewed by the American Society for Heating, Refrigeration, and Air Conditioning Engineers, the American Society of Mechanical Engineers, and the Solar Energy Industries Association. While this review was under way, Dr. A. Clark and Dr. W. Dickenson of Lawrence Livermore Laboratory organized a meeting on the agricultural and industrial process heat applications of solar energy and drafted that portion of the plan.

Dr. Patil reviewed the comments on the Interim Report, and organized a two-day workshop to achieve a consensus among the DOE laboratory representatives and the Program Managers of the Solar Heating and Cooling R\&D and Agricultural and Industrial Process Heat Branches. The Program Managers responsible for the final content of various portions of the plan included Mr. W. Auer, Mr. M. Davis, Mr. J. Greyerbiehl, Mr. R. LeChevalier, Mr. M. Maybaum, and Dr. S. Sargent; Ms. M. Lydick assisted with this task. Following the workshop, Ms. A. Kailo of SCl edited the final draft of the program plan and coordinated the production of the graphics material and the typed manuscript.

Dr. Frederick H. Morse

August 1978 
c

THIS PAGE

WAS INTENTIONALLY

LEFT BLANK 


\section{TABLE OF CONTENTS}

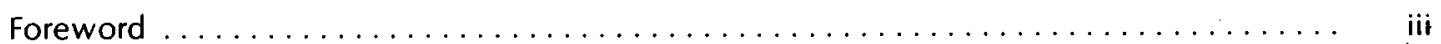

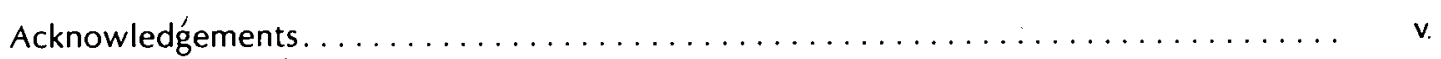

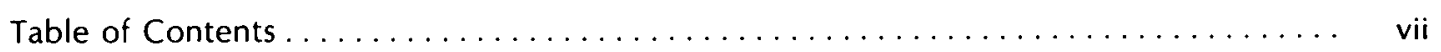

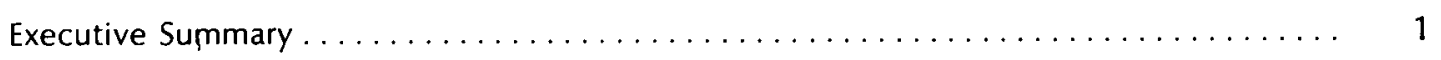

\section{Part I. PLAN}

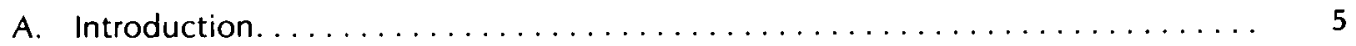

Solar Heating and Cooling Program ...................... 5

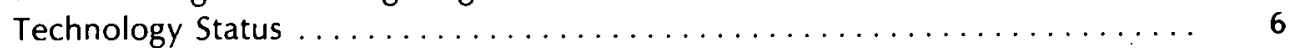

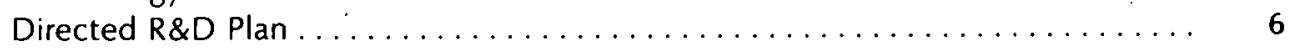

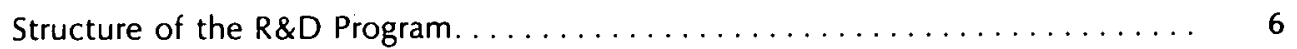

Structure of the R\&D Plan .......................... 8

Implementation........................... 8

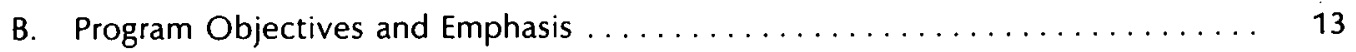

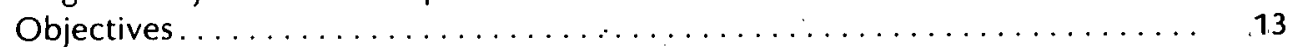

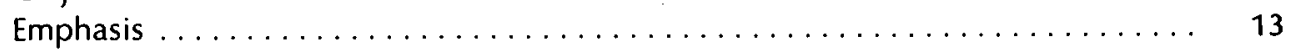

\section{Part II. PATHS}

A. R\&D Program Structure: Heating and Cooling of Buildings ............ 19

Liquid-Heating Collectors for Service Hot Water: Path $W 1 \ldots \ldots \ldots \ldots \ldots \ldots 23$

Air-Heating Collectors for Service Hot Water: Path W2 . . . . . . . . . . 27

Combined Solar and Heat Pump Systems for Space Heating: Path $\mathrm{H} 1 \ldots \ldots \ldots .31$

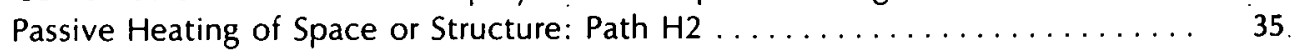

Air-Heating Collectors for Space Heating: Path $\mathrm{H} 3 \ldots \ldots \ldots \ldots \ldots \ldots \ldots . \ldots . \ldots . \ldots . \ldots$

Liquid-Heating Collectors for Space Heating: Path $\mathrm{H} 4 \ldots \ldots \ldots \ldots \ldots \ldots \ldots$.

High Temperature Collectors with Absorption or Heat Engine/Vapor Compression

Chillers for Space Cooling: Path C1 ................... 47

Medium Temperature Collectors with Absorption, Heat Engine/Vapor Compression, or Other Chillers for Space Cooling: Path C2.............. 51

Flat Plate, Advanced, Non-Concentrating Collectors with Desiccant Chiller/Dehumidifier for Space Cooling: Path C3 ................ 55

Passive and Hybrid Cooling: Path C4...................... 59

Combined Solar and Heat Pump Systems for Space Cooling: Path C5 ....... 63

B. R\&D Program Structure: Agricultural and Industrial Process Heat. . . . . . . . . 67

Passive Heating for Shelters and Greenhouses: Path HP .............. 75

Air-Heating Collectors for Shelters and Greenhouses: Path HA ......... 78 
Liquid-Heating Collectors for Shelters and Greenhouses: Path $\mathrm{HL} \ldots \ldots \ldots \ldots$

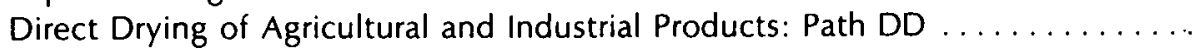

Air-Heating Collectors for Drying: Path DA.

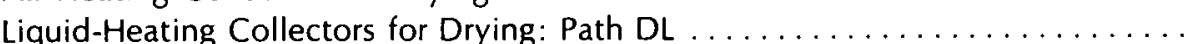

Liquid-Heating Collectors for Process Hot Water: Path WL. . . . . . . . . . .

Air-Heating Collectors for Process Hot Water: Path WA ............... 99

Liquid-Heating Collectors for Process Steam: Path SL . . . . . . . . . . 103

Passive Cooling for Agricultural and Industrial Process Applications: Path CP . . 107

Active Cooling and Refrigeration for Agricultural and Industrial Process Applica-

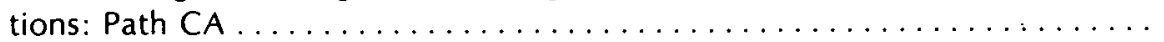

\section{PART III. TASKS}

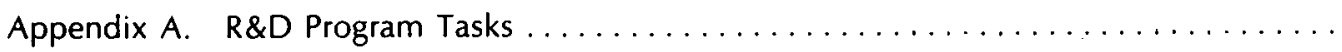

I. Solar Collectors.................................... 121

II. Thermal Energy Storage and Heat Exchange . . . . . . . . . . . . . . . . 165

III. Solar Chillers, Air Conditioners, and Heat Pumps.................. 189

IV. Systems and Controls. .............................. 209

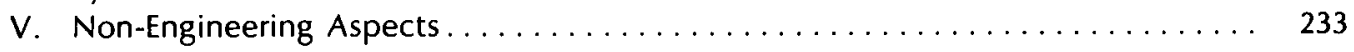

Appendix B. Priorities of Non-Engineering Tasks $\ldots \ldots \ldots \ldots \ldots \ldots \ldots \ldots \ldots \ldots \ldots \ldots$

\section{FIGURES}

\begin{tabular}{|c|c|}
\hline gure & \\
\hline I-1 & Path Diagram Examples \\
\hline $1-2$ & System Analysis Interaction. \\
\hline $11-1$ & aths to Solar Water Heating \\
\hline $\mathrm{II}-2$ & aths to Solar Space Heating. \\
\hline $11-3$ & aths to Solar Space Cooling \\
\hline II-4 & Liquid-Heating Collectors for Service Hot Water: Path W1 Activity Schedule \\
\hline $11-5$ & Liquid-Heating Collectors for Service Hot Water: Path W1 Task Flow Chart \\
\hline II-6 & Air-Heating Collectors for Service Hot Water: Path W2 Activity Schedule... \\
\hline II-7 & Air-Heating Collectors for Service Hot Water: Path W2 Task Flow Chart.... \\
\hline $11-8$ & $\begin{array}{l}\text { Combined Solar and Heat Pump Systems for Space Heating: Path } \mathrm{H} 7 \text { Activity } \\
\text { Schedule } \ldots \ldots \ldots \ldots \ldots \ldots \ldots\end{array}$ \\
\hline $11-9$ & $\begin{array}{l}\text { Combined Solar and Heat Punip Systems for Space Heating: Path } \mathrm{H} \text { T Task Flow } \\
\text { Chart } \ldots \ldots \ldots \ldots \ldots \ldots \ldots \ldots \ldots \ldots \ldots \ldots \ldots \ldots \ldots \ldots \ldots \ldots \ldots \ldots \ldots\end{array}$ \\
\hline-10 & or Structure: Path $\mathrm{H} 2$ Activity Schedule:....... \\
\hline $11-11$ & Passive Heating of Space or Structure: Path H2 Task Flow Chart. \\
\hline $11-12$ & ollectors for Space Heating: Path H3 Activity Schedule. \\
\hline $11-13$ & Air-Heating Collectors for Space Heating: Path H3 Task Flow Chart \\
\hline $11-14$ & Liquid-Heating Collectors for Space Heating: Path H4 Activity Schedule \\
\hline-15 & for Space Heating: Path H4 Tasl \\
\hline $11-16$ & $\begin{array}{l}\text { High Temperature Collectors with Absorption or Heat Engine/Vapor Compression } \\
\text { Chillers for Space Cooling: Path C1 Activity Schedule.................. }\end{array}$ \\
\hline $11-17$ & $\begin{array}{l}\text { High Temperature Collectors with Absorption or Heat Engine/Vapor Compression } \\
\text { Chillers for Space Cooling: Path C1 Task Flow Chart } \ldots \ldots \ldots \ldots \ldots \ldots\end{array}$ \\
\hline $11-18$ & $\begin{array}{l}\text { Medium Temperature Collectors with Absorption, Heat Engine/Vapor Compres- } \\
\text { sion, and other Chillers for Space Cooling: Path C2 Activity Schedule. }\end{array}$ \\
\hline
\end{tabular}


II-19 Medium Temperature Collectors with Absorption, Heat Engine/Vapor Compression and Other Chillers for Space Cooling: Path C2 Task Flow Chart........

II-20 Flat Plate/Advanced, Non-Concentrating Collectors with Desiccant Chiller/Dehumidifier for Space Cooling: Path C3 Activity Schedule .........

II-21 Flat Plate/Advanced, Non-Concentrating Collectors with Desiccant Chiller/Dehumidifier for Space Cooling: Path C3 Task Flow Chart ........ 58

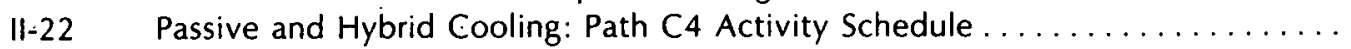

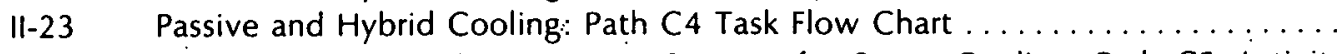

II-24 Combined Solar and Heat Pump Systems for Space Cooling: Path C5 Activity Schedule....

II-25 Combined Solar and Heat Pump Systems for Space Cooling: Path C5 Task Flow

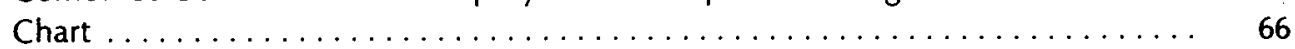

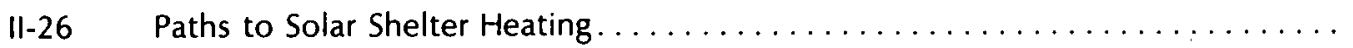

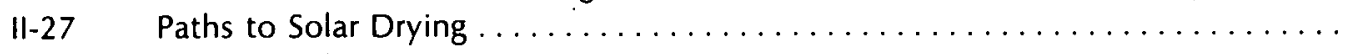

II-28 Paths to Solar Process Hot Water . . . . . . . . . . . . . . . . . . . . . .

II-29 Paths to Solar Process Steam. . . . . . . . . . . . . . . . . . . . . . . . . .

II-30 Paths to Solar Cooling and Refrigeration . . . . . . . . . . . . . . . . .

II-31 Passive Heating for Shelters and Greenhouses: Path HP Activity Schedule......

Il-32 Passive Heating for Shelters and Creenhouses: Path HP Task Flow Chart .......

II-33 Air-Heating Collectors for Shelters and Greenhouses: Path HA Activity Schedule

II-34. Air-Heating Collectors for Shelters and Greenhouses: Path HA Task Flow Chart .

II-35 Liquid-Heating. Collectors for Shelters and Greenhouses:

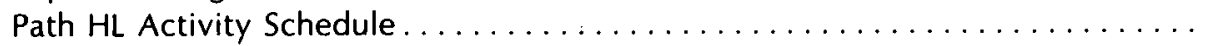
Liquid-Heating Collectors for Shelters and Creenhouses: Path HL Task Flow Chart Direct Drying of Agricultural and Industrial Products: Path DD Activity Schedule Direct Drying of Agricultural and Industrial Products: Path DD Task Flow Chart .

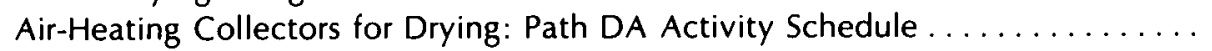

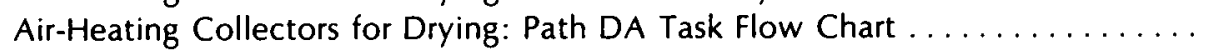
Liquid-Heating Collectors for Drying: Path DL Activity Schedule............ Liquid-Heating Collectors for Drying: Path DL Task Flow Chart ............. Liquid-Heating Collectors for Process Hot Water: Path WL Activity Schedule... Liquid-Heating Collectors for Process Hot Water: Path WL Task Flow Chart .... Air-Heating Collectors for Process Hot Water: Path WA Activity Schedule ..... Air-Heating Collectors for Process Hot Water: Path WA Task Flow Chart . ..... Liquid-Heating Collectors for Process Steam: Path SL Activity Schedule ........ Liquid-Heating Collectors for Process Steam: Path SL Task Flow Chart ......... Passive Cooling for Agricultural and Industrial Process Applications: Path CP AC-

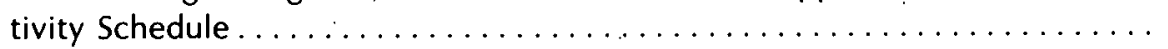

II-50 Passive Cooling for Agricultural and Industrial Process Applications: Path CP Task

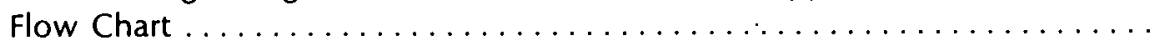

II-51 Active Cooling and Refrigeration for Agricultural and Industrial Process Applica-

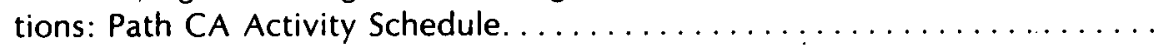

II-52 Active Cooling and Refrigeration for Agricultural and Industrial Process Applica-

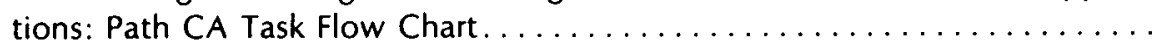

\section{TABLES}

Path Descriptions for Heating and Cooling of Buildings ................ 


\section{EXECUTIVE SUMMARY}

\section{R\&D PROGRAM PLAN}

This report presents the DOE/Conservation and Solar Applications (CS) program plan for research and development in the use of solar energy for heating and cooling and for agricultural and industrial process applications.

The objectives of the DOE solar energy R\&D program are to identify potentially cost-effective systems for building, agricultural, and industrial process heating and cooling applications, and to provide the emerging solar energy industry with the materials, components, information, and methodology needed for designing, producing, and installing these systems. To a significant extent, the application of solar energy for heating and cooling involves components (such as heat pumps, air conditioning machines, and controls) which are used in conventional HVAC systems. The relatively new and rapidly developing solar energy industry is also producing many of the required components. The DOE program builds on this technology and attempts to assist the solar energy industry to accelerate the development of cost-effective components and systems.

As part of the preparation and revision of this program plan, meetings were held with representatives from small business, industry, universities, and the Government. The following conclusions were reached:

- Cost effectiveness is the major problem to be addressed.

- The state of the art varies greatly for different components and applications, with solar cooling technology generally less developed than solar heating.

- Wide variations in applications and climatic zones necessitate careful analysis to determine the most cost-effective approaches.

- Cost-effective retrofit domestic hot water systems are available in certain regions, but retrofit heating and cooling and agricultural and industrial process heat systems are not well developed. Techniques to facilitate optimization of retrofit design are also not readily available.

- Although there are no scientific barriers to the production of steam from solar energy, there are engineering and technoeconomic obstacles which must be overcome.

As a result of these conclusions, a DOE-directed, appliations-oriented R\&D program was initiated. The plan for this directed R\&D program is the subject of the present report. The previous components-oriented $R \& D$ program, which made significant contributions to the present state of technology, is being strengthened by the applications strategy. The directed program, then, is a continuation of the previous program, but with a shift in emphasis.

The main feature of the directed program is the focus on specific approaches, called paths, to the application of solar energy. A path is simply the linking of a method of energy collection or rejection with a particular application. Eleven such paths are identified for building applications and eleven for agricultural and industrial process applications.

The paths described in this report for the solar heating and cooling of buildings are:

- Service hot water (2): liquid-heating collectors, air-heating collectors.

- Space heating (4): combined solar and heat pump systems; passive heating of space or structure; air-heating collectors; liquid-heating collectors.

- Space cooling (5): high temperature collectors with absorption or heat engine/vapor compression chillers; medium temperature collectors with absorption, heat engine/vapor compression, and other chillers; flat plate/advanced, non-concentrating collectors with desiccant chiller/dehumidifier; passive and hybrid cooling; combined solar and heat pump systems. 
The paths for agricultural and industrial applications are:

Shelter heating (3): passive heating; air-heating collectors; liquid-heating collectors.

- Drying (3): direct drying; air-heating collectors; liquid-heating collectors.

- Process Hot Water (2): liquid-heating collectors; air-heating collectors.

- Process Steam (1): liquid-heating collectors.

- Cooling and Refrigeration (2): passive cooling; active cooling and refrigeration.

The 22 heating and cooling/agricultural and industrial paths differ in character. Some require an emphasis on materials development, some on system analysis, and some on component development and testing. In order to move along any of the paths, specific tasks must be undertaken, either in series or in parallel. Approximately 360 tasks have been identified in 5 categories: collectors; storage and heat exchange; chillers, air conditioners, and heat pumps; systems and controls; and non-engineering aspects. Because most of the tasks pertain to more than one path, the paths are interdependent. The importance of each task to a given path is indicated by a number assigned on a 1 (unimportant) to 10 (critical) scale. The tasks for each path are placed in functional categories and arranged in sequence, giving each path a logical development.

In FY 1977, after the distribution of the Interim Report ${ }^{1}$, a series of 11 competitive solicitations was issued by ERDA's Division of Solar Energy. These solicitations called for proposals specifically related to one or more tasks in the directed R\&D plan. With the initiation of the 1.35 projects resulting from these solicitations, as well as those projects already underway, many of the tasks described in this report are under study, either fully or in part. Other tasks will

IInterim Report, National Program Plan for Research and Development in Solar Heating and Cooling, ERDA 76-144, November 1976. This report may be obtained from the Superintendent of Documents, U.S. Covernment Printing Office, Washington, D.C. 20402. begin as indicated in the plan. The balanced involvı ment of industry, universities, small business, an government organizations, which characterized the previous R\&D program, was continued by the new awards.

Since the R\&D program is a part of DOE's total energy program, it has many points of impact on other DOE programs and organizations and on other Federal agencies. Implementation of the R\&D program is being coordinated with the appropriate groups, with special emphasis being placed on integration with the residential and commercial demonstration programs.

The 22 solar heating and cooling paths for building, agricultural, and industrial process applications will be cost effective if key problems can be solved. As technology advances and project results are analyzed, the paths will be evaluated periodically and priorities will be adjusted. Milestone schedules and the emphasis given various tasks will be altered correspondingly.

A final point remains to be made concerning the R\&D program plan. The plan calls for both information dissemination and component development. While major milestones are indicated for each path, it is expected that new components and systems information will be developed throughout the duration of the program.

\section{R\&D PROGRAM REPORT}

The present report is divided into three parts: Plan, Paths, and Tasks. The report is organized to allow a reader to gain an overview of the R\&D program plan without necessarily becoming involved in all of its details.

The Executive Summary and Part I of the report give the overview of the program plan. Part II describes the 11 paths to the solar heating and cooling of buildings and the 11 paths for agricultural and industrial process applications. Part III (the appendices) presents detailed information on the tasks. Appendix $A$ includes brief descriptions of these tasks and of the non-engineering tasks. Appendix $B$ indicates the importance of each non-engineering task to the overall $R \& D$ program. 



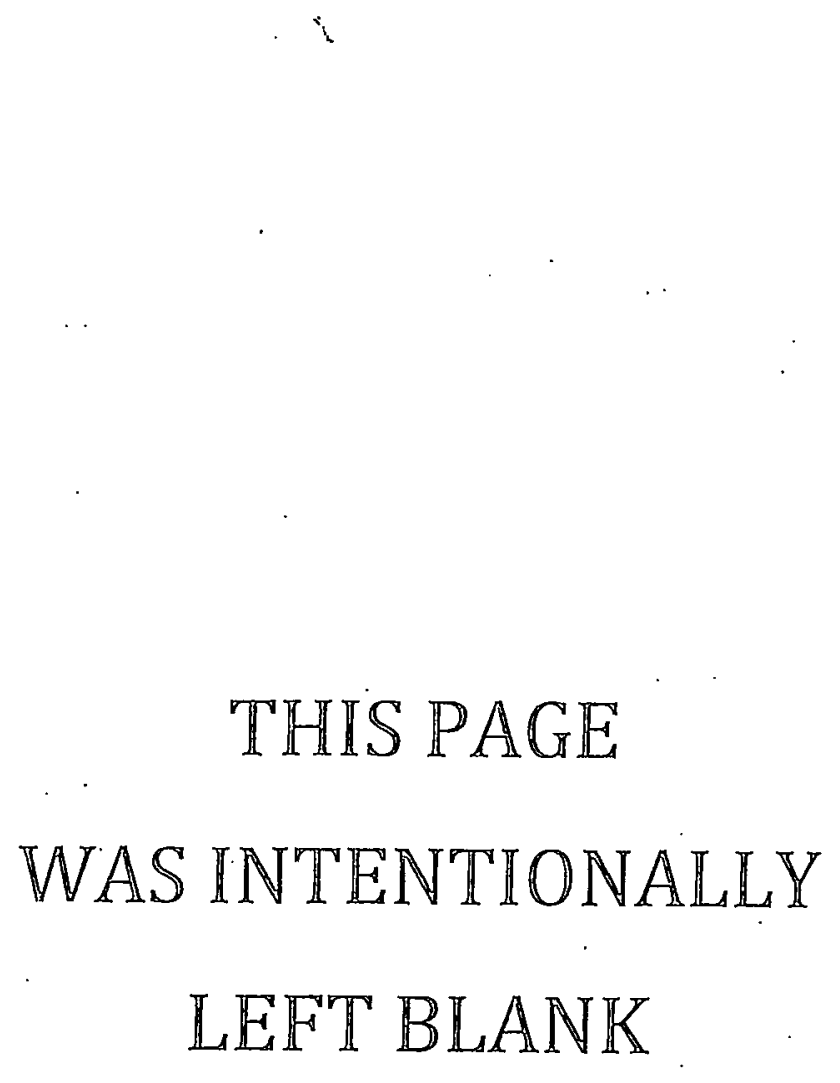




\section{SECTION A}

\section{INTRODUCTION}

This report presents DOE's research and development program plan for solar heating: and cooling for. building, agricultural, and industrial applications. It is intended for those who are familiar with the basics of solar heating and cooling, and offers insight into probable advances in components and systems.

The use of solar energy for these applications involves the integration of existing components (such as HVAC equipment) with new inherently solar components (collectors, storage) into system configurations best suited to meet the application requirements. The expanding solar energy industry is developing the expertise to perform the required system integration. Building on existing technology and supporting work on a wide range of problems, the R\&D program seeks to assist the solar energy industry in developing the cost-effective components and systems essential for the widespread use of solar energy to meet building, agricultural, and industrial heating and cooling needs.

Under the provisions of the Energy Reorganization Act, ${ }^{1}$ ERDA has the central responsibility for the Federal Covernment's solar energy program. This responsibility was transferred to DOE upon its formation. ${ }^{2}$. Other Federal agencies, industries, universities, small businesses, and state and local governments are involved in solar energy activities, contributing to the national solar energy effort. ERDA's program, the largest and most heavily funded activity of the solar energy effort, gave that effort substance, shape, and stimulus.

Tó carry out its leadership role as mandated by the Solar Energy Act, ${ }^{3}$ ERDA prepared a National Solar 1974.

'Energy Reorganization Act of 1974, P.L. 93-438, October 11 565).

2Department of Energy Organization Act (Public Law 95-91; Stat.

3Solar Energy Research, Development and Demonstration Act of 1974, P.L. 93-473, October 26, 1974.
Energy R\&D Plan. ${ }^{4}$ The primary goal of this plan was to work with industry to develop, demonstrate, and introduce, at the earliest possible time, economically competitive and environmentally acceptable solar energy systems to meet a significant fraction of the nation's energy requirements. Program plans for the applications of solar energy for the heating and cooling of buildings and for agricultural and industrial processes were prepared. ${ }^{5}$ The present report details the R\&D program outlined in these earlier documents.

\section{SOLAR HEATING AND COOLING PROGRAM}

The overall objective of the DOE solar heating and cooling program is to stimulate the development of an industrial, commercial, and professional capability for producing and distributing various solar energy systems, thus reducing the demand on fossil fuel supplies. The major elements of the program are:

- Research and development;

- Residential building demonstrations;

- Commercial building demonstrations;

- Federal Buildings Program; and

- Agricultural and industrial process demonstrations.

The R\&D Program will result in advanced components and systems with improved efficiency, lower costs, and longer life. The three demonstration programs will indicate ways to use available technology to meet the thermal requirements of buildings

${ }^{4}$ National Solar Energy Research and Development Plan, ERDA-48, October 1975.

${ }^{5}$ National Program for Solar Heating and Cooling, Residential and Commercial Applications, ERDA 76-6, October 1976; Program Description, Solar Energy for Agriculture and Industrial Process Heat, ERDA 76-88, June 1976 . 
and of agricultural and industrial processes. The Federal Buildings Program will encourage the use of solar heating and cooling systems in Federal buildings, thereby providing a significant market demand.

\section{TECHNOLOGY STATUS}

In preparing this R\&D program plan, several meetings were held with representatives from industry, universities, and Covernment laboratories and agencies to:

- Assess the present state of the art;

- Identify major problems limiting improved performance and/or reduced costs; and

- Recommend short- and long-term R\&D tasks to solve these problems.

In discussing the status of the national solar energy effort, it became clear that:

- Cost effectiveness is the major problem to be addressed.

- The state of the art varies greatly for different components and applications, with solar cooling technology generally less developed than solar heating.

- Wide variations in applications and climatic zones necessitate careful analysis to determine the most cost-effective approaches.

- Cost-effective retrofit domestic hot water systems are available in certain regions, but retrofit heating and cooling and agricultural and industrial process heat systems are not well developed. Techniques to facilitate optimization of retrofit design are also not readily available.

- Although there are no scientific barriers to the production of steam from solar energy, there are engineering and technoeconomic obstacles which must be overcome.

\section{DIRECTED R\&D PLAN}

The ERDA components-oriented R\&D program, ${ }^{6}$ which had already made significant contributions to

\footnotetext{
$h$ The components-oriented R\&D program is described in the $\mathrm{Na}$ tional Program Plan for Solar Heating and Cooling of Buildings-Project Summaries: Vol. III Research and Development, ERDA 76-145, November 1976. This report may be obtained from the Superintendent of Documents.
}

the state of technology, was strengthened by the ir itiation of the directed (applications-oriented) R\&L program. ${ }^{7}$ The present document is the first revision of this plan. The objective of the directed program is to provide the energy industry and other users with the means (components, information, etc.) to develop cost-effective solar heating and cooling systems. The $R \& D$ plan details promising approaches for achieving this objective and outlines a systematic program for providing materials, components, and systems designed to establish the cost effectiveness of each approach as rapidly as possible.

The directed $R \& D$ plan is recognized as a significant element in a total commercialization activity. A successful R\&D program will provide a direct marketing and production stimulus to advance the state of solar heating and cooling technology.

\section{STRUCTURE OF THE R\&D PROGRAM}

The R\&D program is based on the development of specific approaches-paths-to particular solar energy applications. A path links a method of energy collection or rejection with an application. Each path has a single objective: to develop the cost-effective technology to achieve the specific path application as quickly as possible.

Paths for the solar heating and cooling of buildings may sometimes lead to more than one application. Space heating paths, for example, generally involve hot water heating; space cooling generally involves both space and hot water heating. Agricultural and industrial process paths seldom relate to more than one application.

At the same time, there are many different paths leading to a given application of solar energy. Based on existing technology, some paths show more promise than others for developing economically competitive solar energy systems at the earliest possible time. Additional paths may be worth pursuing and, as a result of the R\&D program, still other paths may become attractive. Nevertheless, to best meet its short-term objectives, the program plan details only 11 paths to the use of solar energy for the following building applications (Table 1-1):

Service hot water;

Space heating; and

Space cooling.

'ERDA 76-144, op. cit.. 
TABLE I-1

PATH DESCRIPTIONS FOR HEATING

AND COOLING OF BUILDINGS

\begin{tabular}{|c|c|c|}
\hline APPLICATION & DESIGNATION & PATH DESCRIPTION \\
\hline $\begin{array}{l}\text { Service } \\
\text { Hot } \\
\text { Water }\end{array}$ & $\begin{array}{l}\text { W1 } \\
\text { w2. }\end{array}$ & $\begin{array}{l}\text { Liquid-Heating Collectors } \\
\text { Air-Heating Collectors }\end{array}$ \\
\hline $\begin{array}{l}\text { Space } \\
\text { Heating } \\
\end{array}$ & $\begin{array}{l}\mathrm{H} 1 \\
\mathrm{H} 2 \\
\mathrm{H} 3 \\
\mathrm{H} 4\end{array}$ & $\begin{array}{l}\text { Combined Solar and Heat Pump } \\
\text { Passive Heating of Space or Structure } \\
\text { Air-Heating Collectors } \\
\text { Liquid-Heating Collectors }\end{array}$ \\
\hline $\begin{array}{l}\text { Space } \\
\text { Cooling }\end{array}$ & $\begin{array}{l}\mathrm{C} 1 \\
\mathrm{C} 2 \\
\mathrm{C} 3 \\
\mathrm{C} 4\end{array}$ & $\begin{array}{l}\text { High Temperature Collectors with } \\
\text { Absorption or Heat Engine/Vapor } \\
\text { Compression Chillers } \\
\text { Medium Temperature Collectors with } \\
\text { Absorption, Heat Engine/Vapor } \\
\text { Compression, and Other Chillers } \\
\text { Flat Plate/Advanced, Non-Concentrating } \\
\text { Collectors with Desiccant Chiller/ } \\
\text { Dehumidifier } \\
\text { Passive and Hybrid Cooling } \\
\text { Combined Solar and Heat Pump }\end{array}$ \\
\hline
\end{tabular}


The plan also calls for 11 paths to the use of solar energy for the following agricultural and industrial process applications (Table I-2):

- Shelter heating;

- Drying;

- Process hot water;

- Process steam; and

- Cooling and refrigeration.

Figure $1-1$ gives two examples of paths to solar heating and cooling and several examples of building applications, identifying:

- Energy source or sink;

- Methods of solar energy collection or heat rejection;

- Energy conditioning, if required; and

- Application.

Some paths require an emphasis on materials development, some on system analysis, and others on component development and testing. To move along any of the paths, specific tasks must be undertaken, either in parallel or in series. Tasks have been identified, grouped in five functional categories (Table 1-3), and arranged in sequence to allow the paths to develop in a logical order. The importance of each task to a given path is indicated. The five task categories are:

- Collectors;

- Storage and heat exchange;

- Air-conditioning and heat pumps;

- Systems and controls; and

- Non-engineering aspects.

\section{STRUCTURE OF THE R\&D PLAN}

This R\&D program plan consists of three major parts. The Executive Summary and Part I give an overview of the plan. Part II describes the paths to solar heating and cooling of buildings and the paths for agricultural and industrial processes, giving the following information for each path:

- A brief description of key features;

- The R\&D strategy;
- The R\&D emphasis;

- The timing of major task groupings; and

- The key milestones.

Part III (the appendices) provides detailed information on the tasks. Appendix A contains brief descriptions of tasks, including the non-engineering tasks. Where appropriate, the importance of the task to the path on which it occurs is indicated. Appendix $B$ gives the importance of the non-engineering tasks to the overall R\&D program.

The task descriptions in Part III of this report are specific enough to provide a statement of a problem, yet general enough to allow the program to remain flexible and responsive to changes in solar heating and cooling technology. Most of the identified tasks are common to several of the paths, and various paths are thus interdependent. Results from building tasks will often apply to agricultural and industrial process applications. However, because of the unique nature of the process path involved, distinct agricultural and industrial process tasks have been identified and integrated into the above categories.

With the report organized in this way, the reader can gain an overview of the plan without necessarily becoming involved in its details. Detailed information on tasks is available in the appendices.

\section{IMPLEMENTATION}

Prior to the development of this directed R\&D plan, the R\&D program consisted of projects based on unsolicited proposals. ${ }^{8}$ With the distribution of the interim National Program Plan for Research and Development in Solar Heating and Cooling, ${ }^{9}$ the procurements shifted to solicited proposals.

In FY 1977, a series of 11 Requests for Proposals (RFP's) and Program Research and Development Announcements (PRDA's) was issued by the Research and Development Branch of ERDA's Division of Solar Energy. These solicitations called for proposals specifically related to one or more tasks in the directed R\&D plan. Out of the 1200 proposals received, approximately 140 projects were selected for support. The balanced involvement of industries, universities, small

BERDA 76-145, op), cit.

'ERDA 76-144, op. cit.. 


\begin{tabular}{|l|l|l|}
\hline APPLICATION & DESIGNATION & \multicolumn{1}{|c|}{ PATH DESCRIPTION } \\
\hline Shelter Heating & HP & Passive Heating \\
& HA & $\begin{array}{l}\text { Air-Heating Collectors } \\
\text { Liquid-Heating Collectors }\end{array}$ \\
\hline Drying & HL & Direct Drying \\
& DA & $\begin{array}{l}\text { Air-Heating Collectors } \\
\text { Liquid-Heating Collectors }\end{array}$ \\
\hline Process \\
Hot Water & DL & Liquid-Heating Collectors \\
& WL & Air-Heating Collectors \\
\hline $\begin{array}{l}\text { Process } \\
\text { Steam }\end{array}$ & WA & Liquid-Heating Collectors \\
\hline $\begin{array}{l}\text { Cooling and } \\
\text { Refrigeration }\end{array}$ & SL & Active Cooling and Refrigeration \\
\hline
\end{tabular}




\begin{tabular}{|c|c|c|c|}
\hline $\begin{array}{c}\text { ENERGY } \\
\text { SOURCE/ } \\
\text { SINK }\end{array}$ & $\begin{array}{c}\text { ENERGY } \\
\text { COLLECTION/REJECTION }\end{array}$ & $\begin{array}{l}\text { ENERGY } \\
\text { CONDITIONING }\end{array}$ & APPLICATION \\
\hline
\end{tabular}

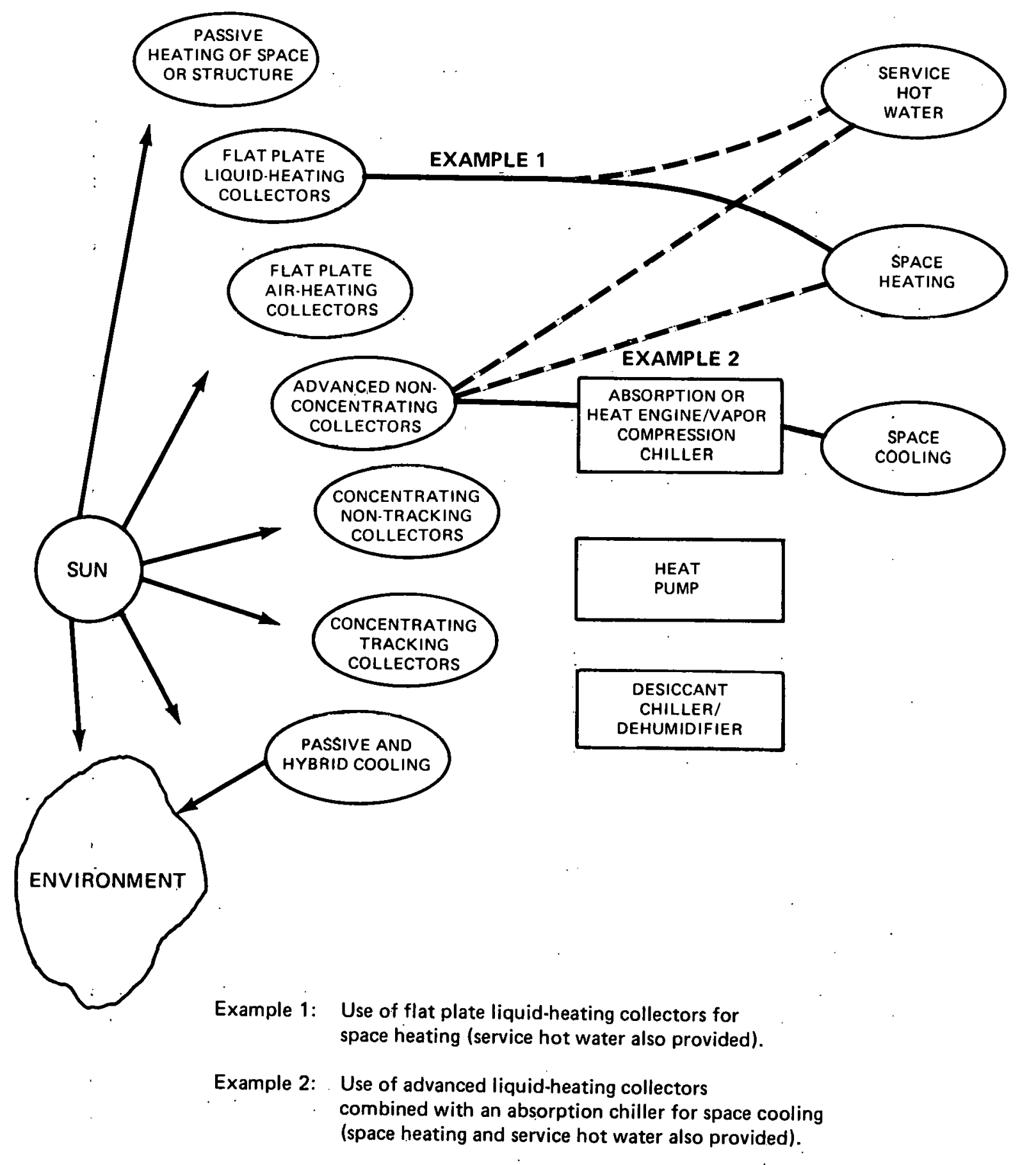

FIGURE I-1

PATH DIAGRAM EXAMPLES 


\section{TABLE I-3 \\ TASK CLASSIFICATIONS}

\section{MAJOR CLASSIFICATION}

\begin{tabular}{|c|c|}
\hline . & $\begin{array}{l}\text { A. System Studies Related to Collectors } \\
\text { B. Theory and Basic Phenomena } \\
\text { C. Flat Plate Liquid-Heating Collectors } \\
\text { D. Flat Plate Air-Heating Collectors } \\
\text { E. Advanced Non-Concentrating Collectors } \\
\text { a) Evacuated Tube Collectors } \\
\text { b) Heat Pipes } \\
\text { c) Honeycombs } \\
\text { d) Others } \\
\text { F. Concentrating Collectors } \\
\text { G. Reflectors for Flat Plate Collector Augmentation } \\
\text { H. Materials } \\
\text { a) Selective Surfaces } \\
\text { b) Glazing } \\
\text { c) Glazing Surface Coatings } \\
\text { d) Sealants } \\
\text { e) Coolants } \\
\text { f) Insulation } \\
\text { g) Absorber Surfaces. } \\
\text { h) Mirror Surfaces } \\
\text { I. Test Procedures }\end{array}$ \\
\hline $\begin{array}{l}\text { II. THERMAL ENERGY STORAGE } \\
\text { AND HEAT EXCHANGE }\end{array}$ & $\begin{array}{l}\text { A. System Studies felated to Storage. } \\
\text { B. Piping, Ducting, Heat Exchangers } \\
\text { C. Water Tank Storage } \\
\text { D. Rock Bed Storage } \\
\text { E. Phase-Change Storage } \\
\text { F. Chemical Storage } \\
\text { G. Test Procedures }\end{array}$ \\
\hline $\begin{array}{l}\text { III. SOLAR CHILLERS, AIR } \\
\text { CONDITIONERS, AND HEAT } \\
\text { PUMPS }\end{array}$ & $\begin{array}{l}\text { A. System Studies Related to Air Conditioning and Heat Pumps } \\
\text { B. Absorption Chillers } \\
\text { C. Heat Engine/Vapor Compression Chillers } \\
\text { D. Passive and Hybrid Cooling Components } \\
\text { E. Desiccant Chillers/Dehumidifiers } \\
\text { F. Other Chillers } \\
\text { G. Heat Pumps } \\
\text { H. Agricultural/Industrial Cooling/Refrigeration } \\
\text { I. Test Procedures }\end{array}$ \\
\hline IV. SYSTEMS AND CONTROLS & $\begin{array}{l}\text { A. Integrated Active Solar Energy Systems } \\
\text { B. System Design Methods } \\
\text { C. Controllers, Valves, and Actuator Components } \\
\text { D. Instrumentation and Data Acquisition } \\
\text { E. Passive and Hybrid Solar Energy Systems } \\
\text { F. System Studies } \\
\text { G. Test Procedures }\end{array}$ \\
\hline V. NON-ENGINEERING ASPECTS & $\begin{array}{l}\text { A. Economic and Financial Analysis } \\
\text { B. Consumer Attitudes and Behavior } \\
\text { C. Marketing, Architecture, and Construction } \\
\text { D. Utility Interface } \\
\text { E. Legal, Regulatory, and Legislative Considerations } \\
\text { F. Education and Training } \\
\text { G. Social and Environmental Considerations }\end{array}$ \\
\hline
\end{tabular}


businesses, and government organizations, which characterized the prior research and development program, was continued by these awards. ${ }^{10}$ Several of the DOE laboratories continue to provide technical review and program support.

While the further implementation of this directed R\&D program will still be based on solicitations (RFP's and PRDA's), the support of fundamental and innovative research related to longer-term objectives will continue to be based on unsolicited proposals.

Work on some elements of the directed R\&D plan was initiated by other ERDA groups. For example:

+ , :

- All solar radiation tasks became the responsibility of the Environmental and Research Studies Branch of ERDA's Division of Solar Energy. Projects related to these tasks were initiated by that branch.

10See updated project summary report. National Program Plan for Solar Heating and Cooling of Buildings-Project Summaries: Vol. II Research and Development, DOE/CS-0010, February 1978
- Some of the thermal storage tasks became th responsibility of the Thermal Energy Storag. Branch of ERDA's Division of Conservation. The initiation of these was coordinated with the Research and Development Branch.

- Many of the non-engineering tasks described in this plan were initiated within the Division of Solar Energy. The Barriers and Incentives Branch was generally responsible for these nonengineering tasks, ensuring coordination between that program, the R\&D program, and related work underway in the residential, commercial, agricultural, and industrial process demonstration programs.

Tasks which pertain only to the demonstration program are not included in this R\&D plan. Many tasks, however, are the common responsibility of the R\&D and demonstration programs. In those instances, advantage will be taken of available services established as part of the demonstration program, with additional activities supported only as required to meet the special needs of the R\&D program. 


\section{SECTION B PROGRAM OBJECTIVES AND EMPHASIS}

\section{OBJECTIVES}

The general objective of the solar heating and cooling research and development program is to assist in creating a viable solar energy industry by improving the efficiency of solar energy components and systems and reducing their costs. Specific objectives are to identify potentially cost-effective systems for building, agricultural, and industrial process heating and cooling applications and to provide the emerging solar industry with the materials, components, information, methodology needed for designing, producing, and installing these systems.

\section{EMPHASIS}

The R\&D plan emphasizes the following program elements:

- Materials-evaluation, development, and characterization of materials suitable for a broad spectrum of applications in solar components.

- Components-development of components with appropriate quality, reliability, and cost for specific system applications and the mathematical theory, validated models, and performance test results necessary for system integration.

- Systems-identification, evaluation, and development of new or retrofit solar heating and cooling systems for various types of buildings, process applications, climates, and auxiliary energy forms, and the determination of their actual and predicted thermal performance and economic viability in relation to competing energy sources.

- Information-dissemination of results of all R\&D projects, with special attention to system test results. As much information as possible will be put into handbook form.

Though the development aspect of the R\&D program will be stressed, with an emphasis on developing present technology to meet short-term objectives in the use of solar energy, fundamiental research related to long-term objectives will continue to be supported.

The directed R\&D program will meet the needs of a developing solar heating and cooling industry by:

- Supporting the development of regionally costeffective competitive retrofit systems for combined space and water heating and space cooling.

- Supporting the testing, evaluation, and development of materials and processes required for the engineering of successful components and systems.

- Supporting the development of components having improvèd performance and/or lower cost.

- Designing and conducting tests of systems with advanced components to provide the full range of data essential to the development of new solar heating and cooling systems.

- Providing valid data, information, and computing techniques that the potential users of solar energy may require in order to determine costs and benefits.

- Evaluating various economic, environmental, social, institutional, and legal factors which could influence the manner in which solar thermal energy is used.

In general, a product should be developed by the industry that will eventually market it. The R\&D program will concentrate on providing the technology and information required, so that the industry can develop the product as quickly and effectively as possible. Additional support will be given when it is desirable to obtain a prototype or pre-prototype for testing.

The major areas of emphasis of the R'D program are discussed in the following paragraphs. 


\section{Evaluation, Development, and Characterization of Materials}

Stringent demands are placed on the materials required for the proper functioning of solar heating and cooling components. Generally, these materials must have long service life and low initial cost, must be useful in a particular environment (such as a home or factory' and compatible within a system, and must be available. Materials requirements often present complex problems. For example, the liquid coolant now used in solar components is a mixture of ethylene or propylene glycol and water. At temperatures that occur in normal collector operation, this mixture forms glycolic acids which can cause system corrosion and breakdown.

The R\&D costs to determine materials characteristics and requirements and to improve the materials used in solar energy system components cannot be borne by a single manufacturer. Thus, Federal program support is necessary.

\section{Development of Components}

The plan stresses the development of components that are completely characterized so that they may be integrated with other components to form systems that best exploit their capabilities. Thus, developers of components are expected to produce hardware that is functional, reliable, maintainable; and inexpensive. They must also provide the information required by the system analyst to determine the cost effectiveness of the component and how well it will perform in a given application.

To properly evaluate the potential of a particular solar energy systėm component or configuration, its performance must be mathematically characterized. Mathematical models that account both for steady state operation and for dynamic or transient performance must be developed and must be calibrated by comparison with steady state and transient tests made on prototypes. The entire operation of a system must then be validated to confirm that the model correctly describes component interaction.

Manufacturers frequently undertake some type of system modeling when they plan a new product line. However, validating the model is often beyond the means of any single manufacturer. As a result, this important step is usually omitted or performed inadequately, resulting in components that are inappropriate for the systems for which they were designed. Manufacturers of absorption chillers, for instance, are often familiar with the steady state modeling of these units but unfamiliar with their transient modeling, because transient modeling is not often necessary for conventional operation. The transient characterization becomes important, though, when the chiller is incorporated in a solar heat collection system where the input temperature to the generator system may not be constant. Therefore, the transient behavior of the chiller and its influence on overall system operation must be understood. Manufacturers may be unable to afford a complete modeling and validation, but it is important that they understand the operation of all system components.

\section{System Development and Analysis}

Developers of new systems and systems using advanced components will utilize the information made available through the directed components research and development program to synthesize configurations that are cost effective for specific applications, regions, and climatic zones.

The study of systems begins with configuration studies to identify either components requiring development or new systems made possible by advanced components. Systems models are then developed to predict performance and hence to identify those components and their characteristics that are most promising. The effects on system performance and cost competitiveness of climate, load, competing energy costs, and system operation strategies are then evaluated on a regional basis. This leads to a large set of possible studies. The schematic in Figure 1-2 illustrates the variety of interactions among the efforts involved in a systems study. As an example, solar collectors can be combined with heat pumps in several ways to provide net heat output. Perhaps 15 U.S. climatic zones and several building types should be considered; fuel types and prices vary greatly with locale. As a result, this concept has never been evaluated comprehensively. The system study portion of the $R \& D$ program is designed to fill this need.

To ensure the validity and usefulness of these study results, experimental systems tests under real and simulated climatic and local conditions will be performed. These tests will provide the data required to validate the performance predictions. They will also yield information on operating and maintenance characteristics. Only the most promising configurations will be tested and full use will be made of existing systems within the R\&D and demonstration programs. In addition, when suitable arrangements can be made, systems built privately or by other government institutions will be used. 


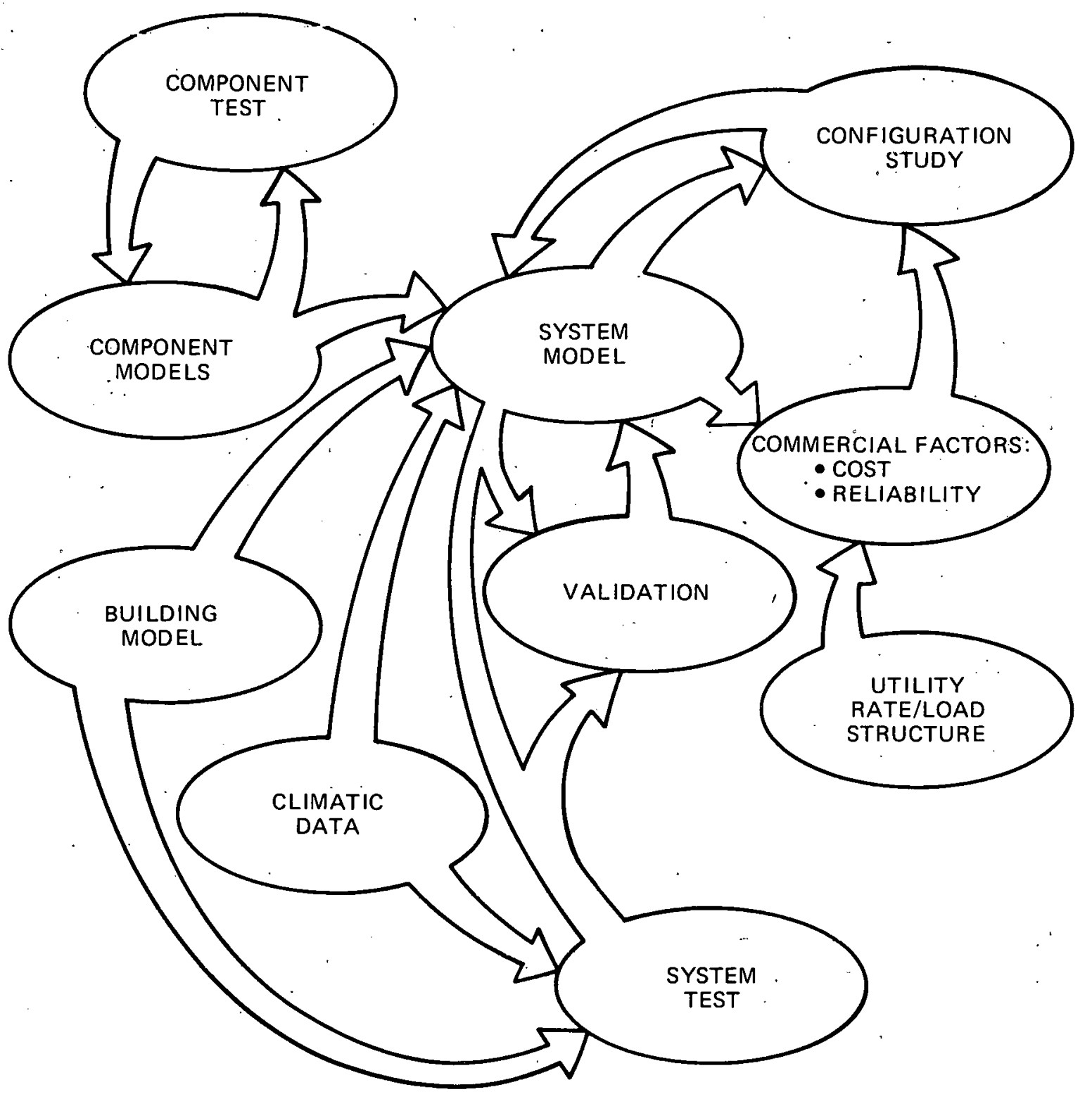

FIGURE $1-2$

SYSTEM ANALYSIS INTERACTION 
A comprehensive test plan will be developed to document test requirements, procedures, required facilities, and results.

\section{Dissemination of Information}

Information on materials characterization, component development, and system development and testing will be disseminated to the various user groups. This will be done through reports, conference proceedings, and summary materials such as design guides, handbooks, and compendia of the results of those tasks which specifically address information collection and system analysis. Publications will be phased to correspond to the R\&D plan accomplishments. Data collection and information dissemination activities will be coordinated, when possible, with the centralized data collection and information dissemination system established under the Solar Heating and Cooling Demonstration Program.

\section{Assessment of Non-Engineering Aspects}

The economic, institutional, and social environment in which solar heating and cooling technology will be applied must be analyzed. Such assessment necessi- tates:

- Collection and dissemination of information ol economics, legislation, market structures, consumer attitudes, etc.;

- Analysis of policies that may have an impact on the commercialization of solar heating and cooling; and

- Research on factors that may affect the acceptance of solar heating and cooling systems and development of acceptance design goals for the R\&D program.

The information gathered can be used in establishing priorities for the R\&D program as well as for individual paths in the program. It can also be used to identify possible impediments to the widespread use of solar energy systems. Once impediments are identified, policies can be designed to overcome them.

Approximately 40 non-engineering tasks have bcen identified and grouped according to the seven classifications in Table I-3. (The tasks are described in Section V of Appendix A.) Because these tasks involve questions common to all solar applications, they are not associated with particular paths. Instead, the importance of each task to the total R\&D program (including both building and agricultural and industrial process applications) is given in Table B-1. 
PART II. PATHS 
THIS PAGE

WAS INTENTIONALLY

LEFT BLANK 


\section{SECTION A R\&D PROGRAM STRUCTURE: HEATING AND COOLING OF BUILDINGS}

This section describes in detail the 11 paths to the solar heating and cooling of buildings. Figures II- 1 to II-3 show the paths to solar heating of water, solar heating of buildings, and solar cooling of buildings. Detailed summaries of each path include a general description, a discussion of the recommended R\&D strategy, a tabulation of the principal R\&D task groups, and charts which indicate task sequence and - milestones. 


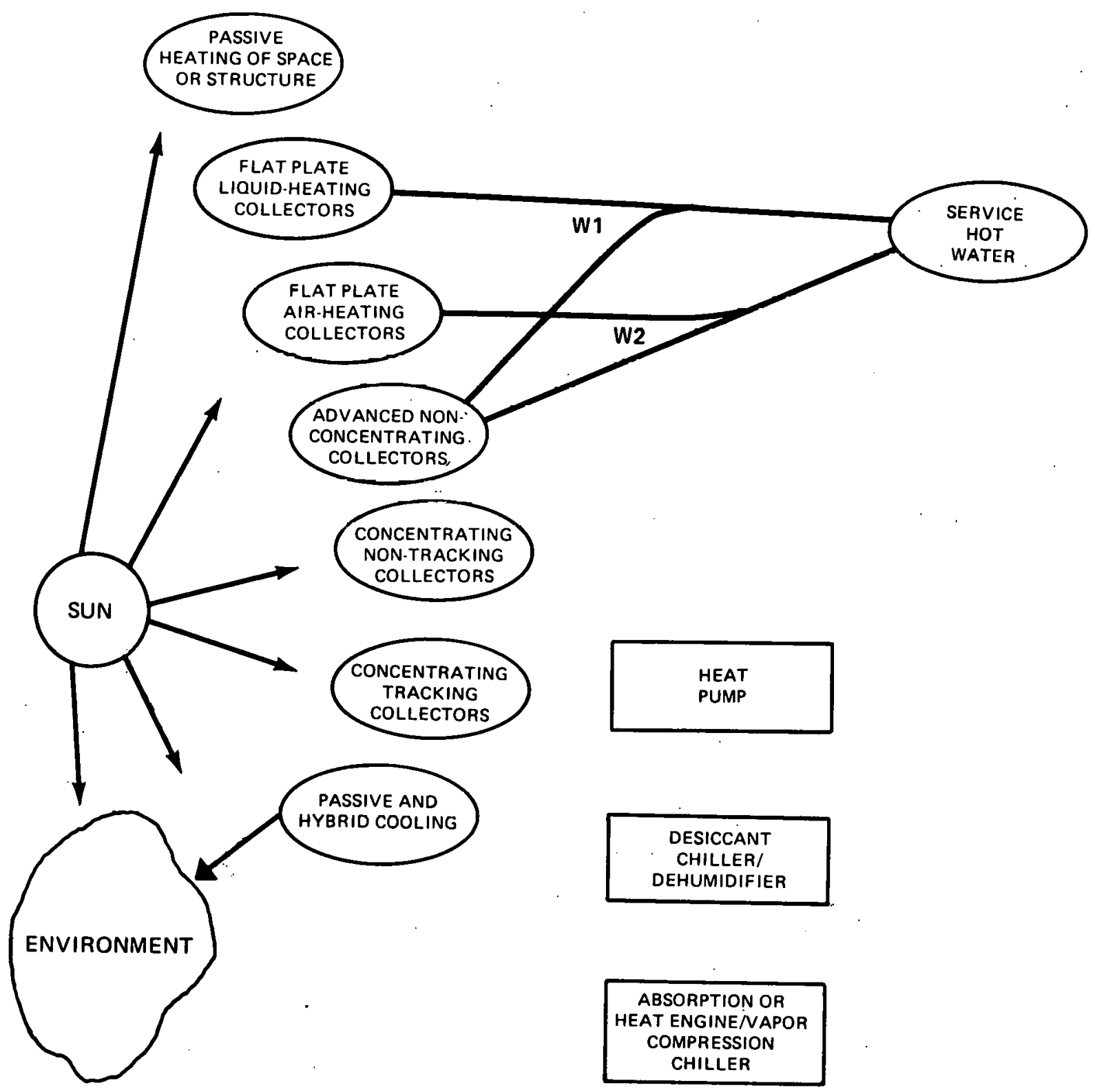




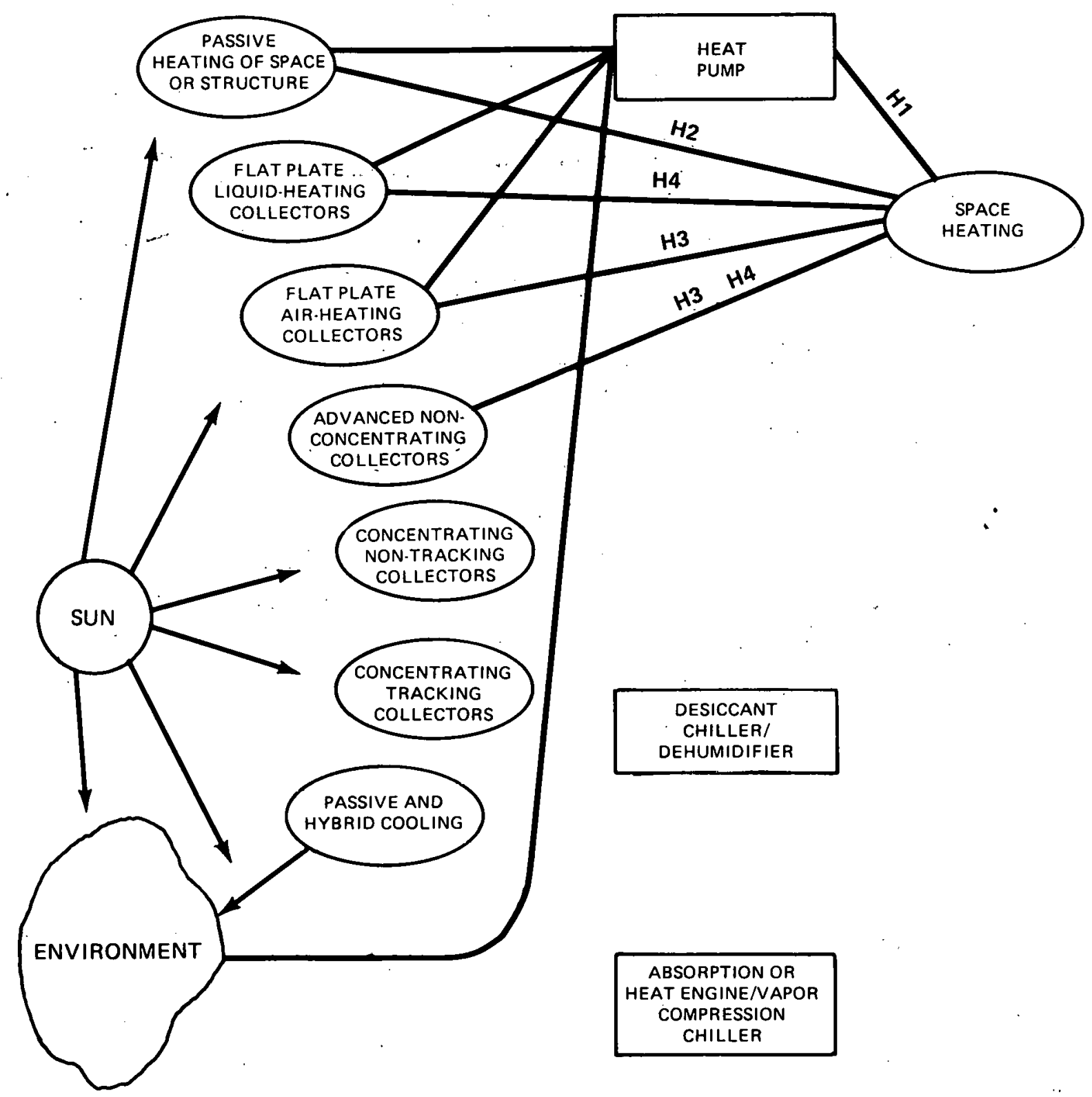




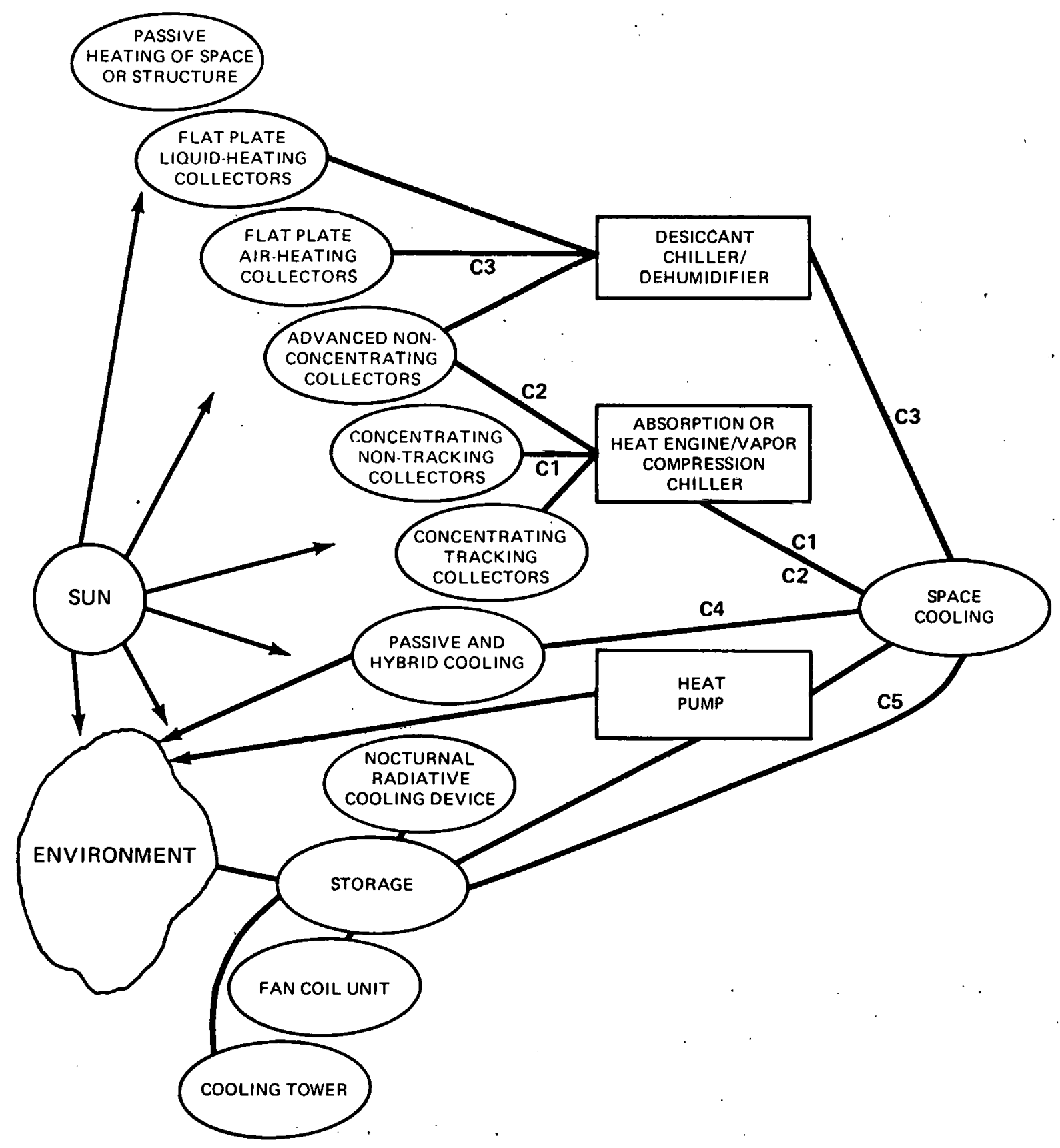




\section{LIQUID-HEATING COLLECTORS \\ FOR \\ SERVICE HOT WATER \\ PATH W1}

\section{GENERAL}

In this system, water or another liquid passes through liquid-heating collectors (flat plate and/or advanced non-concentrating) and transfers heat to a water storage tank, either directly or through a heat exchanger. Thermal storage usually will be in either the normal domestic hot water tank or in a separate preheater tank. Freeze protection is a major design consideration in most climates. Hot water heating is more economical than space heating because the equipment can be used all year, thus achieving a high total energy yield from the collectors. Because the required collector area is small (from 5 to $200 \mathrm{sq}$. $\mathrm{ft}$.), ample rooftop space is usually available, even in a retrofit situation. Since the initial cost of a hot water heating system is low, many people are able to install them. A special problem arises because the system must interact with the potable water supply without danger to the health of the users or others.

\section{R\&D STRATEGY}

The objective of this path is to assist the small but viable and developing solar water heater industry. To accomplish this objective, the basic characteristics of the many approaches to supplying service hot water will be identified. The emphasis will be on determining basic climate/performance requirements, including a survey of various approaches to freeze protection, methods of integration with existing hot water systems, desirable/undesirable characteristics of existing use patterns, and cost-performance characteristics of existing marketed systems. This will be accompanied by materials characterization, testing, and evaluation. Several areas will be stressed:

- Stratification in the storage tank and how it is affected by the shape, type, and location of the auxiliary heaters and plumbing connections;

- Novel design of appropriate heat exchangers operating at low flow rates and with small temperature drops (taking advantage of the fact that the structural limitations are minimal); and
- The appropriate method of connecting collectors:

\section{R\&D EMPHASIS}

\section{Evaluation, Development, and Charac- terization of Materials}

Collectors: glazings, surface coatings, sealants, weight, connecting hoses, reliability, lower cost

Coolants: emphasis on non-toxic environmentally acceptable coolants

Heat exchangers: less expensive, more reliable materials

Liquid/multi-metallic corrosion effects

Freeze protection techniques

Insulation materials

Storage tanks: economical, reliable, lightweight

\section{Development of Components}

Collectors, including method of connecting

Storage tanks: enhancement of stratification and improved auxiliary heater design and configuration

Heat exchangers: fluid-to-fluid and direct contact Reflectors

Pumping systems: more efficient pumps

Simple controls

\section{System Development and Analysis}

Performance identification: energy yield on a regional basis as a function of climate, system configuration, design, operational strategy, component performance characteristics, domestic hot water use pattern and temperature requirement, and collector shading 
Market identification: Determiniation of desirable system and component performance/cost characteristics

Cost identification: survey of current installed system costs

Techniques and implications of retrofitting

Architectural integration

Simplified performance prediction methods
Preparation of handbooks for design and analys of systems

Integration with auxiliary energy system, utility effects

\section{System Testing}

Data gathering on test systems

Model and theory validation 


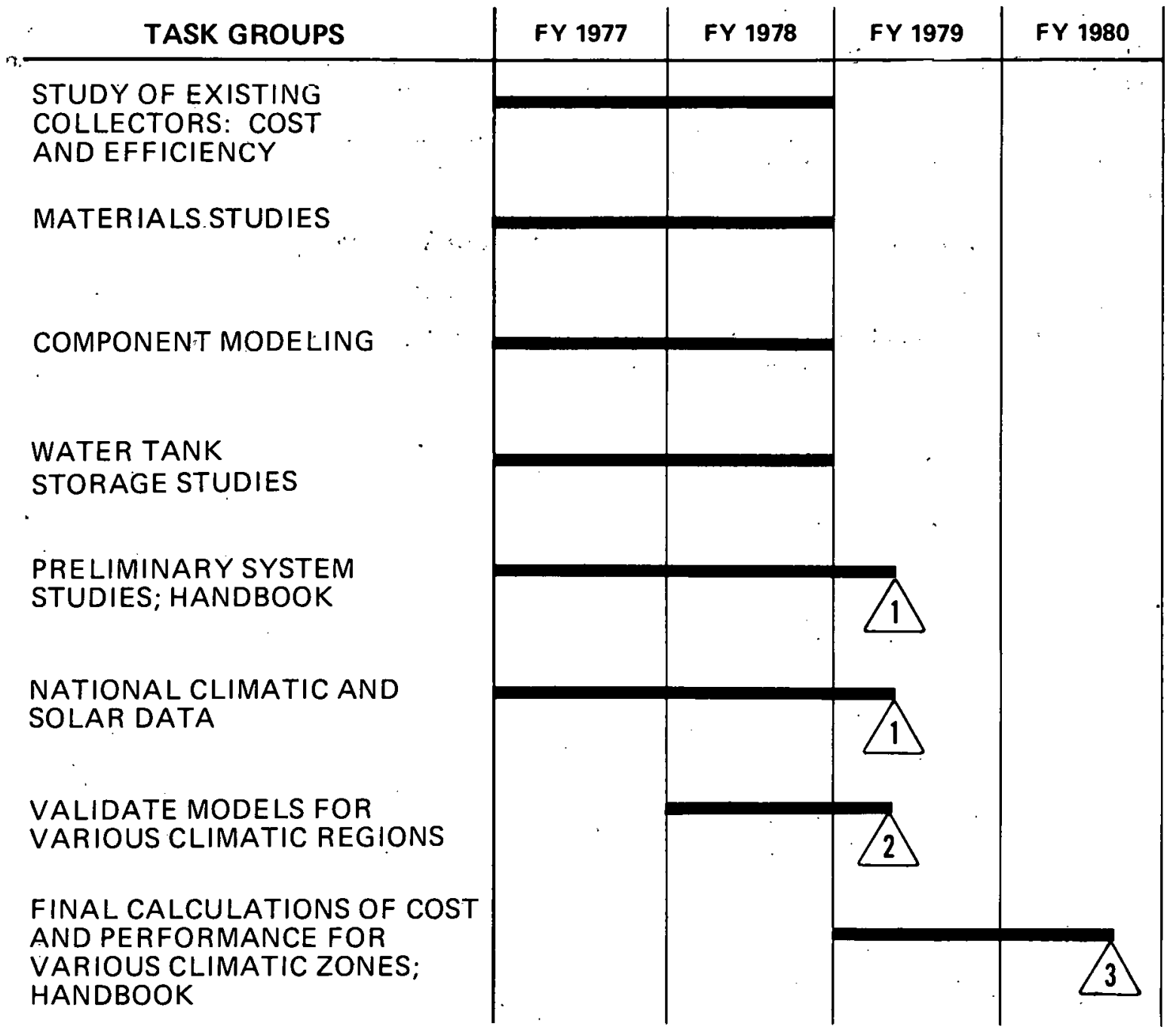

\section{MILESTONES}

$1 / 79$ 1

Complete system studies

identifying performance and cost characteristics for systems chosen for various climatic regions. This will be done assuming validity of current simulation techniques and the characteristics of existing hardware. Publish preliminary handbook.
$1 / 79$

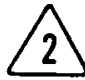

Complete a review of system simulation techniques (based on improved system and collectors). validate mathematical models, and certify that the final phase should proceed.

$6 / 80$

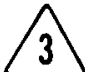

Repeat above system analysis based on validated models and improved components. Publish revised handbook. 


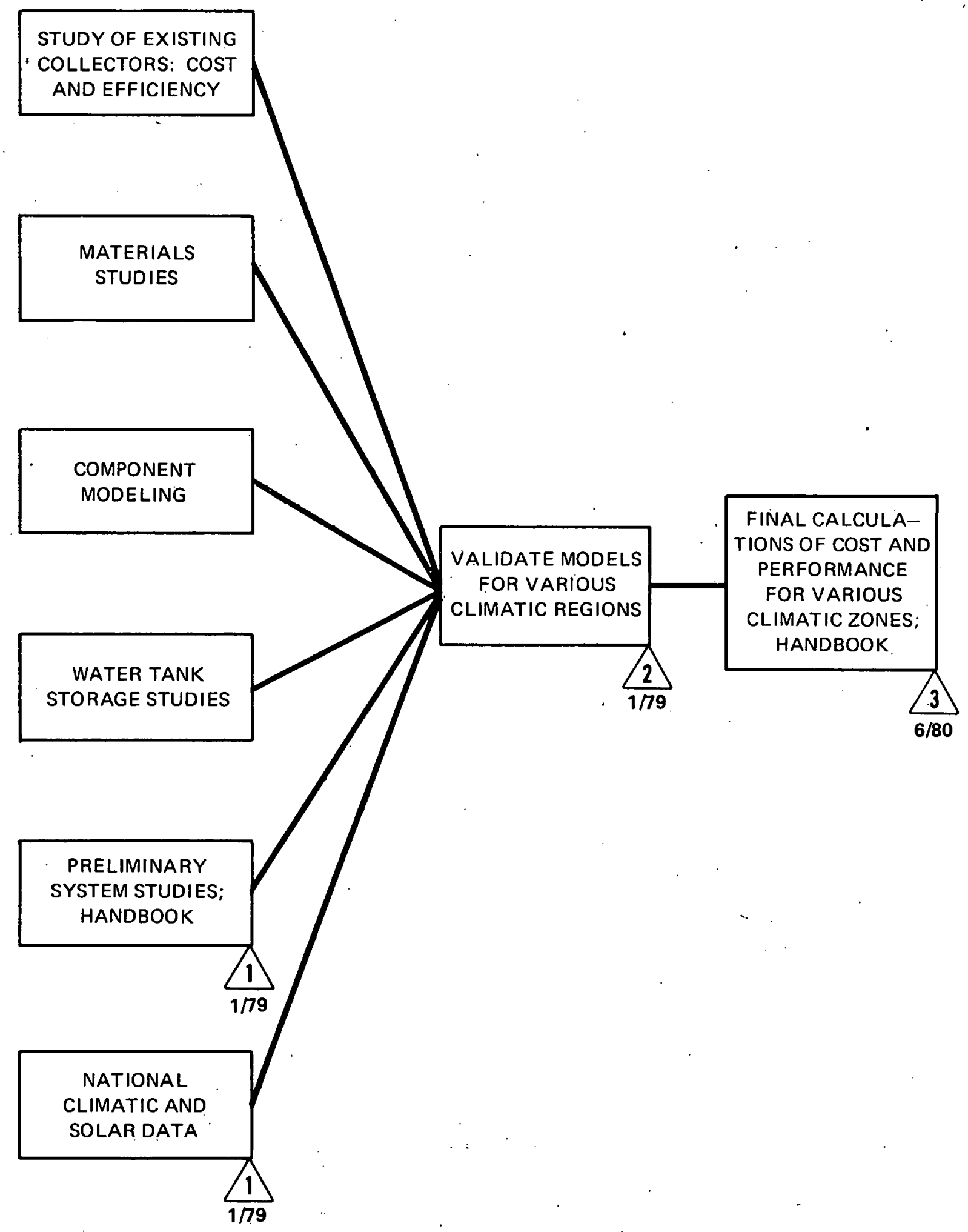

FIGURE $\|-5$

LIQUID-HEATING COLLECTORS FOR SERVICE HOT WATER

PATH W1 TASK FLOW CHART 


\section{AIR-HEATING COLLECTORS FOR SERVICE HOT WATER PATH W2}

\section{GENERAL}

The use of air-heating collectors for service hot water presents two problems: (1) not enough is known about their method of application; and (2) they may be subject to significant heat transfer losses. The heat transfer loss occurs because a heat exchanger is required between the air flowing through the collector and the service water to be heated. The performance of an air-heating system may therefore be lower than liquid-heating collectors but air offers several advantages: it is non-freezing, non-corroding, and non-toxic. Terminal storage for air-heating collectors will generally be either the normal domestic hot water tank or a separate preheater tank.

\section{R\&D STRATEGY}

The objective of this path is to determine the requirements for operational and economic viability of the air-heating approach. The program will emphasize identification of the performance characteristics for various collectors and climates, with materials work directed principally toward improved collector durability and performance. Systems will be assembled to reduce costs and a few systems will be evaluated. Emphasis will be on determining system designs that compensate for the heat-exchange temperature drops inherent in this type of system. Storage tanks and auxiliary heaters will be designed to maximize stratification. The best pattern of collector connection will be determined.

\section{R\&D EMPHASIS}

\section{Evaluation, Development, and Charac- terization of Materials}

Collector: glazing, surface coatings, sealants
Materials for suppression of collector convection losses

Insulation material

\section{Development of Components}

Air-heating collectors

Heat exchangers: air-to-water

Tanks: emphasis on stratification and proper design and configuration of auxiliary heaters

Reflectors

Fans with improved performance

\section{System Development and Analysis}

Performance identification: energy yields as a function of collector performance, system design characteristics, climate, storage size and configuration, water use characteristics, and region

Market identification: System.and component characteristics demanded by market

Cost identification: emphasis on existing equipment and pre-packaging

Retrofit installation compatibility

Integration with auxiliary energy system, utility effects

Development of design and analysis handbooks

\section{System Testing}

:Conduct model and theory validation testing 


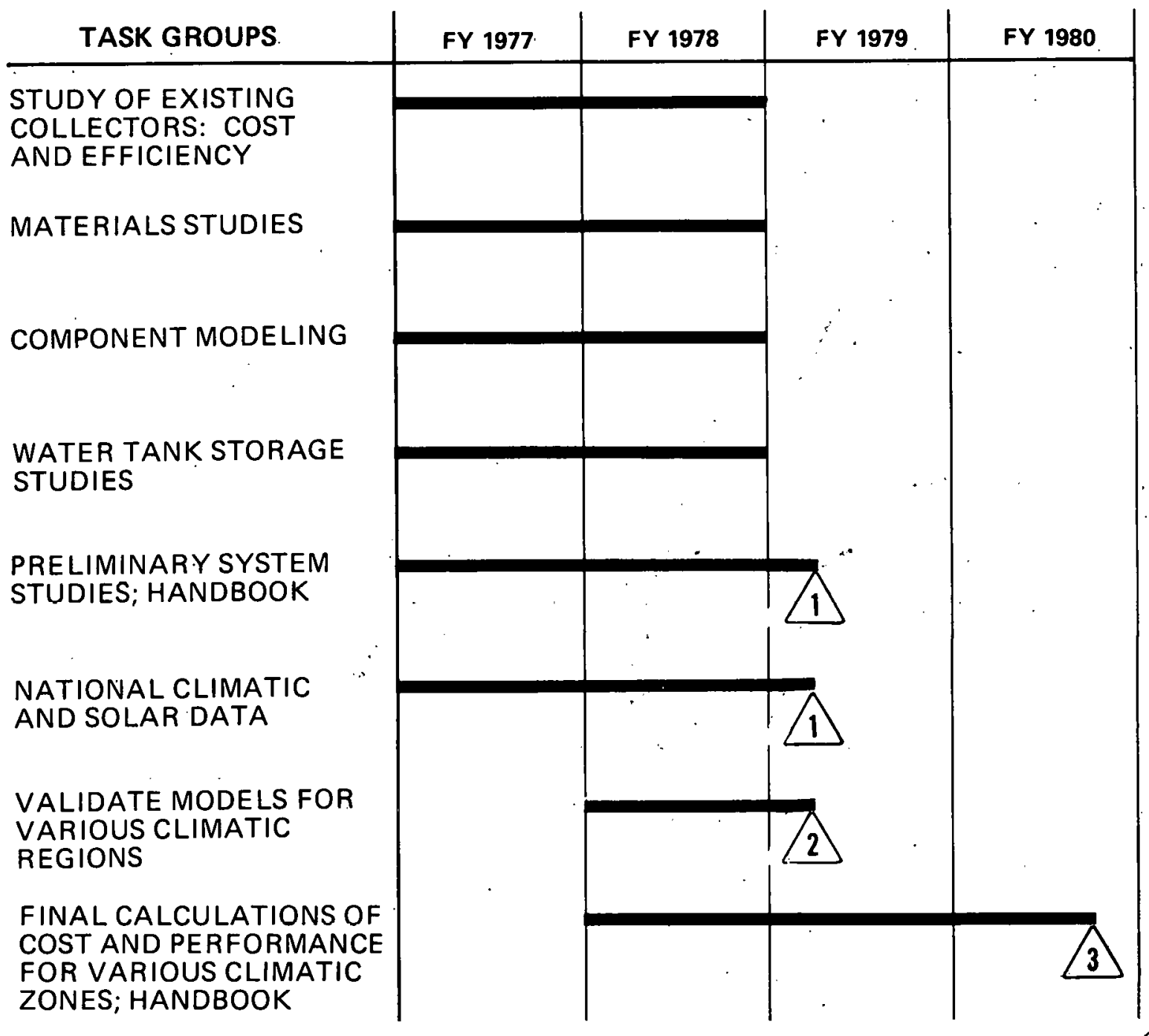

\section{MILESTONES}

$1 / 79$

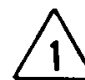

Complete system studies identifying performance and cost characteristics for systems chosen for various climatic regions. This will be done assuming validity of current simulation techniques and characteristics of existing hardware. Publish preliminary handbook.
$1 / 79$

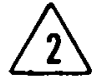

Complete a review of system simulation techniques (based on improved system and collectors), validate mathematical models, and certify that the final phase should proceed.

$6 / 80$

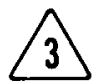

Repeat above system analysis based on validated models and improved components. Publish revised handbook.

\section{FIGURE II- 6 \\ AIR-HEATING COLLECTORS FOR SERVIICE HOT WATER PATH W2 ACTIVITY SCHEDULE}




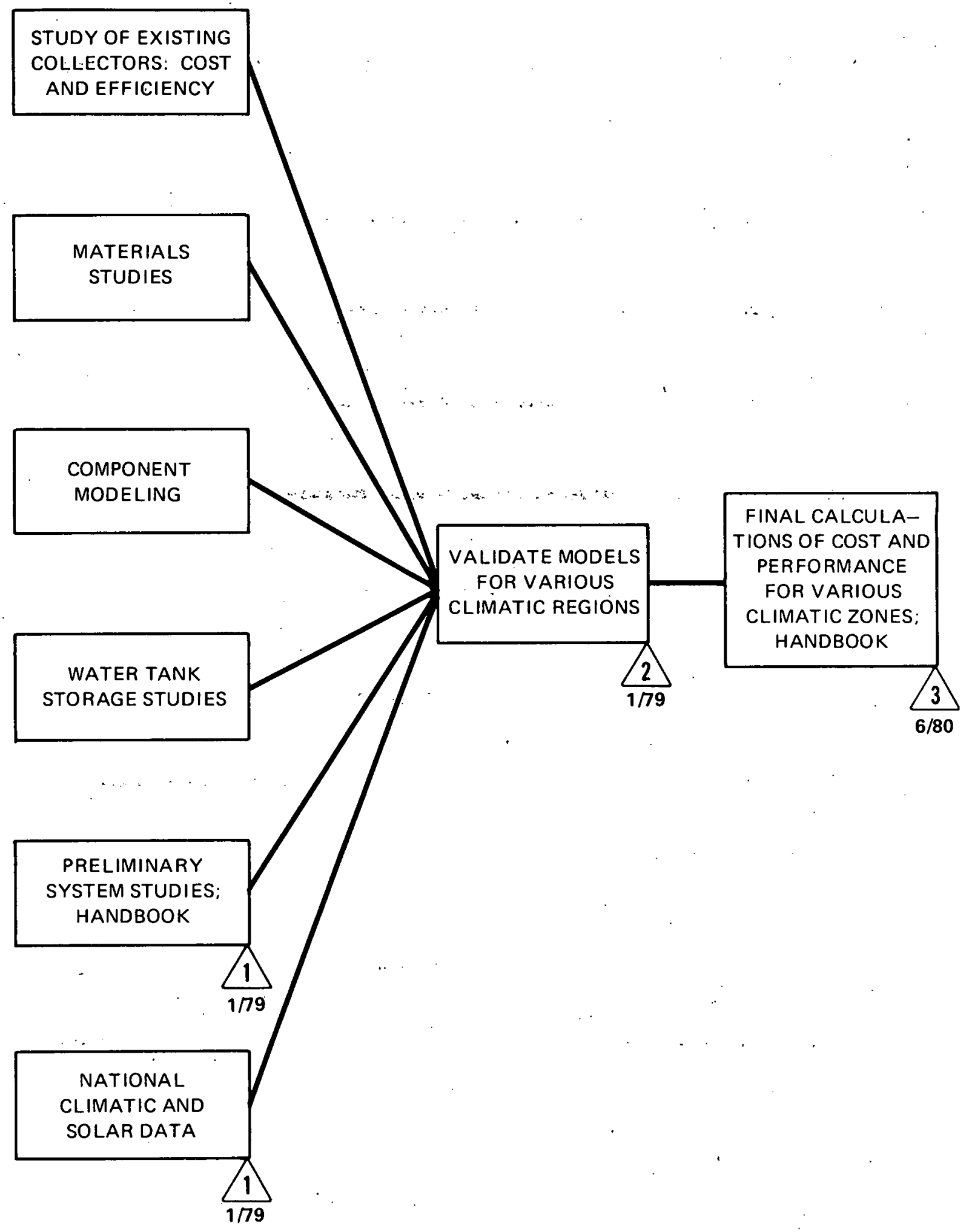

FIGURE II-7

AIR-HEATING COLLECTORS FOR SERVICE HOT WATER

PATH W2 TASK FLOW CHART 


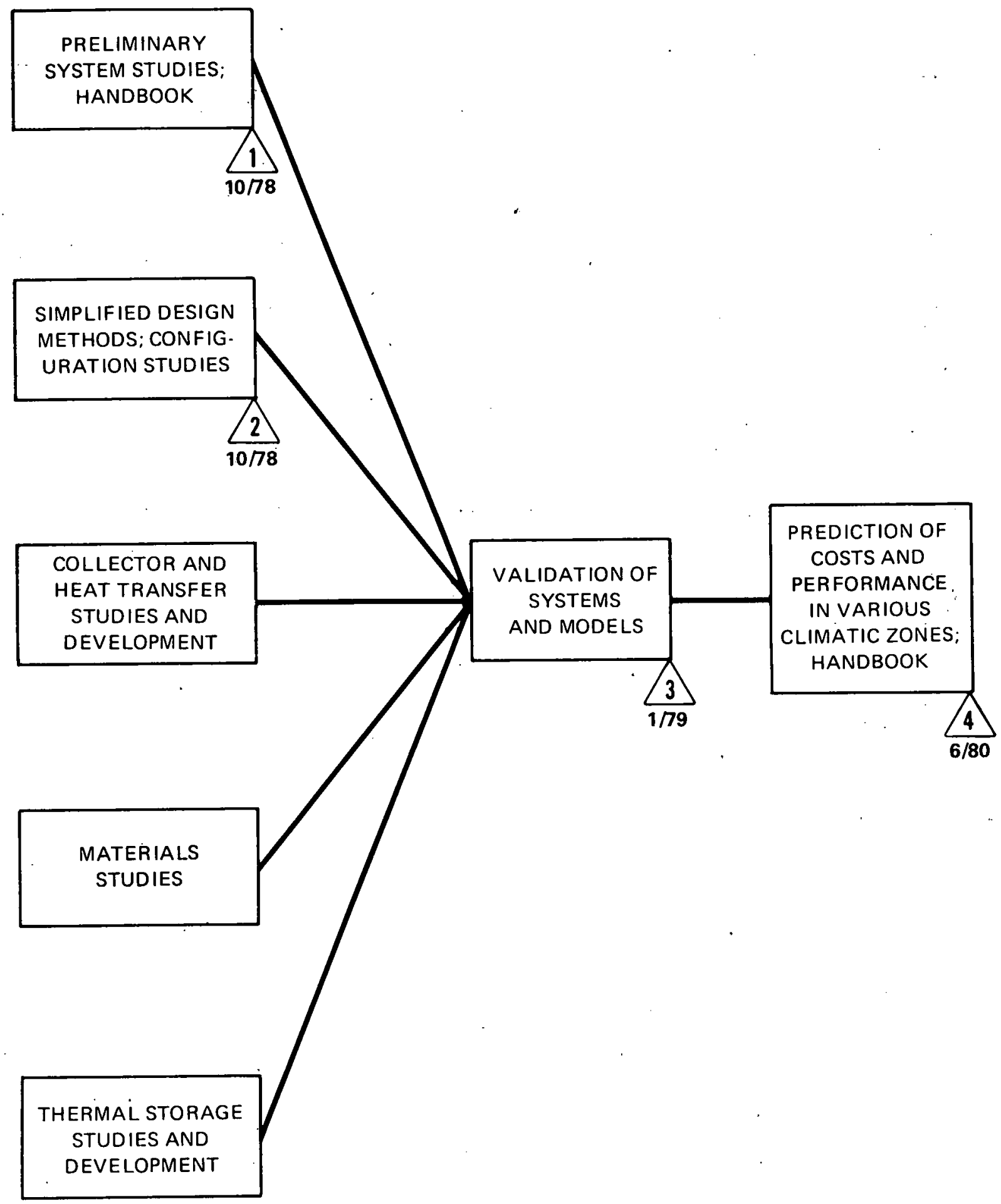

FIGURE II-13 


\section{COMBINED SOLAR AND HEAT PUMP SYSTEMS FOR SPACE HEATING PATH H1}

\section{GENERAL}

The coupling of heat pumps with solar energy systems has been an object of investigation for a number of years. This work indicates that these combinations can potentially reduce electrical energy requirements to a minimum and offer possible relief to utilities through peak load reduction.

The performance of heat pump systems can be improved significantly by basic component changes to allow better load matching and use of more favorable heat sources and sinks. Solar energy systems (collection, storage, and controls) can be more advantageously combined with these improved heat pumps to provide these favorable sources and sinks.) The development of low cost, low temperature collection and storage mechanisms for these systems is appropriate.

Although many system configurations are possible, they can be grouped into two general classes. In parallel systems, the heat pump moves heat from the environment (typically from outside ambient air) to storage and/or load. Solar collectors transfer heat from insolation to storage/load in parallel with the heatpump. In series systems, solar collectors transfer heat from insolation to storage, and the heat pump moves the heat from storage to the load. If the storage temperature is higher than that needed for direct heating, the heat pump is bypassed.

The economic attractiveness of using combined solar and heat pump systems is enhanced if a cooling requirement exists. However, using presently available systems solely for winter heating is not yet aconomically feasible.

\section{R\&D STRATEGY}

The objective of this path is the introduction of cost-effective combined heat pump and solar heating systems into the market. However, the differences between the parallel and series systems, arising from the temperatures at which the various components operate, demand different R\&D strategies if all the benefits attainable from each system are to be realized. In the parallel system, the heat pump typically uses ambient air as its energy source, so its source temperature will tend toward low values during the winter heating season. The collectors and storage, on the other hand, must operate at high enough temperatures to supply the load directly. In the series system, the storage provides the energy source for the heat pump; collectors, storage, and heat pump source all tend to operate at intermediate temperatures.

Because of these operating characteristics, a parallel system can use heat pumps optimized for stand-alone operation without a solar energy system, and solar components designed for use without a heat pump. On the other hand, to use such components in a series system would represent a serious mismatch. The high temperature capabilities of the collectors would be wasted, and the heat pump, optimized for operation at intermediate source temperatures, would not be able to take full advantage of the thermodynamically possible higher efficiencies at these source temperatures.

A comprehensive analysis of system sensitivity will be made through computer simulation of those configurations identified as attractive. This sensitivity analysis will be done for various climatic zones and design parameters, and performance predictions will be made both for currently available heat pumps and 
for improved performance heat pumps. Several operating systems will be built to validate the model and obtain operating experience. Improved performance heat pumps will be developed and cost trade-offs studied. The technology base for the required collectors, storage, heat pumps, and other subsystems will be established.

The solar heating and cooling R\&D program of the Electric Power Research Institute (EPRI) emphasizes the development of combined solar and heat pump systems for space heating with the purpose of providing energy load management flexibility for electric utilities. Cooperation between EPRI and DOE has been established to avoid unnecessary duplication of effort.

\section{SYSTEM TESTS}

The R\&D program will consider sponsoring test marketing efforts in addition to several full operating system tests. These systems will be carefully designed to correspond to configurations identified as optimum for the different climatic zones. The system tests will be thoroughly instrumented, and their performance monitored and evaluated. The primary purpose is to validate the computer models used to choose the optimum systems and to identify appropriate design improvements.

\section{R\&D EMPHASIS}

\section{Evaluation, Development, and Charac- terization of Materials}

Since most of the applications are low temperature $\left[50^{\circ} \mathrm{C}\left(120^{\circ} \mathrm{F}\right)\right]$, the emphasis will be on characterization of low cost conventional materials. This applies to glazings, sealants, coolants, and insulation.

\section{Development of Components}

Collectors: emphasis on low temperature, low cost, and integration with structure.

Heat pumps: redesign for solar operation allowing higher source temperatures and possibly eliminating defrost requirements

Storage: large capacity, low temperature, low cost

Simulator studies

\section{System Development and Analysis}

Performance identification: transient and part load performance, energy yield as a function of system configuration and design, collector performance, climate, storage characteristics, and heat pump characteristics

Load profile determination and utility interactions

Combined solar and heat pump system configuration studies

Cost identification: survey of costs using existing equipment and technology, cost allocation due to summer use of heat pump for cooling

Architectural integration

Testing and evaluation standards

\section{System Testing}

Data gathering on existing systems

New system field tests

Model and theory validation

Design procedures and guidance 


\begin{tabular}{|c|c|c|c|c|c|c|}
\hline TASK GROUPS & FY 1977 & FY 1978 & FY 1979 & FY 1980 & FY 1981 & FY 1982 \\
\hline $\begin{array}{l}\text { SURVEY AND CONFIGURA. } \\
\text { TION STUDIES }\end{array}$ & & & & & & \\
\hline MATERIALS STUDIES & & & & & & \\
\hline COLLECTOR EVALUATION & & & & & & \\
\hline $\begin{array}{l}\text { COMPONENT } \\
\text { DEVELOPMENT }\end{array}$ & & & & & & \\
\hline $\begin{array}{l}\text { DESIGN COMPETITION } \\
\text { AND TESTING }\end{array}$ & & & & & & \\
\hline $\begin{array}{l}\text { CONSTRUCTION OF } \\
\text { OPERATIONAL TEST } \\
\text { SYSTEMSL }\end{array}$ & & & & & & \\
\hline $\begin{array}{l}\text { EVALUATION, MODEL } \\
\text { VALIDATION, DESIGN PRO- } \\
\text { CEDURES, AND GUIDANCE/ } \\
\text { HANDBOOKS }\end{array}$ & & & & & & \\
\hline
\end{tabular}

\section{MILESTONES}

9/79 Publication of the results of combined solar and heat pump configuration studies, identifying the most effective design approaches for each climatic zone.

$3 / 80$

Award of several contracts for
design, construction, and testing.
$6 / 80$

3

Construction of operational test systems.

12/81 4

Validation of computer simulation models. Publication of design procedures and guidance/handbooks for major system configurations. 


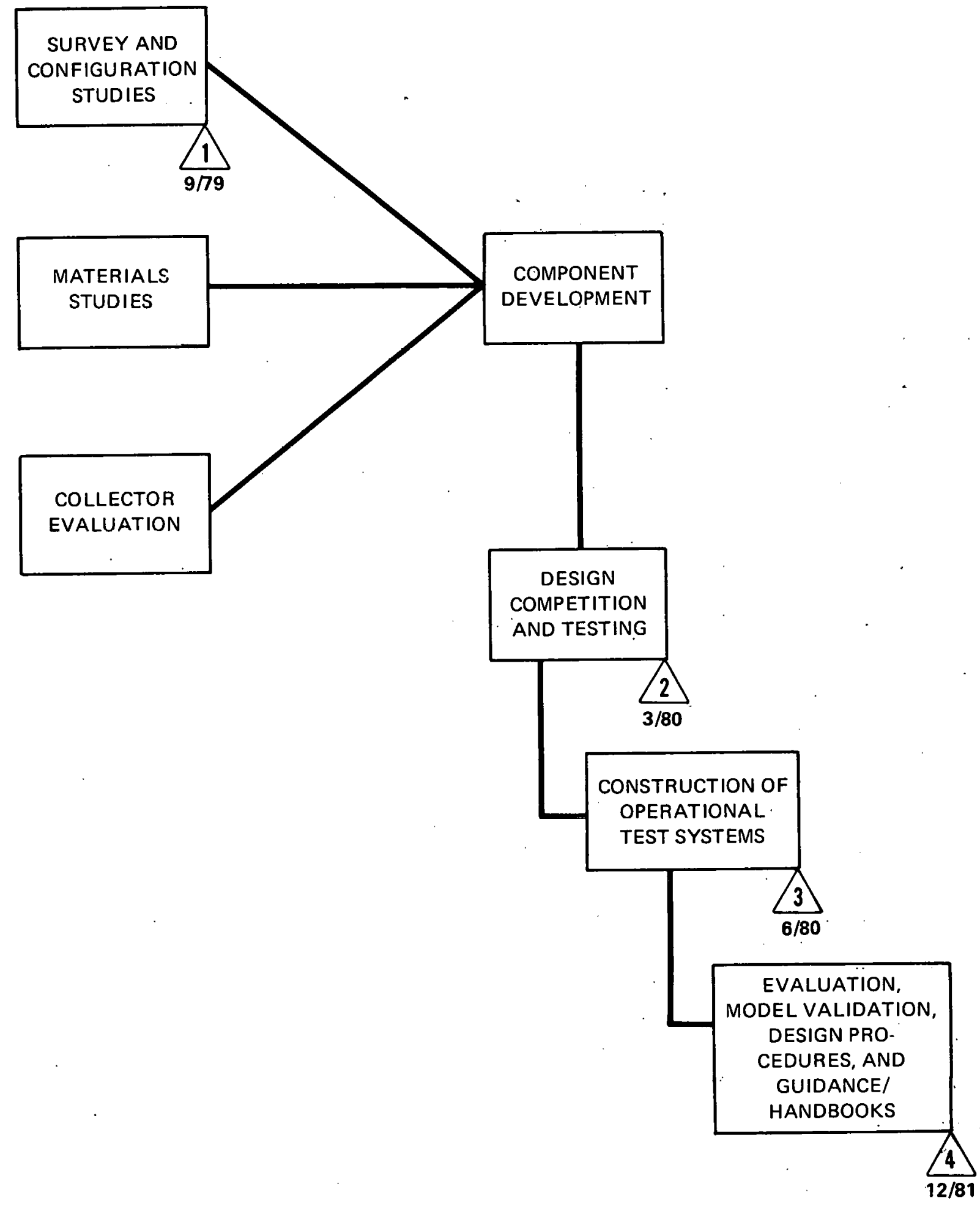

FIGURE $\|-9$

COMBINED SOLAR AND HEAT PUMP SYSTEMS FOR SPACE HEATING

PATH H1 TASK FLOW CHART 


\section{PASSIVE HEATING OF SPACE OR STRUCTURE PATH H2}

\section{GENERAL}

For many buildings, the solar radiation which arbitrarily falls on their roofs, walls, and windows can provide a significant fraction of the building's heat requirements. By improving the thermal resistance of a structure and increasing its ability to make effective use of solar radiation, up to $50 \%$ or more of the heat requirement can be met. Design techniques for accomplishing this include increasing the thermal resistance of windows, walls, and roofs and adding special skylights and controllable clerestory windows.

To obtain solar heating fractions greater than $50 \%$, thermal storage is generally needed to minimize daytime overheating. The excess energy gained during the daylight hours can be stored in the floors, walls, and other portions of the building which have large thermal capacity. Specially designed storage units such as containers filled with water may be located in or adjacent to the heated spaces, or separate thermal storage units may be coupled to the heated space by natural or forced circulation.

Movable insulation in many forms can be used to decrease heat losses at night or on sunless days. Such devices may also be used with both passive (direct) and active (conventional) heating and cooling systems to keep temperature variations within acceptable limits. They also add the capability of automatic temperature control to passive systems.

\section{R\&D STRATEGY}

Emphasis will be placed on determining direct solar heat gain, heat storage, and heat release and circulation characteristics for various system designs, as well as on developing components which have promise for mass production. Computer models of these systems will be developed and validated by tests. The significance of geographical regions in terms of heating and rooling requirements and solar availability must be re- studied, using the best available climatic and insolation data.

Architectural integration is vitally important to this path and the work of the American Institute of Architects/Research Corporation (AIA/RC) should be reviewed to avoid duplication. Information dissemination through journals of the technical societies, as well as specialized handbooks and the presentation of papers at professional society meetings is essential.

\section{R\&D EMPHASIS}

\section{Evaluation, Development, and Characterization of Materials}

Corrosion-proof containers for water with and without conventional anti-freeze additives

Coating materials for fluid containers exposed to long periods of solar radiation

Phase change materials and containers for heat storage at various temperature levels

$\mathrm{U}-\mathrm{V}$ resistance of glazing materials

Resistance to fading of fabrics, etc., which are exposed to solar radiation

\section{Development of Components}

Fenestration insulating devices: determine insulating capability, fire resistance (in the case of foamed materials), and resistance to deterioration after repeated use (movable insulation is very important)

Thermic diode wall or roof structure

Heat pipes or thermal siphon devices for the more effective distribution of energy within buildings

Light and heat control fenestration devices; evaluation of probable costs, benefits 
High heat capacity of prefabricated concrete structural elements incorporating water tubes, heat of fusion material, etc.

High thermal mass furnishings and mass floor systems appropriate to direct gain systems

Roof storage concepts using night-sky radiative cooling

\section{System Modeling}

Identification of basic characteristics and development of algorithms for each major type of passive system

Validation of system by comparison with actual test results, correction of models as required

Development of modeis which accurately represent the time lags in heavy construction such as Trombe-type concrete walls, adobe, and masonry construction

\section{System Development and Analysis}

Determination of energy yields as functions of system type, climatic zones, and desig parameters

Cost of prototypes and mass produced devices; cost characteristics relative to system type

Cost distribution for components with combined functions (walls, floors, ceilings, and fenestration that have both structural and thermal effects upon buildings)

Architectural integration

Examination of qualities of various generic passive systems from standpoint of human comfort

Assessment of cost vs. level of comfort or degree of control

Examination of multi-zonal effects in passive systems

\section{System Testing}

Data gathering and correlation on operating passive solar heating systems

Theory and model validation 


\begin{tabular}{|c|c|c|c|c|c|}
\hline , TASK GROUPS & FY 1977 & FY 1978 & FY 1979 & FY 1980 & FY 1981 \\
\hline \multicolumn{6}{|l|}{$\begin{array}{l}\text { SYSTEM STUDIES OF } \\
\text { EXISTING BUILDINGS }\end{array}$} \\
\hline \multicolumn{6}{|l|}{ BASIC STUDIES } \\
\hline \multicolumn{6}{|l|}{ MATERIALS STUDIES } \\
\hline \multicolumn{6}{|l|}{ CONTROL STUDIES } \\
\hline & & & $\angle 2$ & & \\
\hline \multirow{2}{*}{\multicolumn{6}{|c|}{$\begin{array}{l}\text { MONITORING OF } \\
\text { INNOVATIVE BUILDINGS }\end{array}$}} \\
\hline & & & & & \\
\hline \multicolumn{6}{|l|}{ HYBRID SYSTEMS } \\
\hline \multirow{2}{*}{\multicolumn{6}{|c|}{$\begin{array}{l}\text { OPTIMIZED PASSIVE } \\
\text { HEATING SYSTEMS }\end{array}$}} \\
\hline & & & & & \\
\hline
\end{tabular}

\section{MILESTONES}

Each milestone refers to the preparation and distribution of a handbook on current designs for buildings that will be heated predominantly by. passive solar heating of the space or structure.

$10 / 78$

1 Handbook based on results of existing buildings.

$4 / 79$

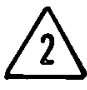

Handbook based on results of basic, materials, and control studies.

6/79

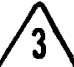

Handbook based on variants and improvement of currently existing buildings.

10/79 Handbook based on results of 4 second generation buildings.

10/81 Handbook based on results of 5 validated system analyses and experiments with optimized system designs.

FIGURE II-10

PASSIVE HEATING OF SPACE OR STRUCTURE

PATH H2 ACTIVITY SCHEDULE 


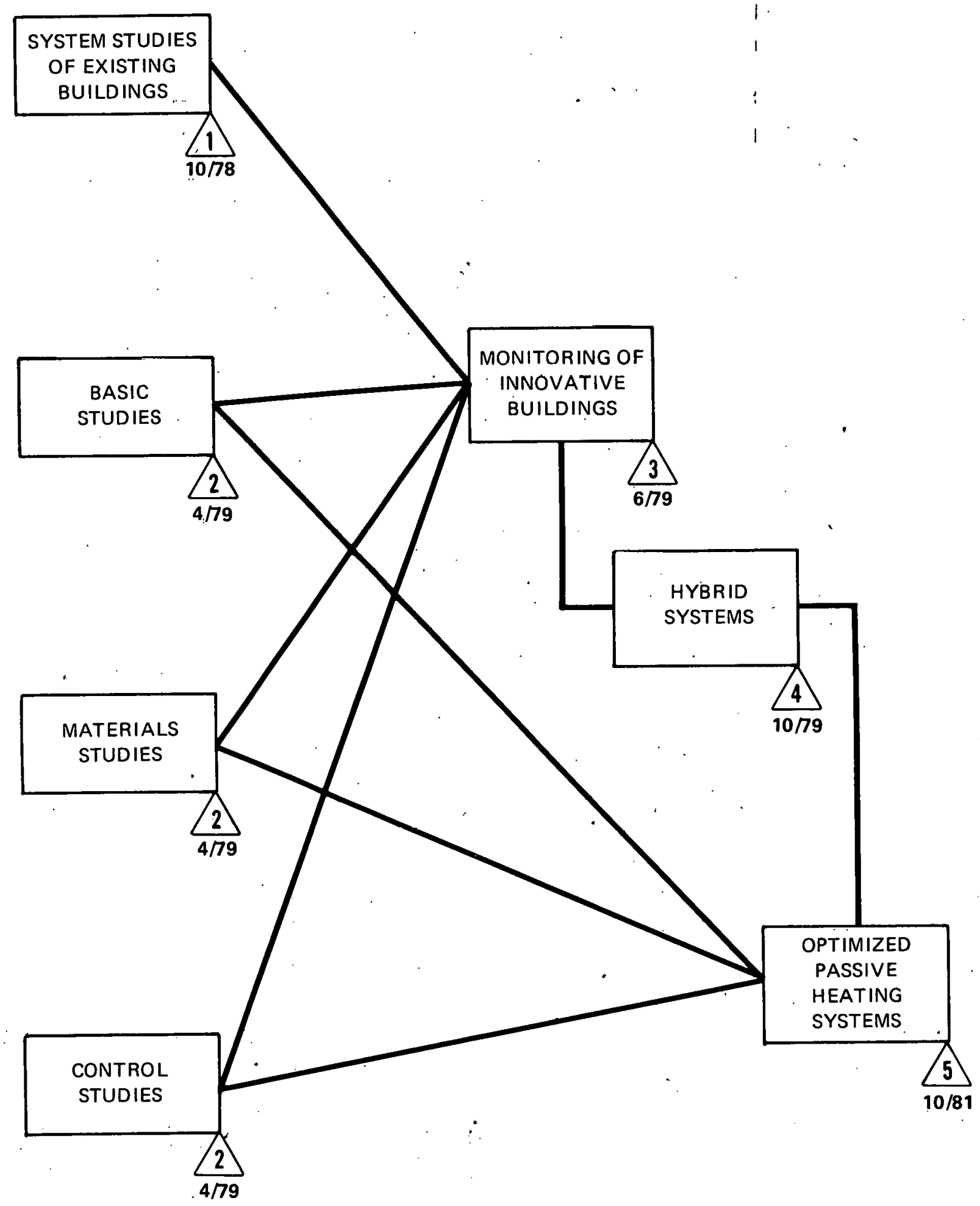

FIGURE II-11

PASSIVE HEATING OF SPACE OR STRUCTURE

PATH H2 TASK FLOW CHART 


\section{AIR HEATING COLLECTORS FOR SPACE HEATING PATH H3}

\section{GENERAL}

In a space heating system using an air-heating collector (flat plate or non-concentrating), air passes through channels in the collector and is heated. The heat is transferred to a storage system, usually a bin of rocks adjacent to or within the heated space. Where space or weight limitations require it, other storage media, such as containers of water or a phase-change material (paraffin or hydrated salt), may be considered.

Although air systems tend to have low heat transfer coefficients, the system can be designed for performance comparable to that of a system using liquidheating collectors and water tank storage. In addition, the air system offers potential advantages in cost, ease of installation, maintainability, convenience, and durability, and lends itself to a combined space heating and domestic hot water heating application. The system's primary disadvantage is that the volume required for thermal storage and ductwork may argue against its use in retrofit applications. Alternative uses of the thermal storage component, such as for swimming pools, should be investigated.

\section{R\&D STRATEGY,}

Emphasis will be placed on bringing air system state of the art up to the level achieved for liquid systems. This can be done through collector development stressing performance, cost optimization, materials, and testing, and through system development stressing design and layout configurations that minimize system costs. Hybrid systems using direct solar gains will also be extensively investigated.

\section{R\&D EMPHASIS}

\section{Evaluation, Development, and Charac- terization of Materials}

Collectors: glazings, surface coatings, sealants
Phase-change materials suitable for use in stratified storage configurations

\section{Development of Components}

\section{Collectors}

Improved heat transfer in collectors

Rock beds

Tube bundles, including phase change

Model and theory validation

\section{System Development and Analysis}

Performance identification: energy yield as a function of system configuration design and locale, collector performance, solar load ratio, climate, air leakage, storage characteristics, and operating strategy

Evaluation and development of simplified system design and performance prediction techniques

Cost identification: survey of costs in existing systems and breakdown of costs by major categories

Architectural integration

Assessment of domestic hot water add-on and retrofit potential

Integration with auxiliary energy system, utility effects

\section{System Testing}

Data gathering on existing systems

Model and theory validation: emphasis on storage behavior and various energy loss mechanisms 


\begin{tabular}{|c|c|c|c|c|}
\hline TASK GROUPS & FY 1977 & FY 1978 & FY 1979 & FY 1980 \\
\hline $\begin{array}{l}\text { PRELIMINARY SYSTEM } \\
\text { STUDIES; HANDBOOK }\end{array}$ & & & & \\
\hline $\begin{array}{l}\text { SIMPLIFIED DESIGN METHODS } \\
\text { CONFIGURATION STUDIES }\end{array}$ & & & & \\
\hline $\begin{array}{l}\text { VALIDATION OF SYSTEMS } \\
\text { AND MODELS }\end{array}$ & & & & \\
\hline $\begin{array}{l}\text { COLLECTOR AND HEAT } \\
\text { TRANSFER STUDIES AND } \\
\text { DEVELOPMENT }\end{array}$ & & & & . \\
\hline MATERIALS STUDIES & & & & \\
\hline $\begin{array}{l}\text { THERMAL STORAGE STUDIES } \\
\text { AND DEVELOPMENT }\end{array}$ & & & & \\
\hline $\begin{array}{l}\text { PREDICTION OF COSTS AND } \\
\text { PERFORMANCE IN VARIOUS } \\
\text { CLIMATIC ZONES; HANDBOOK }\end{array}$ & & & & \\
\hline
\end{tabular}

\section{MILESTONES}

10/78

1.
Preliminary system studies lead to choice of likely systems for various climatic zones. Publish handbook.

$10 / 78$

As a result of system studies, collector development, materials studies, and construction of final simulations, likely systems are confirmed for various climatic zones.

$1 / 79$

3

Models chosen are assembled and simulations are validated based on data from operating systems. Results are published.

$6 / 80$

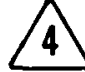

Handbook summarizes system cost and performance characteristics. 
THIS PAGE

\section{WAS INTENTIONALLY LEFT BLANK}


THIS PAGE

\section{WAS INTENTIONALLY LEFT BLANK}




\section{LIQUID-HEATING COLLECTORS FOR \\ SPACE HEATING \\ PATH H4}

\section{GENERAL}

Solar liquid-heating collectors for space heating, the most familiar of the solar heating paths, have received extensive development, but systems using them are expensive to purchase and install. Extensive research and development is necessary to determine the best configurations and operating techniques in various climates. For instance, where space heating determines the collector array size or where a net space cooling requirement cannot be met by night-effect or evaporative cooling, a chiller coupled to the liquid system might provide a small cooling capacity. Thermal storage will usually be in an insulated water tank.

This path will likely be developed regardless of the early results of the directed R\&D program. It is appropriate to stimulate its development by providing the best possible materials and information.

\section{R\&D STRATEGY}

The growing national industry in this area will be supported by collector R\&D that stresses materials characterization and development. Installation costs will be reduced by simplifying manifolding, connections, and thermal storage assemblies. Results of numerous system tests will be made available, computer simulation codes will be validated, and simplified methods of system design will be determined and described.

\section{R\&D EMPHASIS}

\section{Evaluation, Development, and Characterization of Materials}

Collectors: glazings and coatings, sealants, selec- tive surtaces, coolants, and insulation

\section{Development of Components}

\section{Collectors}

Thermal storage tanks, advanced concepts such as phase change, seasonal storage

\section{System Development and Analysis}

Validation and documentation of detailed computer simulation models using test results for existing systems

Development of simplified handbook methods for system design and performance prediction

Cost identification: survey of costs of existing systems with breakdown of costs as to equipment and labor for the various subsystems

Integration with auxiliary energy system, utility effects

Investigation of alternative use of system components such as swimming pool thermal storage system

\section{System Testing}

Continued compilation of data from adequately instrumented system tests:

- Compilation of functional operational results;

- System component evaluation of life and reliability 


\begin{tabular}{|c|c|c|c|c|}
\hline TASK GROUPS & FY 1977 & FY 1978 & FY 1979 & FY 1980 \\
\hline \multicolumn{5}{|l|}{$\begin{array}{l}\text { PRELIMINARY SYSTEM } \\
\text { STUDIES; HANDBOOK }\end{array}$} \\
\hline \multicolumn{5}{|c|}{$\begin{array}{l}\text { SIMPLIFIED DESIGN METHODS; } \\
\text { CONFIGURATION STUDIES }\end{array}$} \\
\hline \multicolumn{5}{|c|}{$\begin{array}{l}\text { VALIDATION OF SYSTEMS } \\
\text { AND MODELS }\end{array}$} \\
\hline \multicolumn{5}{|l|}{$\begin{array}{l}\text { COLLECTOR STUDY } \\
\text { AND DEVELOPMENT }\end{array}$} \\
\hline \multicolumn{5}{|l|}{ MATERIALS STUDIES } \\
\hline . & & & & \\
\hline $\begin{array}{l}\text { STORAGE TANK } \\
\text { DEVELOPMENT }\end{array}$ & & & & \\
\hline $\begin{array}{l}\text { PREDICTION OF COSTS } \\
\text { AND PERFORMANCE } \\
\text { IN VARIOUS CLIMATIC } \\
\text { ZONES; HANDBOOK }\end{array}$ & & & & \\
\hline
\end{tabular}

\section{MILESTONES}

$10 / 78$

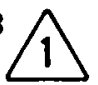

Preliminary system studies lead to choice of likely systems for various climatic zones. Publish handbook.

10/78 As a result of system studies, collector development, materials studies, and construction of final simulations, likely systems are confirmed for various climatic zones.
$1 / 79$

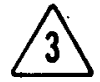

Systems are constructed or chosen from demonstration program, and codes are validated.

$6 / 80$

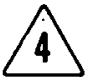

Publication of results.

Handbook summarizes system cost and performance characteristics. 
THIS PAGE

\section{WAS INTENTIONALLY LEFT BLANK}


THIS PAGE

\section{WAS INTENTIONALLY LEFT BLANK}




\section{HIGH TEMPERATURE COLLECTORS WITH ABSORPTION OR HEAT ENGINE/VAPOR COMPRESSION CHILLERS* FOR SPACE COOLING PATH C1}

\section{GENERAL}

High temperature collectors $\left[150^{\circ} \mathrm{C}\left(300^{\circ} \mathrm{F}\right)\right.$ and higher] can provide significant performance advantages and broaden the technical options for solar cooling and refrigeration. Absorption air conditioning candidates for the higher operating temperatures may include the double effect water/ $\mathrm{LiBr}$ systems, the ammonia/water systems, and new refrigerant/absorbent systems. Heat engines will especially benefit from the elevated temperature range since the performance of these engines is closely tied to Carnot efficiencies. In addition to the Rankine and Stirling cycles currently under development, other high temperature cooling options are the Brayton cycle, Vapor Jet Compression, and chemical systems. Although the desiccant cooling concepts are under development for medium temperatures, it is quite likely that improved performance using new fluid pairs could result from the availability of higher temperatures. This directed R\&D program will require cost-benefit data and proof of the marketability of the end product to support the selections of any one of these concepts before the concept will be supported for engineering development.

A variety of collectors are under development for these high temperature systems. In the $150^{\circ} \mathrm{C}\left(300^{\circ} \mathrm{F}\right)$ temperature range, low concentration ratio tracking or non-tracking collectors are given high priority. Evacuated tube collectors with diffuse or focused concentrators are also given high priority.

Thermal storage is a major problem at temperatures above the boiling point of water. The use of pressurized water would probably be the most costeffective solution, but other approaches such as the

-The term chiller in this document is considered synonymous ith direct expansion and chilled water refrigeration outputs. use of collector coolant for storage should also be considered. Hot storage may be as brief as two to three hours, providing only enough time to smooth out variations in solar input and to accommodate the load's natural time lag. Cold water storage will probably be more cost effective for long term thermal storage. Large quantities of cold water will be required, however.

\section{R\&D STRATEGY}

Cooling R\&D will be guided by the cost benefit potential and marketability of the finished product. Three levels of R\&D-applied research, technology development, and field testing - will be required.

Applied research involves conceptual design studies of components, systems, and/or materials. Feasibility analyses will be conducted and preliminary marketing investigations will identify the market potential and possible barriers to consumer acceptance. During the advanced development phase, engineering designs will be completed, prototype models will be designed, fabricated, and evaluated, and marketing reassessment will be conducted. Multiple pre-production models and/or systems will be built and evaluated in field test installations. Detailed marketing studies to substantiate a broadened test marketing program will be formulated.

Technology development will emphasize systems, chillers, high temperature collectors, and system compatible storage concepts. Simple and reliable concentrating/non-concentrating collectors, both tracking and fixed, must be developed. The collectors must demonstrate efficiencies and reliabilities compatible with the cost-benefit goals of the total system concept. Chiller development must demonstrate improved performance and reliability as dictated by the system 
end use. The chiller design and its application in the system operation must address performance under the expected part load and cyclic performance.

This high temperature cooling technology will emphasize the commercial, light commercial, and multifamily residential market, in that order. Careful attention. must be given to local codes associated with high temperature/pressure usage.

\section{R\&D EMPHASIS}

\section{Evaluation, Development, and Characterization of Materials}

Refrigerant characterizations and stability

Lens and mirror materials

Selective surfaces

Storage systems

Liquid coolants

\section{Development of Components}

Development of models for heat loss mechanisms for various absorber/container configurations and materials

Validation of models and theory of operation in the following areas:

- Fresnel lens concentrators;

- Parabolic trough concentrators;

- Compound-parabolic concentrators;

- Mirror tower reflectors and collectors;

- Absorption chillers operating under design, offdesign, and transient conditions;
- Rankine/vapor compression chillers operatin! under design, off-design, and transient conditions; and

- Other cooling and refrigeration concepts under design, off-design, and transient conditions.

\section{System Development and Analysis}

Performance identification: net energy yield as a function of system configuration, collector performance, chiller performance, storage size and configuration, and climatic zone

Cost identification: cost characteristics for various collector and system options

* Market studies: regional and building technology definition; cost benefit and market capture polential

Architectural integration: methods of mounting movable hardware on buildings

Integration with service hot water (or process hot water, as in laundries) and space heating

Integration with auxiliary energy system

\section{System Testing}

Construction of research, advanced development, and development system tests for each approach considered attractive in a given climate

Detailed data gathering on above tests

Model and theory validation

Detailed cost and performance calculations in various climatic zones, summarized in a haridbook 


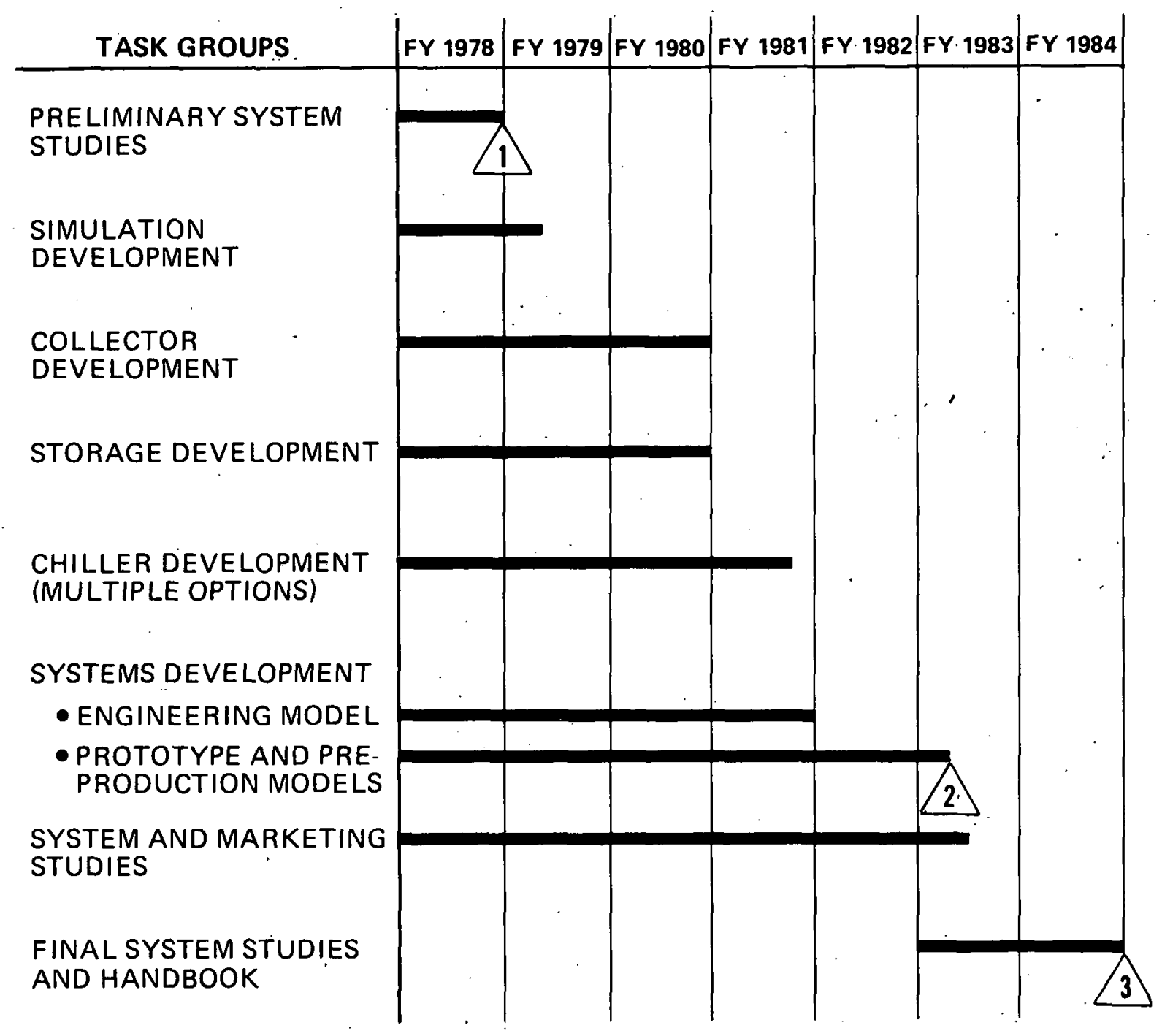

\section{MILESTONES}

$10 / 78$

1 Preliminary system studies concepts and system/subsystem requirements.

1/83 Availability of cooling systems

2 in limited quantities for field test programs and of preproduction systems for large scale test marketing.
$10 / 84$ System studies completed for various climatic regions; handbook. 


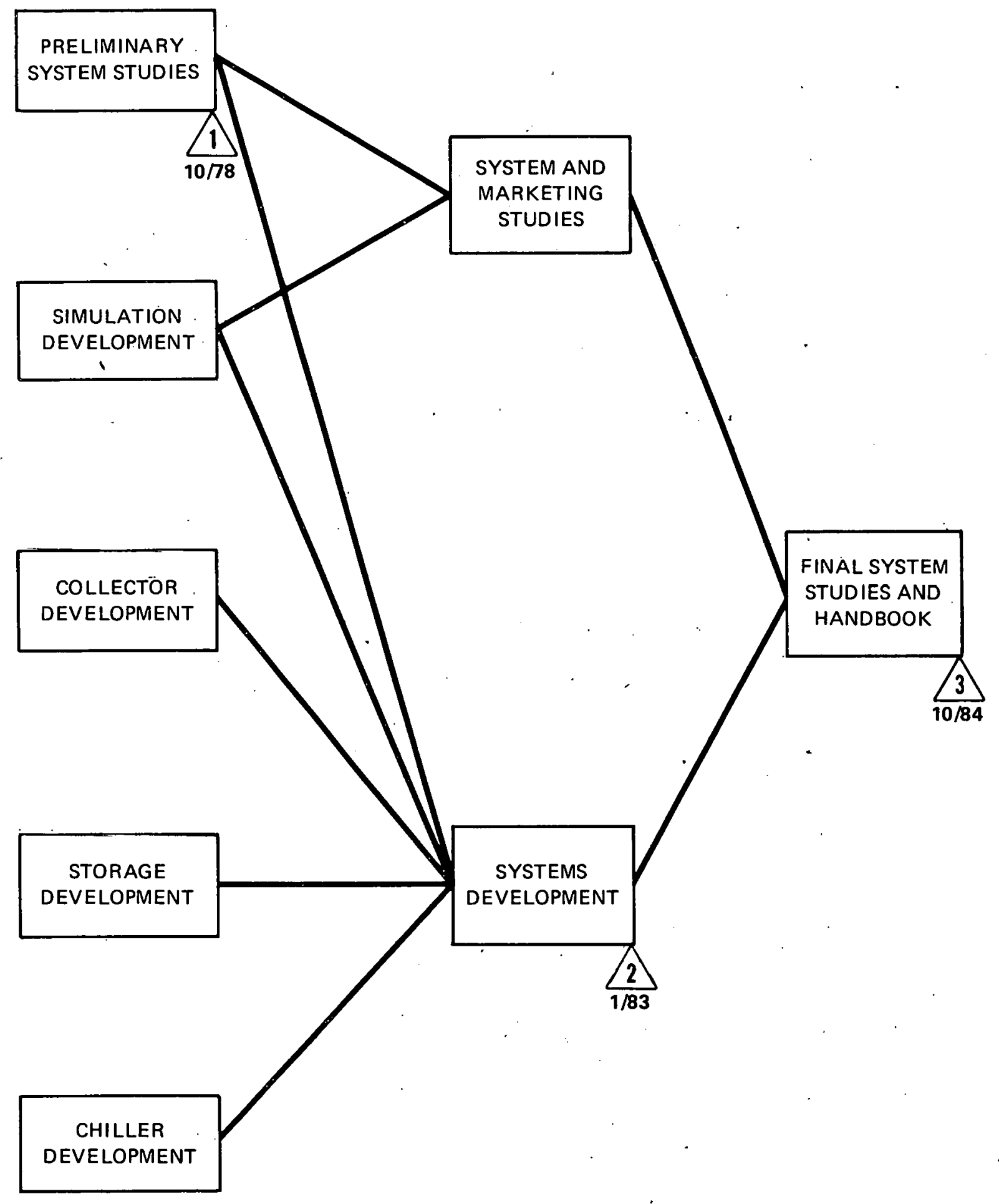

FIGURE II-17

HIGH TEMPERATURE COLLECTORS WITH ABSORPTION OR

- HEAT ENGINE/VAPOR COMPRESSION CHILLERS FOR SPACE COOLING PATH C1 TASK FLOW CHART 


\section{MEDIUM TEMPERATURE COLLECTORS WITH ABSORPTION, HEAT ENGINE/VAPOR COMPRESSION, AND OTHER CHILLERS FOR SPACE COOLING PATH C2}

\section{GENERAL}

Low-loss, fixed-mount, solar liquid-heating collectors will be used to provide suitable inlet temperatures for absorption or heat engine driven chillers. The collectors will include medium temperature $K<120^{\circ} \mathrm{C}$ $\left(250^{\circ} \mathrm{F}\right)$ ] non-concentrating collectors such as evacuated tubes, honeycomb type collectors, selective surface collectors, heat pipes, and various combinations of these. These collectors have the potential for operating at reasonable $(40 \%)$ efficiencies at temperatures up to $120^{\circ} \mathrm{C}\left(250^{\circ} \mathrm{F}\right)$, and they may therefore be suitable heat sources for chillers operating at generator inlet water temperatures up to $110^{\circ} \mathrm{C}$ $\left(230^{\circ} \mathrm{F}\right)$. This path will include standard selective-surface collectors suitable for a generator inlet temperature of $90^{\circ} \mathrm{C}\left(195^{\circ} \mathrm{F}\right)$. [This path differs from Path $\mathrm{C} 7$ in including only those generators with temperatures of $110^{\circ} \mathrm{C}\left(230^{\circ} \mathrm{F}\right)$ or lower.]

Pressurized water is probably the most cost-effective approach to accomplishing thermal storage above the boiling point of water. Other approaches such as using the collector coolant for storage might also be investigated. Hot storage may be used for short periods, perhaps as little as two or three hours, to smooth out variations in solar input and to accommodate the natural time lag of the cooling load. Cold storage of water or phase-change material may be more cost effective for long-term thermal storage. Large quantities of cold water or coolant will be required, however, because the working $\Delta T$ is small. Phasechange hot storage should be considered, because it is highly desirable that the chillers have a constant tem- arature source.

\section{R\&D STRATEGY}

Cooling R\&D will be guided by cost benefit potential and marketability of the finished product. Three levels of R\&D-applied research, technology development, and field testing-will be required.

Applied research involves conceptual design studies of components, systems, and/or materials. Feasibility analyses will be conducted and preliminary marketing investigations will identify the market potential and possible barriers to consumer acceptance. During the advanced development phase, engineering designs will be completed, prototype models will be designed, fabricated, and evaluated, and marketing reassessment will be conducted. Multiple pre-production models and/or systems will be built and evaluated in field test installations. Detailed marketing studies to substantiate a broadened test marketing program will be formulated.

Three areas must be emphasized: medium temperature, high efficiency non-concentrating collectors; low temperature generators; and on-off cycling. Required temperatures will be achieved through the use of high performance collectors. Simple, reliable collectors capable of daily efficiencies over $40 \%$ at fluid temperatures averaging near $120^{\circ} \mathrm{C}\left(250^{\circ} \mathrm{F}\right)$ must be developed. Since the absorption chiller will be one of the most expensive items in the system, it must operate at nearly maximum output.

Advanced systems must be designed and constructed to identify operating characteristics in the field and to validate detailed system models. Because this path includes generators with temperatures of 
$.110^{\circ} \mathrm{C}\left(230^{\circ} \mathrm{F}\right)$ or lower, it will be necessary to redesign the absorption generator or heat engine/vapor compression unit to maintain adequate performance. The absorption machines may also require condensers cooled by cooling towers. (This will be a problem in domestic applications and in areas where make-up water is expensive.)

\section{R\&D EMPHASIS}

\section{Evaluation, Development, and Characterization of Materials}

Clazing and glazing coatings, sealants, selective surfaces, coolants, insulation, and absorbent/refrigerant pairs

\section{Development of Components}

Models for heat loss mechanisms for various collector absorber/container configurations and materials

Validation of models and development of chillers optimized for solar applications

Models of transient performance of chillers and air cycles

\section{System Development and Analysis}

Performance identification: net energy yield as a function of system configuration, collector performance, chiller performance, storage size and configuration, and climatic zone

Cost identification: cost characteristics as a function of the various collector and system options

Market studies: regional and building technology definition; cost benefit and market capture potential

Architectural integration: methods of mounting hardware on buildings

Integration with domestic hot water (or process hot water, as in laundries) and space heating, freeze protection

Integration with auxiliary energy system

\section{System Testing}

Construction of research, advanced development, and development models for each approach considered attractive in a given climate

Detailed data gathering on above tests

Model and theory validation 


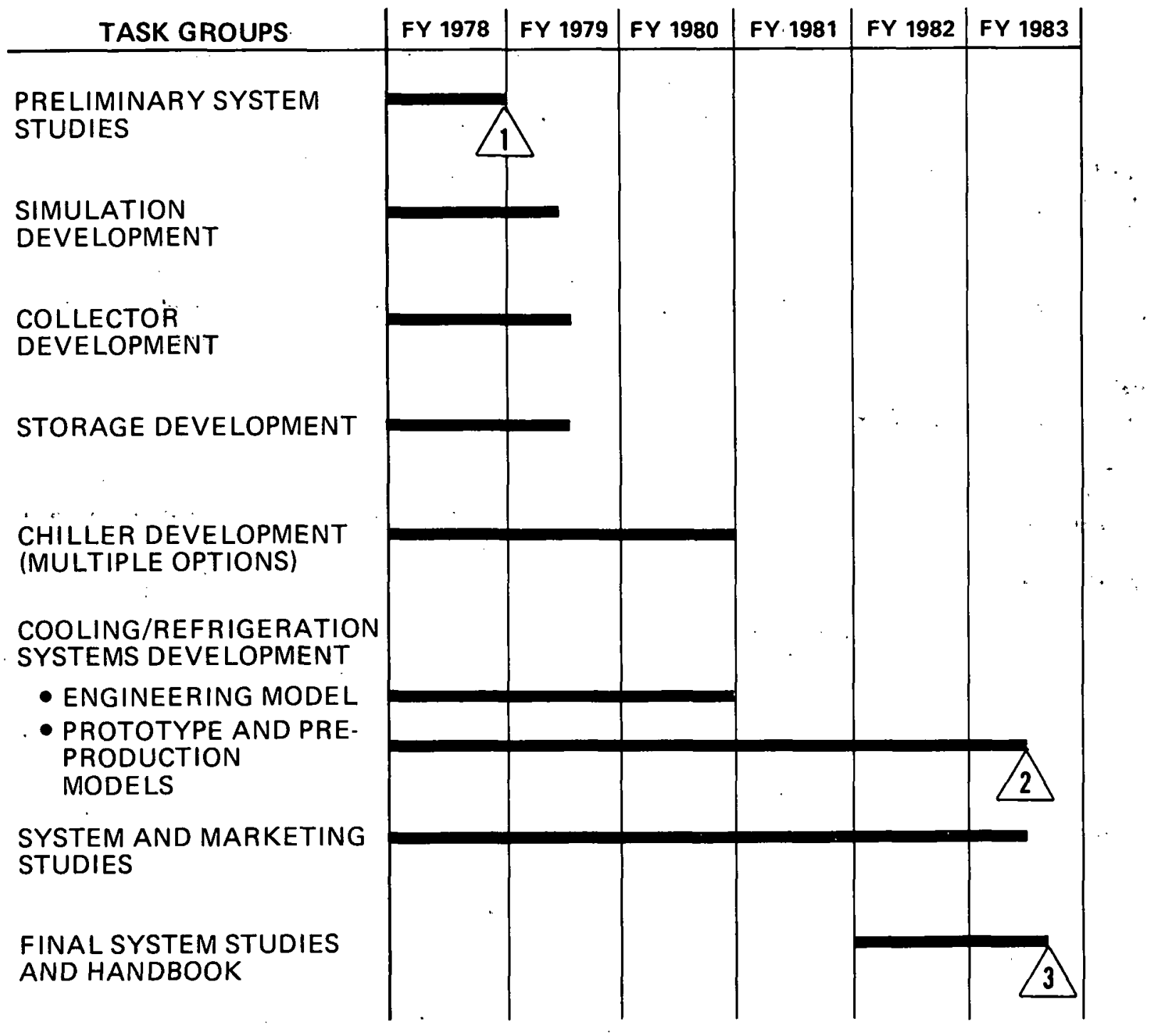

\section{MILESTONES}

10/78 Preliminary system studies

1 identifying advanced cooling

$7 / 83$

System studies completed for
3 various climatic regions; concepts and system/subsystem handbook. requirements. 2. Availability of cooling systems test programs and of preproduction systems for large scale test marketing. 


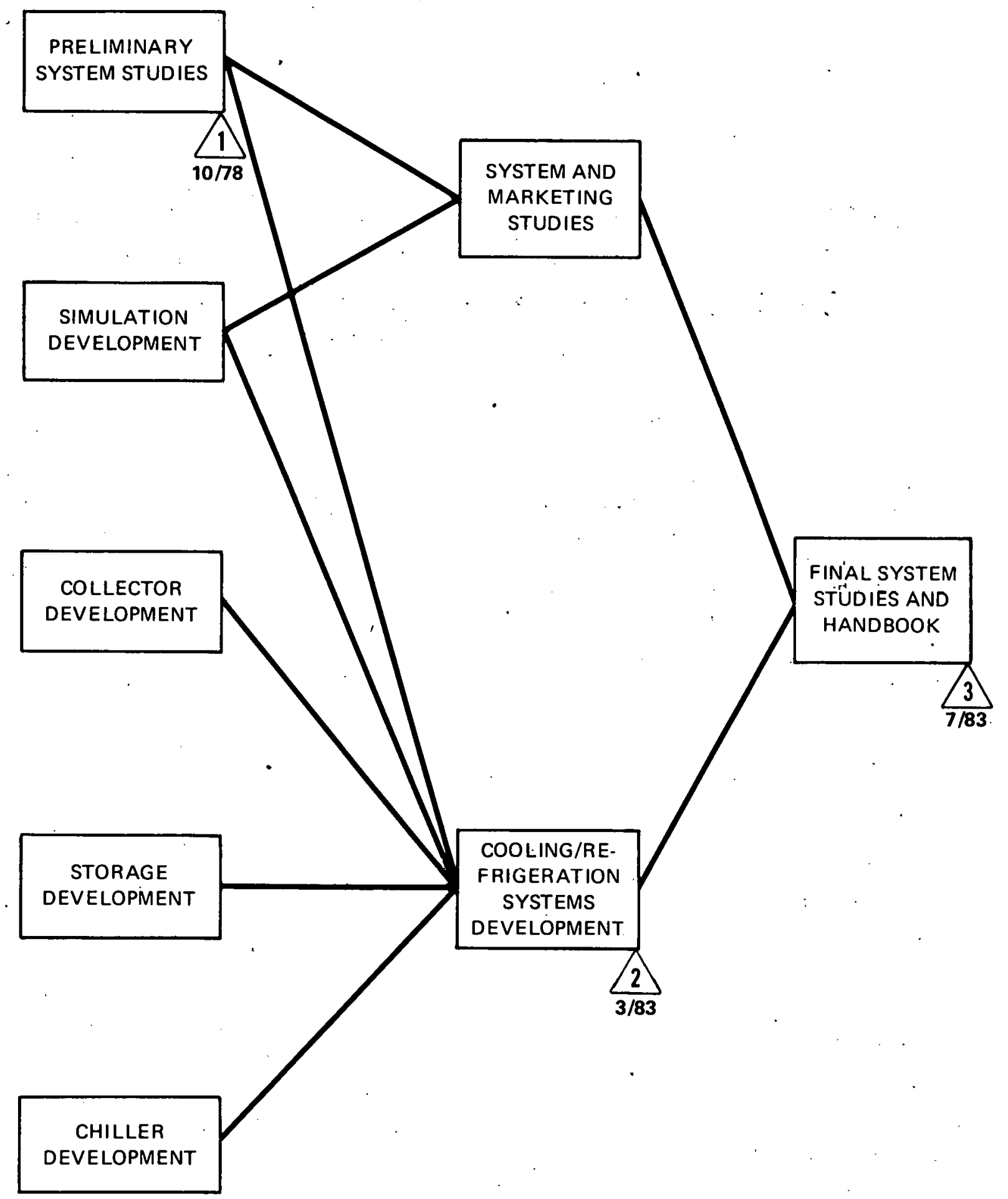

FIGURE $\mid 1-19$

MEDIUM TEMPERATURE COLLECTORS WITH ABSORPTION, HEAT ENGINE/VAPOR COMPRESSION, AND OTHER CHILLERS

PATH C2 TASK FLOW CHART 


\section{FLAT PLATE/ADVANCED, NON-CONCENTRATING COLLECTORS WITH DESICCANT CHILLER/ DEHUMIDIFIER FOR SPACE COOLING AND DEHUMIDIFICATION PATH C3}

\section{GENERAL}

Desiccant chilling involves the dehydration of air by contact with a hygroscopic or a desiccant material. The air is either kept at a constant temperature or cooled after dehydration; it is then chilled by the evaporation of water into the air: Solar heat is used to redry the desiccant. This process can be carried out at temperatures as low as $70^{\circ} \mathrm{C}\left(160^{\circ} \mathrm{F}\right)$, though this lowers the coefficient of performance (COP) significantly. The path is most attractive where the solar collector requirement is governed by the space heating load. This allows the same collectors to be used during the summer for space cooling. Combinations of desiccant systems with solar air heaters are effective, because the desiccant is usually most easily reconstituted by contact with hot air (which carries off the moisture). Though solar liquid heaters could also be used with a desiccant chiller, this approach has a lower priority because it requires more equipment and is therefore likely to be more expensive.

As is normal with this type of collector, thermal storage will be accomplished by means of a rock bed for an air-heating collector and a water tank for a liquid-heating collector.

\section{R\&D STRATEGY}

This path requires considerable research and development. Mathematical models which adequately represent the process kinetics and sub-system interactions must be developed and validated. Solid desiccants capable of being reconstituted at low operating temperatures $\left[55-70^{\circ} \mathrm{C}\left(130-160^{\circ} \mathrm{F}\right)\right]$ are needed. Desiccant bed design concepts," material structures, and air handling systems must be developed, with emphasis being placed on subsystems that require a minimum of parasitic electrical input energy for air circulation.
These subsystems must be durable, mechanically simple, and suitable for integration into an air heating collector/rock bed storage space heating system. Isothermal systems which can be reconstituted at low temperature and adiabatic systems which are simpler but require higher temperature and reconstitution will both be pursued and compared.

\section{R\&D EMPHASIS}

\section{Evaluation, Development, and Characterization of Materials}

Process kinetics: dynamic and equilibrium data for various candidate materials over a range of operating temperatures

Desiccant bed structures: simple, rugged, and inexpensive methods of presenting the desiccant material to space air with low pressure drop without significantly reducing heat and mass transfer

Material deterioration: data on structural integrity and process stability in the face of adverse conditions

\section{Development of Components}

High effectivity heat exchangers ( $>90 \%$ )

Moisture separation

Desiccant beds (high dynamic response and low air pressure loss)

Model and validate desiccant bed dynamics

Air handling equipment

Air system seals (static and dynamic)

Control system (concepts and hardware) 


\section{System Development and Analysis}

Comparative analysis of various desiccant system approaches and alternate cooling concepts as a function of system size and site climate

System modeling and performance identification: system performance as a function of subsystem performance, climate, and system configuration, conitrol strategy, and application factors

Performance sensitivity analysis: accounting for component degradation, moisture carryover, load variation, operating set point, and control strategy

Cost identification: overall evaluation of add-on cost characteristics of desiccant subsystems in various candidate system approaches
Integration strategy with various auxiliary energ sources

Performance and cost-effectiveness study of dehumidification subsystem when integrated with other cooling systems

\section{System Testing}

Construction of suitable system identified from the system analysis

Performance testing of the system in appropriate climatic zones

System model validation with controlled testing results 


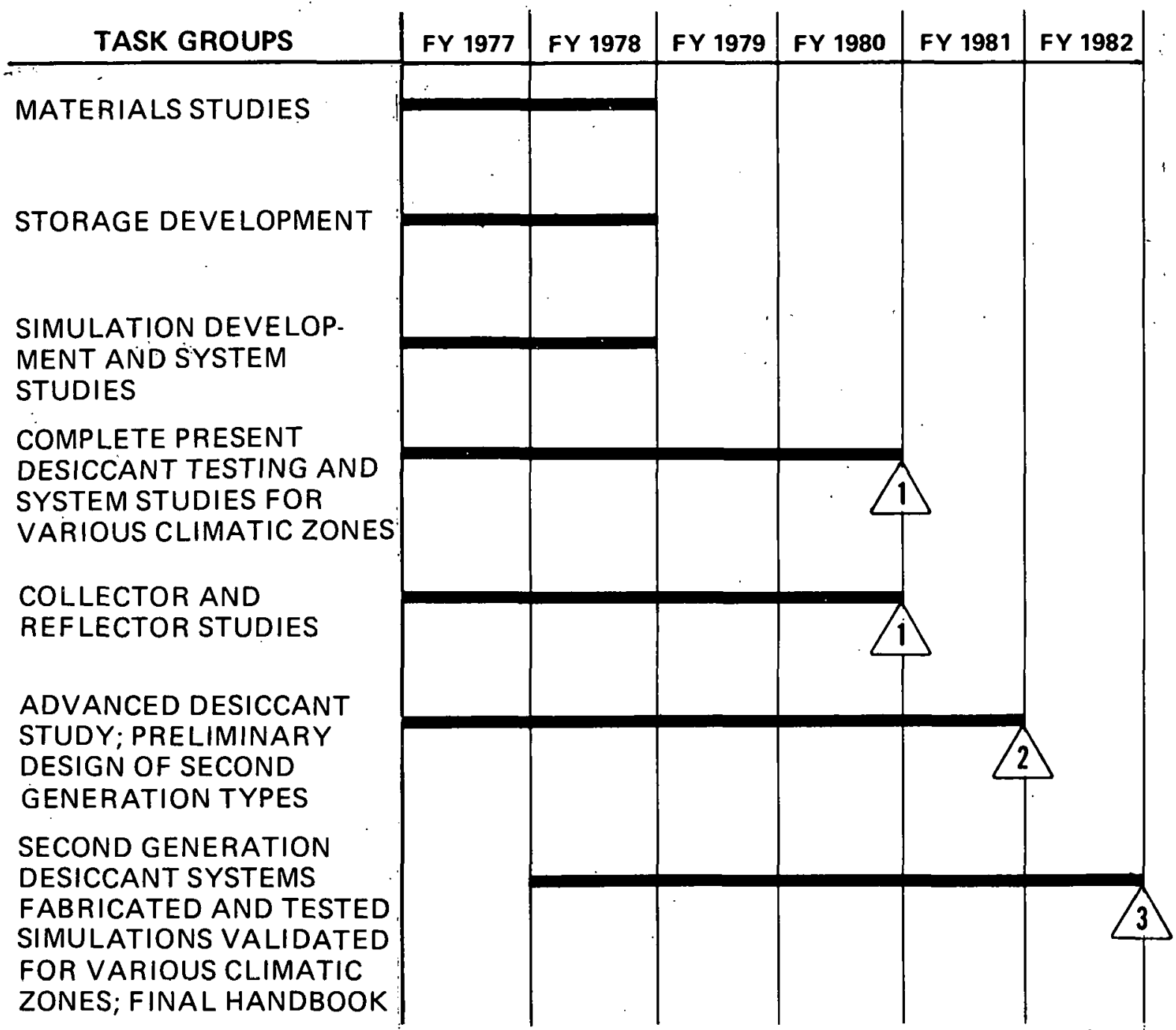

\section{MILESTONES}

$10 / 80$

1. Completion of collector and experiments, and system studies.

Publish preliminary handbook to show cost and performance potential in various climatic zones.
$10 / 81$

Completion of desiccant

2 survey and study of their possibilities, problems, and preliminary designs. Construct those second generation systems that show most promise.

10/82

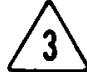

Publish handbook showing applications and potential in various climatic zones. 


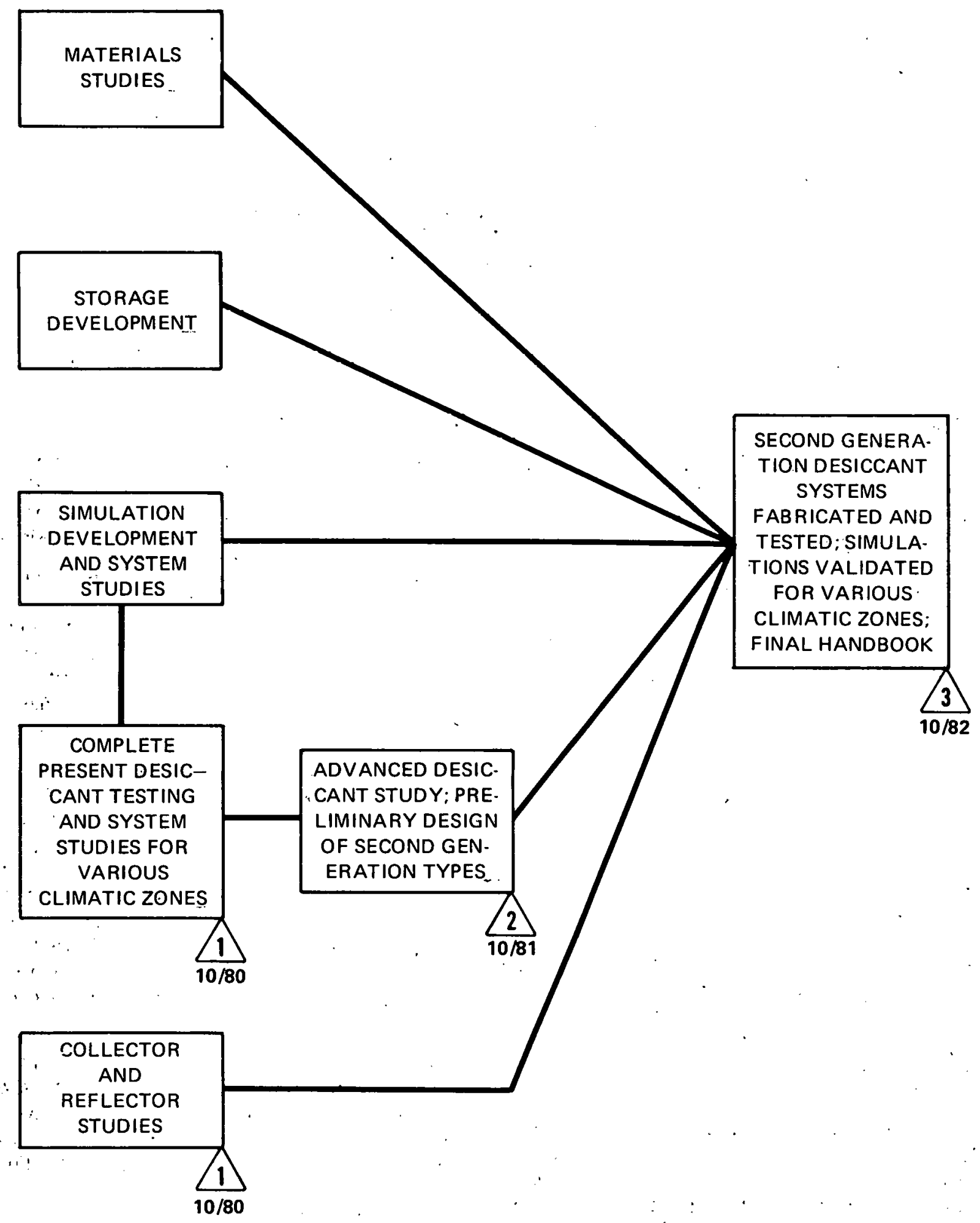

FIGURE II-21

FLAT PLATE/ADVANCED, NON-CONCENTRATING COLLECTORS WITH

DESICCANT CHILLER/DEHUMIDIFIER FOR SPACE COOLING AND DEHUMIDIFICATION PATH C3 TASK FLOW. CHART 


\section{PASSIVE AND HYBRID COOLING PATH C4}

\section{GENERAL}

Many buildings can be cooled through direct interaction with their environment even when dry bulb temperatures are high. The effectiveness of techniques in which cooling is achieved by means of evaporation and radiative heat loss to the sky is dependent on several parameters, the most important of which are relative humidity at ground level, total precipitable atmospheric water vapor, elevation, and cloud cover. These methods can be augmented by the convective exchange of cool night air in regions having sufficient diurnal temperature variation. The purpose of further research and development in this area is to expand the knowledge of the processes involved, and thereby expand the geographic areas where this approach is feasible.

One method which has already been developed uses roof ponds which serve as passive heat dissipators by combining the processes of radiation to the sky, convection, and evaporation. In winter, with proper manipulation of insulation or water flow, heating can also be accomplished, and thermal storage is possible using roof ponds, and structures with large thermal capacity. Heat flow inward in winter and outward in summer can be controlled either by movable insulation or by controlled fluid flow.

A second method is an active system which uses 'a blower to circulate cool night air through a rock bed thermal storage system. The system can store either warmth or coolness, with the latter being created by means of evaporation. In some climates, night air can be used directly without evaporative cooling.

Other methods that can be used to achieve cooling include seasonal storage of ice and use of the cooler ground temperature found a meter or more below the iurface.

\section{R\&D STRATEGY}

$R \& D$ emphasis will be on determining the heat rejection, storage, and absorption characteristics of various designs, and on generating and validating thermal simulation computer models for future designs.

Once validated, the models will be used to determine the most effective parameters for each design, the useful geographical range for each, and the energy savings that should be expected for each design in various climatic zones. Architectural integration and cost effectiveness will be stressed. Experience has indicated that both of these goals can be achieved.

Activities must be closely coordinated with those carried on for paths $H_{1}, H 2$, and $H 3$. In path $H 1$, for example, experience in both Japan and Arizona has shown that economical cooling can be accomplished by the use of a heat pump which rejects heat during the day to a storage tank which, in turn, dissipates heat at night through a roof top radiator. By raising the temperature of the roof a few degrees above the atmospheric temperature, improved radiation transfer to the sky can be accomplished, and evaporative cooling is also more effective.

Information dissemination is extremely important for this path. The public must be made familiar with the general performance characteristics of passive and hybrid cooling systems, and reliable design procedures must be effectively introduced into architectural training curricula.

\section{R\&D EMPHASIS}

\section{Resource Assessment}

Determination of direct cooling potential by radiative, evaporative, and convective techniques in all geographical areas 
Evaluation of potential of night-ventilation cooling in various high thermal-mass systems

Study potential interference from the existing built environment, terrain, and vegetation

\section{Evaluation, Development, and Characterization of Materials}

Structural or coating materials for storing water in containers in sunlight-transparent or translucent film

Phase-change materials and containers for heat storage above or slightly below room temperature.

High transmissivity infrared glazings

Selective infrared emitter materials

\section{Development of Components}

Thermic diode or roof structures

Heat pipes or thermal siphon devices for the more effective distribution of energy within buildings

Light and heat flow-control devices

Rock bin thermal storage

Honeycomb-type windscreens for infrared radiators

\section{System Modeling}

Identification of basic characteristics of each type of system

Preparation and validation of system models

\section{System Development and Analysis}

Performance identification: energy yield for heating and cooling as a function of system type, climatic zone, and design

Cost identification: cost characteristics relative to system type; cost allocation when components have combined functions (a wall, for instance, that has structural and heat storage functions or a roof which provides weather protection and heat absorption/dissipation)

Performance of systems using exterior radiatorconvectors (essentially unglazed flat plate collectors used as night-sky radiators)

Combination with space heating systems

Architectural integration

Retrofit potential

\section{System Testing}

Data gathering on operating systems

Model validation

Evaluation of the long term effect of humidification-drying cycles on rock bed storage in various climates; if adverse effects are noted, evaluation of fungicides or other remedies

Evaluation of human comfort factors, including dry bulb temperature, globe temperature, humidity, and air speed 


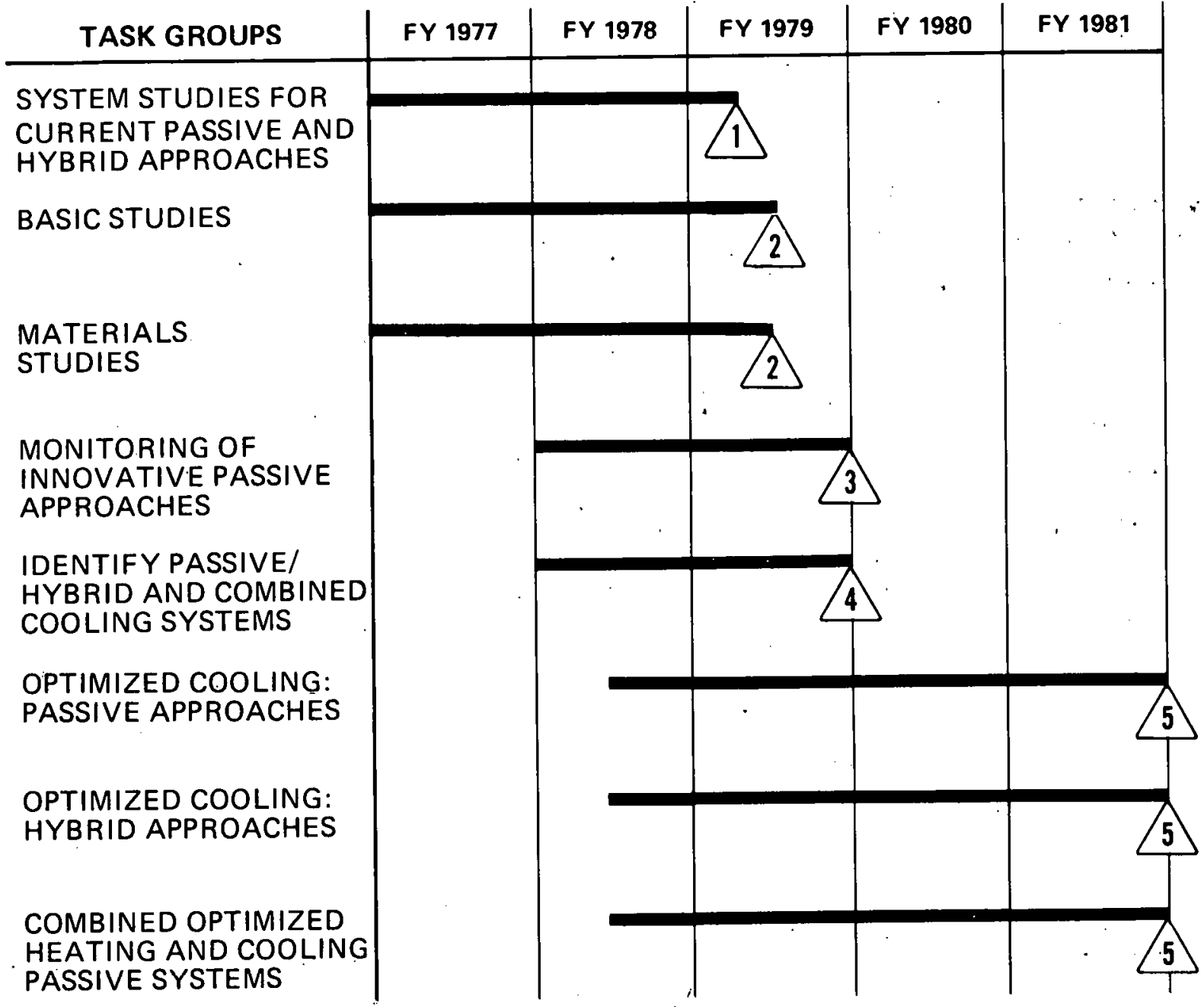

\section{MILESTONES}

Each milestone refers to the preparation and distribution' of a handbook on current designs for buildings that will be cooled predominantly by passive and hybrid cooling techniques.

1/79 Handbook based on first round system studies of passive and active techniques.

4/79 Handbook based on results of basic and materials studies.

10/79 Handbook based on variants and improvements of current passive cooling techniques.
$10 / 79$ Handbook based on results of hybrid system tests.

$10 / 81$ Handbook based on optimized passive cooling systems, hybrid cooling systems, and combined heating and cooling passive systems.

FIGURE II-22 


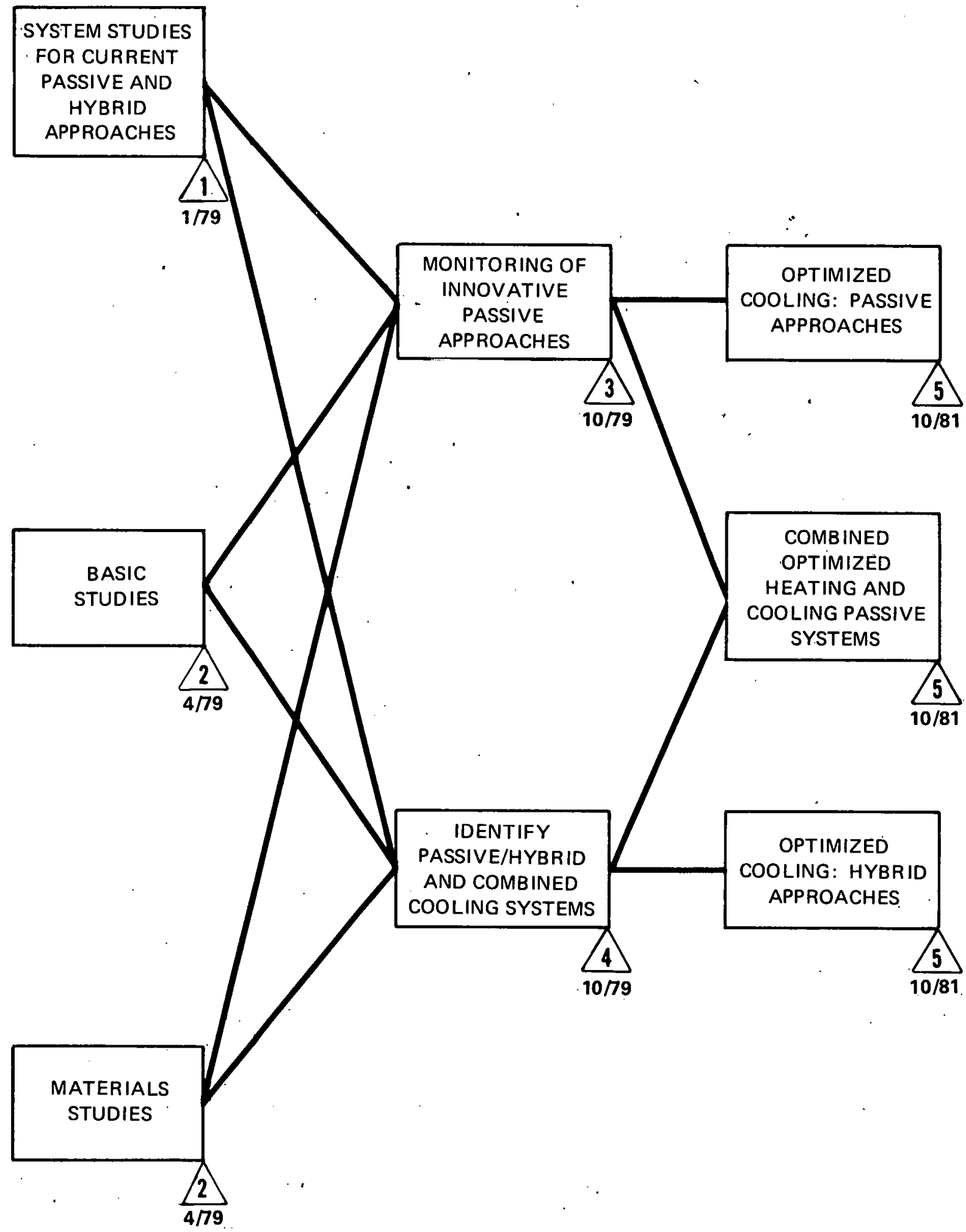

FIGURE $\| 1.23$

PASSIVE AND HYBRID COOLING

PATH C4 TASK FLOW CHART 


\section{COMBINED SOLAR AND HEAT PUMP SYSTEMS FOR SPACE COOLING PATH C5}

\section{GENERAL}

The objective of this path is to develop the optimum application of the space cooling capabilities of combined solar heat pump systems. All three major components of the system (collector, storage, and heat pumps) can be configured to reject heat to the environment. The heat pump can reject heat directly to the environment, but must normally do so at maximum ambient temperatures. The heat pump can reject heat to storage during peak ambient conditions or can be used to cool storage during minimum ambient temperatures. Cool storage temperatures can also be produced by several nocturnal heat dissipation means such as radiation cooling, fan/coil units, or cooling towers.

Nocturnal radiation cooling is geographically limited, but such nighttime dissipation of heat via the collector may be possible in some climates. The use of a fan/coil unit for nocturnal dissipation by forced air convector is more widely applicable.

The extent of energy savings from this path will depend on the efficiency of the heat pump when operating with small source-to-sink temperature differences. The advanced heat pumps presently being developed in conjunction with this path and Path $\mathrm{H} 1$ will be well matched to this cooling application, since they are being designed to operate very efficiently at small source-to-sink temperature differences.

\section{R\&D STRATEGY}

A comprehensive analysis of optimum heat dissipation techniques will be made through computer simulation. This analysis will examine various climatic zones and design parameters, and performance predictions will be made both for currently available heat pumps (with associated dissipation equipment) and for improved performance heat pumps. Optimum system control strategies will be developed to employ the most advantageous dissipation technique in varying ambient conditions. Appropriate operating systems will be built to validate detailed system models and to obtain operating experience. Cost trade-offs will be studied.

\section{SYSTEM TESTS}

The R\&D program will consider sponsoring test marketing efforts in addition to several full operating system tests. These systems will be carefully designed to correspond to configurations which have been identified as optimum for the several different climatic zones. The system tests will be thoroughly instrumented, and their performance monitored and evaluated. The primary purpose is to validate the computer models used to choose the optimum systems and to identify appropriate design improvements.

\section{R\&D EMPHASIS}

\section{Evaluation, Development, and Characterization of Materials}

Glazings, coatings, and surfaces for radiation, natural convection, and forced convection cooling

\section{Development of Components}

Develop heat dissipation models for various system configurations and operating techniques 
Heat pumps optimized for cooling as a part of a solar heating and cooling system

Identify/develop improved dissipation equipment (fan coils, cooling towers, and collectors) to optimize various system configurations

\section{System Development and Analysis}

Performance identification: transient and part load performance, energy yield as a function of system configuration and design, climate, collector perfor-. mance, storage characteristics, and heat pump characteristics

Load profile determination and utility interactions

Cost identification: survey of costs using existing heat pumps and associated dissipation equipmer and improved heat pumps and dissipation equi $i_{r}$ ment

Architectural integration

Develop testing and evaluation standards

\section{System Testing}

Construct one system for each configuration considered attractive for a given climate and application

Detailed data gathering on above tests Model and theory validation 


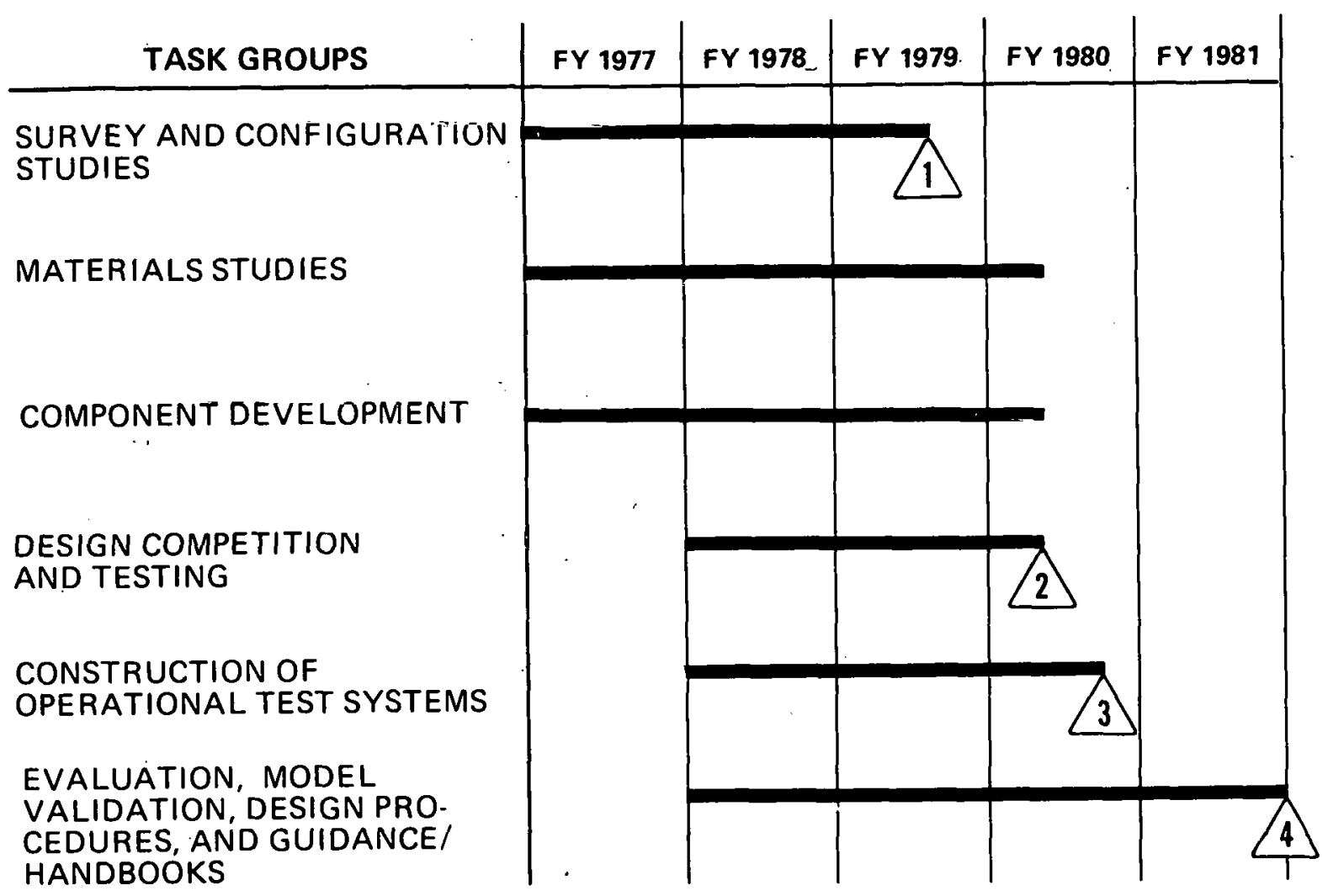

\section{MILESTONES}

$6 / 79$

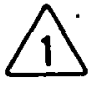

Publication of the results of combined solar and heat pump configuration studies, identifying the most effective design approaches for each climatic zone.

$1 / 80$

2. Award of several contracts for
$6 / 80$

Construction of operational test 3 systems.

10/81 Validation of computer 4 simulation models. Publication of design procedures and guidance/handbooks for major system configurations.

FIGURE $\mid I-24$

COMBINED SOLAR AND HEAT PUMP SYSTEMS

FOR SPACE COOLING

PATH C5 ACTIVITY SCHEDULE 


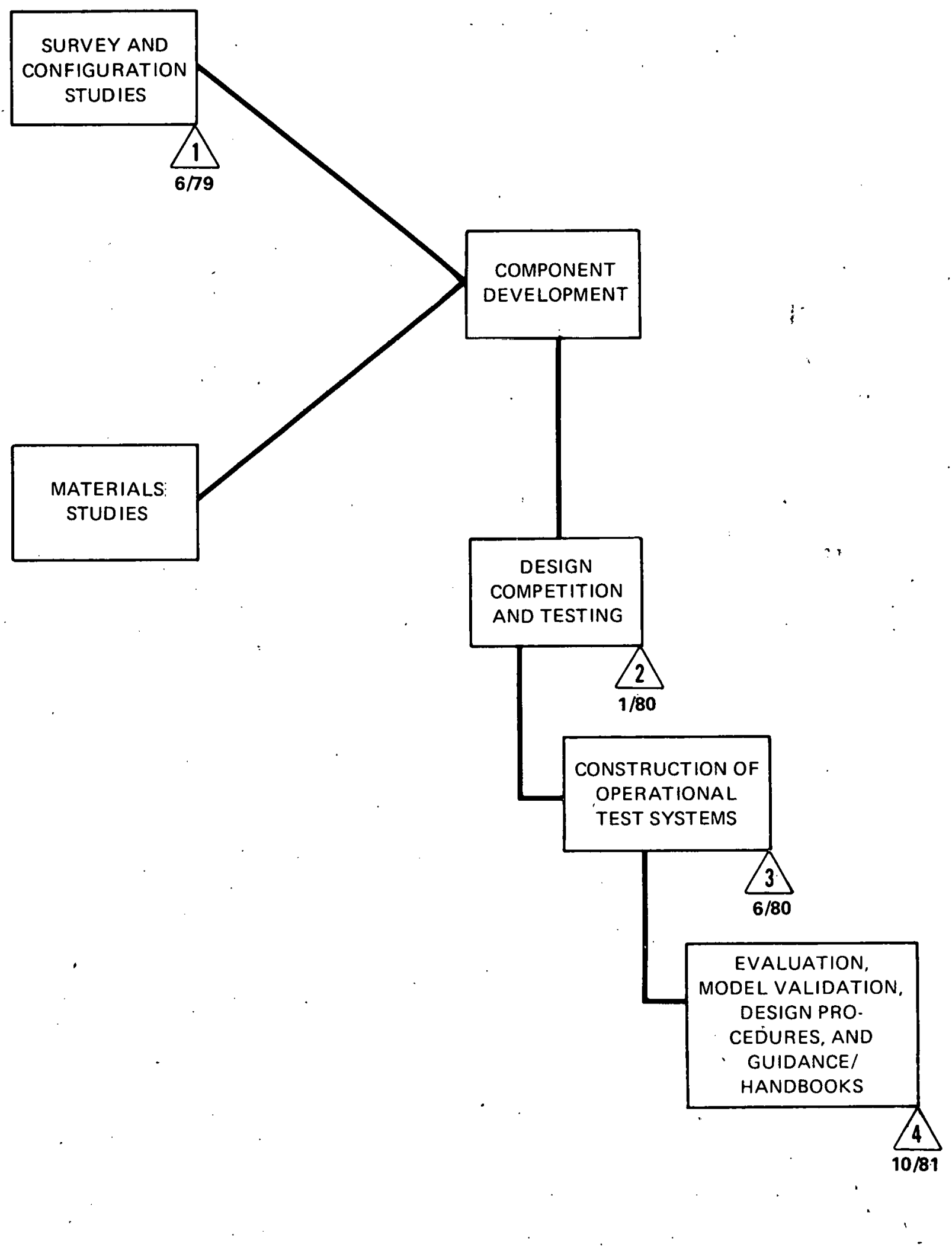




\section{SECTION B \\ R\&D PROGRAM STRUCTURE AGRICULTURAL AND INDUSTRIAL PROCESS HEAT}

The R\&D effort required for the agricultural and industrial process paths will be similar to that required for the heating and cooling of buildings paths. However, several additional points must be considered regarding agricultural and industrial process applications:

- Industrial process systems are generally very large and consume substantial amounts of energy. Energy uses are more varied than in the building applications, and tailoring the systems to meet particular applications is a major challenge.

- There is a wide range of temperature and humidity requirements; - also, some industrial uses demand very exact temperature control, while others tolerate broad variation (e.g., some warehouses). The possible solar energy uses, represent a very broad spectrum of conditions as contrasted with only two temperature regions for heating and cooling: room temperature and hot wash water.

- Industrial process heat loads are usually predictable and constant throughout the year, allowing maximum utilization of solar heating systems.

- Although only about $3 \%$ of total U.S. energy is used on farms and ranches, agriculture is a vital area of energy usage which will be affected by fossil fuel shortages. Energy uses on farms are varied, ranging from the heating of animal shelters to the drying of crops. Solar energy systems must be tailored for the different applications.
- Industry requires short payback periods for new process systems, generally from 3 to 5 years. Solar energy systems with low initial costs but high maintenance costs may be the most costeffective approach, because industrial plants have trained maintenance personnel available.

- Aesthetic requirements in agriculture and industry are not critical. Systems must be durable, because they. often will operate in hostile environments. However, more area may be available so that less efficient, lower cost hardware may be utilized if this would lead to more competitive systems. Storage facilities in the form of ponds, liquid waste systems, and tanks may be available.

- In agriculture, because of the seasonal nature of energy demands, there is a large potential for multi-use solar energy systems, combining, for instance, animal housing and crop drying or farmhouse and greenhouse heating. Hence, there is an advantage to simple, portable systems. Because the farmer will probably build and maintain the system, it should consist of materials that are readily attainable and easy to handle.

- The state/Federal tax structure plays an important role in determining the cost of industrial process heat, whether fossil or solar. Tax incen:tives and low interest loans can be of crucial importance in the early acceptance of solar energy systems by agriculture and industry.

In parallel with general R\&D, it is necessary to develop solar energy systems to meet the require- 
ments of the individual farmer and industrial plant user of energy and of particular geographic regions. When systems are shown to be cost effective, the principles behind their operation must be made available to other users.

Because of the large variety of applications, the R\&D program for agricultural and industrial process heat should, in addition to providing basic handbooks, supply descriptions of as many examples of working solar energy systems as possible. These descriptions should include reasons for choice of materials, components, and designs, as well as schematics and photographs. An accurate summary of costs and operating experience should also be included.

Figures II-26 to II-30 illustrate the 11 agricultural and industrial process heat paths. It should be emphasized that not all paths are of equal importance and that all possible paths are not included. As a result of the R\&D program, other paths are likely to be developed. Although much of the basic R\&D is covered under the paths for the solar heating and cooling of buildings, there are significant requirements for applied research and technology development which are specific to the agricultural and industrial areas. For example, process steam, typically at temperatures from $100-400^{\circ} \mathrm{C}$ $\left(212-750^{\circ} \mathrm{F}\right)$, is an important industrial requirement. Similarly, there is a requirement for large-scale industrial refrigeration (temperatures below about $4^{\circ} \mathrm{C}$ $\left.\left(40^{\circ} \mathrm{F}\right)\right)$, primarily for food freezing, freeze drying, and ice production. 


\begin{tabular}{|c|c|c|c|}
\hline $\begin{array}{l}\text { ENERGY } \\
\text { SOURCE/ } \\
\text { SINK }\end{array}$ & $\begin{array}{l}\text { ENERGY } \\
\text { COLLECTION/REJECTION }\end{array}$ & $\begin{array}{c}\text { ENERGY } \\
\text { CONDITIONING }\end{array}$ & APPLICATION \\
\hline
\end{tabular}

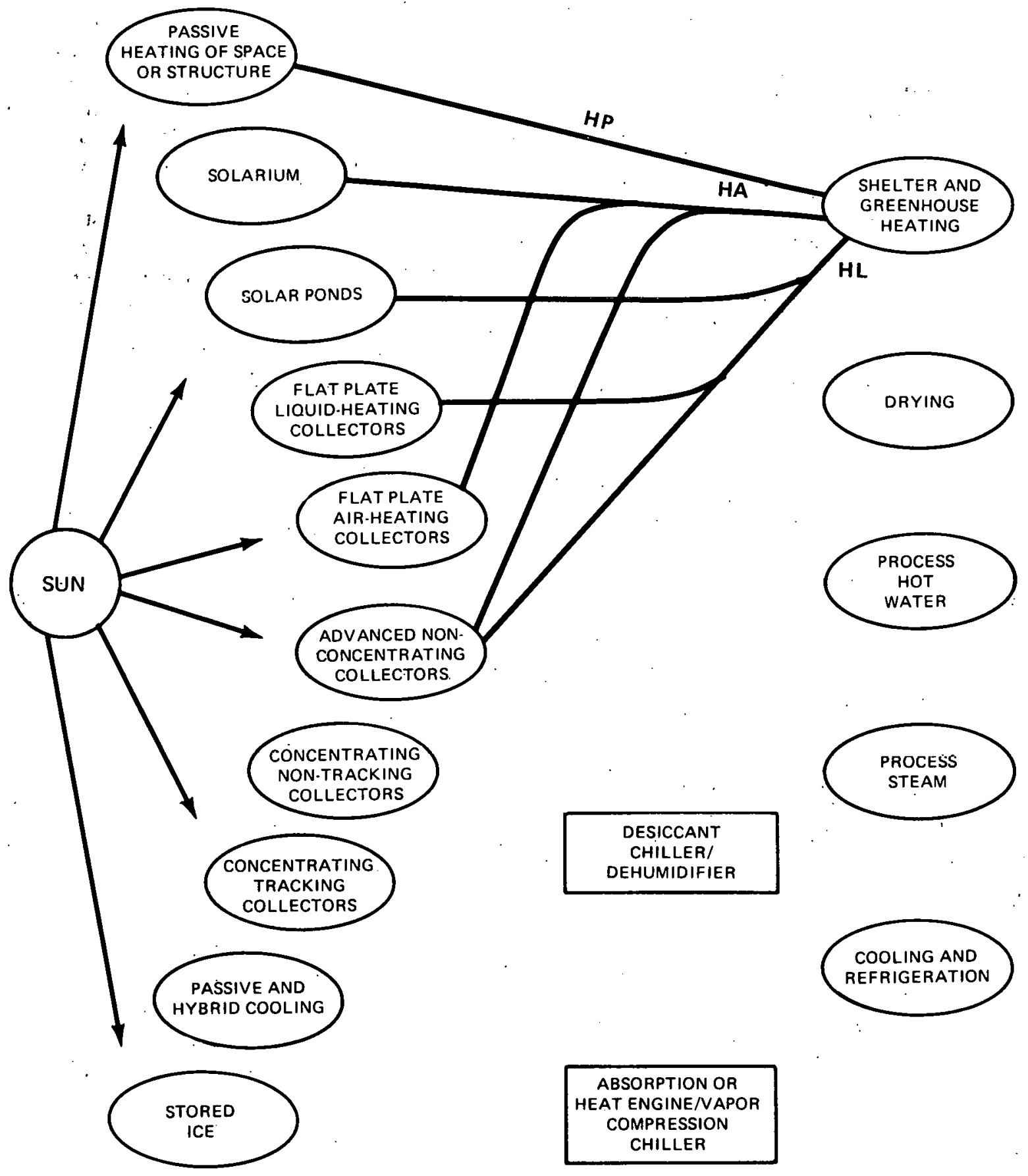

FIGURE II-26

PATHS TO SOLAR SHELTER HEATING 


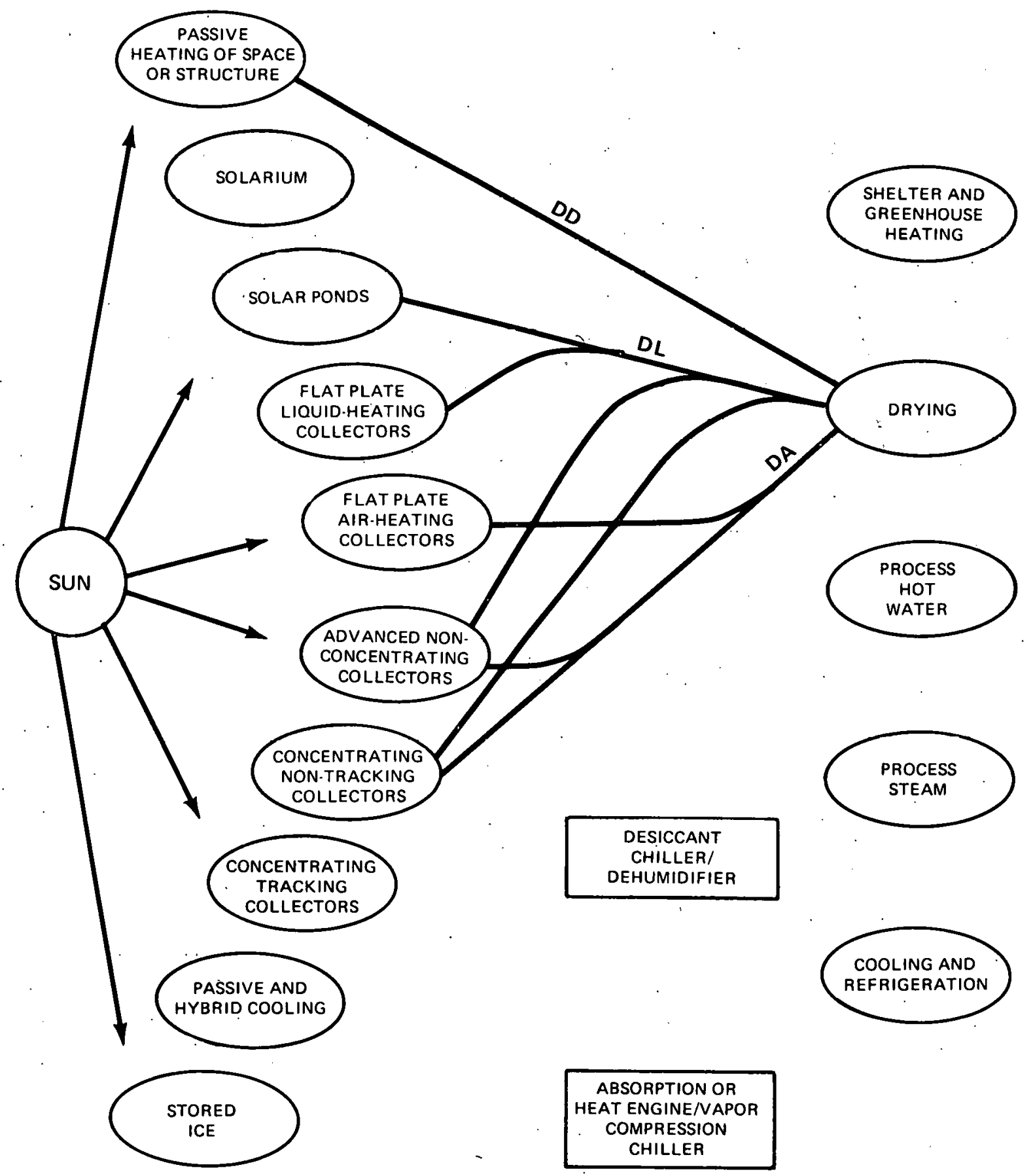




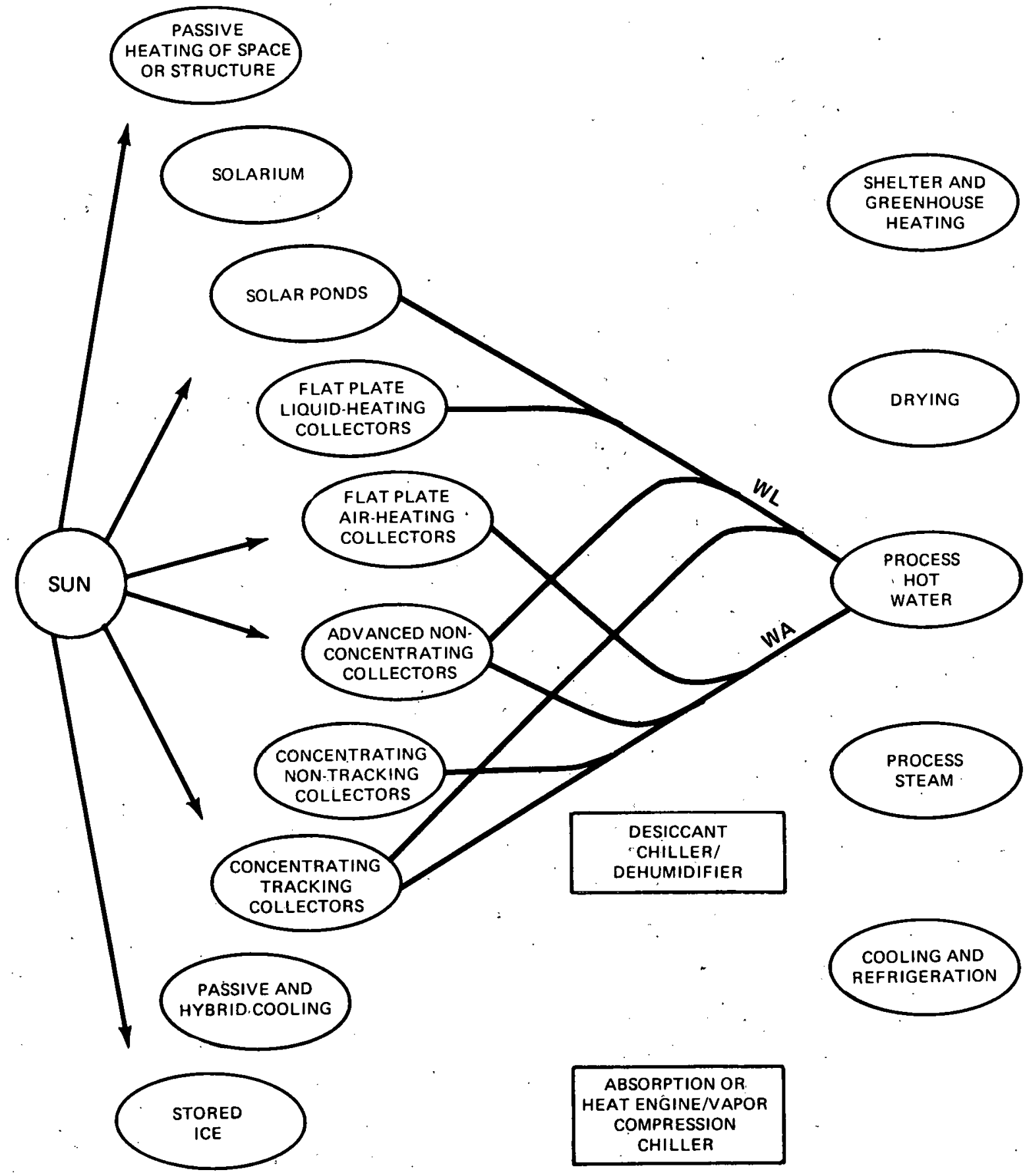




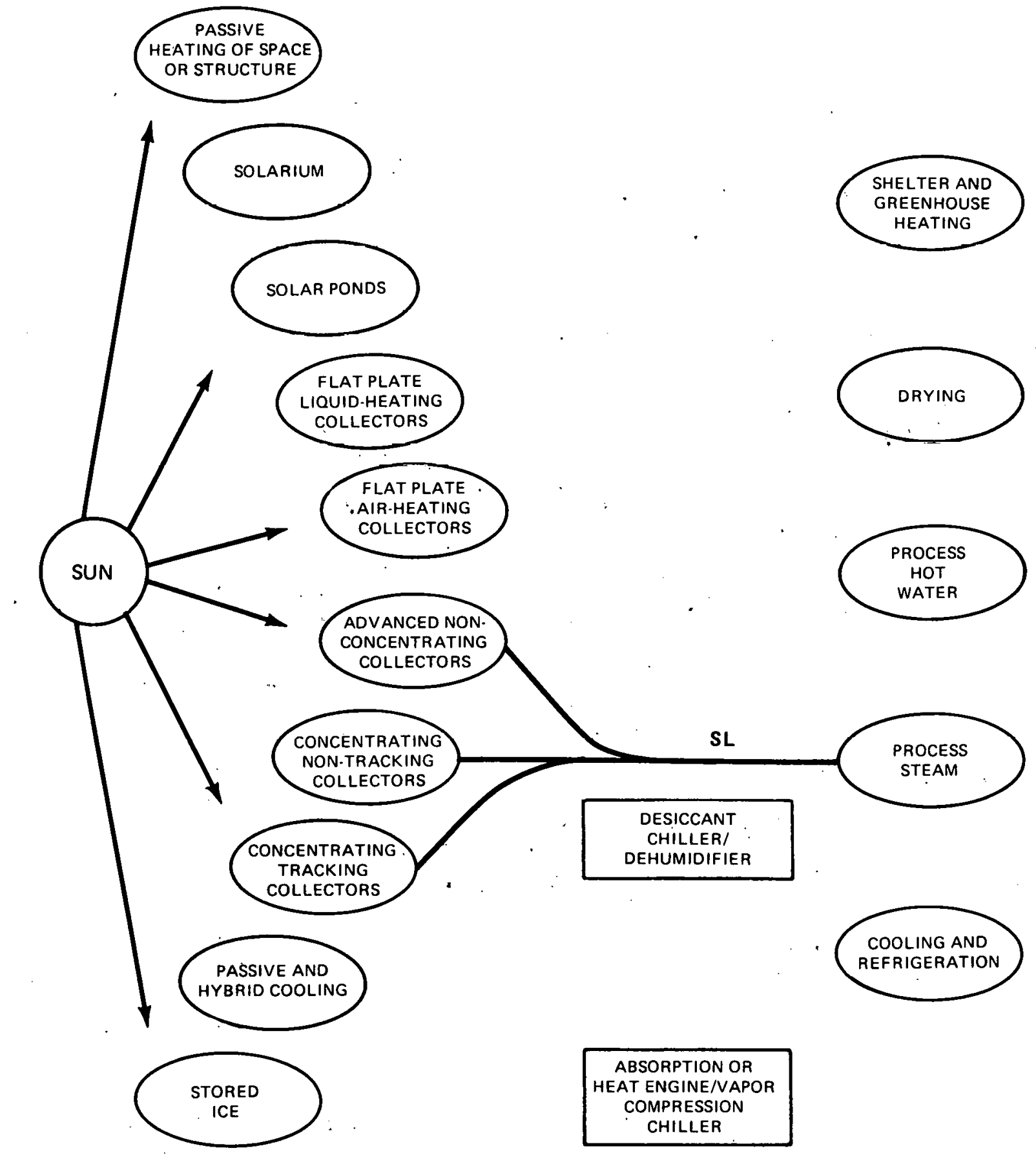




\begin{tabular}{|c|c|c|c|}
\hline $\begin{array}{l}\text { ENERGY } \\
\text { SOURCE/ } \\
\text { SINK }\end{array}$ & $\begin{array}{l}\text { ENERGY } \\
\text { COLLECTION/REJECTION }\end{array}$ & $\begin{array}{l}\text { ENERGY } \\
\text { CONDITIONING }\end{array}$ & APPLICATION \\
\hline
\end{tabular}

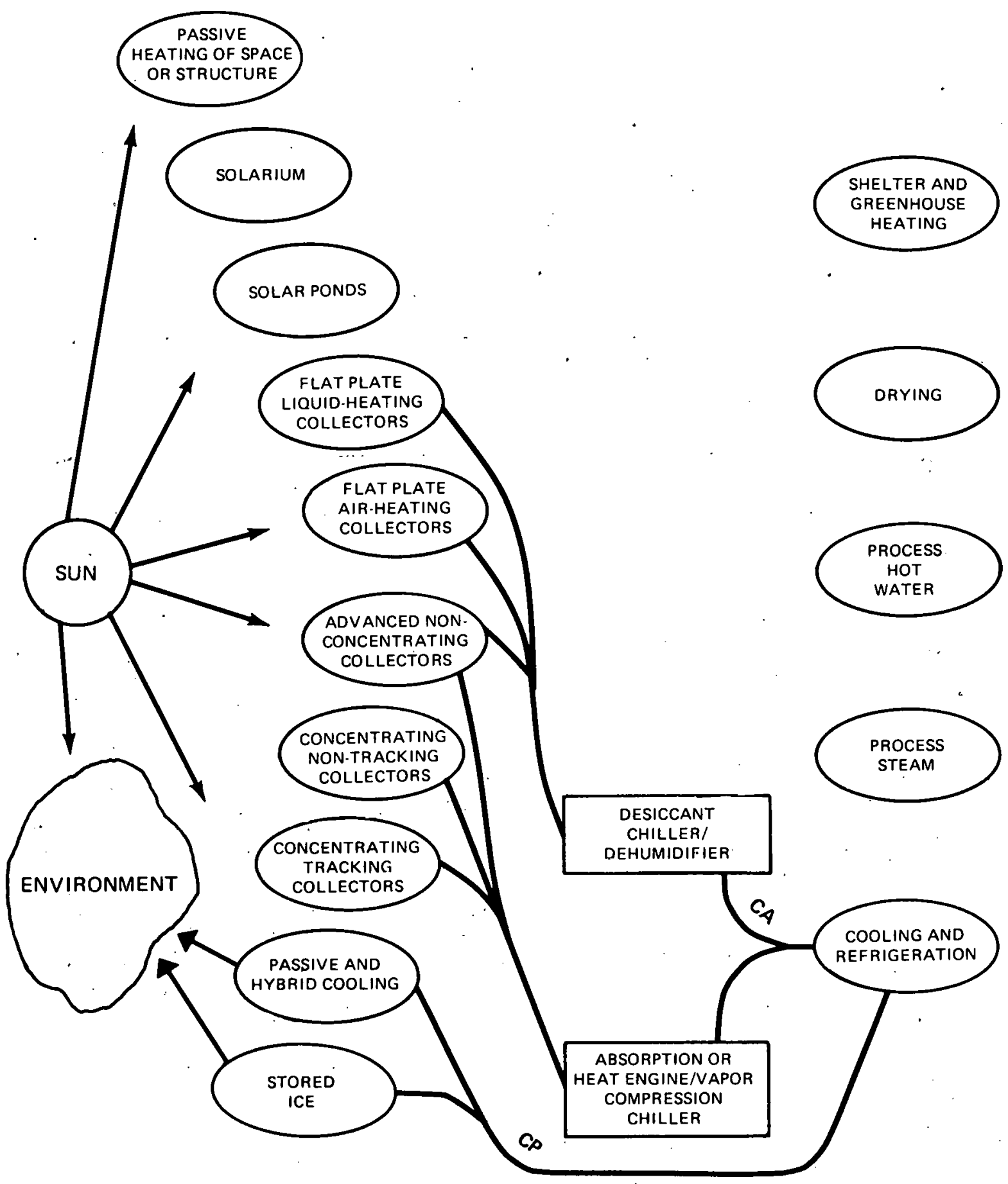

FIGURE $\|-30$

PATHS TO SOLAR COOLING AND REFRIGERATION 


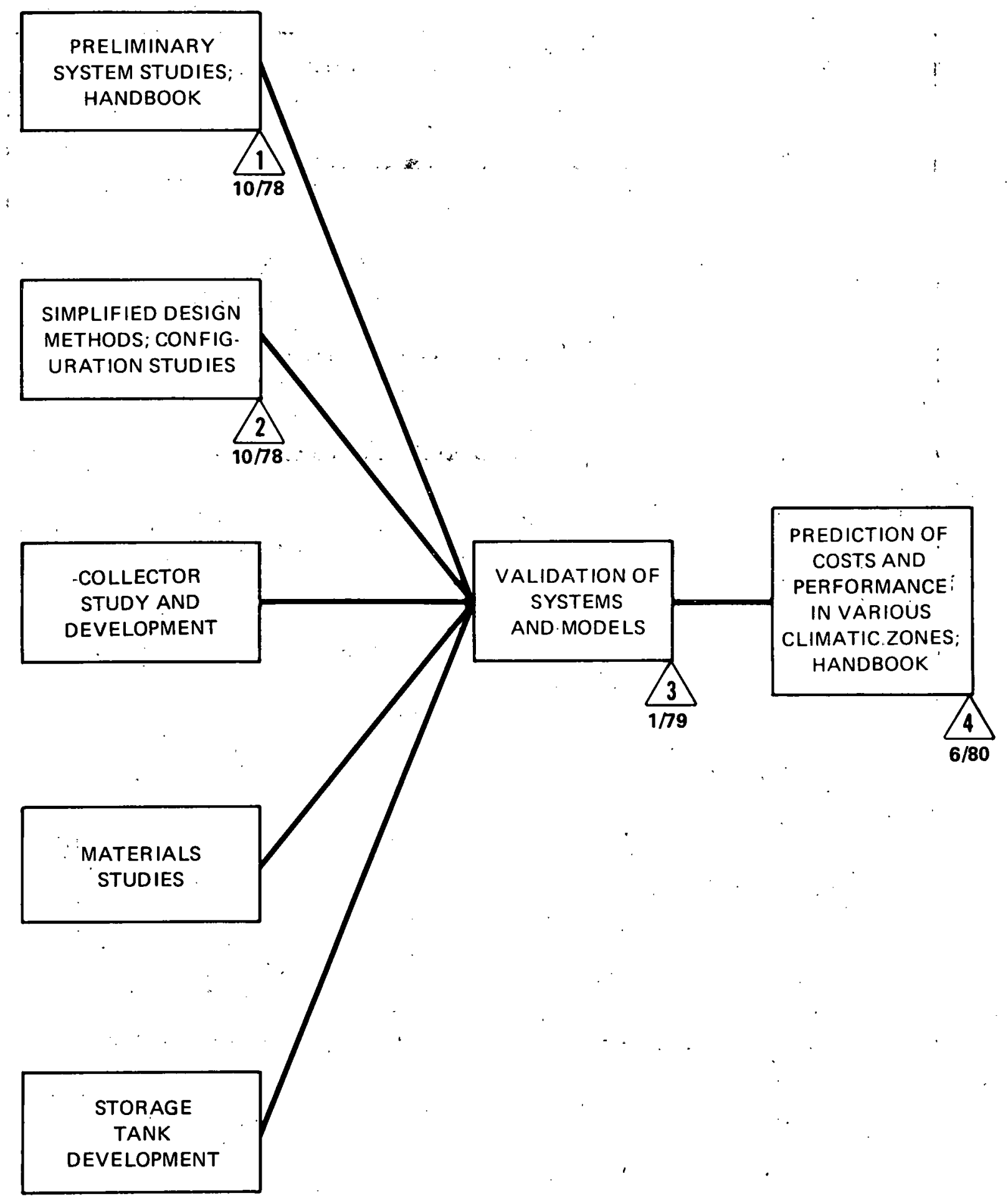

FIGURE II-15 


\section{PASSIVE SOLAR HEATING FOR SHELTERS AND GREENHOUSES PATH HP}

\section{GENERAL}

Most existing shelters utilize some degree of passive solar heating. However, developing passive and passive/hybrid designs for animal shelters and greenhouses which obtain the maximum direct heat from the sun, especially for cold climates, is a complex building design problem. Much of the work indicated in Path $\mathrm{H}_{2}$ is appropriate here, but different types of structures and applications must be considered. Tolerable temperature spreads, humidities, and air changes will differ for each use. Proper insulation and ventilation of structure as well as installation of heat recovery equipment are of utmost importance. Of particular interest is the development of multi-use systems in which a greenhouse is combined with other types of rural shelters or residences.

If thermal storage beyond that of the structure itself is needed, overnight storage may be cost effective. The use of thermal mass within the structure, rather than a separate storage system, has considerable merit.

\section{R\&D STRATEGY}

Different kinds of well instrumented prototype structures will be designed and constructed in various climatic regions. The results of continual monitoring and analysis of performance should lead to structure modifications and improvements.

\section{R\&D EMPHASIS}

\section{Evaluation, Development, and Characterization of Materials}

Partially covered by Path $\mathrm{H} 2$; greater range of tem- peratures, air change rates, and humidity must be considered

\section{Development of Components}

Covered by Path $\mathrm{H} 2$

\section{System Modeling}

Development of flexible models for each generic type of structure, including load characteristics

Cost parameters and retrofit potential to be included in each system model

Effect of energy conservation to be included in each model

\section{System Development and Analysis}

Management of solar light to meet illumination and/or phototropism requirements of different types of structures

Investigation and optimization of control strategies

\section{System Testing}

Data gathering and model validation

Determination of ability of systems to maintain required tolerances for temperature, humidity, light, and other environmental parameters. 


\begin{tabular}{|c|c|c|c|c|}
\hline TASK GROUPS & FY 1978 & FY 1979 & FY 1980 & FY 1981 \\
\hline $\begin{array}{l}\text { SYSTEM STUDIES OF } \\
\text { EXISTING SHELTERS } \\
\text { AND GREENHOUSES }\end{array}$ & & $\angle$ & & \\
\hline BASIC STUDIES & & & & \\
\hline MATERIALS STUDIES & & & & \\
\hline CONTROL STUDIES & & & & \\
\hline HYBRID SYSTEMS & & & & \\
\hline $\begin{array}{l}\text { VARIANTS OF EXISTING } \\
\text { STRUCTURES }\end{array}$ & & & & \\
\hline $\begin{array}{l}\text { SECOND GENERATION OF } \\
\text { PASSIVE HEATING SYSTEMS }\end{array}$ & & & & \\
\hline
\end{tabular}

\section{MILESTONES}

Each milestone refers to the preparation and distribution of a handbook on current designs for buildings that will be heated predominantly by passive solar heating of the space or structure.

$1 / 79$

A

Handbook based on results of

existing structures and current research.

10/79 Handbook based on results of

2 basic studies, materials and control

studies, and results with hybrid systems.
10/80

Handbook based on variants 3 and improvement of currently existing structures.

10/81 4 Handbook based on results of 


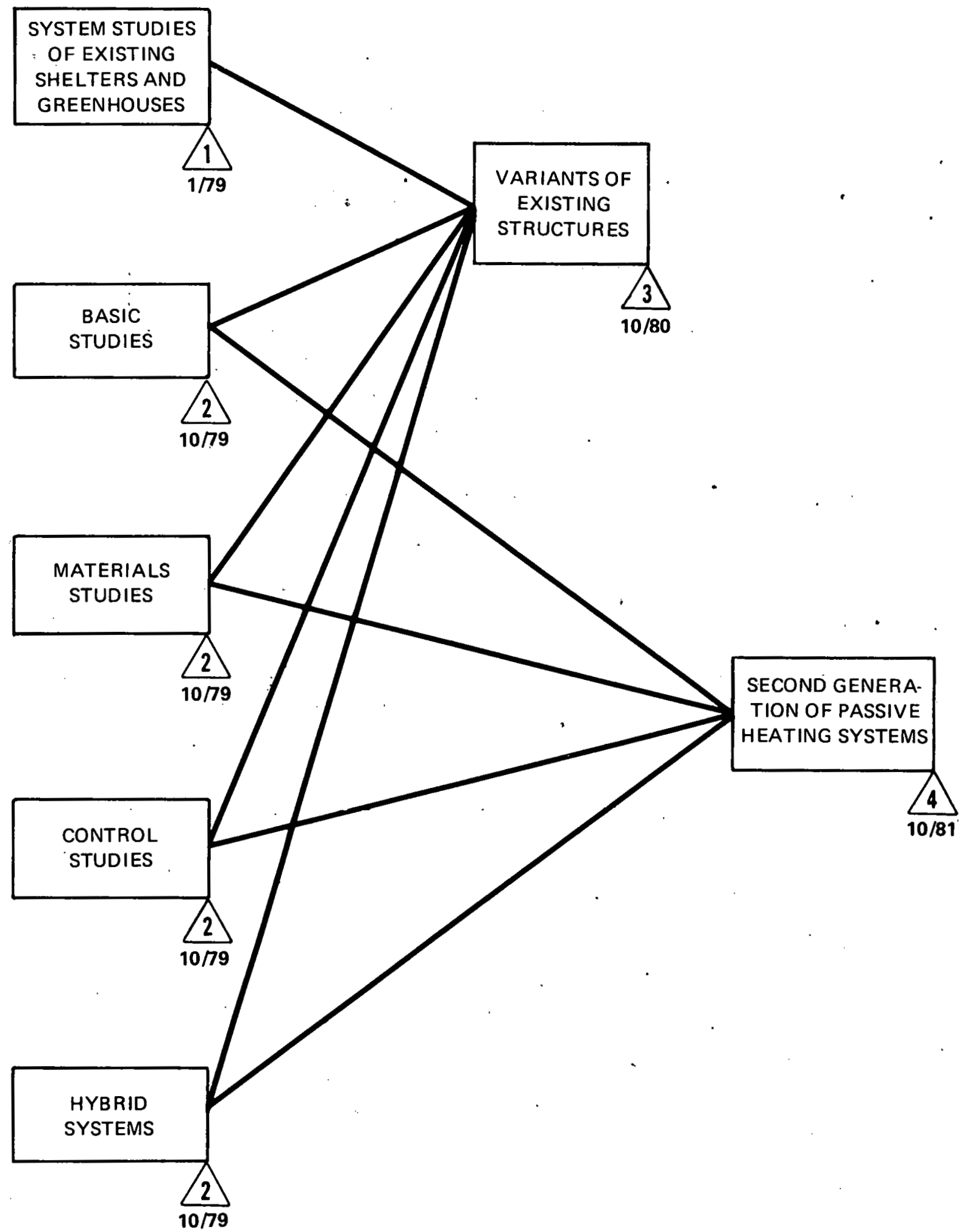

FIGURE II-32

PASSIVE HEATING FOR SHELTERS AND GREENHOUSES

PATH HP TASK FLOW CHART 


\section{AIR-HEATING COLLECTORS \\ FOR \\ SHELTERS AND GREENHOUSES \\ PATH HA}

\section{GENERAL}

The comments about air-heating collector systems made in Path $\mathrm{H} 3$ are generally applicable here. The potential advantages of air-heating collectors-lower initial cost, one less heat-exchange step, easier maintainability-are particularly important. In many agricultural buildings, special ventilation requirements create a need for high air circulation rates. Heat recovery systems can play an important role in recovering heat from exhaust air. Some uses require only enough heat to keep goods from freezing or prevent condensation.

Though rock is presently considered the best storage medium, other possibilities such as bundles of plastic tubes filled with water need to be examined. Also, direct air-liquid heat exchange, using water tanks or chemical phase-change storage, should be studied.

\section{R\&D STRATEGY}

Collector designs offering potential cost effectiveness will be developed and tested. Plastics, often the material of lowest initial cost, may be essential in providing minimum cost heat based on Jife-cycle costing considerations. Manifolding and ducting problems will be addressed because of their particular importance for large area systems.

\section{R\&D EMPHASIS}

\section{Evaluation, Development, and Characterization of Materials}

Partially covered by Path $\mathrm{H} 3$
Material compatibility with food process standards

\section{Development of Components}

Standardized test procedures for air collectors

Weatherable plastic and elastomeric materials

Development of reliable, low-cost hardware

Improved dampers, manifolding, and ducting

Large area module collectors

Various storage media that might replace rocks

Control systems

\section{System Development and Analysis}

Identification of systems providing maximum "energy/present value dollar" over expected lifetime.

Examination of various storage configurations

Retrofit potential

Control strategy optimization

\section{System Testing}

Testing of systems incorporating competing collector designs over extended period at test stations with different climatic and use conditions

Validation of computer predictions of system performance 


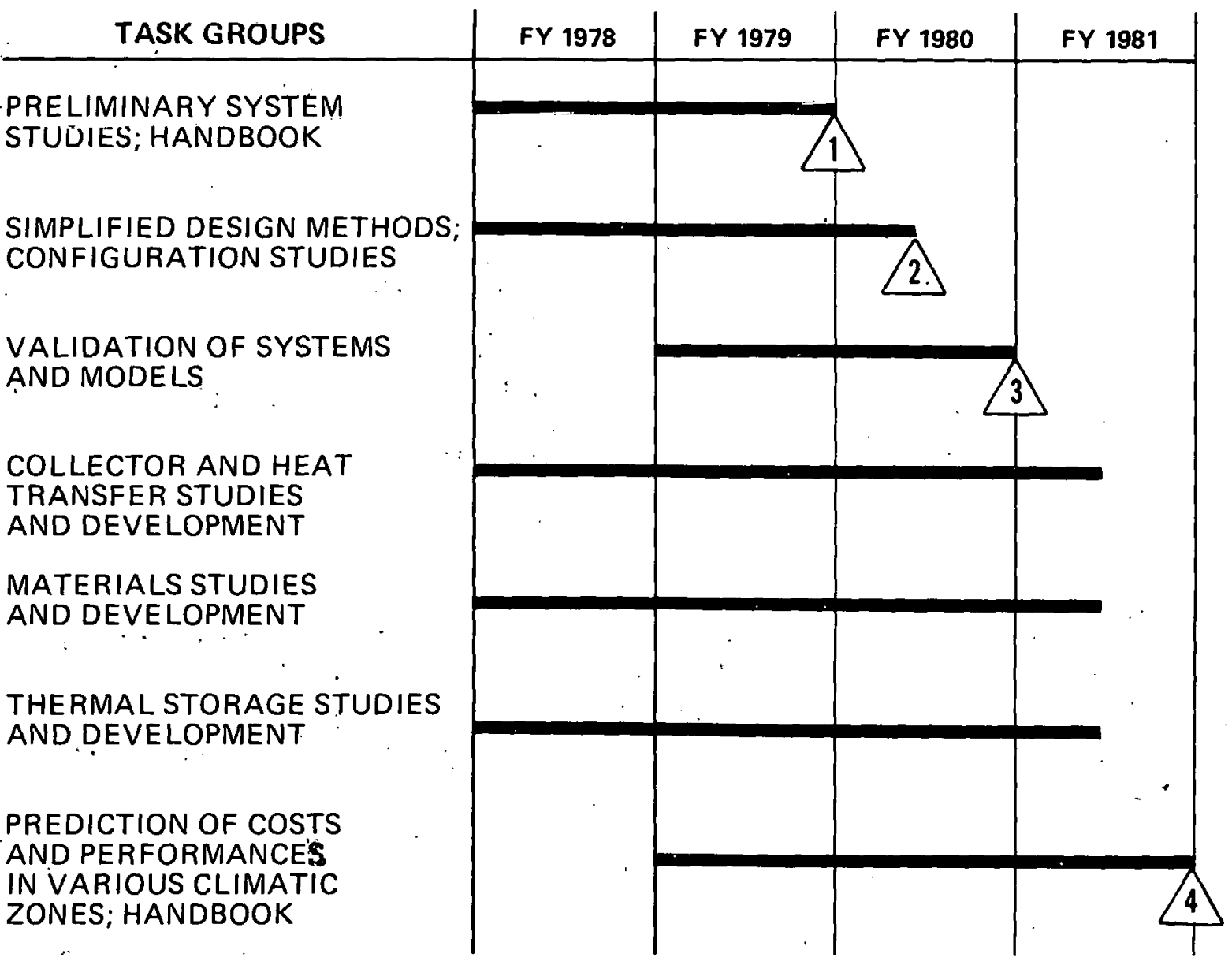

\section{MILESTONES}

10/79 Preliminary system studies lead 1 to choice of likely systems for various climatic zones. Publish handbook.

2. As a result of system, studies, collector development, and materials studies, likely systems are confirmed for various climatic zones.
10/80 Models chosen are assembled and validated based on data from operating systems. Results. are published.

10/81 Handbook summarizes system 4. cost and performance characteristics. 


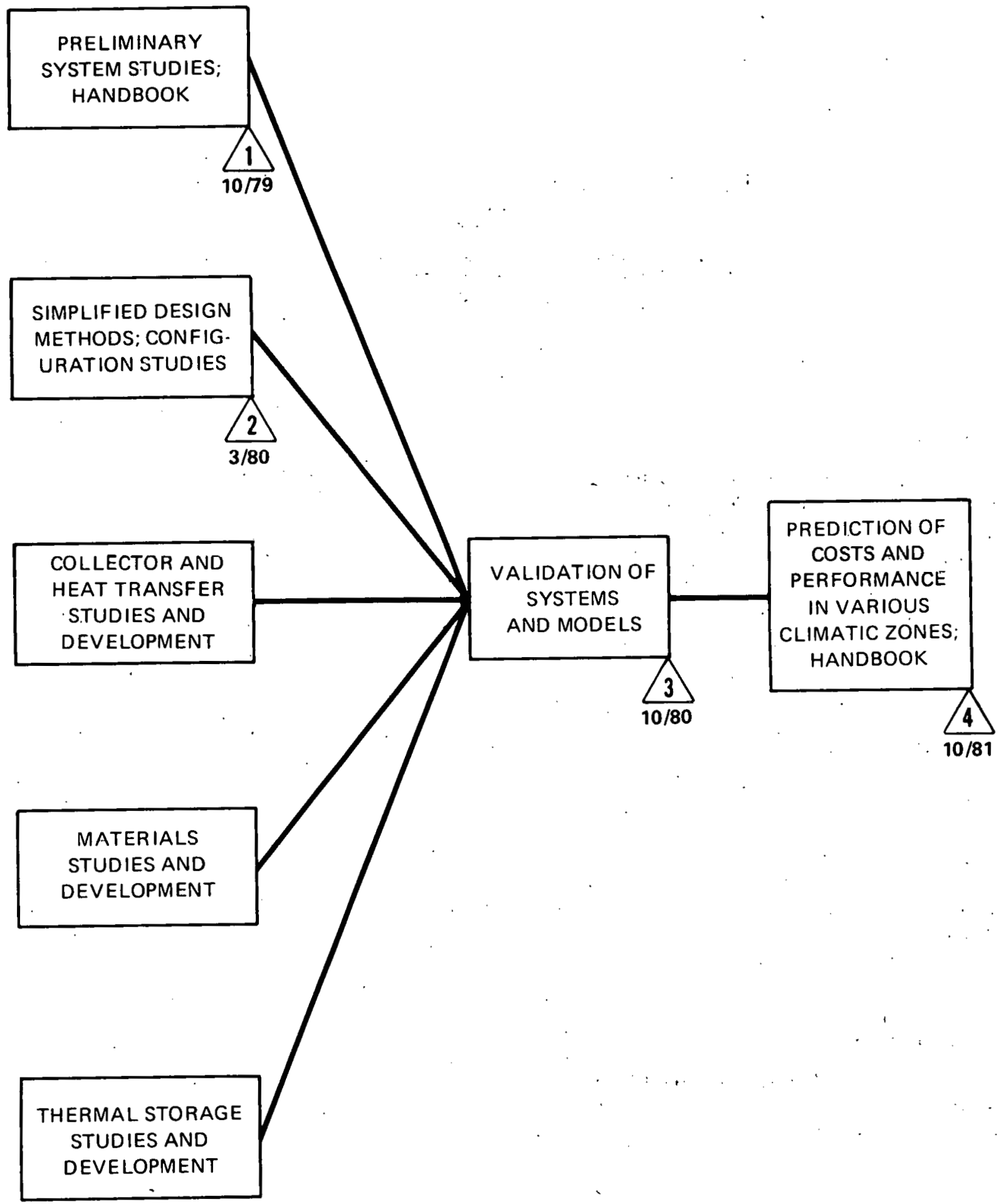




\section{LIQUID-HEATING COLLECTORS FOR SHELTERS AND GREENHOUSES PATH HL}

\section{GENERAL}

The majority of solar space heating systems are based on liquid-heating collectors and water storage tanks. Most of these systems interface with the hot air heating system via a liquid-air heat exchanger. Typical causes of trouble or failure include: corrosion, scaling, freezing, leaking, and breakage of glazings.

Solar ponds, both the shallow and non-convective types, are of particular relevance to agriculture and process heat applications since they can be made in large size and at a low cost per unit energy collected. The salt-gradient solar pond has integral storage capabilities over periods of three months or more. Water from shallow solar ponds may be stored in large insulated reservoirs with only small heat losses. Large area, trickle-collector systems also have potential. A detailed study should be made of stratification in large water storage tanks as a function of tank capacity, plumbing connections, shape, orientation, internal geometry, foundation, and type of construction.

\section{R\&D STRATEGY}

The work already underway (see Path $\mathrm{H} 4$ ) will be supplemented by the development of solar ponds and other large modular, low cost collectors for the heating of agricultural structures. The use of ponds in conjunction with heat pumps will be investigated.

\section{R\&D EMPHASIS}

\section{Evaluation, Development, and Characterization of Materials}

Partially covered by Path $\mathrm{H} 4$

Weatherable films and sheets

\section{Development of Components}

\author{
Industrial-sized heat pumps \\ Large volume storage reservoirs \\ Large area collector modules
}

\section{System Development and Analysis}

Analysis of hydraulic and thermal problems associated with large area shallow solar pond systems

Hydrostatic and hydrodynamic stability studies of non-convective salt-gradient ponds

Analysis of other large area, low cost collector systems

Study of stratification and associated hydraulics in large volume water storage tanks

\section{System Testing}

Testing of stability and performance of scale and full-size models of non-convective salt-gradient ponds.

Validation of computer predictions of system performance of non-convective ponds, shallow solar ponds, and other large area collector systems in various operational modes 


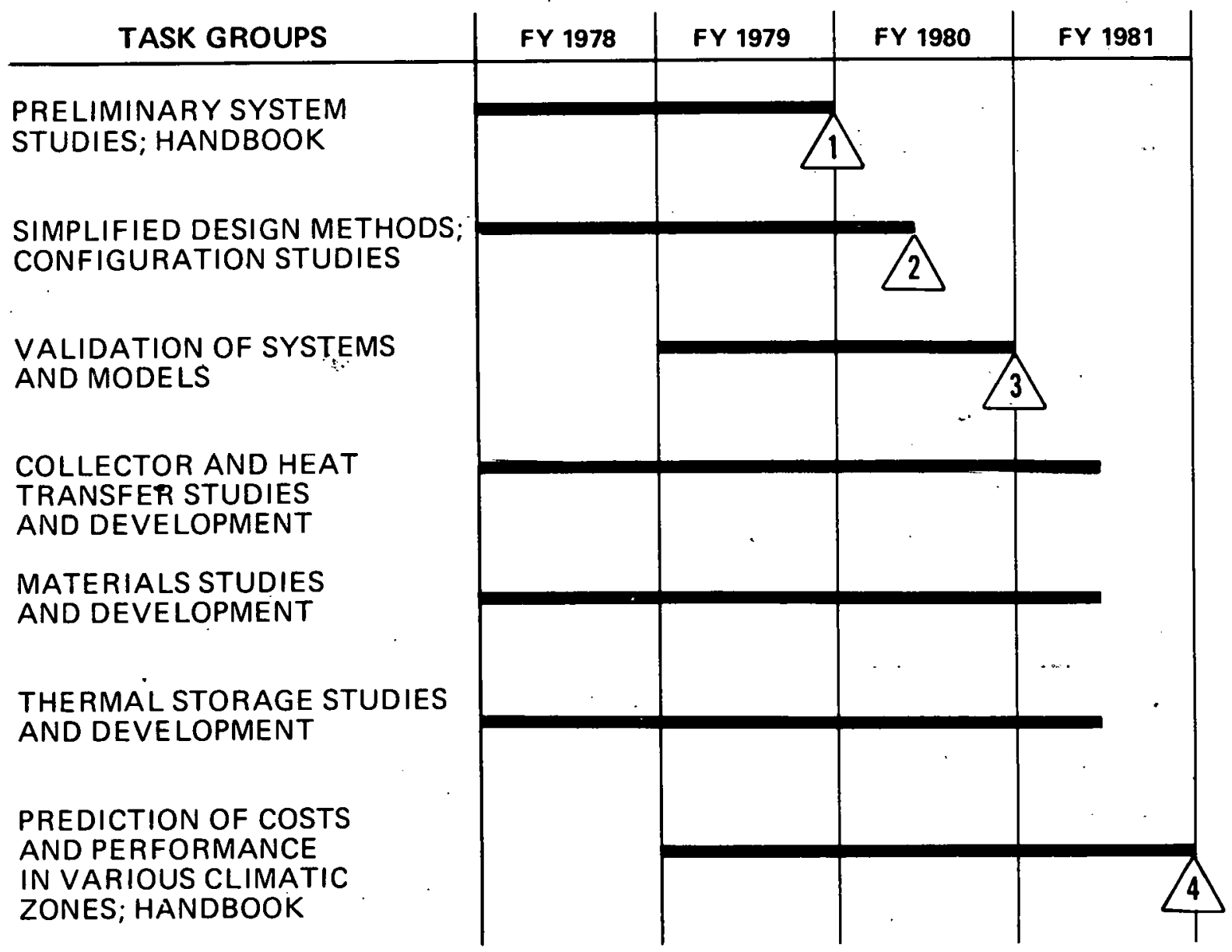

\section{MILESTONES}

$10 / 79$

Preliminary system studies lead to choice of likely systems for various climatic zones. Publish handbook.

$3 / 80$

2 As a result of system studies, collector development, and materials studies, likely systems are confirmed for various climatic zones.
10/80

3 Systems are constructed or program, and codes are validated.

10/81 Publication of results.

4 Handbook summarizes system cost and performance charac. teristics. 


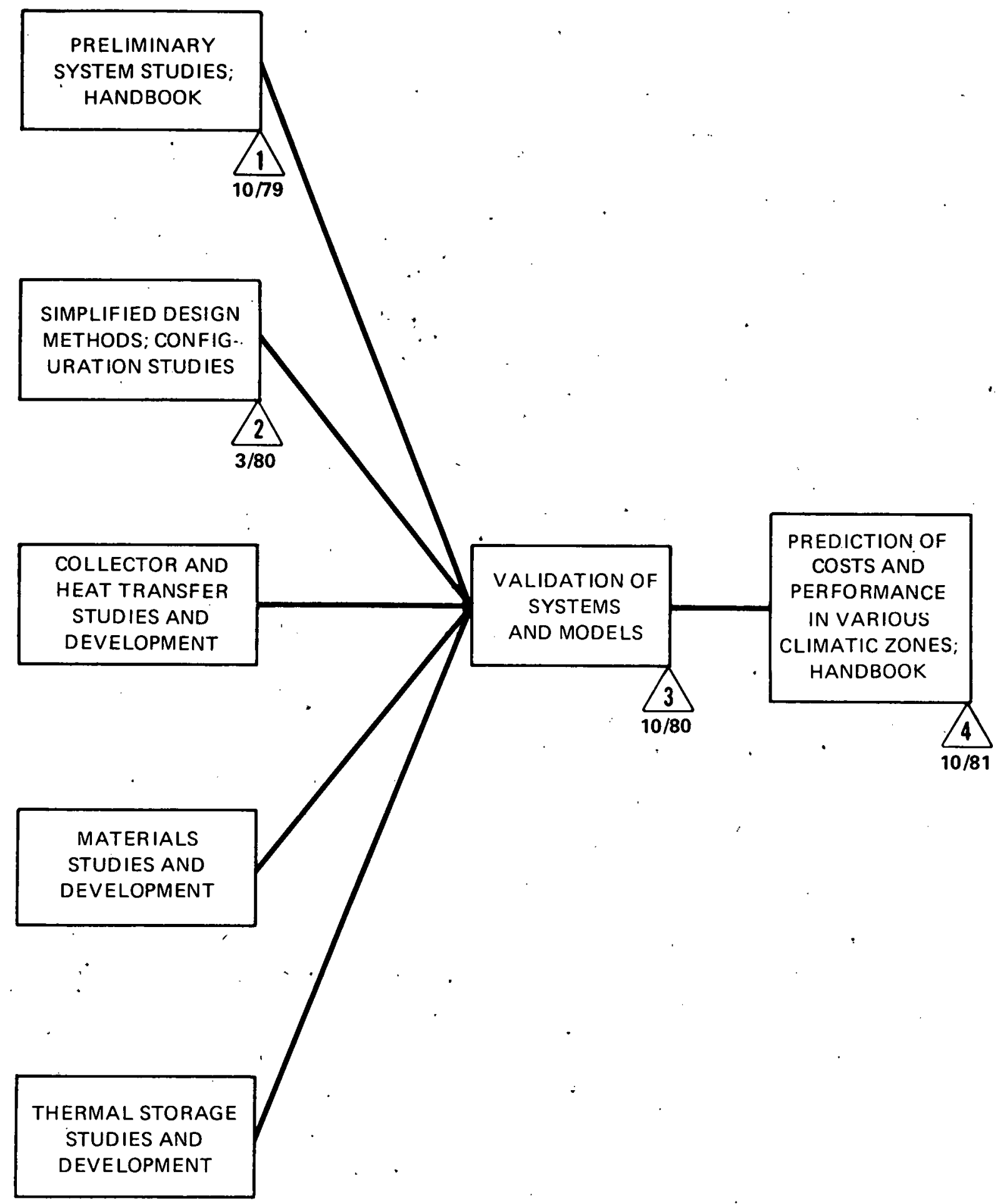




\section{DIRECT DRYING OF AGRICULTURAL AND INDUSTRIAL PRODUCTS PATH DD}

\section{GENERAL}

In the direct drying of agricultural and industrial products, the product to be dried serves as the absorber in the solar collector. The product may be uniformly spread on a conveyor belt which slowly moves the product under a transparent glazing. Drying could also be accomplished in a batch mode. It would probably be necessary to circulate an air stream between the product layer and the glazing to remove moisture and prevent condensation on the underside of the glazing. In humid areas, predrying of the air might also be required. Predrying could be done using a desiccant which might be periodically regenerated using solar heat. Heat could then be recovered from the air as it exits the collector, as well as from the dried product.

Direct drying is a natural application for solar energy because the drying temperatures required are not high. When higher drying temperatures are needed, a concentrating collector or mirror augmentation could be used, again with the product to be dried serving as the absorber of solar heat.

\section{R\&D STRATEGY}

Until now, this approach has received very little attention. Numerous basic characteristics need to be studied for each class of product to be dried. For example, drying paint requires very different conditions from drying raisins. Emphasis will be on investigation of temperature ranges for drying various products, the surface characteristics of products as they pertain to absorption of solar radiation, possible out-gassing problems, and investigation of batch versus continuous modes of drying. After these general system studies, innovative collector design and testing will be stressed.

\section{R\&D EMPHASIS}

\section{Evaluation, Development, and Characterization of Materials}

Stable, easily cleanable, low-cost glazings

Energy absorption characteristics of various products

\section{Development of Components}

Reflector augmentation for flat plate collectors

Conveyor belts to serve as collector absorber beds

Concentrating collectors with receiver designed to directly accept product to be dried

\section{System Development and Analysis}

Basic thermodynamic and mass transfer processes Heat recovery from dried products

Use of concentrating collectors of special design

Integration of solar with conventional fuel-fired drying

Logistics of product movement and storage

Batch versus continuous modes of drying

\section{System Testing}

Validation of computer model predictions

Testing of innovative collection systems 


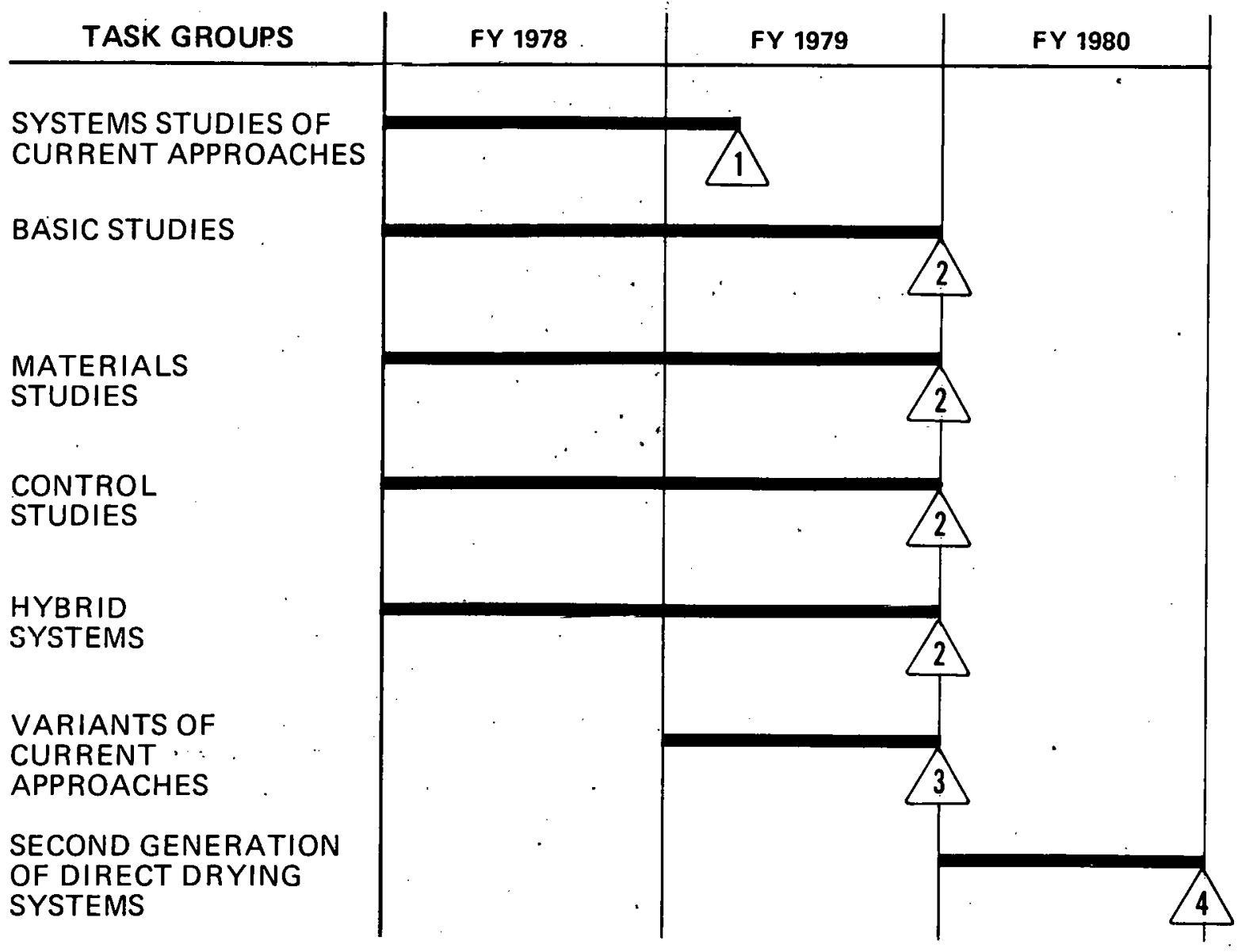

\section{MILESTONES}

Each milestone refers to the preparation and distribution of a handbook on current designs for buildings that will be heated predominantly by direct solar heating of the space or structure.

$1 / 79$

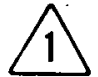

1

Handbook based on results of existing systems and current research.

$10 / 79$ 2
Handbook based on results of basic studies, materials and control studies, and results with hybrid systems.
$10 / 79$ 3 Handbook based on variants

$10 / 80$ Handbook based on results of
second generation systems. 


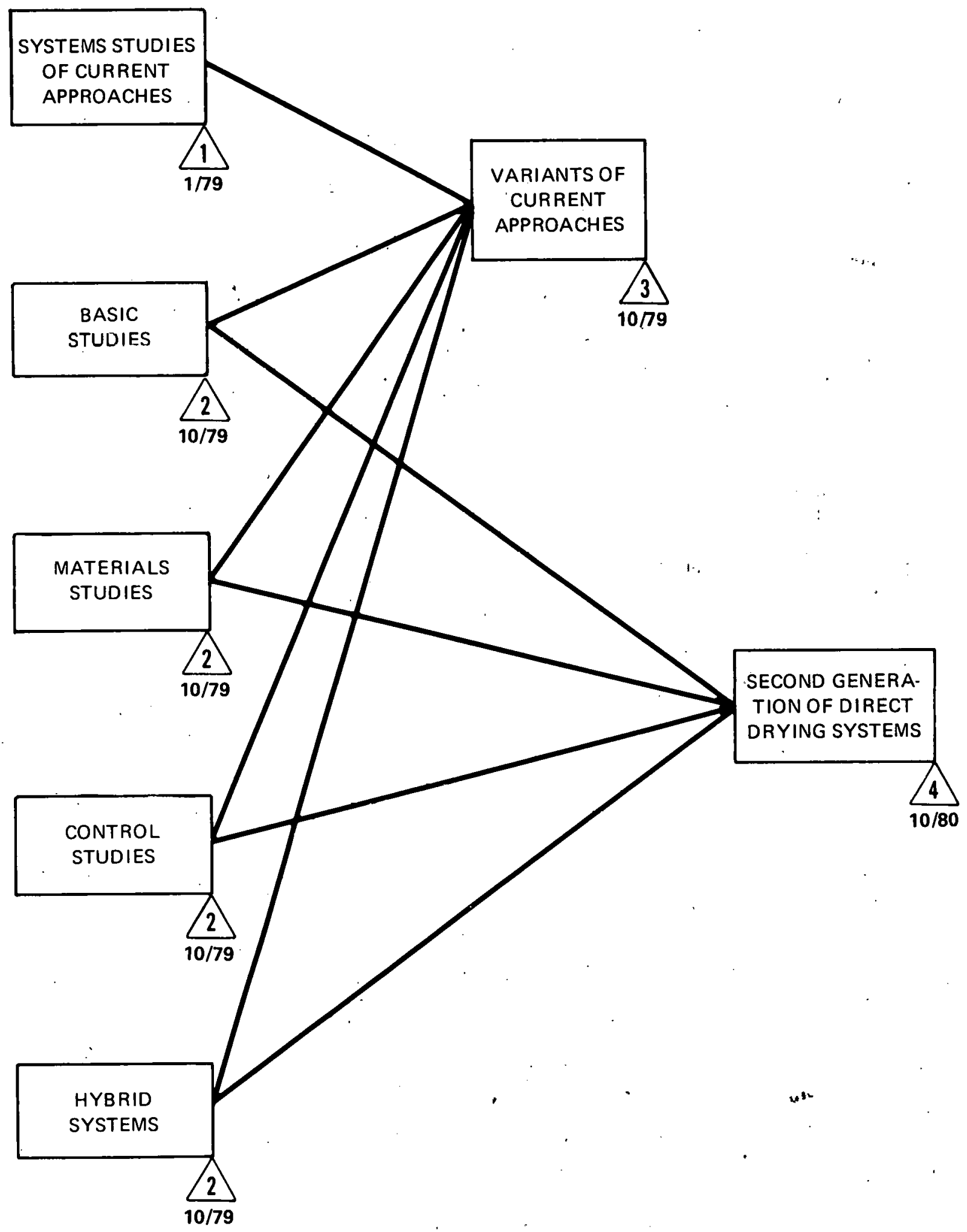

FIGURE II-38

DIRECT DRYING OF AGRICULTURAL AND INDUSTRIAL PRODUCTS PATH DD TASK FLOW CHART 


\section{AIR-HEATING COLLECTORS FOR DRYING PATH DA}

\section{GENERAL}

Drying and concentration of agricultural products, as well as the industrial drying of milk, paper, wood, chemicals, and other materials, presently requires large amounts of fossil fuel, particularly natural gas and propane. Drying is a natural application for solar energy because the temperatures required are usually not very high, although some applications require temperatures of $75^{\circ} \mathrm{C}\left(170^{\circ} \mathrm{F}\right)$ and higher. The most common method of drying is to heat the material being dried in the presence of a moving air stream of low or moderate humidity. If predrying of the air is necessary, desiccants may be regenerated intermittently with solar heat, perhaps at a higher temperature than needed for the drying. Heat recovery systems, with necessary filtration, can be used to recover heat from exhaust air and from dried products. As with shelter heating, multi-use systems (e.g., grain drying/animal shelters and crop curing/animal shelters) can be of great importance.

The large bulk and weight of rock beds for heat storage may not be a problem because space is generally available, particularly for agricultural applications. New types of storage systems are of interest in proportion to their cost effectiveness. R\&D on chemical and phase-change storage is certainly warranted, particularly for use with those processes requiring constant temperatures. Any storage system must be compared from an economic point of view with the alternative of a standby air heater using either fossil fuel or crop residues (which will probably be required in any event). With no storage, solar drying is done when the sun is shining, thus decreasing the amount of fuel required.

\section{R\&D STRATEGY}

R\&D strategy will focus on applications which are the most promising economically. Hence, applications where solar energy will displace the most expensive fossil fuels and where drying is required most of the year, perhaps in multi-use applications, will receive priority consideration.

\section{R\&D EMPHASIS}

\section{Evaluation, Development, and Characterization of Components}

Improved production, fabrication, and sealing processes for plastic materials

Stable, low cost, high transmissivity glazing

Sensible heat and chemical storage materials for temperatures up to $400^{\circ} \mathrm{C}\left(750^{\circ} \mathrm{F}\right)$

Absorbing surfaces with high conductivity and durability

Compatibility with food processing standards

\section{Development of Components}

Concentrating collectors for higher temperature applications

Collector design for improved heat transfer from absorber to air

Use of low cost fixed reflectors to increase collection

Improvement in weatherable components 


\section{System Development and Analysis}

Rock bed and product bed analysis for minimum blower power and maximum heat storage at acceptable heat transfer rates

Development or modification of computer codes capable of predicting performance of collector/storage systems under a variety of load requirements
Investigation of multi-use applications to obtai maximum solar heat per invested dollar

Study of collector fluid flow rate optimization

\section{System Testing}

Building/testing of promising systems

Validation of computer model predictions 


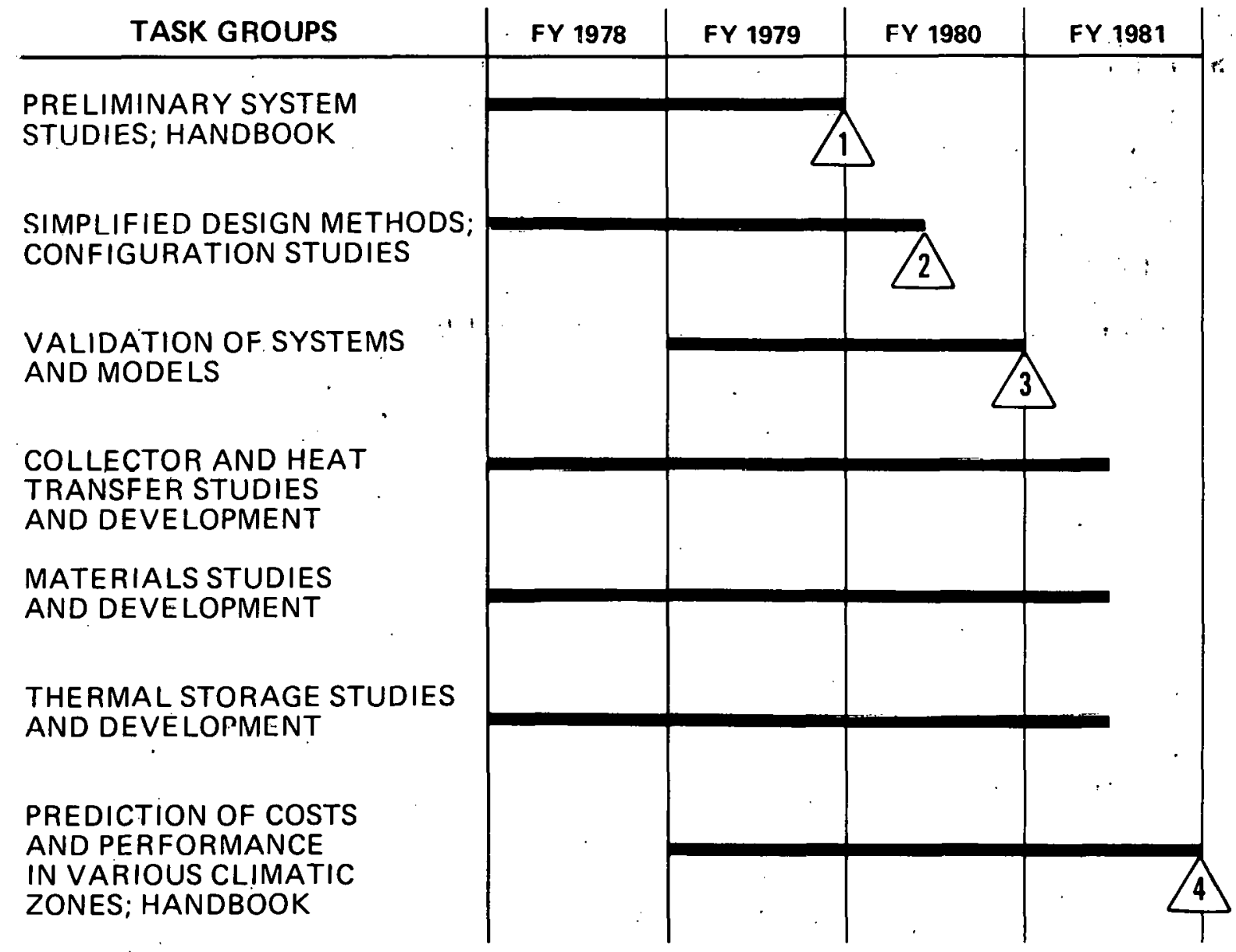

\section{MILESTONES}

10/79 Preliminary system studies lead 1 to choice of likely systems for various climatic zones. Publish handbook.

$3 / 80$

2 As a result of system studies, collector development, and materials studies, likely systems are confirmed for various climatic zones.
$10 / 80$

3 Models chosen are assembled from operating systems. Results are published.

10/81 Handbook summarizes system cost and performànce characteristics.

FIGURE II-39

AIR-HEATING COLLECTORS FOR DRYING

PATH DA ACTIVITY SCHEDULE 


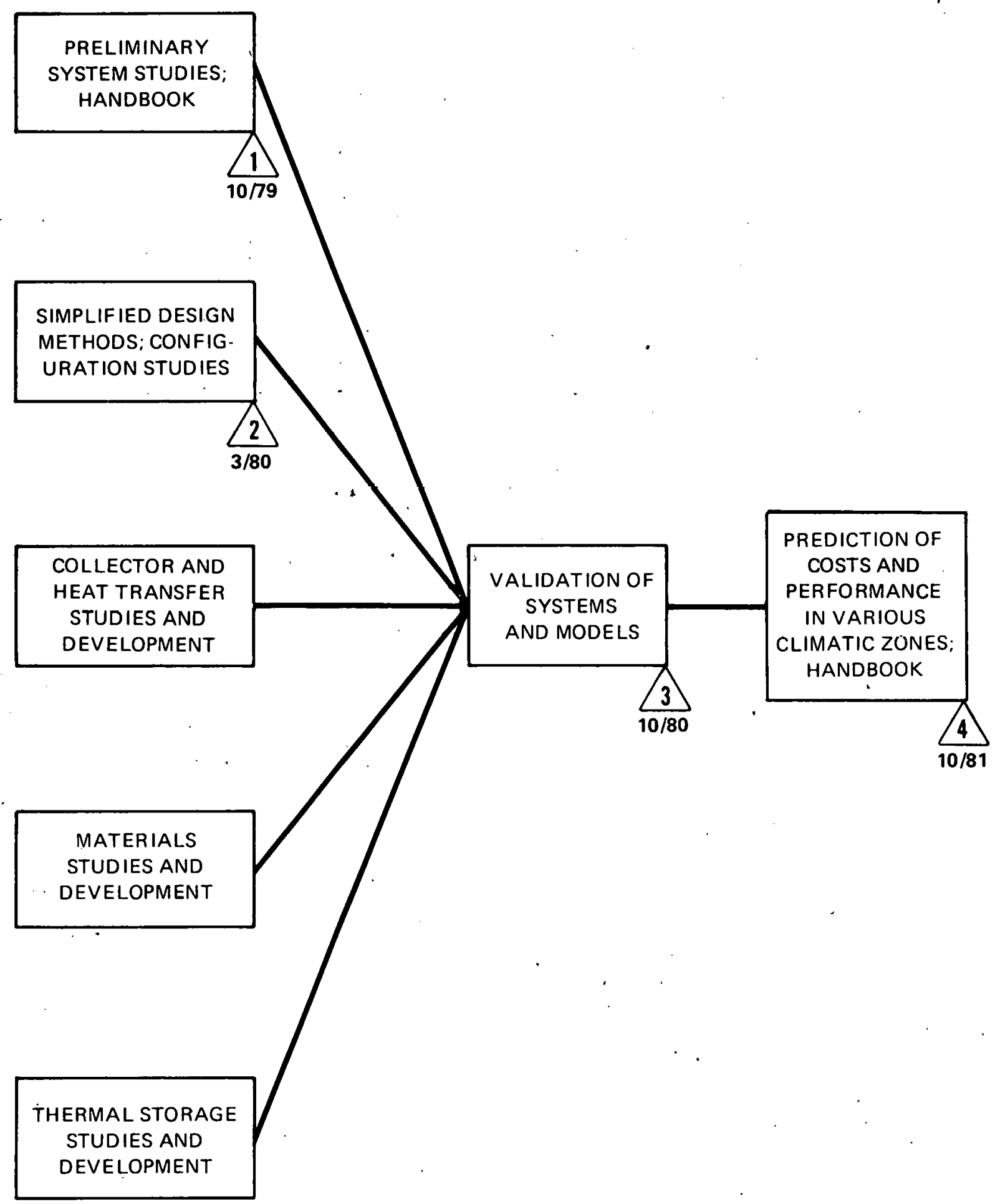




\section{LIQUID-HEATING COLLECTORS FOR DRYING PATH DL}

\section{GENERAL}

The comments made under Path HL are generally applicable here.

Water, with much higher specific heat than air, provides good heat transfer and the possibility of thermosiphoning. The need for an additional heat exchanger is a disadvantage of using solar-heated water for drying applications; leakage, freezing, erosion, and corrosion in the collector also present problems.

Storage of heat in the form of hot water is the least expensive storage method available, except for use of existing structure thermal mass. The storage tanks for agriculture and industrial process systems will be large, leading to the possibility of improved temperature stratification in the tank. Cement, galvanized steel, and fiberglass tanks all have temperature limitations and may require special liners to provide acceptable corrosion lifetimes in the presence of hot water, especially very hot water of variable $\mathrm{PH}$. Chemical storage and storage of dried desiccants present interesting possibilities for long-term storage.

\section{R\&D STRATEGY}

The comments made under Path $D A$ also pertain here. R\&D for liquid collectors and storage systems is discussed in the heating and cooling of buildings section. Typical agricultural and industrial process systems are on a large scale with a wide variety of temperatures and applications.

\section{R\&D EMPHASIS}

\section{Evaluation, Development, and}

\section{Characterization of Materials}

“ Desiccants for use as a long-term storage medium

Heat transfer liquid characterization

\section{Development of Components}

Large volume, low cost storage tanks including underground reservoirs with water-proofed insulation

Low cost, high capacity liquid-to-air heat exchangers.

Low cost, simple control systems

Solar ponds

\section{System Development and Analysis}

Development of computer codes to predict temperature stratification in large volume liquid tanks

\section{System Testing}

Measurement of temperature stratification in large volume storage tanks under various types of input and output flow 


\begin{tabular}{|c|c|c|c|c|}
\hline TASK GROUPS & FY 1978 & FY 1979 & FY 1980 & FY 1981 \\
\hline \multicolumn{5}{|l|}{$\begin{array}{l}\text { PRELIMINARY SYSTEM } \\
\text { STUDIES; HANDBOOK }\end{array}$} \\
\hline \multicolumn{5}{|c|}{$\begin{array}{l}\text { SIMPLIFIED DESIGN METHODS; } \\
\text { CONFIGURATION STUDIES }\end{array}$} \\
\hline \multicolumn{5}{|c|}{$\begin{array}{l}\text { VALIDATION OF SYSTEMS } \\
\text { AND MODELS }\end{array}$} \\
\hline \\
\hline \multicolumn{5}{|l|}{$\begin{array}{l}\text { TRANSFER STUDIES } \\
\text { AND DEVELOPMENT }\end{array}$} \\
\hline \multicolumn{5}{|l|}{$\begin{array}{l}\text { MATERIALS STUDIES } \\
\text { AND DEVELOPMENT }\end{array}$} \\
\hline \multirow{2}{*}{\multicolumn{5}{|c|}{$\begin{array}{l}\text { THERMAL STORAGE STUDIES } \\
\text { AND DEVELOPMENT }\end{array}$}} \\
\hline & & & & \\
\hline \multirow{2}{*}{\multicolumn{5}{|c|}{$\begin{array}{l}\text { PREDICTION OF COSTS } \\
\text { AND PERFORMANCE } \\
\text { IN VARIOUS CLIMATIC } \\
\text { ZONES; HANDBOOK }\end{array}$}} \\
\hline & & & & \\
\hline
\end{tabular}

\section{MILESTONES}

$10 / 79$

Preliminary system studies lead 1 to choice of likely systems for various climatic zones. Publish handbook.

$3 / 80$

As a result of system studies, collector development, and materials studies, likely systems are confirmed for various climatic zones.
$10 / 80$

3 Systems are constructed or programs and codes are validated.

10/81 Publication of results.

4. Handbook summarizes system cost and performance characteristics. 
THIS PAGE

\section{WAS INTENTIONALLY LEFT BLANK}


THIS PAGE

\section{WAS INTENTIONALLY LEFT BLANK}




\section{LIQUID-HEATING COLLECTORS FOR PROCESS HOT WATER PATH WL}

\section{GENERAL}

The use of solar heat to produce industrial and agricultural process hotwater is a viable technology, but much work must be done before solar energy systems are cost effective and widely accepted. Different applications call for great temperature variations, from tepid to boiling. Consequently, no single type of collector will be optimum for all applications. Conventional, small, flat plate collectors are discussed in detail in the heating and cooling of buildings section. The agricultural and industrial process heat R\&D program should concentrate on the following largearea collector types: concentrating collectors (various types); shallow solar ponds; non-convective solar ponds; and advanced collector concepts.

Concentrating collectors will receive attention under Path SL for producing process steam. Shallow solar ponds are particularly suited for low temperature operations. The non-convective solar pond combines storage with collection. Storage for other collector systems may be obtained by use of large volume, insulated reservoirs. Cost-effective techniques for longterm storage should be developed for instances when solar heat is needed for only a small fraction of the year.

\section{R\&D STRATEGY}

Each of the major collection systems should be developed to the point where an industrial demonstration can be implemented. Minimum control requirements will be established and low cost, simple control and simple piping systems will be developed.
Operating experience and interaction with the industrial user play a central role in determining requirements for system improvements. Therefore, demonstrations should come early, but not until the collector and system concept has been developed and tested.

\section{R\&D EMPHASIS}

\section{Evaluation, Development, and Charac- terization of Materials}

Weatherable glazings

Low cost mirror materials

Low cost insulating materials, impervious to moisture and capable of withstanding high temperatures

\section{Development of Components}

Large volume, insulated reservoirs

Evaluation of cost effectiveness of insulation in large storage systems

Low cost, high capacity liquid-liquid test exchangers

Evacuated collectors 
Minimum cost, simple instrumentation and control systems

Solar ponds

\section{System Development and Analysis}

General purpose computer modeling capability for hot water systems

Analysis of hydrauilic problems associated with large area shallow and non-convecting solar pond systems
Trade-offs between collector area; storage, : energy demand leading to system optimizatiol

\section{System Testing}

Stability and performance testing of non-convective ponds

Validation of computer predictions on performance of complete hot water systems for specific cases

Long-term testing for materials degradation and component lifetimes 


\begin{tabular}{l|l|l|l|l|l|}
\multicolumn{1}{c|}{ TASK GROUPS } & FY 1978 & FY 1979 & FY 1980 & FY 1981 & FY 1982 \\
\hline PRELIMINARY SYSTEM & & & & \\
STUDIES; HANDBOOK & & & & \\
DEVELOPMENT OF SOLAR & & & & \\
PONDS, CONCENTRATING \\
AND ADVANCED \\
COLLECTOR CONCEPTS
\end{tabular}

\section{MILESTONES}

$10 / 79$

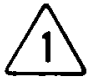

Complete system studies identifying cost and performance characteristics for systems chosen for various climatic regions. This will be done assuming validity of current simulation techniques and the characteristics of existing hardware. Publish preliminary handbook.
6/81

2 Complete a review of system simulation techniques (based on improved system and collectors). Validate mathematical models.

$3 / 82$ 3 Repeat above system analyses based on validated models and improved components. Publish revised handbook. 


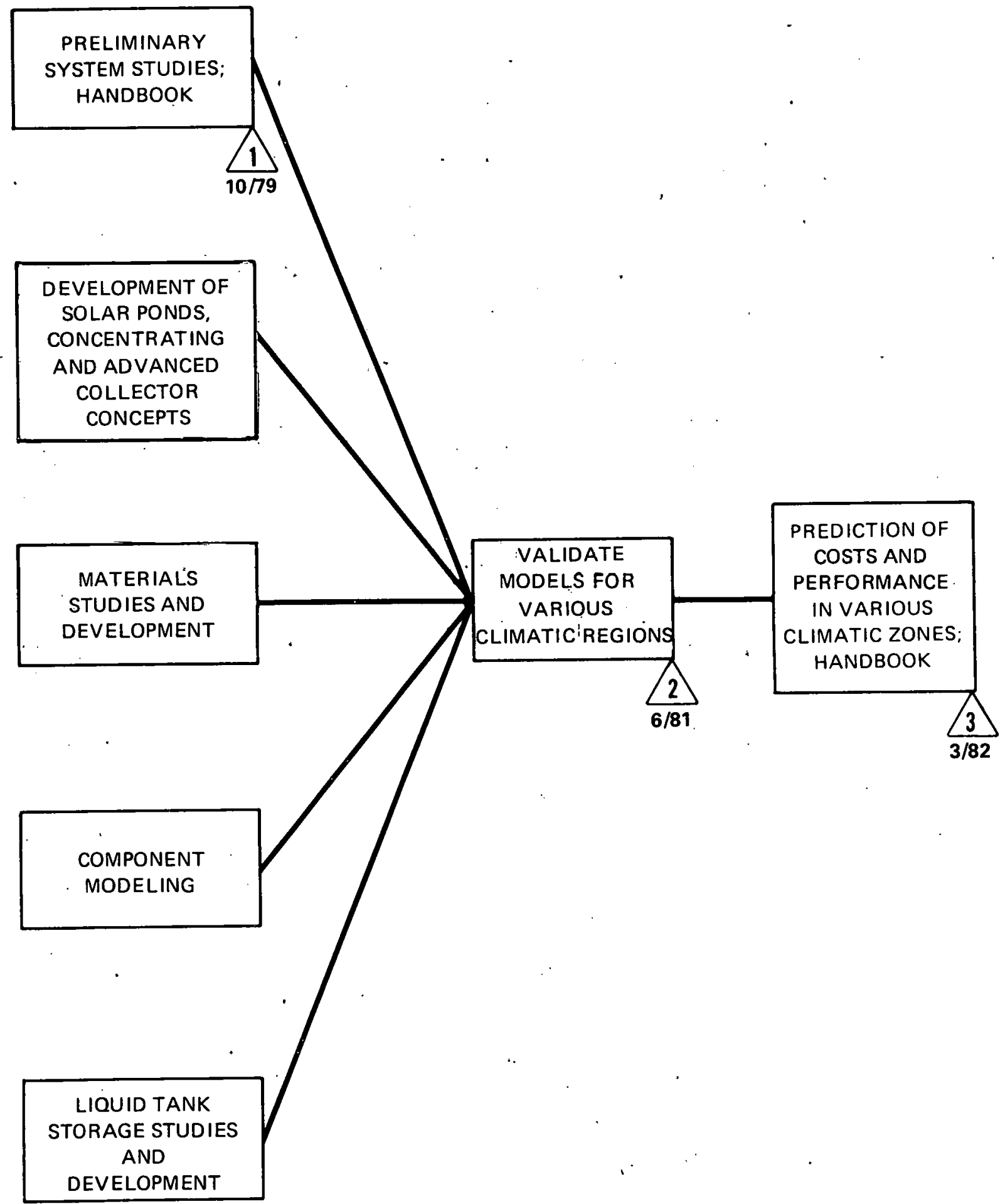

FIGURE |I-44

LIQUID-HEATING COLLECTORS FOR PROCESS HOT WATER

PATH WL TASK FLOW CHART 


\section{AIR-HEATING COLLECTORS FOR \\ PROCESS HOT WATER \\ PATH WA}

\section{GENERAL}

Although this path should have lower priority than Path WL, there will be circumstances where it is advantageous to use air-heating collectors and hot air ducts to produce solar heat for process hot water. For example, air collectors and ducting are likely to weigh less than water collectors and piping and might therefore be appropriate for retrofit on factory rooftops. Using air heaters with a heat exchanger to produce hot water also eliminates the problems of freezing, leaks, and corrosion.

Large rock beds are presently the most cost-effeclive means of storage for hot air systems. An alternative is to produce the hot water via an air-to-liquid heat exchanger and store it in an insulated reservoir.

\section{R\&D STRATEGY}

Several large air-heating systems, differing in type of collector, type of storage, type of heat exchanger, and proposed load characteristics, should be modeled and tested (perhaps at a reduced scale) so that their characteristics are understood. .

\section{R\&D EMPHASIS}

\section{Evaluation, Development, and Charac- terization of Materials}

See Path W2, although a wider temperature range is of interest here

\section{Development of Components}

Reliable, inexpensive air flow meters for low velocities and high temperatures

Air-to-water heat exchangers in large sizes

\section{System Development and Analysis}

Model, analyze, and test à number of reduced scale systems

System cost analyses

\section{System Testing}

Long-term testing required for materials degradation and component lifetimes

Determination of system performance for each system under varying load characteristics 


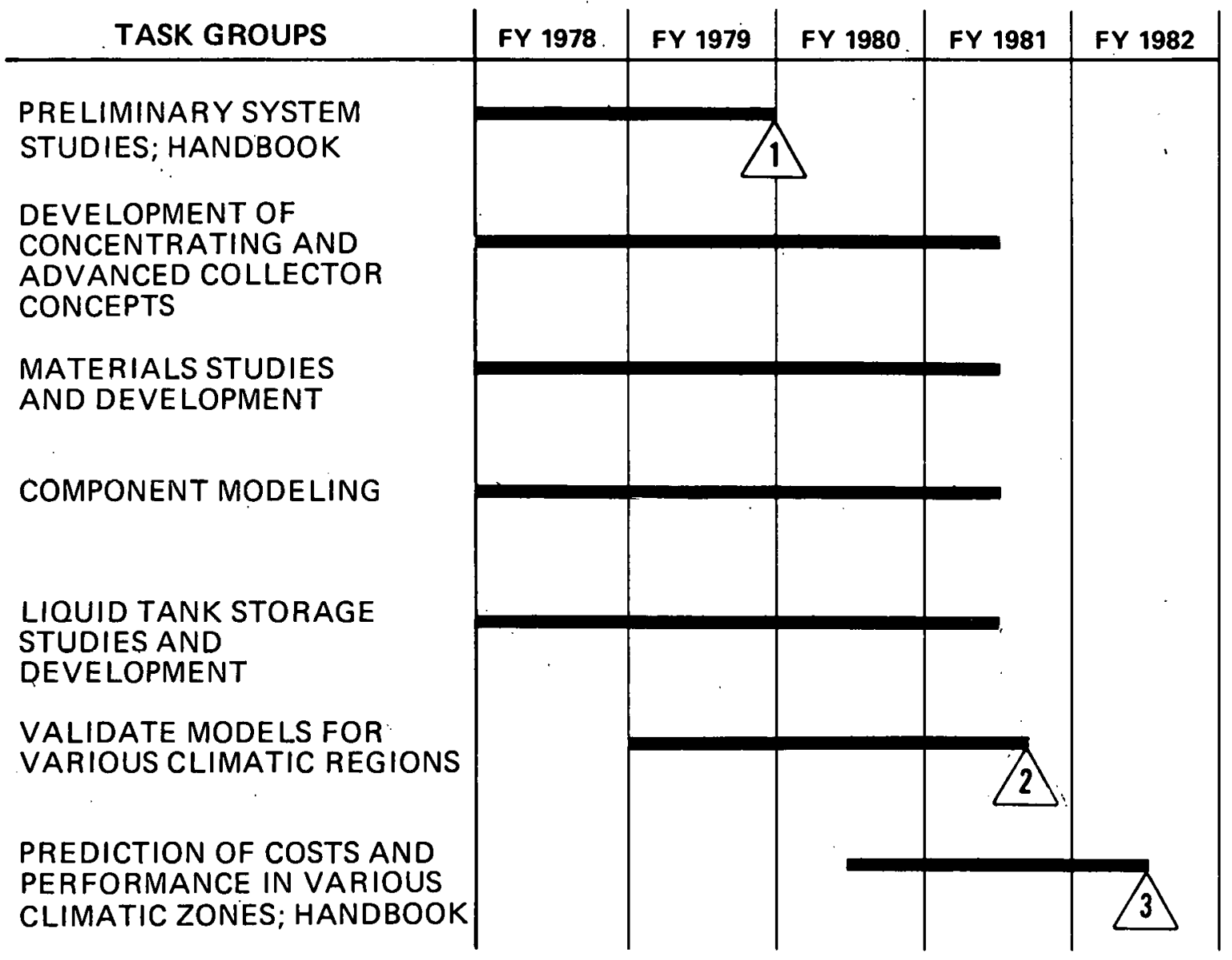

\section{MILESTONES}

10/79

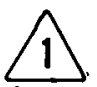

Complete system studies identifying cost and performance characteristics for systems chosen for various climatic regions. This will be done assuming validity of current simulation techniques and characteristics of existing hardware. Publish preliminary handbook.
6/81

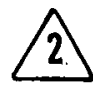

Complete a review of system simulation techniques (based on improved system and collectors). Validate mathematical models.

$4 / 82$ 3 Repeat above system analyses based on validated models and improved components. Publish revised handbook. 


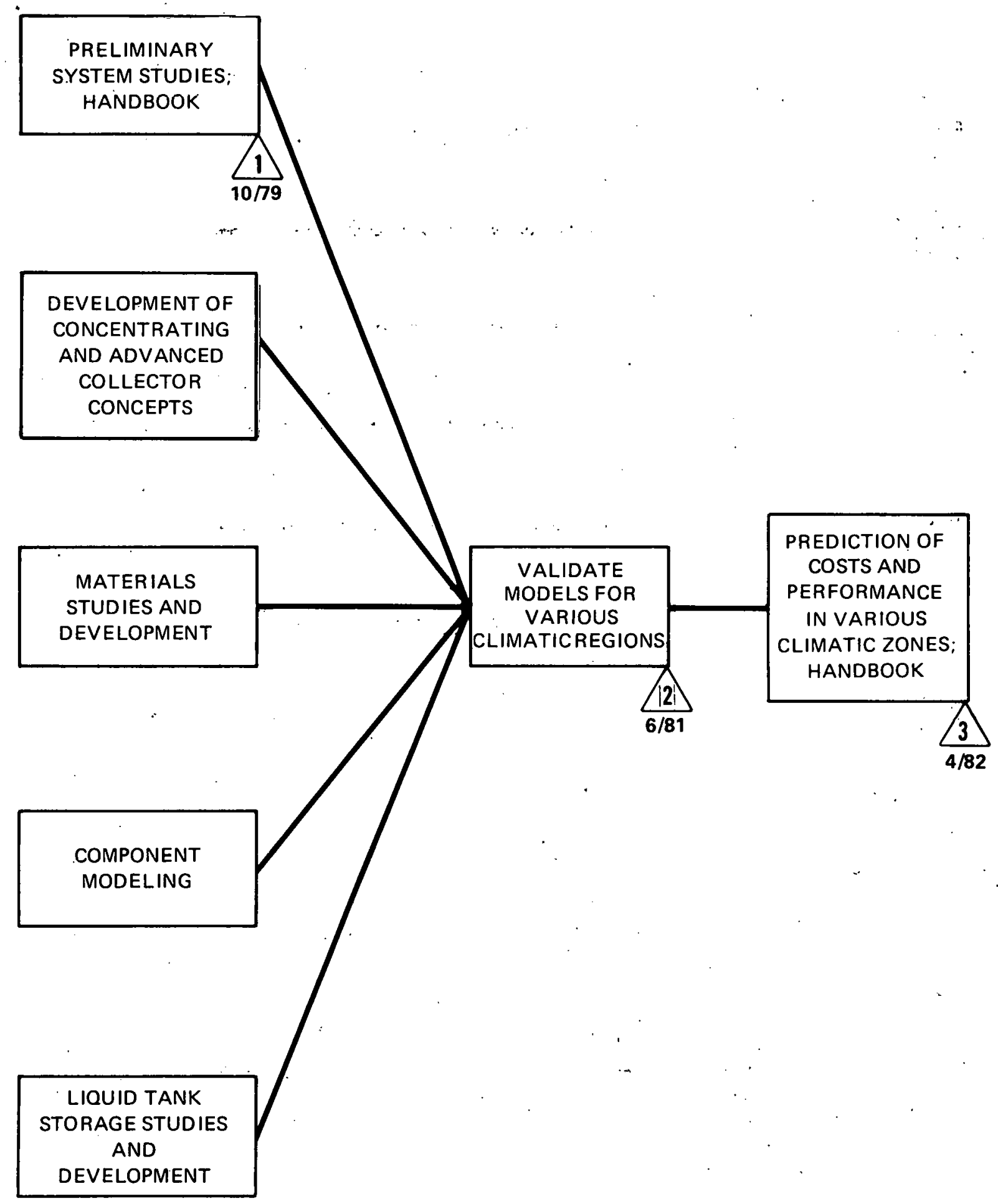

FIGURE II-46

AIR-HEATING COLLECTORS FOR PROCESS HOT WATER

PATH WA TASK FLOW CHART 


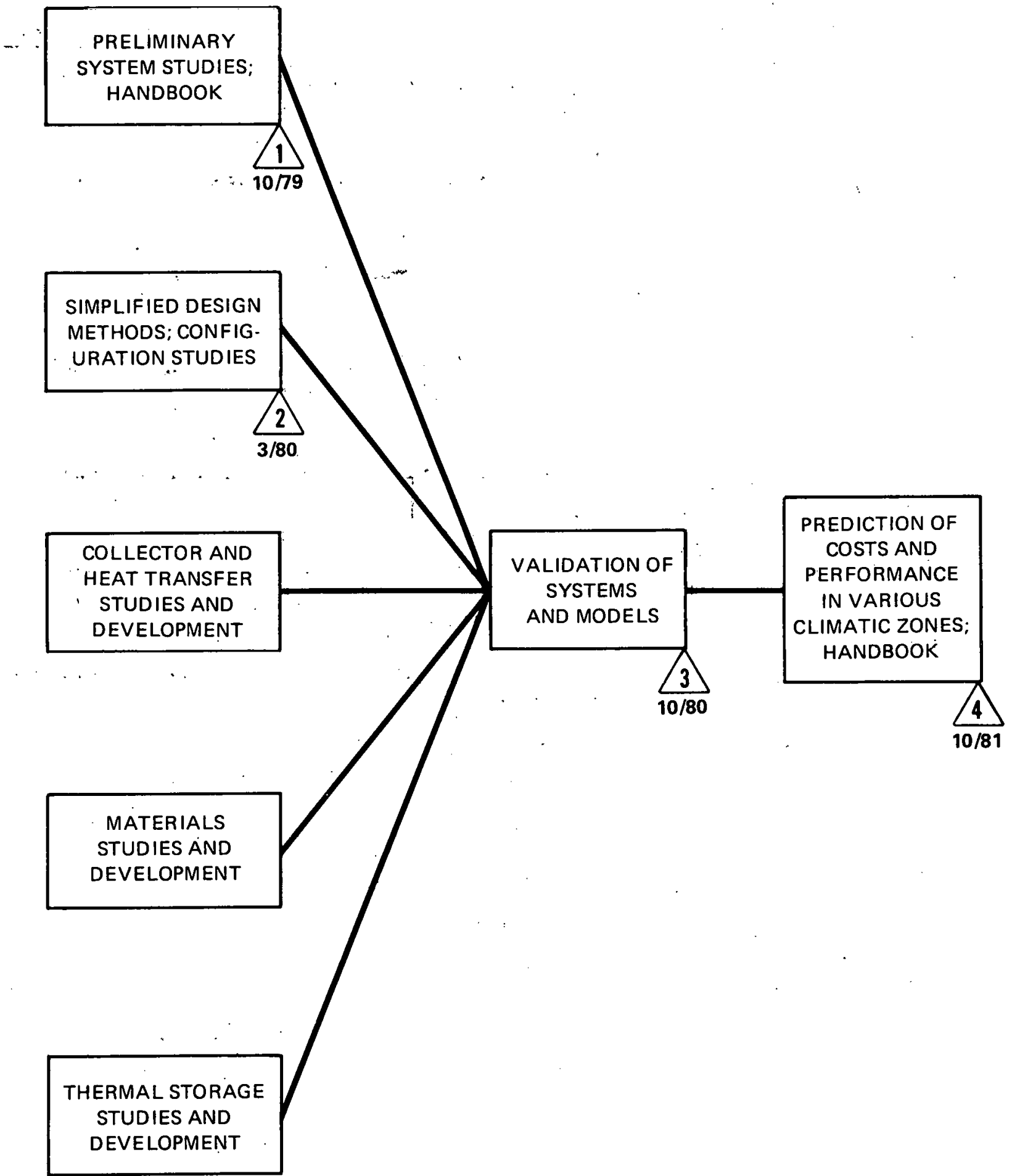

FIGURE II-42

LIQUID-HEATING COLLECTORS FOR DRYING

PATH DL TASK FLOW CHART 


\section{LIQUID-HEATING COLLECTORS \\ FOR \\ PROCESS STEAM \\ .PATH'SL}

\section{GENERAL}

A simple method of producing steam is to pump water into the collector and allow it to boil, then draw off steam. The collector/storage system can be pressurized so that boiling does not occur and the pressurized hot water can be flashed into steam when needed. Additional degrees of freedom appear when a heat exchanger or a liquid other than water is used. For example, a liquid with normal boiling point of $200^{\circ} \mathrm{C}$ $\left(392^{\circ} \mathrm{F}\right)$ can be heated in an unpressurized collector, delivered to a storage tank, and used to produce steam via a heat exchanger at various temperatures, pressures, and flow rates, as desired.

Sensible heat storage in insulated tanks is the most commonly used storage method. Chemical storage (using heat of reaction) or phase-change storage could eventually prove advantageous. Since storage is expensive, in many applications it may be best to use solar heat as a supplement for a conventional boiler, with no storage. However, having some storage capability may significantly increase the fuel savings and extend the usefulness of solar steam.

\section{R\&D STRATEGY}

The objective of this path is to develop solar industrial steam systems which are technically reliable and which can deliver steam at a cost competitive with fossil fuels. Low cost collector systems will be developed and small scale solar steam systems will be modeled, analyzed, and tested as a function of climatic and load parameters.

\section{R\&D EMPHASIS}

\section{Evaluation, Development, and Charac- terization of Materials}

New fluids for use in collectors at $100-400^{\circ} \mathrm{C}$ $\left(212-750^{\circ} \mathrm{F}\right)$

New materials for energy storage at steam temperature

Cost-effective glazings and associated hardware that will withstand high temperatures

\section{Development of Components}

Cost-effective collectors and associated equipment for use at temperatures of $100-400^{\circ} \mathrm{C}$ $\left(212-750^{\circ} \mathrm{F}\right)$

Storage tank/heat exchanger units for service at high temperature

\section{System Development and Analysis}

Development of models for simulation of total process system operation, including a supplementary solar steam system

Estimation of long-term fuel savings possible under various operating models

System cost analyses 


\section{System Testing}

Data gathered on experimental plant systems to validate models and determine design coefficients

Determination of possible environmental problems unique to industry

Determination of system failure modes

Establishment of lifetimes and maintenance requirements 


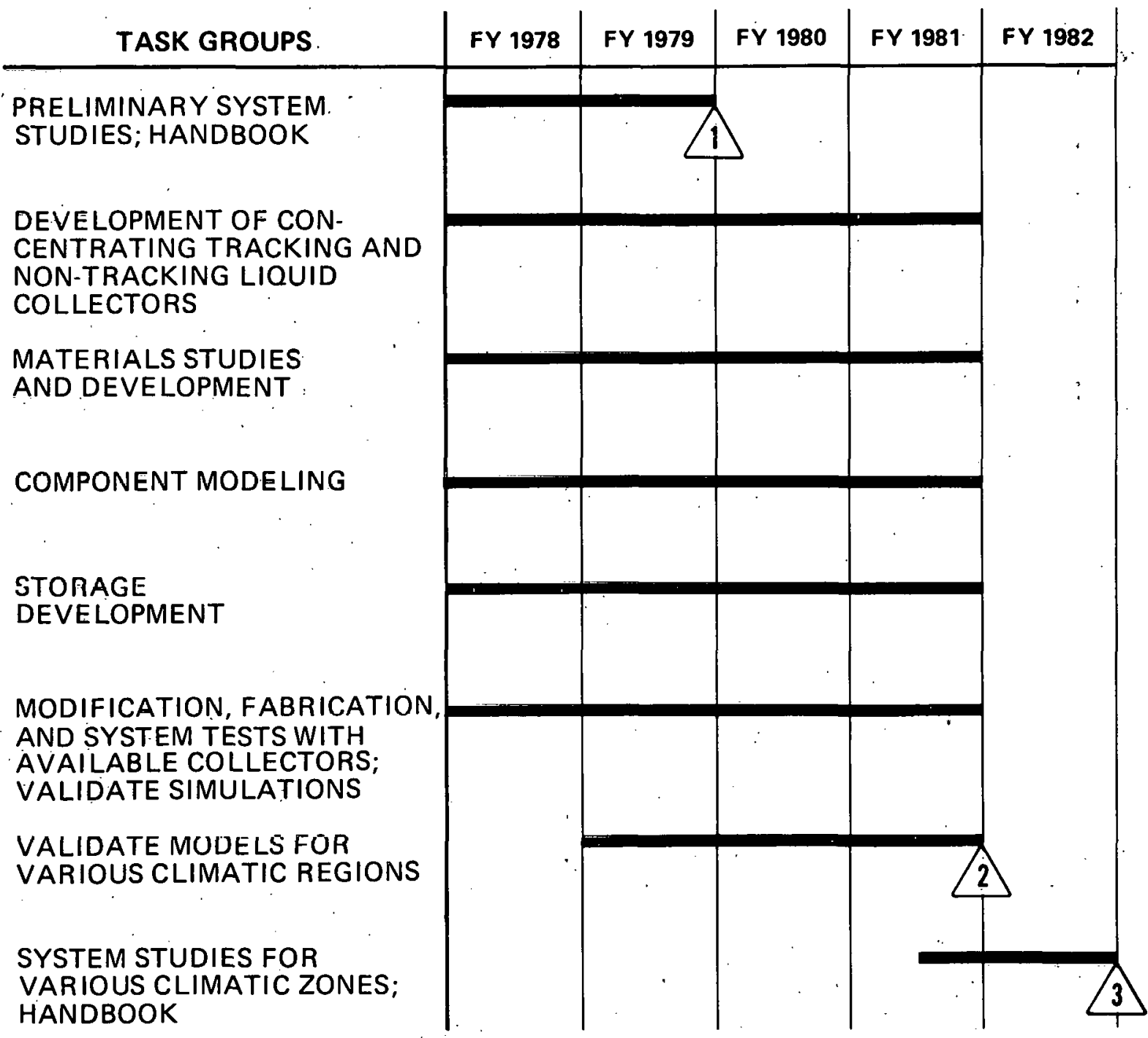

\section{MILESTONES}

$10 / 79$

1
Complete system studies identifying cost and performance characteristics for systems chosen for various climatic regions. This will be done assuming validity of current simulation techniques and characteristics of existing hardware. Publish preliminary handbook.
$10 / 81$

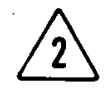

Complete a review of system simulation techniques (based on improved system and collectors). Validate mathematical models.

10/82 Repeat above system analyses 3 based on validated models and improved components. Publish revised handbook. 


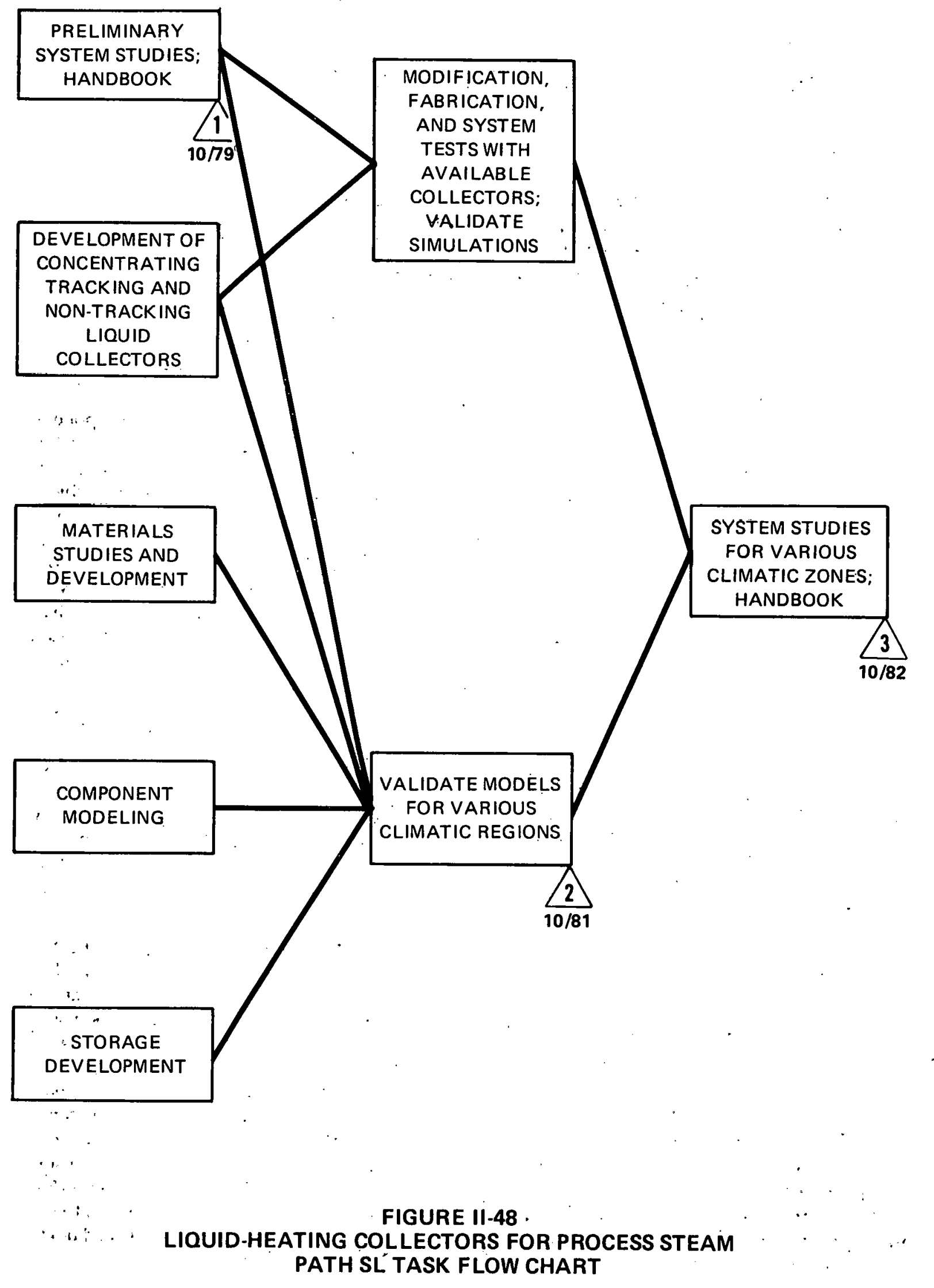




\section{PASSIVE COOLING FOR AGRICULTURAL AND INDUSTRIAL PROCESS APPLICATIONS PATH CP}

\section{GENERAL}

Passive cooling is accomplished by using a naturally cooler part of the environment as a heat sink. Cool night air or a low effective sky temperature enables heat to be removed convectively or radiatively from a structure. Evaporation of water can be used to decrease the temperature, provided that the dew point is sufficiently low. Other direct cooling techniques applicable to agricultural and industrial processes include the seasonal storage of ice and exploitation of the rather uniform temperatures found a short distance below the ground.

A relatively large heat exchange area is generally required since the temperature difference between the heat source and sink is smaller for passive processes than for mechanical cooling systems. The expense of a larger heat exchange area is balanced by lower power requirements and the less stringent thermal properties required of the materials. Furthermore, passive cooling components can often be integrated into the design as structural elements, and in some cases may make use of solar collector hardware at night.

The characteristics of passive cooling systems match especially well with agricultural and industrial cooling requirements when the range of acceptable temperature fluctuations can be extended. A combination of passive and mechanical cooling techniques may be effective for a wider range of applications.

Passive cooling schemes can be classified according to five methods of heat removal: evaporative, radiative, convective, underground, and seasonal ice storage. Air and/or water may be cooled by the evaporation of water (e.g., using a rock bed regenera- tor, "swamp" cooler, wet cooling tower, spray ponds). In some cases, a solar dried desiccant is used to dry the air before the evaporative cooling. Radiation to an effective sky temperature substantially below ambient air temperature is an effective method of heat removal in cloudless locations with low humidity. Convective heat removal involves the use of cold night air to cool a rockbed to provide a source of cool air the following day. Underground heat removal relies on the fact that, below about one meter depth, the ground temperature is essentially constant. If the mean annual temperature is low enough and the thermal conductivity of earth is sufficient, or if underground water is available, this can be a source of cooling. The melting of ice blocks can also provide long-term cooling. The ice may be either frozen in place or frozen elsewhere and transported.

It is not necessary that these passive cooling schemes be used separately. A surface radiating heat to the sky can, for instance, simultaneously lose heat by evaporation or convection if it is wetted or if the ambient night temperature is low enough.

Frequently, the same medium used to store heat in the winter for a solar heating system can be used to store cold in the summer. Thus, a rock bed can be cooled by circulating night air through it and then used to store water cooled by evaporation and nocturnal radiation. In addition to the sensible heat of water, rocks and structural materials are needed for compact sensible heat storage. Ice is a convenient material. However, other materials characterized by low cost, controllable corrosiveness, and large heat of fusion with a transition temperature of about $10-15^{\circ} \mathrm{C}$ $\left(50-59^{\circ} \mathrm{F}\right)$ are needed. Ways must be developed to optimize heat transfer to and from the storage medium to be cooled. 


\section{R\&D STRATEGY}

A few techniques which have worked well on a small scale, such as rock bed regenerators and nighttime cooling from wall or ceiling thermal mass storage, will be tested on a larger scale for specific agricultural and industrial process heat applications. Innovative methods for passive cooling will be explored.

\section{R\&D EMPHASIS}

\section{Evaluation, Development, and Charac- terization of Materials}

Storage materials with a latent heat transition different from $0^{\circ} \mathrm{C}\left(32^{\circ} \mathrm{F}\right)$

Low cost radiating surfaces

\section{Development of Components}

Rock beds, both dry and wet

Stratified water tanks

Water walls

Roof ponds
Movable insulation

Desiccants

Thermal diodes

Heat pipes

Underground conduits

\section{System Development and Analysis}

Computer modeling of all systems selected for construction

Determination of optimum load trade-off between passive cooling system and backup conventional cooling system

\section{System Testing}

Validation of design assumptions by performance verification

Determination of failure modes and other aspects of systems not included in computer models 


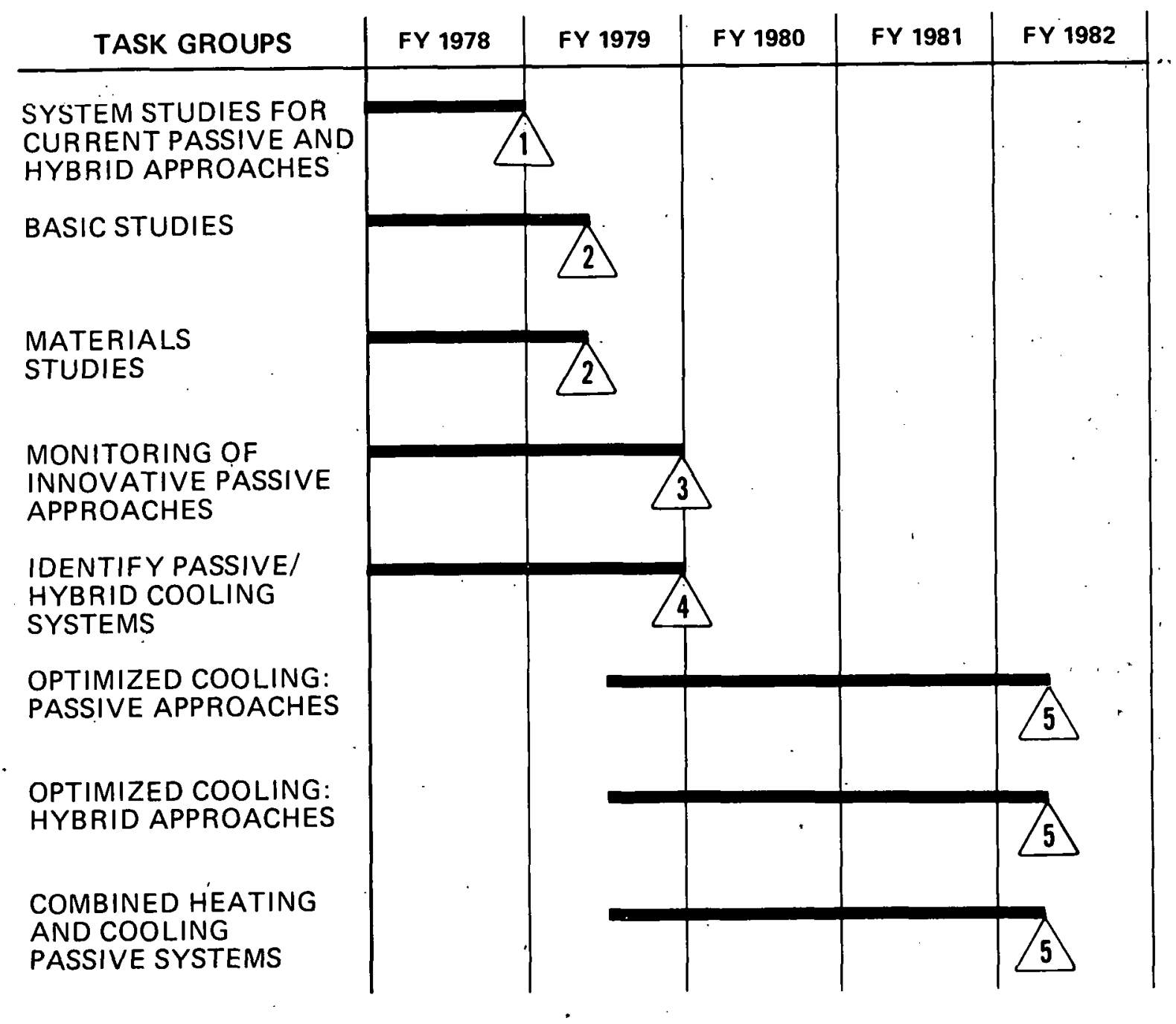

\section{MILESTONES}

Each milestone refers to the preparation and distribution of a handbook on current designs for structures that will be cooled predominantly by evaporative, radiative, and stored ice techniques.

$10 / 78$

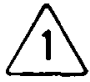

Handbook based on first round system studies of passive and active techniques.

2/79

2. Handbook based on results from basic and materials studies.

10/79 Handbook based on variants and 3 improvements of current passive cooling techniques.
$10 / 79$ Handbook based on results from
hybrid system tests.

$1 / 82$ Handbook based on optimized passive cooling systems, hybrid cooling systems, and combined heating and cooling passive systems. 


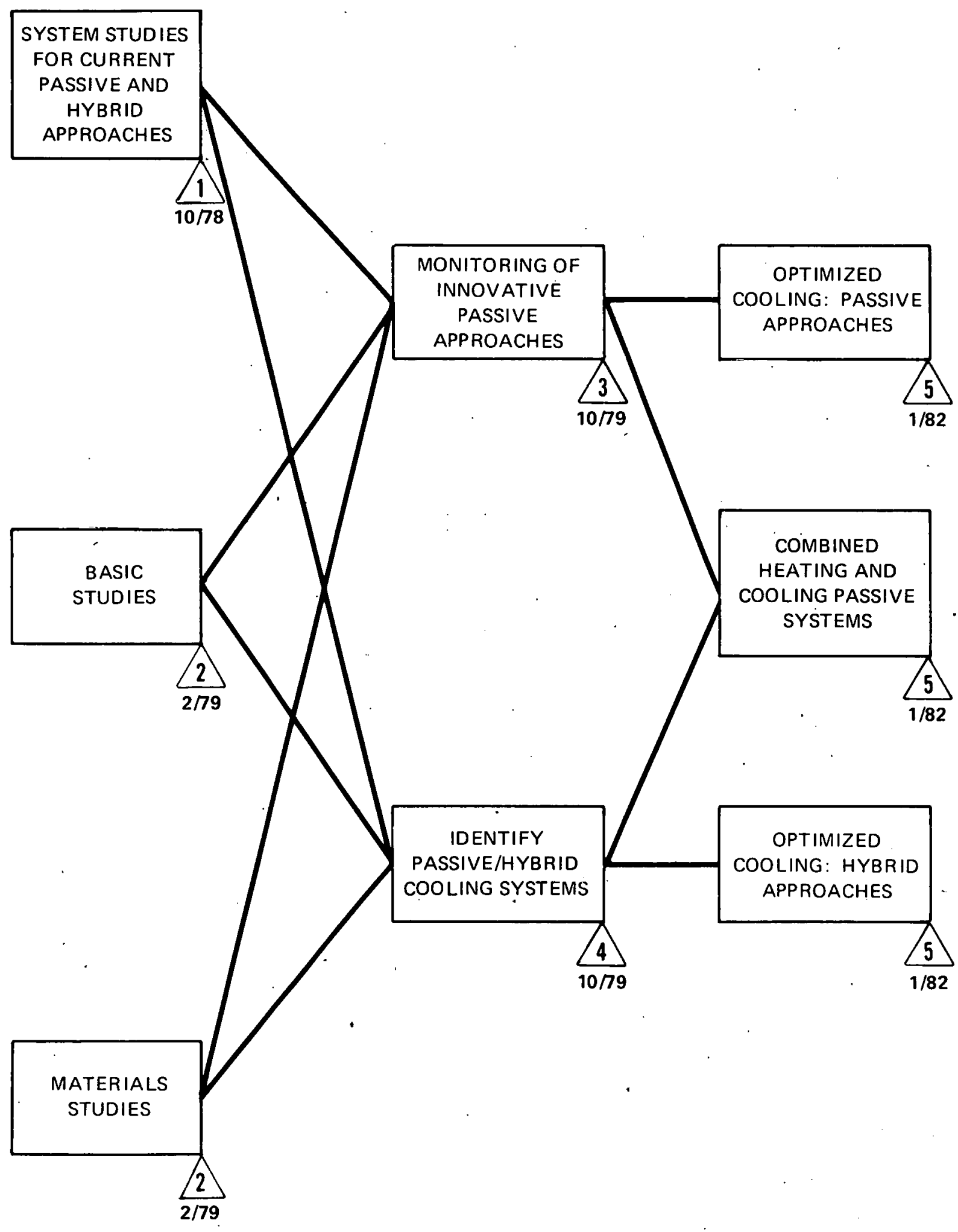

FIGURE II-50

PASSIVE COOLING FOR ÁGRICULTURAL AND INDUSTRIAL PROCESS APPLICATIONS PATH CP TASK FLOW CHART 


\section{ACTIVE COOLING AND REFRIGERATION FOR AGRICULTURAL AND INDUSTRIAL PROCESS APPLICATIONS PATH CA}

\section{GENERAL}

Cooling and refrigeration are both required in many agricultural and industrial processes, particularly those involved with food processing, chemical reactions, and pharmaceuticals. Costs of solar cooling and refrigeration are high. As used here, "cooling" denotes temperatures commonly associated with space conditioning [i.e., approximately $4-13^{\circ} \mathrm{C}\left(40-55^{\circ} \mathrm{F}\right.$ ), while "refrigeration" refers to temperatures below about $4^{\circ} \mathrm{C}$ $\left(40^{\circ} \mathrm{F}\right)$, suitable for chilling or freezing of food.

Both absorption and heat engine/vapor compression systems can be used for cooling and for refrigeration. Lithium bromide-water absorption cycles can be used for industrial space cooling and for process cooling down to about $7^{\circ} \mathrm{C}\left(45^{\circ} \mathrm{F}\right)$, while water-ammonia cycles can produce sub-freezing temperatures for food freezing and ice production. Mechanical vapor compression cycles driven by a solar-activated heat engine can produce either cooling or refrigeration, depending on the refrigerant used.

Large cooling/refrigeration systems will often use cold-side storage, since it is difficult to store the hotside fluid without thermal losses. A latent heat storage material with a transition temperature about $8^{\circ} \mathrm{C}\left(46^{\circ} \mathrm{F}\right)$ would be useful for cooling; either ice or dry ice can be used for food freezing. Latent heat storage systems would provide more compact storage and allow the chillers to operate at a constant cold-side temperature.

\section{R\&D STRATEGY}

The development of high temperature collectors and compact latent heat storage materials will be pursued. Potential advantages of combinations of active and passive cooling systems will be investigated.

\section{R\&D EMPHASIS}

\section{Evaluation, Development, and Charac- terization of Materials}

Storage materials with transition temperatures near $8^{\circ} \mathrm{C}$ for cooling, $8^{\circ} \mathrm{C}\left(46^{\circ} \mathrm{F}\right)$ for refrigeration

Better refrigerant fluids for solar-driven active chillers

\section{Development of Components}

Cold storage modules other than water tanks

Stratification in large cold water storage tanks

Heat-activated engines and absorption chillers

High temperature concentrating and non-concentrating collectors 


\section{System Development and Analysis}

Modeling of complete systems with realistic parameters for solar input, ambient heat load, and cooling/refrigeration requirements

Determination of optimum load trade-off between storage, conventional backup system, and. reliability for various applications ${ }^{\circ}$

Evaluation of combinations of active and passive systems

Analysis with particular emphasis on system operation at off-design conditions

\section{System Testing}

Validation of computer models under various load conditions

Determination of failure modes and other nonquantifiable parameters

Determination of operation requirements and manpower level of skill 


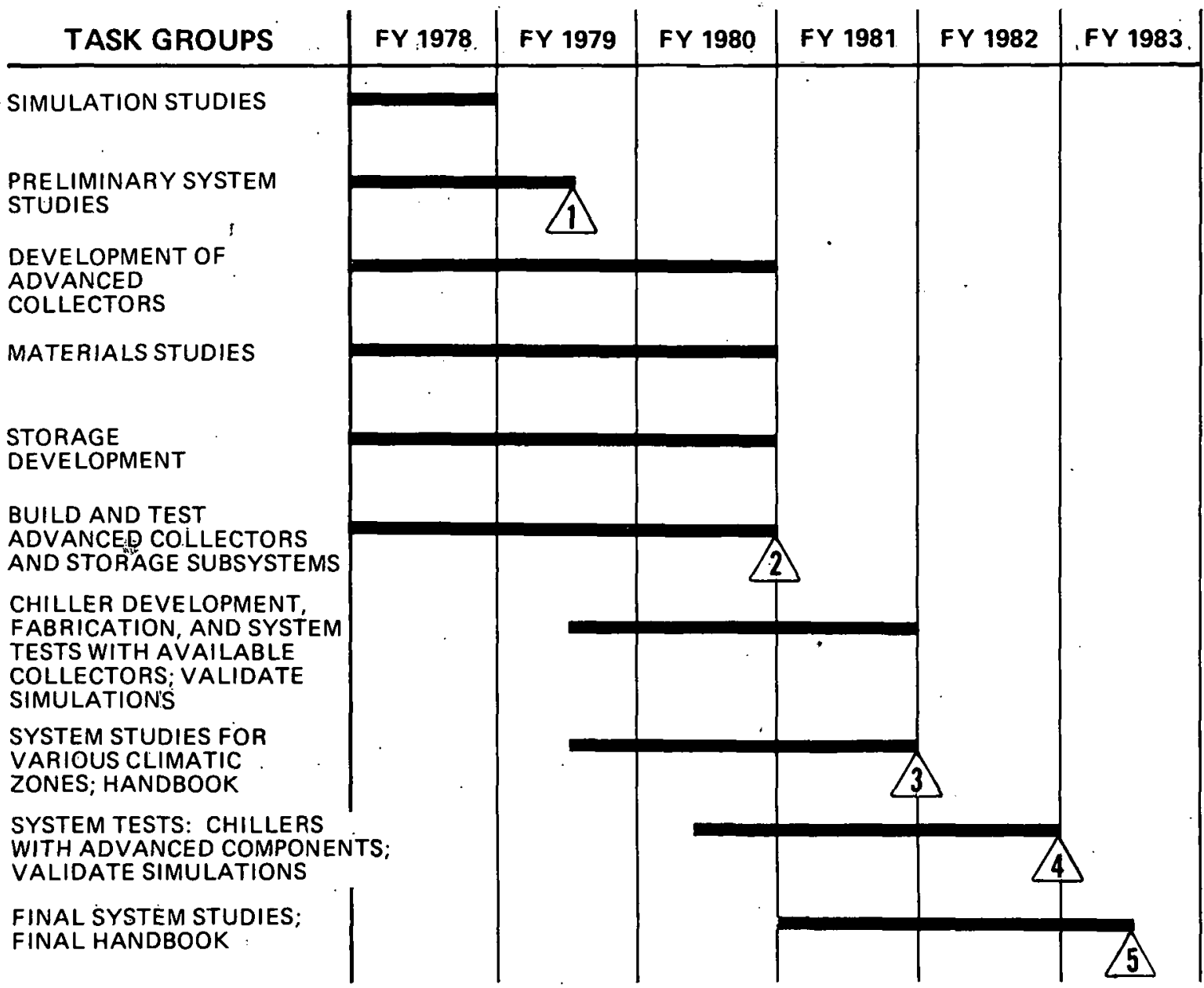

\section{MILESTONES}

4/79

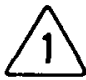

Preliminary system studies and collector development lead to choices of collectors for first generation chiller tests and various types of most promising advanced collectors for further development.

10/80 Advanced collectors are evaluated in

2 simulations and are ready for second generation chiller tests. Storage systems are evaluated.

10/81 Currently available chillers tested (sep3 arately and side by sidel. System studies performed and preliminary handbooks generated for pertinent climatic zones.
10/82

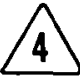

Tests completed with advanced components and original chiller units of varying sizes. (Second generation tests.)

$3 / 83$

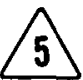

System studies completed for various climatic ranges for ad. vanced collectors and second generation chillers. Publish handbook. 


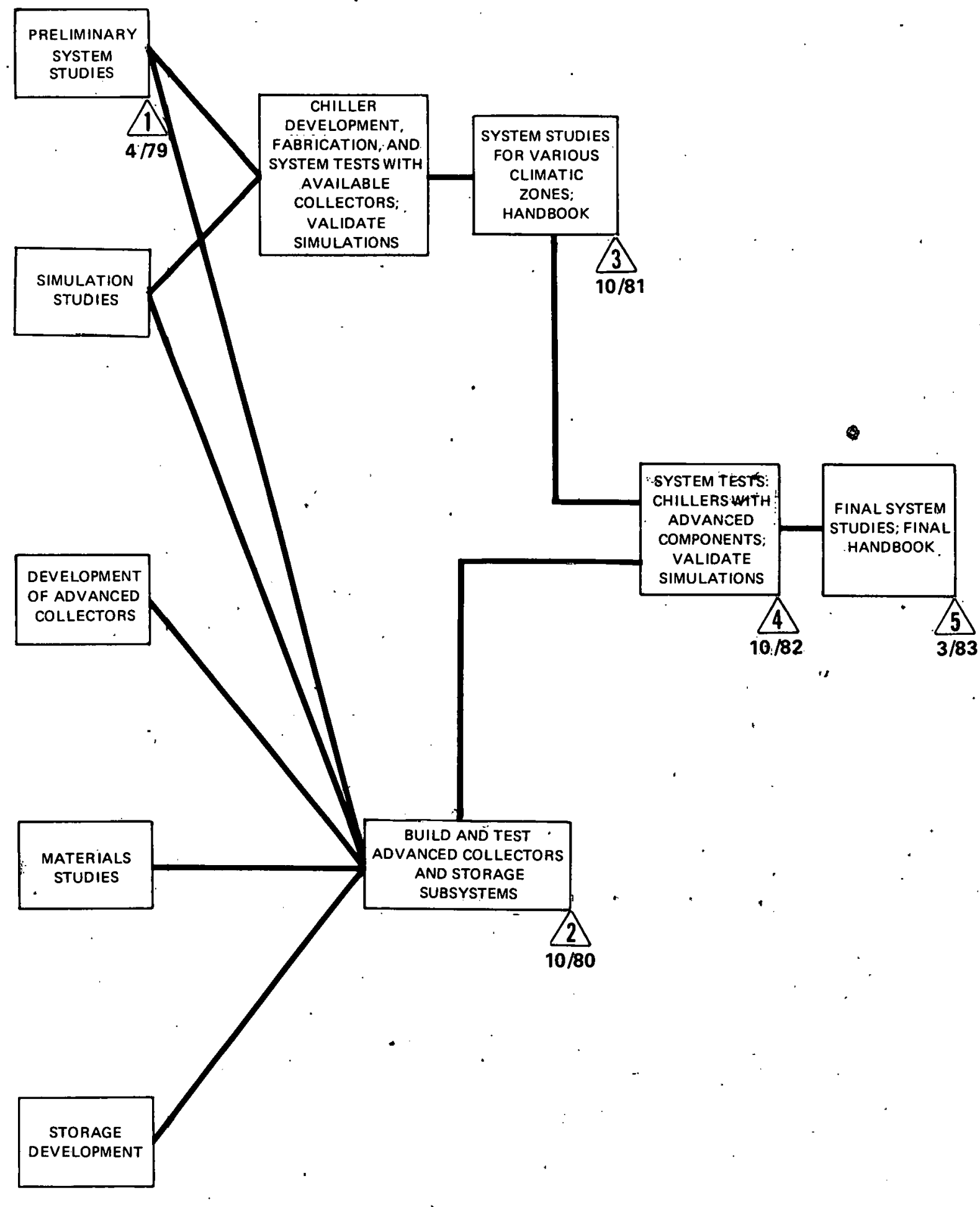

FIGURE II-52 
PART III. TASKS 
THIS PAGE

\section{WAS INTENTIONALLY LEFT BLANK}




\section{APPENDIX A \\ R\&D Program Tasks \\ for the}

Solar Heating and Cooling of Buildings

and

Ágricultural and Industrial Process Heat Applications 


\section{PAGES 18 to 20 WERE INTENTIONALLY LEFT BLANK}




\section{Solar Collectors}

\section{OBJECTIVE}

The objective of the tasks in this category is the development of the technology necessary for a variety of cost-effective air- and liquid-heating solar collectors. The following temperature range classification will be used:

- Low temperature - below $50^{\circ} \mathrm{C}\left(120^{\circ} \mathrm{F}\right)$

- Medium temperature -50 to $75^{\circ} \mathrm{C}\left(120\right.$ to $\left.170^{\circ} \mathrm{F}\right)$

- High temperature - over $75^{\circ} \mathrm{C}\left(170^{\circ} \mathrm{F}\right)$

\section{EMPHASIS}

The solar collector element of the R\&D program emphasizes the following points:

- Development of durable materials for glazings, surface coatings, sealants, compatible absorber plate/coolant combinations, insulation, etc.

- Modeling and testing of various means of increasing solar input (reflectors, tracking) and reducing energy loss (reducing IR emittance, suppressing or eliminating convection, and concentration).

- Optimization of collector design for cost-effective energy collection for each system application.

- Development of large area, low cost collector systems, both of non-concentrating and concentrating types, specifically for providing agricultural/industrial process heat. Collectors are required to produce hot water from $20-120^{\circ} \mathrm{C}\left(68-250^{\circ} \mathrm{F}\right)$, hot air from $20-350^{\circ} \mathrm{C}\left(68-660^{\circ} \mathrm{F}\right)$, and steam from $100-350^{\circ} \mathrm{C}\left(212-660^{\circ} \mathrm{F}\right)$.

\section{TASKS}

\section{I-A. System Studies Related to Collectors}

1-A-1. Perform a cost breakdown for collectors currently being produced or developed. Investigate the following major cost categories: raw materials, parts, labor for assembly, equipment amortization, plant operation and overhead, sales, distribution, and installation. Determine whether the major competing collector types (such as liquid-heating flat plate, air-heating flat plate, evacuated tube, reflecting concentrating and refracting concentrating) differ significantly in cost and whether regional (geographic) differences will influence collector cost appreciably.

\begin{tabular}{|c|c|c|c|c|c|c|c|c|c|c|c|}
\hline \multirow[t]{2}{*}{ PATH } & \multicolumn{2}{|c|}{$\begin{array}{l}\text { SERVICE } \\
\text { HOT WATER }\end{array}$} & \multicolumn{4}{|c|}{ SPACE HEATING } & \multicolumn{5}{|c|}{ SPACE COOLING } \\
\hline & $w 1$ & wi & H1 & $\mathrm{H} 2$ & $\mathrm{H3}$ & $\mathrm{H} 4$ & $\mathrm{C}_{1}$ & $\mathrm{C} 2$ & $\mathrm{C} 3$ & $\mathrm{C} 4$ & $\mathrm{C5}$ \\
\hline $\begin{array}{l}\text { IMPORTANCE } \\
\text { NO. }\end{array}$ & 10 & 10 & 10 & 2 & 8 & 8 & 10 & 10 & 10 & & 10 \\
\hline STATUS & FUU & & 0 & & & & & & & & \\
\hline
\end{tabular}


I-A-2. Study collector sensitivity by determining the effect of changes in collector design on system performance. Use weather data and solar radiation data in a computer simulation of the system, analyzing syst performance for all seasons. Study collector sensitivity with varying surfaces, heat transfer characterist heat loss mechanisms (such as radiation and convection and the use of honeycombs), and changes in collector heat capacities. Make the sensitivity studies for various system configurations and various climates and applications.

\begin{tabular}{|c|c|c|c|c|c|c|c|c|c|c|c|}
\hline & \multicolumn{3}{|c|}{$\begin{array}{c}\text { SERVICE } \\
\text { POTH }\end{array}$} & \multicolumn{4}{|c|}{ SPACE HEATING } & \multicolumn{5}{c|}{ SPACE COOLING } \\
& H1 & W2 & H1 & H2 & H3 & H4 & C1 & C2 & C3 & C4 & C5 \\
\hline $\begin{array}{c}\text { IMPORTANCE } \\
\text { NO. }\end{array}$ & 10 & 10 & 10 & & 10 & 10 & 10 & 10 & 10 & & 10 \\
\hline STATUS & \multicolumn{3}{|l|}{ FEDERAL LAB } \\
\hline
\end{tabular}

1-A-3. Develop a method for determining which solar collectors are most appropriate with respect to their applications in given situations or climatic zones. Determine whether special procedures such as double glazing and the use of selective surfaces are particularly appropriate in certain climatic zones. Evaluate the effect of varying tilt angle, shape, and other collector parameters on collector performance for various climatic zones. Develop a COP for the collector pumping system as a unit.

\begin{tabular}{|c|c|c|c|c|c|c|c|c|c|c|c|}
\hline \multirow[t]{2}{*}{ PATH } & \multicolumn{2}{|c|}{$\begin{array}{l}\text { SERVICE } \\
\text { HOT WATER }\end{array}$} & \multicolumn{4}{|c|}{ SPACE HEATING } & \multicolumn{5}{|c|}{ SPACE COOLING } \\
\hline & $w_{1}$ & w2 & H1 & $\mathrm{H} 2$ & $\mathrm{H3}$ & $\mathrm{H} 4$ & $\mathrm{Cl}$ & $\mathrm{C} 2$ & C3 & $\mathrm{C4}$ & $\mathrm{C5}$ \\
\hline $\begin{array}{l}\text { IMPORTANCE } \\
\text { NO. }\end{array}$ & 10 & 10 & 10 & & 10 & 10 & 10 & 10 & 10 & & 10 \\
\hline STATUS & \multicolumn{6}{|c|}{ FEDERAL LAB } & . & & & & \\
\hline
\end{tabular}

1-A-4. Study the performance of collector arrays. Determine which arrangements of collector rows best balance the effects of shading and limitations on mounting space. This is particularly important for retrofit applications in urban areas. Determine optimum plumbing configurations (series, parallel, and seriesparallel) to maximize collected energy for various fluid outlet temperature ranges. Analyze the effects of plumbing and manifolding on flow distribution and fluid pressure drop through the collector arrays.

\begin{tabular}{|c|c|c|c|c|c|c|c|c|c|c|c|}
\hline \multirow[t]{2}{*}{ PATH } & \multicolumn{2}{|c|}{$\begin{array}{l}\text { SERVICE } \\
\text { HOT WATER }\end{array}$} & \multicolumn{4}{|c|}{ SPACE HEATING } & \multicolumn{5}{|c|}{ SPACE COOLING } \\
\hline & $w_{1}$ & w2 & $\mathrm{H} 1$ & $\mathrm{H} 2$ & H3 & $\mathrm{H} 4$ & $\mathrm{C}_{1}$ & $\mathrm{C2}$ & $\mathrm{C} 3$ & $\mathrm{C4}$ & C5 \\
\hline $\begin{array}{c}\text { IMPORTANCE } \\
\text { NO. }\end{array}$ & 8 & 8 & 8 & & 8 & 8 & 9 & 9 & 8 & & 8 \\
\hline STATUS & \multicolumn{6}{|c|}{ FUNDED RFP/PRDA } & & & & & \\
\hline
\end{tabular}


1-A-5. Develop a standardized method of recording collector data to reduce the time required for supplying system analysis or test data to manufacturers. Standardize instruments, calibration, and measurement produires.

\begin{tabular}{|c|c|c|c|c|c|c|c|c|c|c|c|}
\hline \multirow[t]{2}{*}{ PATH } & \multicolumn{2}{|c|}{$\begin{array}{l}\text { SERVICE } \\
\text { HOT WATER }\end{array}$} & \multicolumn{4}{|c|}{ SPACE HEATING } & \multicolumn{5}{|c|}{ SPACE COOLING } \\
\hline & w1 & w2 & H1 & $\mathrm{H} 2$ & $\mathrm{H} 3$ & $\mathrm{H} 4$ & $\mathrm{Cl}$ & $\mathrm{C} 2$ & C3 & $\mathrm{C} 4$ & $\mathrm{C5}$ \\
\hline $\begin{array}{c}\text { IMPORTANCE } \\
\text { NO. }\end{array}$ & 6 & 6 & 6 & & 10 & 7 & 8 & 8 & 7 & 3 & 5 \\
\hline STATUS & F & $\mathrm{AL}$ & & & & & & & & & \\
\hline
\end{tabular}

1-A-6. Evaluate fully instrumented collector or system tests in the field to determine whether or not collector array performance can be predicted with sufficient accuracy from individual collector test data or collector simulation models.

\begin{tabular}{|c|c|c|c|c|c|c|c|c|c|c|c|}
\hline \multirow{2}{*}{ PATH } & \multicolumn{3}{|c|}{$\begin{array}{c}\text { SERVICE } \\
\text { HOT WATER }\end{array}$} & \multicolumn{4}{|c|}{ SPACE HEATING } & \multicolumn{5}{c|}{ SPACE COOLING } \\
& $\mathrm{W} 1$ & $\mathrm{~W} 2$ & $\mathrm{H} 1$ & $\mathrm{H} 2$ & $\mathrm{H} 3$ & $\mathrm{H} 4$ & $\mathrm{C1}$ & $\mathrm{C} 2$ & $\mathrm{C} 3$ & $\mathrm{C} 4$ & $\mathrm{C}$ \\
\hline $\begin{array}{c}\text { IMPORTANCE } \\
\text { NO. }\end{array}$ & 5 & 5 & 6 & & 5 & 5 & 8 & 8 & 7 & 3 & 7 \\
\hline STATUS & \multicolumn{3}{|l|}{ FEDERAL LAB } \\
\hline
\end{tabular}

I-A-7. Conduct control strategy studies, based on system analysis, to determine how collector and system performances are affected by various control strategies and transient parameters.

\begin{tabular}{|c|c|c|c|c|c|c|c|c|c|c|c|}
\hline \multirow[t]{2}{*}{ PATH } & \multicolumn{2}{|c|}{$\begin{array}{l}\text { SERVICE } \\
\text { HOT WATER }\end{array}$} & \multicolumn{4}{|c|}{ SPACE HEATING } & \multicolumn{5}{|c|}{ SPACE COOLING } \\
\hline & wi & w2 & $\mathrm{HI}$ & $\mathrm{H} 2$ & $\mathrm{H} 3$ & $\mathrm{H} 4$ & $\mathrm{C1}$ & $\mathrm{C} 2$ & $\mathrm{C} 3$ & $\mathrm{C} 4$ & $\mathrm{C5}$ \\
\hline $\begin{array}{c}\text { IMPORTANCE } \\
\text { NO. }\end{array}$ & 2 & 1 & 3 & . & 6 & 6 & 9 & 9 & 4 & 1 & 4 \\
\hline STATUS & & & & & & & & & & & \\
\hline
\end{tabular}


1-A-8. Design, construct, instrument, and operate those collectors or radiators required for certain improved systems. Develop and validate simulations for these devices. If possible, choose the collectors or radiator devices from those available in the demonstration program.

\begin{tabular}{|c|c|c|c|c|c|c|c|c|c|c|c|}
\hline \multirow{2}{*}{ PATH } & \multicolumn{3}{|c|}{$\begin{array}{c}\text { SERVICE } \\
\text { HOT WATER }\end{array}$} & \multicolumn{4}{|c|}{ SPACE HEATING } & \multicolumn{4}{c|}{ SPACE COOLING } \\
& W1 & W2 & $H 1$ & $H 2$ & $H 3$ & $H 4$ & $C 1$ & $C 2$ & $C 3$ & $C 4$ & $C 5$ \\
\hline $\begin{array}{c}\text { IMPORTANCE } \\
\text { NO. }\end{array}$ & 8 & 8 & 8 & & 8 & 8 & 8 & 8 & 8 & 8 & 8 \\
\hline STATUS & \multicolumn{3}{|l|}{ FUNDED } \\
\hline
\end{tabular}

\section{I-B. Theory and Basic Phenomena}

I-B-1. Review the state of the art for collector corrosion processes. Develop a data bank for cataloging basic corrosion processes. Develop a data bank for cataloging basic corrosion information on the various materials and heat-transfer fluids which are used or which might be used in liquid-heating collectors. This data bank will be used to develop a theoretical understanding of corrosion.

\begin{tabular}{|c|c|c|c|c|c|c|c|c|c|c|c|}
\hline \multirow[t]{2}{*}{ PATH } & \multicolumn{2}{|c|}{$\begin{array}{c}\text { SERVICE } \\
\text { HOT WATER }\end{array}$} & \multicolumn{4}{|c|}{ SPACE HEATING } & \multicolumn{5}{|c|}{ SPACE COOLING } \\
\hline & $w_{1}$ & w2 & $\mathrm{H} 1$. & $\mathrm{H} 2$ & $\mathrm{H} 3$ & H4 & C1 & C2 & $\mathrm{C3}$ & $\mathrm{C} 4$ & $\mathrm{C} 5$ \\
\hline $\begin{array}{l}\text { IMPORTANCE } \\
\text { NO. }\end{array}$ & 10 & 10 & 10 & 8 & 2 & 10 & 10 & 10 & 8 & & 10 \\
\hline STATUS & FU: & D & ס & & & & & & & & \\
\hline
\end{tabular}

I-B-2. Determine the effect of wind speed and direction on collector performance for both glazed and unglazed collectors. For unglazed collectors, determine the effect of surface irregularities (such as wind breaks extending from the surface) on collector performance.

\begin{tabular}{|c|c|c|c|c|c|c|c|c|c|c|c|}
\hline \multirow{2}{*}{ PATH } & \multicolumn{2}{|c|}{$\begin{array}{l}\text { SERVICE } \\
\text { HOT WATER }\end{array}$} & \multicolumn{4}{|c|}{ SPACE HEATING } & \multicolumn{5}{|c|}{ SPACE COOLING } \\
\hline & w1 & w2 & H1 & $\mathrm{H} 2$ & $\mathrm{H3}$ & $\mathrm{H} 4$ & C1 & $\mathrm{C} 2$ & C3 & $\mathrm{C} 4$ & $\mathrm{C} 5$ \\
\hline $\begin{array}{l}\text { IMPORTANCE } \\
\text { NO. }\end{array}$ & 4 & 4 & 10 & 8 & 6 & 6 & & 2 & 4 & 7 & 10 \\
\hline STATUS & 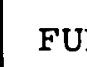 & & & & & & & & & & \\
\hline
\end{tabular}


I-B-3. Determine the effect of condensed watcr and dust on cover-plate performance.

\begin{tabular}{|c|c|c|c|c|c|c|c|c|c|c|c|}
\hline \multirow[t]{2}{*}{ _ PATH } & \multicolumn{2}{|c|}{$\begin{array}{l}\text { SERVICE } \\
\text { HOT WATER }\end{array}$} & \multicolumn{4}{|c|}{ SPACE HEATING } & \multicolumn{5}{|c|}{ SPACE COOLING } \\
\hline & w1 & W2 & $\mathrm{HI}$ & $\mathrm{H} 2$ & H3 & $\mathrm{H} 4$ & $\mathrm{Cl}$ & $\mathrm{C} 2$ & $\mathrm{C} 3$ & $\mathrm{C} 4$ & $\mathrm{C5}$ \\
\hline $\begin{array}{l}\text { IMPORTANCE } \\
\text { NO. }\end{array}$ & 6 & 4 & 4 & 5. & 6 & 6 & 7 & 6 & 4 & 6 & 4 \\
\hline STATUS & $\mathrm{FL}$ & & & & & & & & & & \\
\hline
\end{tabular}

1-B-4. Determine the effect of large scale plate roughness (for example, tubes on the absorber surface, $\mathrm{V}$-corrugations, or cups) on the natural convection heat-transfer loss from the collector. Relate these effects to the performance of various collector types.

\begin{tabular}{|c|c|c|c|c|c|c|c|c|c|c|c|}
\hline \multirow{2}{*}{ PATH } & \multicolumn{3}{|c|}{$\begin{array}{c}\text { SERVICE } \\
\text { HOT WATER } \\
\end{array}$} & \multicolumn{4}{|c|}{ SPACE HEATING } & \multicolumn{5}{c|}{ SPACE COOLING } \\
& W1 & W2 & H1 & H2 & H3 & H4 & C1 & C2 & C3 & C4 & C5 \\
\hline $\begin{array}{c}\text { IMPORTANCE } \\
\text { NO. }\end{array}$ & 4 & 6 & 6 & & 7 & 5 & 3 & 3 & 7 & & 7 \\
\hline STATUS & \multicolumn{3}{|c|}{ RENEWAL (UNSOLICITED) } \\
\hline
\end{tabular}

I-B-5. Study convection heat losses caused by absorber and glazing surfaces that are not individually isothermal. Consider both liquid and air collectors.

\begin{tabular}{|c|c|c|c|c|c|c|c|c|c|c|c|}
\hline \multirow{2}{*}{ PATH } & \multicolumn{3}{|c|}{$\begin{array}{c}\text { SERVICE } \\
\text { HOT WATER } \\
\end{array}$} & \multicolumn{4}{|c|}{ SPACE HEATING } & \multicolumn{5}{c|}{ SPACE COOLING } \\
& W1 & W2 & H1 & H2 & H3 & H4 & C1 & C2 & C3 & C4 & C5 \\
\hline $\begin{array}{c}\text { IMPORTANCE } \\
\text { NO. }\end{array}$ & 3 & 5 & 5 & 5 & 6 & 5 & & 2 & 6 & & 6 \\
\hline STATUS & \multicolumn{3}{|l|}{ FUNDED } \\
\hline
\end{tabular}


I-B-6. Investigate the relationship between Stanton number (heat transfer), friction factor (flow power requirements), flow direction, and Reynolds number for forced convection of air across absorber plates with various extended heat-transfer surfaces ( $V$-corrugations, fins, etc.).

\begin{tabular}{|c|c|c|c|c|c|c|c|c|c|c|c|}
\hline \multirow[t]{2}{*}{ PATH } & \multicolumn{2}{|c|}{$\begin{array}{l}\text { SERVICE } \\
\text { HOT WATER }\end{array}$} & \multicolumn{4}{|c|}{ SPACE HEATING } & \multicolumn{5}{|c|}{ SPACE COOLING } \\
\hline & W1 & w2 & $\mathrm{H1}$ & $\mathrm{H} 2$ & $\mathrm{H} 3$ & $\mathrm{H4}$ & $\mathrm{Cl}$ & $\mathrm{C} 2$ & C3 & $\mathrm{C} 4$ & $\mathrm{C5}$ \\
\hline $\begin{array}{l}\text { IMPORTANCE } \\
\text { NO. }\end{array}$ & & 6 & 4 & & 4 & & & & & & 5 \\
\hline STATUS & $\mathrm{FU}$ & & 1 & $A$; & NEV & 10 & OLI & TED) & & & \\
\hline
\end{tabular}

I-B-7. Investigate the effects on collector performance of reflective coatings on the glazing. Study the optical characteristics of collector glazings and compare the effects of these glazings on direct and diffuse radiation.

\begin{tabular}{|c|c|c|c|c|c|c|c|c|c|c|c|}
\hline \multirow[t]{2}{*}{ P.ATH } & \multicolumn{2}{|c|}{$\begin{array}{l}\text { SERVICE } \\
\text { HOT WATER }\end{array}$} & \multicolumn{4}{|c|}{ SPACE HEATING } & \multicolumn{5}{|c|}{ SPACE COOLING } \\
\hline & w1 & w2 & H1 & $\mathrm{H} 2$ & H3 & $\mathrm{H} 4$ & $\mathrm{C}_{1}$ & $\mathrm{C} 2$ & $\mathrm{C} 3$ & $\mathrm{C} 4$ & C5 \\
\hline $\begin{array}{l}\text { IMPORTANCE } \\
\text { NO. }\end{array}$ & 4 & 4 & 3 & 4 & 3 & 3 & 4 & 7 & 5 & & 3 \\
\hline STATUS & & & & & & & & & & & \\
\hline
\end{tabular}

1-B-8. Determine the effects of coupled natural and forced convection in transpired air-heating collectors. Relate these effects to the surface properties.

\begin{tabular}{|c|c|c|c|c|c|c|c|c|c|c|c|}
\hline \multirow[t]{2}{*}{. PATH } & \multicolumn{2}{|c|}{$\begin{array}{l}\text { SERVICE } \\
\text { HOT WATER }\end{array}$} & \multicolumn{4}{|c|}{ SPACE HEATING } & \multicolumn{5}{|c|}{ SPACE COOLING } \\
\hline & w1 & w2 & $H 1$ & $\mathrm{H} 2$ & H3 & $\mathrm{H} 4$ & $\mathrm{Cl}^{\circ}$ & $\mathrm{C} 2$ & $\mathrm{C} 3$ & $\mathrm{C4}$ & $\mathrm{C5}$ \\
\hline $\begin{array}{l}\text { IMPORTANCE } \\
\text { NO. }\end{array}$ & & 6 & 6 & & 4 & . & & & & & 6 \\
\hline STATUS & & $E D$ & $\mathrm{P} /$ & & & & & & & & \\
\hline
\end{tabular}


1-B-9. Determine the theoretical heat-transfer mechanisms in evacuated collectors. Develop an adequate theoretical analysis of gaseous conduction at rarefied pressures for various geometries and tilt angles. The -..- - ly should include an estimate of the pressure required to eliminate significant conduction effects.

\begin{tabular}{|c|c|c|c|c|c|c|c|c|c|c|c|}
\hline \multirow{2}{*}{ PATH } & \multicolumn{2}{|c|}{$\begin{array}{l}\text { SERVICE } \\
\text { HOT WATER }\end{array}$} & \multicolumn{4}{|c|}{ SPACE HEATING } & \multicolumn{5}{|c|}{ SPACE COOLING } \\
\hline & W1 & w2 & $\mathrm{HI}$ & $\mathrm{H} 2$ & $\mathrm{H3}$ & $\mathrm{H} 4$. & $\mathrm{C} 1$. & $\mathrm{C2}$ & $\mathrm{C3}$ & $\mathrm{C} 4$ & $\mathrm{C} 5$ \\
\hline $\begin{array}{c}\text { IMPORTANCE } \\
\text { NO. }\end{array}$ & & & & & & & 6 & 9 & 10 & & \\
\hline STATUS & \multicolumn{2}{|c|}{ FUNDED } & RFP/ & & & & & & & . & \\
\hline
\end{tabular}

I-B-10. Investigate the aero-elastic effects of wind on collectors and collector mounts.

\begin{tabular}{|c|c|c|c|c|c|c|c|c|c|c|c|}
\hline \multirow[t]{2}{*}{$\ldots$ PATH } & \multicolumn{2}{|c|}{$\begin{array}{l}\text { SERVICE } \\
\text { HOT WATER }\end{array}$} & \multicolumn{4}{|c|}{ SPACE HEATING } & \multicolumn{5}{|c|}{ SPACE COOLING } \\
\hline & W1 & w2 & H1 & $\mathrm{H} 2$ & H3 & $\mathrm{H} 4$ & C1 & $\mathrm{C2}$ & C3 & C4 & $\mathrm{C5}$ \\
\hline $\begin{array}{l}\text { IMPORTANCE } \\
\text { NO. }\end{array}$ & 3 & 3 & 3 & & 3 & & 3 & 3 & 3 & & 3 \\
\hline STATUS & & $A L$ & NS & $C I$ & & & & & & & \\
\hline
\end{tabular}

1-B-11. Compile a record of the performance of liquid-heating and air-heating solar collectors. Include information on all of the following: collector design and construction problems; the corrosion of the collector materials with different coolants and environments; the performance of collector coverings, insulations, and sealants; the effects of mechanical expansion and contraction; the effects of condensation or dirt accumulation inside the cover assembly; collector connections; flow distribution problems; and the integration of collector systems into buildings. The performance record should emphasize problems encountered with these types of collector and should describe methods that have proved effective for dealing with those problems.

\begin{tabular}{|c|c|c|c|c|c|c|c|c|c|c|c|}
\hline \multirow[t]{2}{*}{ PATH } & \multicolumn{2}{|c|}{$\begin{array}{l}\text { SERVICE } \\
\text { HOT WATER }\end{array}$} & \multicolumn{4}{|c|}{ SPACE HEATING } & \multicolumn{5}{|c|}{ SPACE COOLING } \\
\hline & W1 & W2 & $\mathrm{H1}$ & $\mathrm{H} 2$ & $\mathrm{H} 3$ & $\mathrm{H} 4$ & $\mathrm{Cl}_{1}$ & $\mathrm{C} 2$ & $\mathrm{C} 3$ & $\mathrm{C} 4$ & $\mathrm{C5}$ \\
\hline $\begin{array}{l}\text { IMPORTANCE } \\
\text { NO. }\end{array}$ & 8 & 10 & 10 & & 10 & 10 & 10 & 10 & 10 & & 10 \\
\hline STATUS & FU & & & & $\Xi R$ & LA & & & & & \\
\hline
\end{tabular}




\section{I-C. Flat Plate Liquid-Heating Collectors}

I-C-1. Investigate the effectiveness and cost of various methods of freeze protection, including draini chemical anti-freezes, designs for withstanding freeze-thaw cycles, low-loss coefficients, and supplying ad.. tional heat.

\begin{tabular}{|c|c|c|c|c|c|c|c|c|c|c|c|}
\hline \multirow{2}{*}{ PATH } & \multicolumn{3}{|c|}{$\begin{array}{c}\text { SERVICE } \\
\text { HOT WATER } \\
\end{array}$} & \multicolumn{4}{|c|}{ SPACE HEATING } & \multicolumn{4}{c|}{ SPACE COOLING } \\
& W1 & W2 & H1 & H2 & H3 & H4 & C1 & C2 & C3 & C4 & C5 \\
\hline $\begin{array}{c}\text { IMPORTANCE } \\
\text { NO. }\end{array}$ & 10 & & 10 & 10 & & 10 & 10 & 10 & & 7 & 5 \\
\hline STATUS & \multicolumn{3}{|l|}{ FUNDED } & RFP/PRDA \\
\hline
\end{tabular}

1-C-2. Evaluate trickle collectors, analyzing thermal performance characteristics of these collectors in single- and double-glazed configurations. Study the cost of current collectors, their potential for cost reduction, and their durability. Evaluate the entire water collection system associated with a trickle collector array, and discuss the effect of water evaporation over long periods of time. Define water quality control requirements and analyze the effect of high humidity on all collector components.

\begin{tabular}{|c|c|c|c|c|c|c|c|c|c|c|c|}
\hline \multirow[t]{2}{*}{ PATH } & \multicolumn{2}{|c|}{$\begin{array}{c}\text { SERVICE } \\
\text { HOT WATER }\end{array}$} & \multicolumn{4}{|c|}{ SPACE HEATING } & \multicolumn{5}{|c|}{ SPACE COOLING } \\
\hline & w1 & w2 & H1 & $\mathrm{H} 2$ & H3 & $\mathrm{H} 4$ & $\mathrm{C1}$ & $\mathrm{C} 2$ & C3 & $\mathrm{C4}$ & $\mathrm{C5}$ \\
\hline $\begin{array}{c}\text { IMPORTANCE } \\
\text { NO. }\end{array}$ & & & 9 & & & 9 & & & & & 9 \\
\hline STATUS & & ET & & & & & & & & & \\
\hline
\end{tabular}

I-C-3. Evaluate the potential for low cost, non-concentrating liquid heaters/radiators (probably unglazed) as heat sources and sinks in a heat pump-based space heating and cooling system.

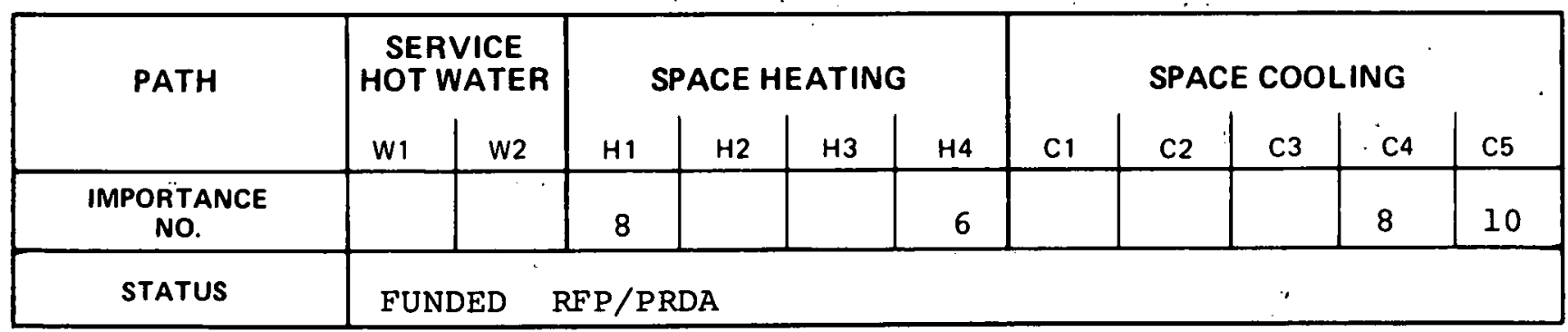


I-C-4. Develop low temperature [below $50^{\circ} \mathrm{C}\left(120^{\circ} \mathrm{F}\right)$ ], non-concentrating, liquid-heating collectors to be used as thermal energy sources for heat pumps and preheating of water. The collectors should offer significant advantages over current models in performance, cost, and/or reliability. Investigate the possibility of in-

ating the collectors into the building structure.

\begin{tabular}{|c|c|c|c|c|c|c|c|c|c|c|c|}
\hline \multirow[t]{2}{*}{ PATH } & \multicolumn{2}{|c|}{$\begin{array}{l}\text { SERVICE } \\
\text { HOT WATER }\end{array}$} & \multicolumn{4}{|c|}{ SPACE HEATING } & \multicolumn{5}{|c|}{ SPACE COOLING } \\
\hline & w1. & w2 & H1 & $\mathrm{H} 2$ & $\mathrm{H3}$ & $\mathrm{H} 4$ & $\mathrm{C}_{1}$ & $\mathrm{C} 2$ & $\mathrm{c3}$ & $\mathrm{C} 4$ & C5 \\
\hline $\begin{array}{c}\text { IMPORTANCE } \\
\text { NO. }\end{array}$ & 5 & & 10 & & & & & & & - & 10 \\
\hline STATUS & \multicolumn{2}{|c|}{ FUNDED } & $\mathrm{P} / 1$ & & & & & & & & \\
\hline
\end{tabular}

1-C-5. Develop medium temperature $\left[50-75^{\circ} \mathrm{C}\left(120\right.\right.$ to $\left.\left.170^{\circ} \mathrm{F}\right)\right]$, non-concentrating, liquid-heating collectors for providing space heating and hot water. The collectors should offer significant advantages over current models in performance, cost, and reliability.

\begin{tabular}{|c|c|c|c|c|c|c|c|c|c|c|c|}
\hline & \multicolumn{3}{|c|}{$\begin{array}{c}\text { SERVICE } \\
\text { POT WATH }\end{array}$} & \multicolumn{4}{|c|}{ SPACE HEATING } & \multicolumn{4}{c|}{ SPACE COOLING } \\
& H1 & W2 & H1 & H2 & H3 & H4 & C1 & C2 & C3 & C4 & C5 \\
\hline $\begin{array}{c}\text { IMPORTANCE } \\
\text { NO. }\end{array}$ & 9 & & 5 & & & 9 & & & & & \\
\hline STATUS & FUNDED & RFP/PRDA & & & & & \\
\hline
\end{tabular}

I-C-6. Develop high temperature [over $75^{\circ} \mathrm{C}\left(170\right.$ to $\left.230^{\circ} \mathrm{F}\right)$ ], non-concentrating, liquid-heating collectors to drive cooling machines and for process heat applications. The collectors should offer significant advantages. over current models in performance, cost, and reliability. Employ selective surfaces, coated glazing, convection suppressors, radiation traps, and other features where appropriate.

\begin{tabular}{|c|c|c|c|c|c|c|c|c|c|c|c|}
\hline \multirow[t]{2}{*}{ PATH } & \multicolumn{2}{|c|}{$\begin{array}{l}\text { SERVICE } \\
\text { HOT WATER }\end{array}$} & \multicolumn{4}{|c|}{ SPACE HEATING } & \multicolumn{5}{|c|}{ SPACE COOLING } \\
\hline & $w 1$ & W2 & $\mathrm{H} 1$ & $\mathrm{H} 2$ & $\mathrm{H3}$ & $\mathrm{H} 4$ & $\mathrm{C} 1$ & $\mathrm{C} 2$ & $\mathrm{C} 3$ & $\mathrm{C} 4$ & $\mathrm{C5}$ \\
\hline $\begin{array}{c}\text { IMPORTANCE } \\
\text { NO. }\end{array}$ & 3 & & 3 & & & 3 & & 9 & 8 & & \\
\hline STATUS & FUl & & $/ P$ & & & & & & & & \\
\hline
\end{tabular}


1-C-7. Develop large-area, non-concentrating, liquid-heating collectors, stressing low cost per unit collector area. In particular, evaluate the possible use of low-cost, weatherable glazing materials and low-cost insulating materials.

\begin{tabular}{|c|c|c|c|c|c|c|c|c|c|c|c|}
\hline \multirow[t]{2}{*}{ PATH } & \multicolumn{3}{|c|}{$\begin{array}{l}\text { SHELTER } \\
\text { HEATING }\end{array}$} & \multicolumn{3}{|c|}{ DRYING } & \multicolumn{2}{|c|}{$\begin{array}{l}\text { PROCESS } \\
\text { HOT WATER }\end{array}$} & \multirow{2}{*}{$\begin{array}{c}\text { PROCESS } \\
\text { STEAM } \\
\text { SL } \\
\end{array}$} & \multicolumn{2}{|c|}{$\begin{array}{l}\text { COOLING/ } \\
\text { REFRIG- } \\
\text { ERATION }\end{array}$} \\
\hline & HP & HA & $\mathrm{HL}$ & DD & DA & $\mathrm{DL}$ & WL & WA. & & $\mathrm{CP}$ & $\mathrm{CA}$ \\
\hline IMPORTANCE NO. & & & 10 & & & 10 & 10 & & 4 & & \\
\hline STATUS & & $\pi$ & $\mathrm{CAB}$ & & & & & & & & \\
\hline
\end{tabular}

I-C-8. Develop more cost-effective shallow solar ponds with emphasis on economies of scale and variety of possible agricultural/industrial applications. Analyze and test performance with 0,1 , and 2 glazings; convection losses vs. glazing spacing; various insulating materials, use of reflectors; different top glazing materials. Curbing, piping, and storage problems should also be considered.

\begin{tabular}{|c|c|c|c|c|c|c|c|c|c|c|c|}
\hline \multirow[t]{2}{*}{ PATH } & \multicolumn{3}{|c|}{$\begin{array}{l}\text { SHELTER } \\
\text { HEATING }\end{array}$} & \multicolumn{3}{|c|}{ DRYING } & \multicolumn{2}{|c|}{$\begin{array}{l}\text { PROCESS } \\
\text { HOT WATER }\end{array}$} & \multirow{2}{*}{$\begin{array}{c}\text { PROCESS } \\
\text { STEAM } \\
\text { SL } \\
\end{array}$} & \multicolumn{2}{|c|}{$\begin{array}{c}\text { COOLING/ } \\
\text { REFRIG- } \\
\text { ERATION }\end{array}$} \\
\hline & HP & HA & $\mathrm{HL}$ & DD & DA & $\mathrm{DL}$ & $W L$ & WA & & $C P$ & $\mathrm{CA}$ \\
\hline IMPORTANCE NO. & & & 7 & & & 7 & 9 & & & & \\
\hline STATUS. & \multicolumn{11}{|c|}{ FEDERAL LAB } \\
\hline
\end{tabular}

I-C-9. Develop and test designs for shallow solar ponds specifically for roof-top applications. Consider various methods of tilting the modules (e.g., segmented water base or a wire mesh constraining water bag). Designs should be developed for various module sizes, inexpensive supports and tie-downs, light-weight curbings, piping, etc.

\begin{tabular}{|c|c|c|c|c|c|c|c|c|c|c|c|}
\hline \multirow[t]{2}{*}{ PATH } & \multicolumn{3}{|c|}{$\begin{array}{l}\text { SHELTER } \\
\text { HEATING }\end{array}$} & \multicolumn{3}{|c|}{ DRYING } & \multicolumn{2}{|c|}{$\begin{array}{l}\text { PROCESS } \\
\text { HOT WATER }\end{array}$} & \multirow{2}{*}{$\begin{array}{c}\text { PROCESS } \\
\text { STEAM } \\
\text { SL }\end{array}$} & \multicolumn{2}{|c|}{$\begin{array}{l}\text { COOLING/ } \\
\text { REFRIG- } \\
\text { ERATION }\end{array}$} \\
\hline & HP & HA & $\mathrm{HL}$ & $D D$ & DA & $D L$ & WL & WA & & $C P$ & $C A$ \\
\hline IMPORTANCE NO. & & & 8 & & & 8 & 8 & & & & \\
\hline STATUS & & & & & & & & & & & . \\
\hline
\end{tabular}


1-C-10. Develop cost-effective and reliable nun-convective solar ponds. Investigate stability problems due to edge effects, wind-induced waves, withdrawal and filling, etc. Consider ways of preventing loss of efficiendue to collection of debris, or other sources of reducing.water clarity such as algae formation. Test thods of extracting heat from ponds. Determine importance of surface heat losses as well as heat losses into the earth. Examine environmental problems such as disposal, seepage, and recycling of salts.

\begin{tabular}{|c|c|c|c|c|c|c|c|c|c|c|c|}
\hline & \multicolumn{3}{|c|}{$\begin{array}{c}\text { SERVICE } \\
\text { HOT WATER }\end{array}$} & \multicolumn{4}{|c|}{ SPACE HEATING } & \multicolumn{5}{c|}{ SPACE COOLING } \\
& $\begin{array}{c}\text { P1 } \\
\text { PATH }\end{array}$ & W2 & H1 & H2 & H3 & H4 & C1 & C2 & C3 & C4 & C5 \\
\hline $\begin{array}{c}\text { IMPORTANCE } \\
\text { NO. }\end{array}$ & & & 10 & & 7 & 7 & & & & & 8 \\
\hline STATUS & \multicolumn{3}{|l|}{ FUNDED RFP/PRDA; RENEWAL (UNSOLICITED) } \\
\hline
\end{tabular}

\begin{tabular}{|c|c|c|c|c|c|c|c|c|c|c|c|}
\hline \multirow[t]{2}{*}{ PATH } & \multicolumn{3}{|c|}{$\begin{array}{l}\text { SHELTER } \\
\text { HEATING }\end{array}$} & \multicolumn{3}{|c|}{ DRYING } & \multicolumn{2}{|c|}{$\begin{array}{l}\text { PROCESS } \\
\text { HOT WATER }\end{array}$} & \multirow{2}{*}{$\begin{array}{c}\text { PROCESS } \\
\text { STEAM } \\
\text { SL }\end{array}$} & \multicolumn{2}{|c|}{$\begin{array}{l}\text { COOLING/ } \\
\text { REFRIG- } \\
\text { ERATION }\end{array}$} \\
\hline & HP & HA & HL & $D D$ & DA & $\mathrm{DL}$ & WL & WA & & $\mathrm{CP}$ & CA \\
\hline IMPORTANCE NO. & & & 8 & & & 8 & 8 & & ' & & \\
\hline STATUS & & & & & & & & & & & \\
\hline
\end{tabular}

\section{I-D. Flat Plate Air-Heating Collectors}

I-D-1. Investigate the possibility of developing a standardized figure of merit for solar air-heating collectors. Study the effects of transmission characteristics, front face heat loss, pressure drop, and heat-transfer mechanisms on collector performance. Include cost/performance trade-offs and the effect of manifolding on cost and pressure drops. Analyze the performance of conventional air heaters and of inflated, bag-type air heaters built into the building walls or roof.

\begin{tabular}{|c|c|c|c|c|c|c|c|c|c|c|c|}
\hline \multirow{2}{*}{ PATH } & \multicolumn{2}{|c|}{$\begin{array}{l}\text { SERVICE } \\
\text { HOT.WATER }\end{array}$} & \multicolumn{4}{|c|}{ SPACE HEATING } & \multicolumn{5}{|c|}{ SPACE COOLING } \\
\hline & $w_{1}$ & w2 & $\mathrm{H1}$ & $\mathrm{H} 2$ & $\mathrm{H3}$ & $\mathrm{H} 4$ & $\mathrm{Cl}$ & $\mathrm{C} 2$ & $\mathrm{C} 3$ & $\mathrm{C} 4$ & $\mathrm{C} 5$ \\
\hline $\begin{array}{c}\text { IMPORTANCE } \\
\text { NO. }\end{array}$ & & 7 & 9 & & 8 & & & & 2 & & 9 \\
\hline STATUS & & RAL & $\mathrm{AB}$ & & & & & & & & \\
\hline
\end{tabular}


1-D-2. Investigate the heat transfer characteristics of the various means proposed for promoting heat transfer from collector absorber surface to air. Study the effect of air flow velocity, fins, extended surfaces, expanded metal sheets, flow over depressions or cups, and the use of turbulators. Evaluate the performar characteristics of air heaters in which the air travels in passages separated from the glazing and also pas: against the underglazing of the collector. This evaluation should include a discuission of the effects of deposits on the glass.

\begin{tabular}{|c|c|c|c|c|c|c|c|c|c|c|c|}
\hline & \multicolumn{3}{|c|}{$\begin{array}{c}\text { SERVICE } \\
\text { POT WATH }\end{array}$} & \multicolumn{4}{|c|}{ SPACE HEATING } & \multicolumn{5}{c|}{ SPACE COOLING } \\
& $\begin{array}{c}\text { HOT } \\
\text { POT }\end{array}$ & W2 & H1 & H2 & H3 & H4 & C1 & C2 & C3 & C4 & C5 \\
\hline $\begin{array}{c}\text { IMPORTANCE } \\
\text { NO. }\end{array}$ & & 8 & 8 & 5 & 10 & & & & 5 & & 10 \\
\hline STATUS & \multicolumn{3}{|c|}{ FUNDED RFP/PRDA; RENEWAL (UNSOLICITED) } \\
\hline
\end{tabular}

I-D-3. Investigate the possibility of building self-pumping air heaters or coolers, including natural convection types and systems using an internal, heat-actuated fan-for example, a Nitinol engine or a rubber heat engine.

\begin{tabular}{|c|c|c|c|c|c|c|c|c|c|c|c|}
\hline \multirow{2}{*}{ PATH } & \multicolumn{3}{|c|}{$\begin{array}{c}\text { SERVICE } \\
\text { HOT WATER } \\
\end{array}$} & \multicolumn{4}{|c|}{ SPACE HEATING } & \multicolumn{5}{c|}{ SPACE COOLING } \\
& W1 & W2 & H1 & H2 & H3 & H4 & C1 & C2 & C3 & C4 & C5 \\
\hline $\begin{array}{c}\text { IMPORTANCE } \\
\text { NO. }\end{array}$ & & 1 & 5 & 10 & 2 & & & & 1 & 5 & 5 \\
\hline STATUS & \multicolumn{4}{|l|}{ FUNDED RFP/PRDA } \\
\hline
\end{tabular}

1-D-4. Establish one or more testing and evaluation facilities for air-heating collectors. Conduct tests and performance evaluations on collectors both as separate components and as parts of working systems.

\begin{tabular}{|c|c|c|c|c|c|c|c|c|c|c|c|}
\hline \multirow[t]{2}{*}{ PATH } & \multicolumn{2}{|c|}{$\begin{array}{l}\text { SERVICE } \\
\text { HOT WATER }\end{array}$} & \multicolumn{4}{|c|}{ SPACE HEATING } & \multicolumn{5}{|c|}{ SPACE COOLING } \\
\hline & $w_{1}$ & w2 & $\mathrm{H} 1$ & $\mathrm{H} 2$ & H3 & $\mathrm{H}_{4}$ & $\mathrm{C}_{1}$ & $\mathrm{C} 2$ & C3 & $\mathrm{C} 4$ & $\mathrm{C} 5$ \\
\hline $\begin{array}{c}\text { IMPORTANCE } \\
\text { NO. }\end{array}$ & & 7 & 10 & 5 & 10 & & & & 3 & & 10 \\
\hline STATUS & \multicolumn{11}{|c|}{ FEDERAL LAB } \\
\hline
\end{tabular}


1-D-5. Evaluale the effects of inlet and exit air manifold design on the performance and costs of air heaters. Studv installation costs and the effects of pressure drop for such systems.

\begin{tabular}{|c|c|c|c|c|c|c|c|c|c|c|c|}
\hline \multirow[t]{2}{*}{ PATH } & \multicolumn{2}{|c|}{$\begin{array}{l}\text { SERVICE } \\
\text { HOT WATER }\end{array}$} & \multicolumn{4}{|c|}{ SPACE HEATING } & \multicolumn{5}{|c|}{ SPACE COOLING } \\
\hline & W1 & w2 & $\mathrm{HI}$ & $\mathrm{H} 2$ & $\mathrm{H3}$ & $\mathrm{H} 4$ & C1 & $\mathrm{C} 2$ & $\mathrm{C} 3$ & $\mathrm{C} 4$ & $\mathrm{C} 5$ \\
\hline $\begin{array}{l}\text { IMPORTANCE } \\
\text { NO. }\end{array}$ & & 5 & & & 6 & & & & 6 & & \\
\hline . STATUS & & D & $\therefore$ & & & & & & & & \\
\hline
\end{tabular}

I-D-6. Develop low-temperature [below $50^{\circ} \mathrm{C}\left(120^{\circ} \mathrm{F}\right)$ ], non-concentrating, air-heating collectors to be used as energy sources for heat pumps. These collectors should offer significant advantages over current models in performance, cost, and reliability. Investigate the possibility of integrating these collectors into the building structure.

\begin{tabular}{|c|c|c|c|c|c|c|c|c|c|c|c|}
\hline & \multicolumn{3}{|c|}{$\begin{array}{c}\text { SERVICE } \\
\text { POT WATH }\end{array}$} & \multicolumn{4}{|c|}{ SPACE HEATING } & \multicolumn{5}{c|}{ SPACE COOLING } \\
& $\begin{array}{c}\text { H1 } \\
\text { POTER }\end{array}$ & W2 & H1 & H2 & H3 & H4 & C1 & C2 & C3 & C4 & C5 \\
\hline $\begin{array}{c}\text { IMPORTANCE } \\
\text { NO. }\end{array}$ & & 3 & 10 & & 6 & & & & & & 10 \\
\hline STATUS & \multicolumn{3}{|l|}{ FUNDED RFP/PRDA } \\
\hline
\end{tabular}

I-D-7. Develop medium temperature $\left[50-75^{\circ} \mathrm{C}\left(120-170^{\circ} \mathrm{F}\right)\right]$, non-concentrating air-heating collectors for space heating, drying, process heat, and service hot water. These collectors should offer significant advantages over current models in performance, cost, and reliability.

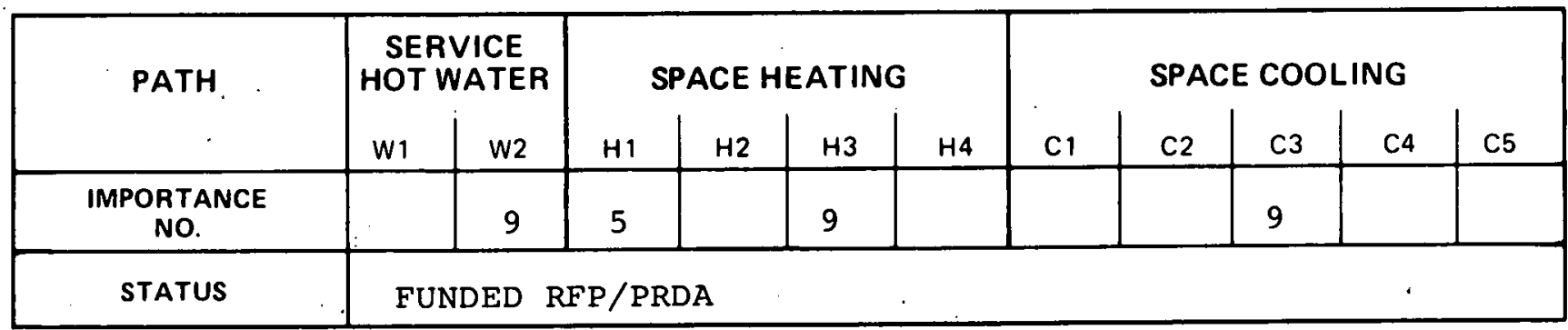




\begin{tabular}{|c|c|c|c|c|c|c|c|c|c|c|c|}
\hline \multirow[t]{2}{*}{ PATH } & \multicolumn{3}{|c|}{$\begin{array}{l}\text { SHELTER } \\
\text { HEATING }\end{array}$} & \multicolumn{3}{|c|}{ DRYING } & \multicolumn{2}{|c|}{$\begin{array}{l}\text { PROCESS } \\
\text { HOT WATER }\end{array}$} & \multirow{2}{*}{$\begin{array}{c}\text { PROCESS } \\
\text { STEEAM } \\
\text { SL }\end{array}$} & \multicolumn{2}{|c|}{$\begin{array}{l}\text { COOLING/ } \\
\text { REFRIG- } \\
\text { ERATIO }\end{array}$} \\
\hline & HP & HA & $\mathrm{HL}$ & DD & DA & $\mathrm{DL}$ & WL & WA & & $\mathrm{CP}$ & $C_{A}$ \\
\hline IMPORTANCE NO. & & 10 & & & 10 & & & 5 & & . & \\
\hline STATUS & & & & & & & & & & & \\
\hline
\end{tabular}

I-D-8. Develop high temperature [over $75^{\circ} \mathrm{C}\left(170\right.$ to $\left.\left.130^{\circ} \mathrm{F}\right)\right]$, non-concentrating, air-heating collectors for driving cooling machines and for process heat applications. These collectors should offer significant advantages over current models in performance, cost, and reliability. Where possible, use selective surfaces, coated glazings, convection suppressors, and radiation traps.

\begin{tabular}{|c|c|c|c|c|c|c|c|c|c|c|c|}
\hline \multirow[t]{2}{*}{ PATH } & \multicolumn{2}{|c|}{$\begin{array}{l}\text { SERVICE } \\
\text { HOT WATER }\end{array}$} & \multicolumn{4}{|c|}{ SPACE HEATING } & \multicolumn{5}{|c|}{ SPACE COOLING } \\
\hline & w1 & w2 & $\mathrm{HI}$ & $\mathrm{H} 2$ & H3 & $\mathrm{H4}$ & $\mathrm{C}_{1}$ & $\mathrm{C2}$ & C3 & $\mathrm{C} 4$ & $\mathrm{C} 5$ \\
\hline $\begin{array}{c}\text { IMPORTANCE } \\
\text { NO. }\end{array}$ & & 3 & 3 & & 7 & & & 9 & 9 & & \\
\hline STATUS & & $R$ & & & & & & & & & \\
\hline
\end{tabular}

\begin{tabular}{|c|c|c|c|c|c|c|c|c|c|c|c|}
\hline \multirow[t]{2}{*}{ PATH } & \multicolumn{3}{|c|}{$\begin{array}{l}\text { SHELTER } \\
\text { HEATING }\end{array}$} & \multicolumn{3}{|c|}{ DRYING } & \multicolumn{2}{|c|}{$\begin{array}{l}\text { PROCESS } \\
\text { HOT WATER }\end{array}$} & \multirow{2}{*}{$\begin{array}{c}\text { PROCESS } \\
\text { STEAM } \\
\text { SL } \\
\end{array}$} & \multicolumn{2}{|c|}{$\begin{array}{l}\text { COOLINGI } \\
\text { REFRIG. } \\
\text { ERATION }\end{array}$} \\
\hline & $\mathrm{HP}$ & HA & $\mathrm{HL}$ & DD & DA & $\mathrm{DL}$ & WL & WA & & $\mathrm{CP}$ & $\mathrm{CA}$ \\
\hline IMPORTANCE NO. & & 8 & & & 8 & & & 6 & & & 5 \\
\hline STATUS & & & & & & & & & & & . \\
\hline
\end{tabular}

I-D-9. Investigate, analyze, and develop air-heating collectors, emphasizing designs of large area that are low cost, durable, possibly stowable, and employ weatherable glazing materials. Study materials limitations, geometrical optimization, optimal design for dampers and blower-duct manifolding. Consider the problems of leaks in the collectors, dampers, and associated ducting.

\begin{tabular}{|c|c|c|c|c|c|c|c|c|c|c|c|}
\hline \multirow[t]{2}{*}{ PATH } & \multicolumn{3}{|c|}{$\begin{array}{l}\text { SHELTER } \\
\text { HEATING }\end{array}$} & \multicolumn{3}{|c|}{ DRYING } & \multicolumn{2}{|c|}{$\begin{array}{l}\text { PROCESS } \\
\text { HOT.WATER }\end{array}$} & \multirow{2}{*}{$\begin{array}{c}\text { PROCESS } \\
\text { STEAM } \\
\text { SL }\end{array}$} & \multicolumn{2}{|c|}{$\begin{array}{l}\text { COOLING/ } \\
\text { REFRIG- } \\
\text { ERATION }\end{array}$} \\
\hline & HP & HA & HL & DD & DA & $D L$ & WL & WA & & $C P$ & $\mathrm{CA}$ \\
\hline IMPORTANCE NO. & & 10 & & & 10 & & & 5 & & & 5 \\
\hline STATUS & & & & & & & & & & & \\
\hline
\end{tabular}


1-D-10. Evaluate and test air-heating collectors with integral storage (high internal mass) to deliver hot air at tomperatures needed for drying.

\begin{tabular}{|c|c|c|c|c|c|c|c|c|c|c|c|}
\hline \multirow[t]{2}{*}{ PATH } & \multicolumn{3}{|c|}{$\begin{array}{l}\text { SHELTER } \\
\text { HEATING }\end{array}$} & \multicolumn{3}{|c|}{ DRYING } & \multicolumn{2}{|c|}{$\begin{array}{l}\text { PROCESS } \\
\text { HOT WATER }\end{array}$} & \multirow{2}{*}{$\begin{array}{c}\text { PROCESS } \\
\text { STEAM } \\
\text { SL }\end{array}$} & \multicolumn{2}{|c|}{$\begin{array}{l}\text { COOLINGI } \\
\text { REFRIG- } \\
\text { ERATION }\end{array}$} \\
\hline & $\mathrm{HP}$ & HA & $\mathrm{HL}$ & DD & DA & DL & $W L$ & WA & & $\mathrm{CP}$ & $\mathrm{CA}$ \\
\hline IMPORTANCE NO. & & 8 & & & 8 & & & 6 & & - & 5 \\
\hline STATUS & & & & & & & & & & & \\
\hline
\end{tabular}

\section{I-E. Advanced Non-Concentrating Collectors}

\section{I-Ea. Evacuated Tube Collectors}

I-Ea-1. Evaluate current and proposed designs for evacuated collectors. The evaluation should include collector performance, potential cost effectiveness, and the implications of using the collector in various system configurations and for various applications.

\begin{tabular}{|c|c|c|c|c|c|c|c|c|c|c|c|}
\hline \multirow[t]{2}{*}{ PATH } & \multicolumn{2}{|c|}{$\begin{array}{l}\text { SERVICE } \\
\text { HOT WATER }\end{array}$} & \multicolumn{4}{|c|}{ SPACE HEATING. } & \multicolumn{5}{|c|}{ SPACE COOLING } \\
\hline & $w_{1}$ & w2 & $\mathrm{H1}$ & $\mathrm{H} 2$ & $\mathrm{H3}$ & $\mathrm{H} 4$ & C1 & $\mathrm{C2}$ & $\mathrm{C} 3$ & C4. & $\mathrm{C5}$ \\
\hline $\begin{array}{c}\text { IMPORTANCE } \\
\text { NO. }\end{array}$ & 3 & 3 & & & 6 & 6 & 6 & 9 & 4 & & \\
\hline STATUS & FUI & 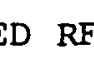 & & & 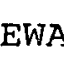 & (UN & IC & D) & & & \\
\hline
\end{tabular}

I-Ea-2. Continue the development of high temperature evacuated collectors $\left[95-150^{\circ} \mathrm{C}\left(200-300^{\circ} \mathrm{F}\right)\right]$ that have the potential for low costs. The collectors will be used to supply energy for conventional absorption chillers, for Rankine/vapor compression chillers, and for process heat.

\begin{tabular}{|c|c|c|c|c|c|c|c|c|c|c|c|}
\hline \multirow{2}{*}{ PATH } & \multicolumn{3}{|c|}{$\begin{array}{l}\text { SERVICE } \\
\text { HOT WATER }\end{array}$} & \multicolumn{4}{|c|}{ SPACE HEATING } & \multicolumn{5}{c|}{ SPACE COOLING } \\
& $\mathrm{W1}$ & $\mathrm{W} 2$ & $\mathrm{H} 1$ & $\mathrm{H} 2$ & $\mathrm{H} 3$ & $\mathrm{H} 4$ & $\mathrm{C} 1$ & $\mathrm{C} 2$ & $\mathrm{C} 3$ & $\mathrm{C} 4$ & $\mathrm{C}$ \\
\hline $\begin{array}{c}\text { IMPORTANCE } \\
\text { NO. }\end{array}$ & 3 & 3 & & & 5 & 5 & 6 & 9 & 4 & & \\
\hline STATUS & \multicolumn{3}{|l|}{ FUNDED RFP/PRDA } \\
\hline
\end{tabular}


1-Ea-3. Evaluate the effect of various design parameters on the performance and cost effectiveness of evacuated collectors. The parameters should include anti-reflection coatings on and within the cover ti.hfor both solar and infrared radiation, geometry and shape of tube (acceptance angle, concentration, interc tion area, etc.), and mirror reflector characteristics. Establish at least two test facilities for these collectors in different climates, one with a high percentage of direct radiation and one with a high percentage of diffuse radiation. At the test facilities, determine loss coefficient, radiation absorbing characteristics, and other primary parameters of the collectors.

\begin{tabular}{|c|c|c|c|c|c|c|c|c|c|c|c|}
\hline \multirow{2}{*}{ PATH } & \multicolumn{3}{|c|}{$\begin{array}{c}\text { SERVICE } \\
\text { HOT WATER }\end{array}$} & \multicolumn{3}{|c|}{ SPACE HEATING } & \multicolumn{5}{c|}{ SPACE COOLING } \\
& W1 & W2 & H1 & H2 & H3 & H4 & C1 & C2 & . C3 & C4 & C5 \\
\hline $\begin{array}{c}\text { IMPORTANCE } \\
\text { NO. }\end{array}$ & 3 & 3 & & & 5 & 5 & 6 & 9 & 4 & & \\
\hline STATUS & \multicolumn{3}{|l|}{ FUNDED RFP/PRDA } \\
\hline
\end{tabular}

I-Ea-4. Develop performance testing procedures for evacuated collectors, covering collector efficiency, figures of merit, and collector effectiveness in different climates.

\begin{tabular}{|c|c|c|c|c|c|c|c|c|c|c|c|}
\hline \multirow[t]{2}{*}{ PATH } & \multicolumn{2}{|c|}{$\begin{array}{l}\text { SERVICE } \\
\text { HOT WATER }\end{array}$} & \multicolumn{4}{|c|}{ SPACE HEATING } & \multicolumn{5}{|c|}{ SPACE COOLING } \\
\hline & w1 & w2 & H1 & $\mathrm{H} 2$ & H3 & $\mathrm{H} 4$ & $\mathrm{C}_{1}$ & $\mathrm{C} 2$ & $\mathrm{C3}$ & $\mathrm{C} 4$ & $\mathrm{C5}$ \\
\hline $\begin{array}{c}\text { IMPORTANCE } \\
\text { NO. }\end{array}$ & & & & & & & 4 & 8 & & & \\
\hline STATUS & & $\mathrm{AI}$ & & & ; & & $\mathrm{L}$ & & & & \\
\hline
\end{tabular}

I-Ea-5. Investigate the effects of snow, ice, hail, stagnation temperatures, and thermal stress on evacuated collectors with special attention to high temperature designs. Study solutions to any problems caused by the highly insulating nature of the evacuated tubes.

\begin{tabular}{|c|c|c|c|c|c|c|c|c|c|c|c|}
\hline \multirow[t]{2}{*}{ PATH } & \multicolumn{2}{|c|}{$\begin{array}{l}\text { SERVICE } \\
\text { HOT WATER }\end{array}$} & \multicolumn{4}{|c|}{ SPACE HEATING } & \multicolumn{5}{|c|}{ SPACE COOLING } \\
\hline & $w_{1}$ & w2 & $\mathrm{H1}$ & $\mathrm{H} 2$ & H3 & $\mathrm{H} 4$ & $\mathrm{C}_{1}$ & $\mathrm{C} 2$ & $\mathrm{C} 3$ & $\mathrm{C} 4$ & C5 \\
\hline $\begin{array}{c}\text { IMPORTANCE } \\
\text { NO. }\end{array}$ & & & & & 5 & 5 & & 7 & & & \\
\hline -STATUS & \multicolumn{11}{|c|}{ RENEWAL (UNSOLICITED) } \\
\hline
\end{tabular}


I-Eb. Heat Pipes

-.,-1. Study the potential of heat pipes in various collectors, including air- and liquid-heating collectors, cuated collectors, and stationary or movable concentrating collectors. [stimiate cost and quality control requirements for heat pipes used in such collectors, and evaluate the effectiveness of the thermal diode characteristics of heat pipes.

\begin{tabular}{|c|c|c|c|c|c|c|c|c|c|c|c|}
\hline \multirow{2}{*}{ PATH } & \multicolumn{2}{|c|}{$\begin{array}{l}\text { SERVICE } \\
\text { HOT WATER }\end{array}$} & \multicolumn{4}{|c|}{ SPACE HEATING } & \multicolumn{5}{|c|}{ SPACE COOLING } \\
\hline & w1 & W2 & $\mathrm{H1}$ & $\mathrm{H} 2$ & H3 & $\mathrm{H} 4$ & $\mathrm{C} 1$ & $\mathrm{C} 2$ & $\mathrm{C} 3$ & $\mathrm{C} 4$ & $\mathrm{C5}$ \\
\hline $\begin{array}{l}\text { IMPORTANCE } \\
\text { NO. }\end{array}$ & 3 & 2 & & 2 & 4 & 5 & 6 & 8 & 6 & & \\
\hline STATUS & & D & , & & & & & & & & \\
\hline
\end{tabular}

I-Eb-2. Evaluate heat pipe collector designs, determining types (e.g., mesh, groove, or artery) that are most useful. Optimize the working fluid for lifetime collector performance, and evaluate methods for eliminating problems caused by the high $\Delta \mathrm{T}$ associated with heat removal at the heat pipe condenser. Study the possibility of making the design fail-safe against thermal runaway for heat fluxes characteristic of flat plate collectors and for heat fluxes associated with concentration ratios of up to 10X. All of these evaluations should include cost considerations.

\begin{tabular}{|c|c|c|c|c|c|c|c|c|c|c|c|}
\hline \multirow[t]{2}{*}{ PATH } & \multicolumn{2}{|c|}{$\begin{array}{l}\text { SERVICE } \\
\text { HOT WATER }\end{array}$} & \multicolumn{4}{|c|}{ SPACE HEATING } & \multicolumn{5}{|c|}{ SPACE COOLING } \\
\hline & w1 & w2 & H1 & $\mathrm{H} 2$ & H3 & $\mathrm{H4}$ & $\mathrm{C}_{1}$ & $\mathrm{C} 2$ & C3 & $\mathrm{C} 4$ & $\mathrm{C} 5$ \\
\hline $\begin{array}{l}\text { IMPORTANCE } \\
\text { NO. }\end{array}$ & 3 & 1 & & 3 & 3 & 4 & 6 & 6 & 6 & & \\
\hline STATUS & $\mathrm{FU}$ & $E D$ & $/ \mathrm{P}$ & & & & & & & & \\
\hline
\end{tabular}

1-Eb-3. Develop the most promising high performance heat pipe collectors to be used with absorption or Rankine cycle chillers for solar cooling.

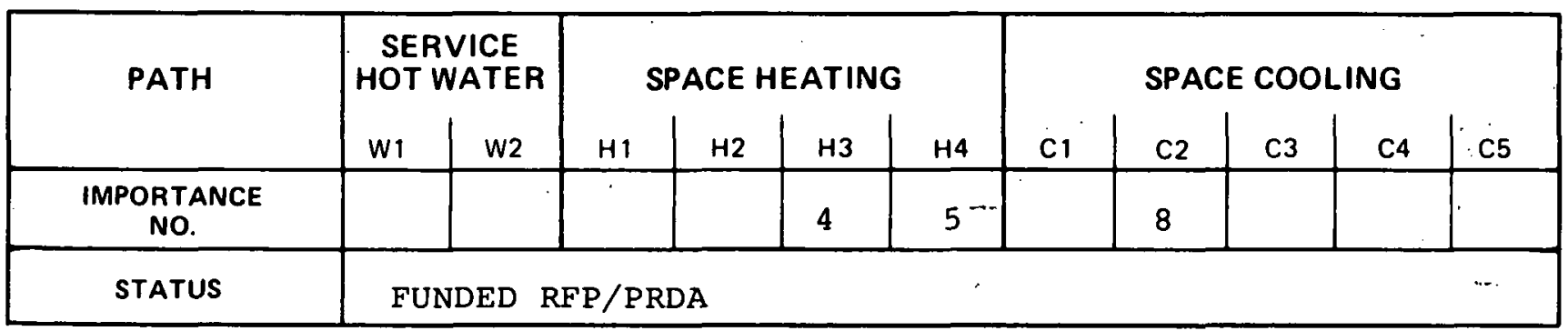


I-Ec. Honeycombs

I-Ec-1. Evaluate the effect of varying conditions, cell geometrics, IR coatings, etc., on the performance thin-wall glass honeycomb flat plate collectors.

\begin{tabular}{|c|c|c|c|c|c|c|c|c|c|c|c|}
\hline \multirow[t]{2}{*}{ PATH } & \multicolumn{2}{|c|}{$\begin{array}{l}\text { SERVICE } \\
\text { HOT WATER }\end{array}$} & \multicolumn{4}{|c|}{ SPACE HEATING } & \multicolumn{5}{|c|}{ SPACE COOLING } \\
\hline & W1 & w2 & $\mathrm{H} 1$ & $\mathrm{H} 2$ & $\mathrm{H} 3$ & $\mathrm{H} 4$ & $\mathrm{C}_{1}$ & $\mathrm{C} 2$ & $\mathrm{C} 3$ & $\mathrm{C} 4$ & $\mathrm{C} 5$ \\
\hline $\begin{array}{c}\text { IMPORTANCE } \\
\text { NO. }\end{array}$ & 4 & 4 & & & 5 & 6 & & 8 & 6 & & \\
\hline STATUS & & IL & T & & & & & & & & \\
\hline
\end{tabular}

1-Ec-2. Develop cost-effective techniques for manufacturing thin-wall glass honeycomb for use in flat plate collectors.

\begin{tabular}{|c|c|c|c|c|c|c|c|c|c|c|c|}
\hline \multirow{2}{*}{ PATH } & \multicolumn{3}{|c|}{$\begin{array}{c}\text { SERVICE } \\
\text { HOT WATER }\end{array}$} & \multicolumn{4}{|c|}{ SPACE HEATING } & \multicolumn{5}{c|}{ SPACE COOLING } \\
& W1 & W2 & H1 & H2 & H3 & H4 & C1 & C2 & C3 & C4 & C5 \\
\hline $\begin{array}{c}\text { IMPORTANCE } \\
\text { NO. }\end{array}$ & 4 & 4 & 2 & & 5 & 6 & & 8 & 6 & & - \\
\hline STATUS & \multicolumn{3}{|c|}{ RENEWAL (UNŚlOLICITED) } \\
\hline
\end{tabular}

I-Ec-3. Continue to develop materials for use as honeycombs in radiation trap collectors. Possibilities include glass and plastics (Mylar, Teflon, Tedlar, Lexan, Nylon, and phenathalene polycarbonate, polyphenolene oxide, TPX, polyformethylpentane l, spiracell, rubber, etc.). Study the effect of thermal expansion and degradation on overheating and the effect of the index of refraction on collector performance. Analyze costs and manufacturability.

\begin{tabular}{|c|c|c|c|c|c|c|c|c|c|c|c|}
\hline \multirow{2}{*}{ PATH } & \multicolumn{2}{|c|}{$\begin{array}{l}\text { SERVICE } \\
\text { HOT WATER }\end{array}$} & \multicolumn{4}{|c|}{ SPACE HEATING } & \multicolumn{5}{|c|}{ SPACE COOLING } \\
\hline & w1 & w2 & $\mathrm{H1}$ & $\mathrm{H} 2$ & H3 & $\mathrm{H} 4$ & $\mathrm{C} 1$ & $\mathrm{C} 2$ & $\mathrm{C} 3$ & $\mathrm{C4}$ & $\mathrm{C5}$ \\
\hline $\begin{array}{l}\text { IMPORTANCE } \\
\text { NO. }\end{array}$ & 3 & 3 & & & 5 & 5 & & 7 & 3 & & \\
\hline STATUS & $\mathrm{CO}$ & LETE & & & & & & & . & & \\
\hline
\end{tabular}


I-Ec-4. Develop the most promising high performance honeycomb liquid heater to be used with absorption or Rankine cycle chillers for solar cooling.

$1,1, \pi$

\begin{tabular}{|c|c|c|c|c|c|c|c|c|c|c|c|}
\hline \multirow{2}{*}{$\begin{array}{c}\text { PATH } \\
\vdots \\
\end{array}$} & \multicolumn{2}{|c|}{$\begin{array}{l}\text { SERVICE } \\
\text { HOT WATER }\end{array}$} & \multicolumn{4}{|c|}{ SPACE HEATING } & \multicolumn{4}{|c|}{ SPACE COOLING } & \\
\hline & W1 & w2 & $\mathrm{H1}$ & $\mathrm{H} 2$ & $\mathrm{H3}$ & $\mathrm{H} 4$ & $\mathrm{Cl}$ & $\mathrm{C} 2$ & C3 & $\mathrm{C} 4$ & $\mathrm{C} 5$ \\
\hline $\begin{array}{l}\text { IMPORTANCE } \\
\text { NO. }\end{array}$ & 3 & 3 & & & 4 & 6 & & 8 & 6 & & \\
\hline
\end{tabular}

I-Ec-5. Continue to study heat-transfer mechanisms in honeycomb collectors, emphasizing the effect of coupled wall conduction and radiation on natural convection. Investigate the effect of cell shape, properties, and tilt angle on honeycomb designs.

\begin{tabular}{|c|c|c|c|c|c|c|c|c|c|c|c|}
\hline \multirow[t]{2}{*}{ PATH } & \multicolumn{2}{|c|}{$\begin{array}{l}\text { SERVICE } \\
\text { HOT WATER }\end{array}$} & \multicolumn{4}{|c|}{ SPACE HEATING } & \multicolumn{5}{|c|}{ SPACE COOLING } \\
\hline & w1 & w2 & H1 & $\mathrm{H} 2$ & $\mathrm{H3}$ & $\mathrm{H} 4$ & $\mathrm{C}_{1}$ & $\mathrm{C} 2$ & $\mathrm{c3}$ & $\mathrm{C} 4$ & $\mathrm{C} 5$ \\
\hline $\begin{array}{c}\text { IMPORTANCE } \\
\text { NO. }\end{array}$ & 3 & 3 & & & 7 & 7 & & 8 & 6 & & \\
\hline STATUS & \multicolumn{2}{|c|}{ RENEWAL } & IVJ & -1 & & & & & & & \\
\hline
\end{tabular}

1-Ec-6. Develop honeycomb materials with low emissivity to suppress convection above radiative cooling surfaces. Investigate the effects of dirt and moisture accumulation and aging on the infrared properties of these materials. Determine materials and configurations which best block direct solar radiation from the surface while allowing the surface to emit infrared radiation to the sky.

\begin{tabular}{|c|c|c|c|c|c|c|c|c|c|c|c|}
\hline \multirow[t]{2}{*}{ PATH } & \multicolumn{2}{|c|}{$\begin{array}{l}\text { SERVICE } \\
\text { HOT WATER }\end{array}$} & \multicolumn{4}{|c|}{ SPACE HEATING } & \multicolumn{4}{|c|}{ SPACE COOLING } & \\
\hline & W1 & w2 & $\mathrm{H1}$ & $\mathrm{H} 2$ & $\mathrm{H3}$ & $\mathrm{H4}$ & $\mathrm{C} 1$ & $\mathrm{C} 2$ & $\mathrm{C} 3$ & $\mathrm{C4}$ & C5 \\
\hline $\begin{array}{c}\text { IMPORTANCE } \\
\text { NO. }\end{array}$ & & & & & & & & & & 6 & \\
\hline STATUS & & & & & & & & & & & \\
\hline
\end{tabular}




\begin{tabular}{|c|c|c|c|c|c|c|c|c|c|c|c|}
\hline \multirow{2}{*}{ PATH } & \multicolumn{3}{|c|}{$\begin{array}{l}\text { SHELTER } \\
\text { HEATING }\end{array}$} & \multicolumn{3}{|c|}{ DRYING } & \multicolumn{2}{|c|}{$\begin{array}{l}\text { PROCESS } \\
\text { HOT WATER }\end{array}$} & \multirow{2}{*}{$\begin{array}{c}\text { PROCESS } \\
\text { STEAM } \\
\text { SL. } \\
\end{array}$} & \multicolumn{2}{|c|}{$\begin{array}{l}\text { COOLINGI } \\
\text { REFRIG- } \\
\text { ERATION }\end{array}$} \\
\hline & HP & HA & $\mathrm{HL}$ & DD & DA & $\mathrm{DL}$ & WL & WA & & $C P \ldots$ & $\mathrm{CA}$ \\
\hline IMPORTANCE NO. & & & & & & . & & & & 6. & \\
\hline STATUS & & & & & & & & & & & \\
\hline
\end{tabular}

I-Ed. Others

1-Ed-1. Design, build, and test prototype, high temperature honeycomb, transpired, porous bed air heaters.

\begin{tabular}{|c|c|c|c|c|c|c|c|c|c|c|c|}
\hline \multirow[t]{2}{*}{ : PATH } & \multicolumn{2}{|c|}{$\begin{array}{l}\text { SERVICE } \\
\text { HOT WATER }\end{array}$} & \multicolumn{4}{|c|}{ SPACE HEATING } & \multicolumn{5}{|c|}{ SPACE COOLING } \\
\hline & w1 & w2 & H1 & $\mathrm{H} 2$ & H3 & $\mathrm{H} 4$ & C1 & $\mathrm{C} 2$ & C3 & C4 & $\mathrm{C5}$ \\
\hline $\begin{array}{c}\text { IMPORTANCE } \\
\text { NO. }\end{array}$ & & 5 & & & 6 & & & & 9 & & \\
\hline STATUS & & $D R I$ & $/ P$ & & & & & & & & \\
\hline
\end{tabular}

I-Ed-2. Investigate the potential of thermal-trap collectors, paying particular attention to the development of a fail-safe cover plate design and to control of cover plate degradation.

\begin{tabular}{|c|c|c|c|c|c|c|c|c|c|c|c|}
\hline \multirow[t]{2}{*}{ PATH } & \multicolumn{2}{|c|}{$\begin{array}{l}\text { SERVICE } \\
\text { HOT WATER }\end{array}$} & \multicolumn{4}{|c|}{ SPACE HEATING } & \multicolumn{5}{|c|}{ SPACE COOLING } \\
\hline & w1 & w2 & $\mathrm{H1}$ & $\mathrm{H} 2$ & $\mathrm{H3}$ & $\mathrm{H} 4$ & $\mathrm{C1}$ & $\mathrm{C} 2$ & $\mathrm{C} 3$ & $\mathrm{C} 4$ & $\mathrm{C5}$ \\
\hline $\begin{array}{c}\text { IMPORTANCE } \\
\text { NO. }\end{array}$ & 4 & 3 & & & 3 & 4 & & 6 & 5 & & \\
\hline
\end{tabular}


1-Ed-3:Evaluate the potential of black liquids as absorbers for collectors. Study corrosion effects and estimate the expense of providing transparent containers for the fluid.

\begin{tabular}{|c|c|c|c|c|c|c|c|c|c|c|c|}
\hline \multirow[t]{2}{*}{ PATH } & \multicolumn{2}{|c|}{$\begin{array}{l}\text { SERVICE } \\
\text { HOT WATER }\end{array}$} & \multicolumn{4}{|c|}{ SPACE HEATING } & \multicolumn{5}{|c|}{ SPACE COOLING } \\
\hline & W1 & w2 & $\mathrm{H} 1$ & $\mathrm{H} 2$ & $\mathrm{H3}$ & $\mathrm{H} 4$ & $\mathrm{C} 1$ & $\mathrm{C} 2$ & $\mathrm{C} 3$ & $\mathrm{C4}$ & $\mathrm{C5}$ \\
\hline $\begin{array}{l}\text { IMPORTANCE } \\
\text { NO. }\end{array}$ & 5 & & & & & 5 & & & 4 & & \\
\hline STATUS & & D & & & & & & & & & \\
\hline
\end{tabular}

I-Ed-4. Design, develop, and test collectors in which an agricultural or industrial product to be dried serves as the "absorber-plate". Consider various possible designis, including the use of a conveyor belt as the absorber bed on which the product is spread. There will be a need for air circulation over the product to remove moisture or vapors.

\begin{tabular}{|c|c|c|c|c|c|c|c|c|c|c|c|}
\hline \multirow[t]{2}{*}{ PATH } & \multicolumn{3}{|c|}{$\begin{array}{l}\text { SHELTER } \\
\text { HEATING }\end{array}$} & \multicolumn{3}{|c|}{ DRYING } & \multicolumn{2}{|c|}{$\begin{array}{l}\text { PROCESS } \\
\text { HOT WATER }\end{array}$} & \multirow{2}{*}{$\begin{array}{c}\text { PROCESS } \\
\text { STEAM } \\
\text { SL }\end{array}$} & \multicolumn{2}{|c|}{$\begin{array}{l}\text { COOLING/ } \\
\text { REFRIG- } \\
\text { ERATION }\end{array}$} \\
\hline & HP & HA & HL & DD & DA & $\mathrm{DL}$ & $W L$ & WA & & $\mathrm{CP}$ & $\mathrm{CA}$ \\
\hline IMPORTANCE NO. & & & & 10 & & & & & & & \\
\hline STATUS & & & & & & & & & & & \\
\hline
\end{tabular}

\section{I-F. Concentrating Collectors}

I-F-1. Develop a high performance, tracking Fresnel lens concentrator for high temperature applications. The concentration ratio should be approximately $10 \mathrm{X}$, and provision should be made for daily tracking of the sun. Investigate the reduction of heat loss by radiation or convection, the implications of protection against thermal runaway for a collector loss-of-coolant condition, and lifetime costs for the concentrating and tracking mechanisms. Consider how the design might be influenced by given applications - for example, as a source for absorption chillers or process heat.

\begin{tabular}{|c|c|c|c|c|c|c|c|c|c|c|c|}
\hline \multirow[t]{2}{*}{ PATH } & \multicolumn{2}{|c|}{$\begin{array}{l}\text { SERVICE } \\
\text { HOT WATER }\end{array}$} & \multicolumn{4}{|c|}{ SPACE HEATING } & \multicolumn{5}{|c|}{ SPACE COOLING } \\
\hline & w1 & W2 & H1 & $\mathrm{H} 2$ & $\mathrm{H} 3$ & $\mathrm{H} 4$ & C1 & $\mathrm{C}_{2}$ & c3 & $\mathrm{C4}$ & C5 \\
\hline $\begin{array}{c}\text { IMPORTANCE } \\
\text { NO. }\end{array}$ & & & & & & 6 & 10 & & & & \\
\hline STATUS & & $\mathrm{DF}$ & 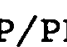 & & & & & & & & \\
\hline
\end{tabular}


I-F-2. Develop a high performance parabolic or compound parabolic mirror concentrator with a 10X concentration ratio. The concentrator should be designed for daily solar tracking and produce temperatures between 95 and $150^{\circ} \mathrm{C}\left(200-300^{\circ} \mathrm{F}\right)$. Emphasize cost effectiveness of the thermal energy produced. Desi should provide for east-west mounting on flat-roofed buildings and for north-south tilted configurations ... daily tracking. Designs should also provide for reduced energy loss through convection suppression, IR radiation suppression, and for protection against thermal runaway in case of a cooling failure.

\begin{tabular}{|c|c|c|c|c|c|c|c|c|c|c|c|}
\hline \multirow[t]{2}{*}{-- PATH } & \multicolumn{2}{|c|}{$\begin{array}{l}\text { SERVICE } \\
\text { HOT WATER }\end{array}$} & \multicolumn{4}{|c|}{ SPACE HEATING } & \multicolumn{4}{|c|}{ SPACE COOLING } & \multirow{2}{*}{. C5 } \\
\hline & W1 & w2 & $\mathrm{H} 1$ & $\mathrm{H} 2$ & $\mathrm{H3}$ & $\mathrm{H} 4$ & $\mathrm{C} 1$ & $\mathrm{C} 2$ & $\mathrm{C} 3$ & $\mathrm{C} 4$ & \\
\hline $\begin{array}{l}\text { IMPORTANCE } \\
\text { NO. }\end{array}$ & & & & & & 6 & 10 & & & . & \\
\hline STATUS & & & & & & & & & & & \\
\hline
\end{tabular}

I-F-3. Evaluate tracking mechanisms for concentrating collector systems that require daily tracking. Consider cost of the drive mechanisms, reliability of the drive systems, requirements for support structures, requirements for pivoting fluid coupling connections, means of fail-safing in case of coolant loss, and the capacity of the systems to withstand high wind and gust loads.

\begin{tabular}{|c|c|c|c|c|c|c|c|c|c|c|c|}
\hline \multirow[t]{2}{*}{ PATH } & \multicolumn{2}{|c|}{$\begin{array}{l}\text { SERVICE } \\
\text { HOT WATER }\end{array}$} & \multicolumn{4}{|c|}{ SPACE HEATING } & \multicolumn{5}{|c|}{ SPACE COOLING } \\
\hline & $w_{1}$ & w2 & $\mathrm{H} 1$ & $\mathrm{H} 2$ & $\mathrm{H3}$ & $\mathrm{H} 4$ & $\mathrm{Cl}_{1}$ & $\mathrm{C} 2$ & C3 & $\mathrm{C} 4$ & $\mathrm{C5}$ \\
\hline $\begin{array}{l}\text { IMPORTANCE } \\
\text { NO. }\end{array}$ & & & & & . & 6 & 10 & & & & \\
\hline STATUS & & $D$ & 10 & & & & & & & & \\
\hline
\end{tabular}

I-F-4. Investigate the potential of concentrating collectors that use plane or cylindrical mirrors of various types, from concentrating parabolic to V-trough. Analyze the effect on collector performance of surface irregularities and of reflectance for various concentration ratios.

\begin{tabular}{|c|c|c|c|c|c|c|c|c|c|c|c|}
\hline \multirow{2}{*}{ : PATH } & \multicolumn{2}{|c|}{$\begin{array}{l}\text { SERVICE } \\
\text { HOT WATER }\end{array}$} & \multicolumn{4}{|c|}{ SPACE HEATING } & \multicolumn{5}{|c|}{ SPACE COOLING } \\
\hline & wi & w2 & $\mathrm{H} 1$ & $\mathrm{H} 2$ & H3 & $\mathrm{H}_{4}$ & $\mathrm{C} 1$ & C2 & c3 & $\mathrm{C} 4$ & $\mathrm{C5}$ \\
\hline $\begin{array}{c}\text { IMPORTANCE } \\
\text { NO. }\end{array}$ & 3 & 3 & & & 3 & 3 & 10 & & 6 & & \\
\hline STATUS & $\mathrm{RE}$ & $A L$ & & 2 & 1 & 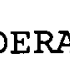 & LAB & & · & & \\
\hline
\end{tabular}


1-F-5. Evaluate the effect on collector performance of dirt and other accumulations on the mirror or Fresnel is of concentrating collectors. Establish requirements for maintaining quality in the concentrating collecoptical systems.

\begin{tabular}{|c|c|c|c|c|c|c|c|c|c|c|c|}
\hline \multirow[t]{2}{*}{ PATH } & \multicolumn{2}{|c|}{$\begin{array}{l}\text { SERVICE } \\
\text { HOT WATER }\end{array}$} & \multicolumn{4}{|c|}{ SPACE HEATING } & \multicolumn{5}{|c|}{ SPACE COOLING } \\
\hline & $W_{1}$ & W2 & $\mathrm{H} .1$ & $\mathrm{H} 2$ & $\mathrm{H} 3$ & $\mathrm{H} 4$ & $\mathrm{C}_{1}$ & $\therefore \mathrm{C} 2$ & C3 & $\mathrm{C} 4$ & $\mathrm{C} 5$ \\
\hline $\begin{array}{c}\text { IMPORTANCE } \\
\text { NO. }\end{array}$ & 3 & 3 & & & 3 & 3 & 7 & & & & \\
\hline STATUS & FU & $\mathrm{D} \quad \mathrm{Rl}$ & $\angle P$ & & & & & & & & \\
\hline
\end{tabular}

I-F-6. Determine the availability of and need for rotary or flexible connections between the absorber tube and the heat transfer fluid line in linear, tracking, concentrating collectors. This includes both compound parabolic concentration and Fresnel lens collectors.

\begin{tabular}{|c|c|c|c|c|c|c|c|c|c|c|c|}
\hline \multirow[t]{2}{*}{ PATH } & \multicolumn{2}{|c|}{$\begin{array}{l}\text { SERVICE } \\
\text { HOT WATER }\end{array}$} & \multicolumn{4}{|c|}{ SPACE HEATING } & \multicolumn{5}{|c|}{ SPACE COOLING } \\
\hline & w1 & w2 & $\mathrm{H} 1$ & $\mathrm{H} 2$ & H3 & $\mathrm{H} 4$ & C1 & $\mathrm{C} 2$ & $\mathrm{C} 3$ & $\mathrm{C4}$ & $\overline{c 5}$ \\
\hline $\begin{array}{c}\text { IMPORTANCE } \\
\text { NO. }\end{array}$ & & & & & & & 7 & & & & \\
\hline STATUS & FU & $D R$ & $/ \mathrm{PI}$ & & & & & & & . & \\
\hline
\end{tabular}

I-F-7. Conduct a comparative study of the cost and performance of the most promising concentrating collectors. Analyze the effects of manifolding, energy collection, tracking, various heat-leak preventive mechanisms, etc.

\begin{tabular}{|c|c|c|c|c|c|c|c|c|c|c|c|}
\hline \multirow[t]{2}{*}{ PATH } & \multicolumn{2}{|c|}{$\begin{array}{l}\text { SERVICE } \\
\text { HOT WATER }\end{array}$} & \multicolumn{4}{|c|}{ SPACE HEATING } & \multicolumn{5}{|c|}{ SPACE COOLING } \\
\hline & w1 & w2 & $H 1$ & $\mathrm{H} 2$ & H3 & $\mathrm{H} 4$ & C1 & $\mathrm{C} 2$ & C3 & $\mathrm{C} 4$ & C5 \\
\hline $\begin{array}{c}\text { IMPORTANCE } \\
\text { NO. }\end{array}$ & & & & & & & 5 & 6 & & & \\
\hline STATUS & & סל & $/ \mathrm{P}$ & & & & & & & & \\
\hline
\end{tabular}


1-F-8. Investigate the potential of high temperature, non-tracking, concentrating collectors that use a Fresnel lens. These collectors will have a concentration ratio of approximately $3 X$, achieve temperatures $c$ $95-150^{\circ} \mathrm{C}\left(200-300^{\circ} \mathrm{F}\right)$. Investigate cost-performance trade-offs for. collectors used as sources for absorptio chillers or for process heat. Study methods for reducing energy loss, including the use of selective surfáces and various means of convection suppression. Make comparisons with tracking Fresnel systems of the same aperture area.

\begin{tabular}{|c|c|c|c|c|c|c|c|c|c|c|c|}
\hline \multirow[t]{2}{*}{ PATH } & \multicolumn{2}{|c|}{$\begin{array}{l}\text { SERVICE } \\
\text { HOT WATER }\end{array}$} & \multicolumn{4}{|c|}{ SPACE HEATING } & \multicolumn{5}{|c|}{ SPACE COOLING } \\
\hline & $w_{1}$ & w2 & H1 & $\mathrm{H} 2$ & H3 & $\mathrm{H} 4$ & C.1. & $\mathrm{C} 2$ & $\mathrm{C} 3$ & $\mathrm{C} 4$ & $\mathrm{C} 5$ \\
\hline $\begin{array}{l}\text { IMPORTANCE } \\
\text { NO. }\end{array}$ & 5 & 4 & & & & 5 & 10 & & & " & \\
\hline STATUS & & $\mathrm{R}$ & & & & & & & & & \\
\hline
\end{tabular}

1-F-9. Continue to develop non-tracking, concentrating, parabolic collectors with $3 X$ concentration ratios. Consider how designs could be modified to reduce mass production costs. Study required manufacturing tolerances for collector shape and placement, and analyze the possibility of reducing energy loss through convection suppression or radiation suppression. Compare tracking and non-tracking parabolic concentrating systems.

\begin{tabular}{|c|c|c|c|c|c|c|c|c|c|c|c|}
\hline \multirow[t]{2}{*}{ PATH } & \multicolumn{2}{|c|}{$\begin{array}{l}\text { SERVICE } \\
\text { HOT WATER }\end{array}$} & \multicolumn{4}{|c|}{ SPACE HEATING } & \multicolumn{5}{|c|}{ SPACE COOLING } \\
\hline & W1 & w2 & $\mathrm{H} 1$ & $\mathrm{H} 2$ & $\mathrm{H3}$ & $\mathrm{H} 4$ & C1 & $\mathrm{C} 2$ & $\mathrm{C} 3$ & $\mathrm{C} 4$ & $\mathrm{C} 5$. \\
\hline $\begin{array}{c}\text { IMPORTANCE } \\
\text { NO. }\end{array}$ & 4 & 4 & & & 4 & 4 & 10 & & & & \\
\hline STATUS & $\mathrm{FU}$ & $D \quad R I$ & $/ P F$ & & ERA & $\angle A B$ & & & & & \\
\hline
\end{tabular}

I-F-10. Investigate inexpensive, concentrating, tracking collectors for space heating and cooling applications.

\begin{tabular}{|c|c|c|c|c|c|c|c|c|c|c|c|}
\hline \multirow{2}{*}{ PATH } & \multicolumn{2}{|c|}{$\begin{array}{l}\text { SERVICE } \\
\text { HOT WATER }\end{array}$} & \multicolumn{4}{|c|}{ SPACE HEATING } & \multicolumn{5}{|c|}{ SPACE COOLING } \\
\hline & W1 & w2 & $\mathrm{Hi}$ & $\dot{\mathrm{H}} 2$ & $\mathrm{H} \dot{3}$ & $\mathrm{H4}$ & C1 & $\mathrm{C} 2$ & $\mathrm{C} 3$ & $\mathrm{C4}$ & $\mathrm{C5}$ \\
\hline $\begin{array}{c}\text { IMPORTANCE } \\
\text { NO. }\end{array}$ & 4 & 4 & & & 4 & 4 & 10 & & & . & \\
\hline STATUS & $\mathrm{FU}$ & ED R & $\mathrm{P} / \mathrm{P}$ & & & & & & & & \\
\hline
\end{tabular}


I-F-11. Investigate the use of evacuated tube absorbers as energy receivers in concentrating collectors. cause temperatures are expected to be very high, especially in stagnation conditions, the study should nsider outgassing, helium penetration, and seal failurc. Investigate possible efficiency gains resulting from use of selective absorber surfaces, anti-reflection coating of the outer glass envelope, and IR reflection coating of the inner surface of the envelope. Investigate the stability of these coatings under normal use and stagnation conditions. Evaluate the possibility of using heat pipe absorbers and study the fabrication costs for each of the features considered. Differentiate between the receiver requirements for $10 X$ concentrators and those for $3 \mathrm{X}$ concentrators. Recommend candidate receivers for each concentration ratio. Perform tests to establish the behavior of prototype receivers.

\begin{tabular}{|c|c|c|c|c|c|c|c|c|c|c|c|}
\hline \multirow[t]{2}{*}{ PATH } & \multicolumn{2}{|c|}{$\begin{array}{l}\text { SERVICE } \\
\text { HOT WATER }\end{array}$} & \multicolumn{4}{|c|}{ SPACE HEATING } & \multicolumn{5}{|c|}{ SPACE COOLING } \\
\hline & $w_{1}$ & W2 & $\mathrm{H} 1$ & $\mathrm{H} 2$ & H3 & $\mathrm{H} 4$ & $\mathrm{C} 1$ & $\mathrm{C} 2$ & $\mathrm{C} 3$ & $\mathrm{C} 4$ & $\mathrm{C} 5$ \\
\hline $\begin{array}{c}\text { IMPORTANCE } \\
\text { NO. }\end{array}$ & 4 & 4 & & & 6 & 6 & 10 & & & & \\
\hline STATUS & & 8 & & & & & & & & & \\
\hline
\end{tabular}

I-F-12. Investigate the use of advanced absorber techniques and insulation for heat retention by the receivers of concentrating collectors. Analyze improvements in efficiency, costs, and longevity of honeycombs, heat pipes, selective absorbers, IR outer coatings, IR reflective inner coatings, and black body traps. Study the potential of foam glass and polyimide foam for high temperature insulation. Choose candidate receivers for $10 \mathrm{X}$ and $3 \mathrm{X}$ concentrators. Build and test the receivers, using appropriate concentrators to test their behavior

\begin{tabular}{|c|c|c|c|c|c|c|c|c|c|c|c|}
\hline \multirow[t]{2}{*}{ PATH } & \multicolumn{2}{|c|}{$\begin{array}{l}\text { SERVICE } \\
\text { HOT WATER }\end{array}$} & \multicolumn{4}{|c|}{ SPACE HEATING } & \multicolumn{5}{|c|}{ SPACE COOLING } \\
\hline & $w_{1}$ & w2 & $\mathrm{H} 1$ & $\mathrm{H} 2$ & H3 & $\mathrm{H} 4$ & $\mathrm{Cl}$ & $\mathrm{C} 2$ & $\mathrm{C} 3$ & $\mathrm{C} 4$ & $\mathrm{C5}$ \\
\hline $\begin{array}{c}\text { IMPORTANCE } \\
\text { NO. }\end{array}$ & 4 & 4 & & & 4 & 4 & 10 & & & & \\
\hline STATUS & & $\mathrm{D} R$ & & & & & & & & & \\
\hline
\end{tabular}

I-F-13. Develop the most cost-effective combinations of receivers and concentrators with concentration ratios near 10X. Conduct collector tests and validate theoretical models.

\begin{tabular}{|c|c|c|c|c|c|c|c|c|c|c|c|}
\hline \multirow[t]{2}{*}{ PATH } & \multicolumn{2}{|c|}{$\begin{array}{l}\text { SERVICE } \\
\text { HOT WATER }\end{array}$} & \multicolumn{4}{|c|}{ SPACE HEATING } & \multicolumn{5}{|c|}{ SPACE COOLING } \\
\hline & w1 & w2 & $\mathrm{H1}$ & $\mathrm{H} 2$ & $\mathrm{H} 3$ & $\mathrm{H} 4$ & C1 & $\mathrm{C} 2$ & $\mathrm{C} 3$ & $\mathrm{C4}$ & $\mathrm{C5}$ \\
\hline $\begin{array}{l}\text { IMPORTANCE } \\
\text { NO. }\end{array}$ & 4 & 4 & & & 4 & 4 & 10 & & & & \\
\hline
\end{tabular}


I-F-14. Develop the most cost-effective combinations of receivers and concentrators with concentration ratios near $3 \mathrm{X}$. Conduct collector tests and validate theoretical models.

\begin{tabular}{|c|c|c|c|c|c|c|c|c|c|c|c|}
\hline \multirow[t]{2}{*}{ PATH } & \multicolumn{2}{|c|}{$\begin{array}{l}\text { SERVICE } \\
\text { HOT WATER }\end{array}$} & \multicolumn{4}{|c|}{ SPACE HEATING } & \multicolumn{5}{|c|}{ SPACE COOLING : } \\
\hline & w1 & w2 & $\mathrm{H} 1$ & $\mathrm{H} 2$ & H3 & $\mathrm{H} 4$ & $\mathrm{Cl}$ & $\mathrm{C} 2$ & C3 & $\mathrm{C4}$ & $\mathrm{C5}$ \\
\hline $\begin{array}{c}\text { IMPORTANCE } \\
\text { NO. }\end{array}$ & 4 & 4 & & 4 & 4 & 10 & & & & . & \\
\hline STATUS & \multicolumn{11}{|c|}{ FUNDED RFP/PRDA } \\
\hline
\end{tabular}

I-F-15. Develop concentrating collectors for use up to approximately $400^{\circ} \mathrm{C}\left(750^{\circ} \mathrm{F}\right)$. The emphasis should be on cost-effectiveness, durability, reliability, simplicity, and fail-safe operation; not on geometrical precision. Develop and test appropriate models.

\begin{tabular}{|c|c|c|c|c|c|c|c|c|c|c|c|}
\hline \multirow[t]{2}{*}{ PATH } & \multicolumn{3}{|c|}{$\begin{array}{l}\text { SHELTER } \\
\text { HEATING }\end{array}$} & \multicolumn{3}{|c|}{ DRYING } & \multicolumn{2}{|c|}{$\begin{array}{l}\text { PROCESS } \\
\text { HOT WATER }\end{array}$} & \multirow{2}{*}{$\begin{array}{c}\text { PROCESS } \\
\text { STEAM } \\
\text { SL } \\
\end{array}$} & \multicolumn{2}{|c|}{$\begin{array}{l}\text { COOLING/ } \\
\text { REFRIG. } \\
\text { ERATION }\end{array}$} \\
\hline & $\mathrm{HP}$ & HA & $\mathrm{HL}$ & DD & DA & $\mathrm{DL}$ & WL & WA & & $\mathrm{CP}$ & CA \\
\hline IMPORTANCE NO. & & 4 & 4 & & 5 & 9 & 9 & 5 & 9 & & 5 \\
\hline STATUS & FU & & & & & & & & & & \\
\hline
\end{tabular}

I-F-16. Design, develop, and test inflated concentrators in cylindrical and spherical geometry. These are typically seasonally adjusted with low concentration ratios.

\begin{tabular}{|c|c|c|c|c|c|c|c|c|c|c|c|}
\hline \multirow[t]{2}{*}{ PATH } & \multicolumn{3}{|c|}{$\begin{array}{l}\text { SHELTER } \\
\text { HEATING }\end{array}$} & \multicolumn{3}{|c|}{ DRYING } & \multicolumn{2}{|c|}{$\begin{array}{l}\text { PROCESS } \\
\text { HOT WATER }\end{array}$} & \multirow{2}{*}{$\begin{array}{c}\text { PROCESS } \\
\text { STEAM } \\
\text { SL } \\
\end{array}$} & \multicolumn{2}{|c|}{$\begin{array}{l}\text { COOLING/ } \\
\text { REFRIG- } \\
\text { ERATION }\end{array}$} \\
\hline & $\mathrm{HP}$ & $\mathrm{HA}$ & $\mathrm{HL}$ & $\mathrm{DD}$ & $\mathrm{DA}$ & DL & WL & WA & & $\mathrm{CP}$ & CA \\
\hline IMPORTANCE NO. & & & & & 5 & & 9 & 5 & 9 & & 5 \\
\hline STATUS & & Jal & LAE & & & & & & & & \\
\hline
\end{tabular}


I-F-17. Analyze, develop, and test drive mechanisms for sun-tracking collectors, to track the sun without auxiliary electric power (using springs, weights, pendulum, sun-actuated thermal expansion of support strucis, etc.).

\begin{tabular}{|c|c|c|c|c|c|c|c|c|c|c|c|}
\hline \multirow[t]{2}{*}{ PATH } & \multicolumn{3}{|c|}{$\begin{array}{l}\text { SHELTER } \\
\text { HEATING }\end{array}$} & \multicolumn{3}{|c|}{ DRYING } & \multicolumn{2}{|c|}{$\begin{array}{l}\text { PROCESS } \\
\text { HOT WATER }\end{array}$} & \multirow{2}{*}{$\begin{array}{c}\text { PROCESS } \\
\text { STEAM } \\
\text { SL } \\
\end{array}$} & \multicolumn{2}{|c|}{$\begin{array}{l}\text { COOLING/ } \\
\text { REFRIG- } \\
\text { ERATION }\end{array}$} \\
\hline & . HP & HA & $\mathrm{HL}$ & DD & DA & $\mathrm{DL}$ & $W L$ & WA & & $\mathrm{CP}$ & $\mathrm{CA}$ \\
\hline IMPORTANCE NO. & & & & & 3 & 3 & 3 & 3 & 6 & & 3 \\
\hline STATUS & & & & & & & . & & & & \\
\hline
\end{tabular}

I-F-18. Investigate, design, test, and demonstrate the use of independent, photovoltaically driven, mechanisms for sun tracking so that a sun-tracking collector need not be connected in any way to a central power source or central control system.

\begin{tabular}{|c|c|c|c|c|c|c|c|c|c|c|c|}
\hline \multirow[t]{2}{*}{ PATH } & \multicolumn{3}{|c|}{$\begin{array}{l}\text { SHELTER } \\
\text { HEATING }\end{array}$} & \multicolumn{3}{|c|}{ DRYING } & \multicolumn{2}{|c|}{$\begin{array}{l}\text { PROCESS } \\
\text { HOT WATER }\end{array}$} & \multirow{2}{*}{$\begin{array}{c}\text { PROCESS } \\
\text { STEAM } \\
\text { SL } \\
\end{array}$} & \multicolumn{2}{|c|}{$\begin{array}{l}\text { COOLING/ } \\
\text { REFRIG- } \\
\text { ERATION }\end{array}$} \\
\hline & HP & HA & $\mathrm{HL}$ & DD & DA & $\mathrm{DL}$ & WL & WA & & $C P$ & CA \\
\hline IMPORTANCE NO. & & & 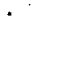 & & 3 & 3 & 3 & 3 & 6 & & 3 \\
\hline STATUS & & & & & & & & & & & \\
\hline
\end{tabular}

I-F-19. Compare the relative merits of sun-seeking, feedback control mechanisms for tracking with simple clock-driven mechanisms. Develop clock-drive tracking mechanisms and test for reliability and tracking accuracy.

\begin{tabular}{|c|c|c|c|c|c|c|c|c|c|c|c|}
\hline \multirow[t]{2}{*}{ PATH } & \multicolumn{3}{|c|}{$\begin{array}{l}\text { SHELTER } \\
\text { HEATING }\end{array}$} & \multicolumn{3}{|c|}{ DRYING } & \multicolumn{2}{|c|}{$\begin{array}{l}\text { PROCESS } \\
\text { HOT WATER }\end{array}$} & \multirow{2}{*}{$\begin{array}{c}\text { PROCESS } \\
\text { STEAM } \\
\text { SL } \\
\end{array}$} & \multicolumn{2}{|c|}{$\begin{array}{l}\text { COOLING/ } \\
\text { REFRIG. } \\
\text { ERATION }\end{array}$} \\
\hline & HP & $\dot{H A}$ & HL & DD & DA & $\mathrm{DL}$ & WL & WA & & $\mathrm{CP}$ & CA. \\
\hline IMPORTANCE NO. & . & & & & 3 & 3 & 3 & 3 & 6 & & 3 \\
\hline STATUS & & & & & & & & & & & \\
\hline
\end{tabular}


I-F-20. Evaluate types of heliostats for agricultural/industrial process steam systems. This task differs from the heliostat program of the solar thermal electric program in that the optical and mechanical requirements of the agricultural/industrial heliostats are less stringent, but the cost constraints are tighter and the heliost fields are likely to be much smaller. Evaluate inexpensive high efficiency receivers of the cavity type for $u$ with heliostat field in producing process steam.

\begin{tabular}{|c|c|c|c|c|c|c|c|c|c|c|c|}
\hline \multirow[t]{2}{*}{ PATH } & \multicolumn{3}{|c|}{$\begin{array}{l}\text { SHELTER } \\
\text { HEATING }\end{array}$} & \multicolumn{3}{|c|}{ DRYING } & \multicolumn{2}{|c|}{$\begin{array}{l}\text { PROCESS } \\
\text { HOT WATER }\end{array}$} & \multirow{2}{*}{$\begin{array}{c}\text { PROCESS } \\
\text { STEAM } \\
\text { SL }\end{array}$} & \multicolumn{2}{|c|}{$\begin{array}{l}\text { COOLING/ } \\
\text { REFRIG- } \\
\text { ERATION }\end{array}$} \\
\hline & HP & HA & $\mathrm{HL}$ & $D D$ & DA & $\mathrm{DL}$ & WL & WA & & $\mathrm{CP}$ & $\mathrm{CA}$ \\
\hline IMPORTANCE NO. & & & & & 2 & 2 & 2 & 2 & 5 & & 2 \\
\hline STATUS & & & & & & & . & & & & : \\
\hline
\end{tabular}

I-F-21. Survey existing automatic solar tracking systems and identify inexpensive, reliable types that can be used with solar concentrators.

\begin{tabular}{|c|c|c|c|c|c|c|c|c|c|c|c|}
\hline \multirow[t]{2}{*}{ PATH } & \multicolumn{2}{|c|}{$\begin{array}{l}\text { SERVICE } \\
\text { HOT. WATER }\end{array}$} & \multicolumn{4}{|c|}{ SPACE HEATING } & \multicolumn{5}{|c|}{ SPACE COOLING } \\
\hline & W1 & W2 & $\mathrm{H} 1$ & $\mathrm{H} 2$ & $\mathrm{H} 3$ & $\mathrm{H} 4$ & $\mathrm{C1}$ & $\mathrm{C} 2$ & C3 & $\mathrm{C4}$ & $\mathrm{C5}$ \\
\hline $\begin{array}{l}\text { IMPORTANCE } \\
\text { NO. }\end{array}$ & & & & & & & 5 & 5 & & & \\
\hline STATUS & & & & & & & & & & & \\
\hline
\end{tabular}

I-F-22. Survey existing systems; analyze, design, and test concentrating collectors of the movable slat, fixed receiver type with one-axis tracking of the slats to determine applicability and merits for producing hot water or process steam.

\begin{tabular}{|c|c|c|c|c|c|c|c|c|c|c|c|}
\hline \multirow[t]{2}{*}{ PATH } & \multicolumn{3}{|c|}{$\begin{array}{l}\text { SHELTER } \\
\text { HEATING }\end{array}$} & \multicolumn{3}{|c|}{ DRYING } & \multicolumn{2}{|c|}{$\begin{array}{l}\text { PROCESS } \\
\text { HOT WATER }\end{array}$} & \multirow{2}{*}{$\begin{array}{c}\text { PROCESS } \\
\text { STEAM } \\
\text { SL }\end{array}$} & \multicolumn{2}{|c|}{$\begin{array}{l}\text { COOLING/ } \\
\text { REFRIG- } \\
\text { ERATION }\end{array}$} \\
\hline & HP & HA & $\mathrm{HL}$ & DD & DA & $\mathrm{DL}$ & WL & WA & & $\mathrm{CP}$ & $\mathrm{CA}$ \\
\hline IMPORTANCE NO. & & & & & 3 & 3 & 3 & 3 & 6 & & \\
\hline STATUS & & $\mathrm{R}$ & $\mathrm{LAB}$ & & & & & & & & \\
\hline
\end{tabular}




\section{I-G. Reflectors for Flat Plate Collector Augmentation}

I-G-1. Study the performance of flat plate collectors equipped with movable and immovable reflectors. nalyze the importance of reflectance by comparing diffuse and specular performance, analyzing the efiects of collector and reflector geometry, and studying the necessity for periodic reflector adjustment. Estimate the effect of reflectance on collector loss-of-coolant temperature excursions. Study the effect of reflectance on collector performance in space heating and cooling applications. Study the use of diffusing or reradiating surfaces (e.g., white gravel) and specular reflectors.

\begin{tabular}{|c|c|c|c|c|c|c|c|c|c|c|c|}
\hline \multirow[t]{2}{*}{ PATH } & \multicolumn{2}{|c|}{$\begin{array}{c}\text { SERVICE } \\
\text { HOT WATER }\end{array}$} & \multicolumn{4}{|c|}{ SPACE HEATING } & \multicolumn{5}{|c|}{ SPACE COOLING } \\
\hline & w1 & W2 & $\mathrm{HI}$ & $\mathrm{H} 2$ & H3 & $\mathrm{H} 4$ & $\mathrm{Cl}$ & $\mathrm{C2}$ & $\mathrm{C} 3$ & $\mathrm{C4}$ & $\mathrm{C5}$ \\
\hline $\begin{array}{c}\text { IMPORTANCE } \\
\text { NO. }\end{array}$ & 6 & 6 & 8 & 6 & 8 & 8 & & 8 & 8 & & \\
\hline STATUS & $\mathbf{F}$ & D & & - & $F$ & $\mathrm{~L}, \mathrm{AB}$ & & & & & \\
\hline
\end{tabular}

I-G-2. Investigate means of mounting reflectors on buildings to enhance the performance of solar collectors. Study the durability of the reflectors and their supporting structure, the wind loading on large reflectors (particularly those mounted above the collector), the effect on the architecture of the house, and potential effects beyond the building's immediate surroundings. Take into consideration safety and construction codes.

\begin{tabular}{|c|c|c|c|c|c|c|c|c|c|c|c|}
\hline \multirow[t]{2}{*}{ PATH } & \multicolumn{2}{|c|}{$\begin{array}{l}\text { SERVICE } \\
\text { HOT WATER }\end{array}$} & \multicolumn{4}{|c|}{ SPACE HEATING } & \multicolumn{5}{|c|}{ SPACE COOLING } \\
\hline & $w_{1}$ & W2 & $\mathrm{H} 1$ & $\mathrm{H} 2$ & $\mathrm{H} 3$ & $\mathrm{H} 4$ & $\mathrm{C} 1$ & $\mathrm{C} 2$ & $\mathrm{C} 3$ & $\mathrm{C4}$ & $\mathrm{C5}$ \\
\hline $\begin{array}{c}\text { IMPORTANCE } \\
\text { NO. }\end{array}$ & 4 & 4 & 6 & 5 & 8 & 5 & & 6 & 6 & & \\
\hline STATUS & & $\mathrm{L}$ & & $\mathrm{TT}$ & ; & & LA & & & & \\
\hline
\end{tabular}

I-G-3. Identify diffuse and specular reflectors that are attractive for use with solar collectors. Study cost, stability, and durability of the various candidate materials. These materials might include such items as white gravel on roof decks, white paint, white porcelain bonded to thin sheet metal, anodized or non-anodized aluminum, standard roofing materials, silvered microglass, conventional mirrors, metalized films, polished and coated aluminum sheet, and aluminized paints.

\begin{tabular}{|c|c|c|c|c|c|c|c|c|c|c|c|}
\hline \multirow[t]{2}{*}{ PATH } & \multicolumn{2}{|c|}{$\begin{array}{l}\text { SERVICE } \\
\text { HOT WATER }\end{array}$} & \multicolumn{4}{|c|}{ SPACE HEATING } & \multicolumn{5}{|c|}{ SPACE COOLING } \\
\hline & W1 & w2 & $\mathrm{H} 1$ & $\mathrm{H} 2$ & $\mathrm{H} 3$ & $\mathrm{H} 4$ & $\mathrm{C} 1$ & $\mathrm{C} 2$ & $\mathrm{C} 3$ & $\mathrm{C} 4$ & $\mathrm{C} 5$ \\
\hline $\begin{array}{c}\text { IMPORTANCE } \\
\text { NO. }\end{array}$ & 4 & 4 & 6 & 5 & 8 & 5 & & 5 & 5 & 5 & \\
\hline STATUS & \multicolumn{11}{|c|}{$A L$ LAB } \\
\hline
\end{tabular}




\begin{tabular}{|c|c|c|c|c|c|c|c|c|c|c|c|}
\hline \multirow[t]{2}{*}{ PATH } & \multicolumn{3}{|c|}{$\begin{array}{l}\text { SHELTER } \\
\text { HEATING }\end{array}$} & \multicolumn{3}{|c|}{ DRYING } & \multicolumn{2}{|c|}{$\begin{array}{l}\text { PROCESS } \\
\text { HOT WATER }\end{array}$} & \multirow{2}{*}{$\begin{array}{c}\text { PROCESS } \\
\text { STEAM } \\
\text { SL } \\
\end{array}$} & \multicolumn{2}{|c|}{$\begin{array}{c}\text { COOLING/ } \\
\text { REFRIG. } \\
\text { ERATION }\end{array}$} \\
\hline & HP. & $\mathrm{HA}$ & $\mathrm{HL}$ & DD & $\mathrm{DA}$ & DL & WL & WA & & $\mathrm{CP}$ & $\mathrm{CA}$ \\
\hline IMPORTANCE NO. & & 3 & 3 & & 4 & 4 & 6 & 4 & 10 & 4 & 4 \\
\hline - STATUS & & & & & & & & & & & \\
\hline
\end{tabular}

\section{I-H. Materials}

\section{I-Ha. Selective Surfaces}

1-Ha-1. Conduct a program for testing failure modes and mechanisms of selective surfaces. Expose candidate surfaces to UV radiation, elevated temperatures, and humidity. Determine their endurance, develop methods for overcoming failures, and assess economic trade-offs.

\begin{tabular}{|c|c|c|c|c|c|c|c|c|c|c|c|}
\hline \multirow[t]{2}{*}{ PATH } & \multicolumn{2}{|c|}{$\begin{array}{l}\text { SERVICE } \\
\text { HOT WATER }\end{array}$} & \multicolumn{4}{|c|}{ ' SPACE HEATING } & \multicolumn{5}{|c|}{ SPACE COOLING } \\
\hline & W1 & W2 & $\mathrm{HI}$ & $\mathrm{H} 2$ & H3 & $\mathrm{H4}$ & $\mathrm{C}_{1}$ & $\mathrm{C} 2$ & c3 & $\mathrm{C} 4$ & $\mathrm{C5}$ \\
\hline $\begin{array}{l}\text { IMPORTANCE } \\
\text { NO. }\end{array}$ & 4 & 6 & & & $7^{\prime}$ & 7 & 8 & 9 & 9 & & \\
\hline STATUS & \multicolumn{11}{|c|}{ FUNDED RFP/PRDA } \\
\hline
\end{tabular}

I-Ha-2. Develop selective infrared radiation surfaces for radiation cooling.

\begin{tabular}{|c|c|c|c|c|c|c|c|c|c|c|c|}
\hline \multirow{2}{*}{ PATH } & \multicolumn{2}{|c|}{$\begin{array}{l}\text { SERVICE } \\
\text { HOT WATER }\end{array}$} & \multicolumn{4}{|c|}{ SPACE HEATING } & \multicolumn{5}{|c|}{ SPACE COOLING } \\
\hline & $w_{1}$ & w2 & $\mathrm{H} 1$ & $\mathrm{H} 2$ & H3 & $\mathrm{H} 4$ & $\mathrm{Cl}$ & $\mathrm{C}_{2}$ & $\mathrm{C} 3$ & $\mathrm{C} 4$ & $\mathrm{C} 5$ \\
\hline $\begin{array}{l}\text { IMPORTANCE } \\
\text { NO. }\end{array}$ & & & & & & & & & & 7 & 7 \\
\hline STATUS & $F$ & & E & & & & & & & & \\
\hline
\end{tabular}


1-Ha-3. Develop techniques for producing black chrome selective surfaces.

T

\begin{tabular}{|c|c|c|c|c|c|c|c|c|c|c|c|}
\hline \multirow{2}{*}{$\begin{array}{l}\text { PATH } \\
-\end{array}$} & \multicolumn{2}{|c|}{$\begin{array}{l}\text { SERVICE } \\
\text { HOT WATER }\end{array}$} & \multicolumn{4}{|c|}{ SPACE HEATING } & \multicolumn{5}{|c|}{ SPACE COOLING } \\
\hline & $w 1$ & w2 & $\mathrm{H1}$ & $\mathrm{H} 2$ & H3 & $\mathrm{H} 4$ & $\mathrm{C}_{1}$ & $\mathrm{C} 2$ & C3 & $\mathrm{C} 4$ & C5 \\
\hline $\begin{array}{c}\text { IMPORTANCE } \\
\text { NO. }\end{array}$ & 4 & 6 & & & 7 & 7 & $8^{\circ}$ & 9 & 9 & & \\
\hline STATUS & & $E D$ & 1 & & & & & & & & \\
\hline
\end{tabular}

1-Ha-4. Evaluate instrumentation for making fast, accurate measurements of absorptance and'emittance. The instrumentation would be used in production process quality control and detection of coating irregularities. Consider the use of $\mathrm{CO}_{2}$ lasers; evaluate the possible use of simplified testing procedures in which only one or two representative temperatures and wave-lengths are used. Recommend quality control testing standards for selective surfaces.

\begin{tabular}{|c|c|c|c|c|c|c|c|c|c|c|c|}
\hline \multirow[t]{2}{*}{ PATH } & \multicolumn{2}{|c|}{$\begin{array}{l}\text { SERVICE } \\
\text { HOT WATER }\end{array}$} & \multicolumn{4}{|c|}{ SPACE HEATING } & \multicolumn{5}{|c|}{ SPACE COOLING } \\
\hline & $w_{1}$ & w2 & $\mathrm{H1}$ & $\mathrm{H} 2$ & H3 & $\mathrm{H} 4$ & C1 & C2 & $\mathrm{C} 3$ & $\mathrm{C} 4$ & C5 \\
\hline $\begin{array}{c}\text { IMPORTANCE } \\
\text { NO. }\end{array}$ & 4 & 6 & 4 & & 6 & 6 & 6 & 6 & 6 & & 4 \\
\hline STATUS & & & & & & & & & & & \\
\hline
\end{tabular}

1-Ha-5. Evaluate and develop selective surfaces based on metal oxides, including black nickel, and copper oxide. The following aspects are to be considered in the evaluation: surface solar spectrum absorptance and IR spectrum emittance; surface stability in different environments (humidity, solar radiation, general abrasion); surface mechanical stability during multiple cycles of expansion and contraction; and surface cost as a function of production rate.

\begin{tabular}{|c|c|c|c|c|c|c|c|c|c|c|c|}
\hline \multirow[t]{2}{*}{ PATH } & \multicolumn{2}{|c|}{$\begin{array}{c}\text { SERVICE } \\
\text { HOT WATER }\end{array}$} & \multicolumn{4}{|c|}{ SPACE HEATING } & \multicolumn{5}{|c|}{ SPACE COOLING } \\
\hline & wi & w2 & $\mathrm{H1}$ & $\mathrm{H} 2$ & $\mathrm{H3}$ & $\mathrm{H} 4$ & $\mathrm{C} 1$ & $\mathrm{C} 2$ & $\mathrm{C} 3$ & $\mathrm{C} 4$ & $\mathrm{C} 5$ \\
\hline $\begin{array}{c}\text { IMPORTANCE } \\
\text { NO. }\end{array}$ & 4 & 6 & 4 & & 7 & 7 & 8 & 9 & 9 & & 4 \\
\hline STATUS & & $\Omega$ & & & & & & & & & \\
\hline
\end{tabular}


1-Ha-6. Evaluate the stability of the following types of selective surfaces: electroplated metal oxides; mildly selective black paints; dipped chemical conversion coating processes; interference films; and semicond $\cdots . .$. tors. Investigate the possibilities of selective surfaces which do not use strategically scarce domes: materials.

\begin{tabular}{|c|c|c|c|c|c|c|c|c|c|c|c|}
\hline \multirow[t]{2}{*}{ PATH } & \multicolumn{2}{|c|}{$\begin{array}{l}\text { SERVICE } \\
\text { HOT WATER }\end{array}$} & \multicolumn{4}{|c|}{ SPACE HEATING } & \multicolumn{5}{|c|}{ SPACE COOLING. } \\
\hline & w1 & W2 & $\mathrm{H} 1$ & $\mathrm{H} 2$ & $\mathrm{H} 3$ & $\mathrm{H} 4$ & $\mathrm{C} 1$ & $\mathrm{C} 2$ & $\mathrm{C} 3$ & $\mathrm{C} 4$ & C5 \\
\hline $\begin{array}{c}\text { IMPORTANCE } \\
\text { NO. }\end{array}$ & 4 & 6 & 2 & & 5 & 5 & 9 & 9 & 6 & & \\
\hline STATUS & $\mathrm{FU}$ & D & $P / P$ & & & & & & & e & $n^{2}$ \\
\hline
\end{tabular}

1-Ha-7. Evaluate various paints and other coatings for application to a night-sky radiative panel. This include's the characterization of materials that have high IR emittance and low absorptance.

\begin{tabular}{|c|c|c|c|c|c|c|c|c|c|c|c|}
\hline \multirow{2}{*}{$\begin{array}{c}\text { PATH } \\
.\end{array}$} & \multicolumn{2}{|c|}{$\begin{array}{c}\text { SERVICE } \\
\text { HOT WATER }\end{array}$} & \multicolumn{4}{|c|}{ SPACE HEATING } & \multicolumn{5}{|c|}{ SPACE COOLING } \\
\hline & $w_{1}$ & w2 & $\mathrm{H} 1$ & $\mathrm{H} 2$ & $\mathrm{H} 3$ & $\mathrm{H} 4$ & C1 & $\mathrm{C} 2$ & c3 & . 44 & C5 \\
\hline $\begin{array}{c}\text { IMPORTANCE } \\
\text { NO. }\end{array}$ & & & & & & & & & & 10 & 9 \\
\hline STATUS & FUN & $\mathrm{D} R F$ & PR & $F E$ & RAI & $A B$ & & & & & \\
\hline
\end{tabular}

1-Ha-8. Develop selective surfaces specifically capable of high temperature operation [about $400^{\circ} \mathrm{C}\left(750^{\circ} \mathrm{F}\right)$ ] and stagnation.

\begin{tabular}{|c|c|c|c|c|c|c|c|c|c|c|c|}
\hline \multirow[t]{2}{*}{ PATH } & \multicolumn{3}{|c|}{$\begin{array}{l}\text { SHELTER } \\
\text { HEATING }\end{array}$} & \multicolumn{3}{|c|}{ DRYING } & \multicolumn{2}{|c|}{$\begin{array}{l}\text { PROCESS } \\
\text { HOT WATER }\end{array}$} & \multirow{2}{*}{$\begin{array}{c}\text { PROCESS } \\
\text { STEAM } \\
\text { SL } \\
\end{array}$} & \multicolumn{2}{|c|}{$\begin{array}{l}\text { COOLING/ } \\
\text { REFRIG. } \\
\text { ERATION }\end{array}$} \\
\hline & HP & HA & $\mathrm{HL}$ & DD & DA & DL & WL & WA & & $C P$ & $\mathrm{CA}$ \\
\hline IMPORTANCE NO. & & & & & & & & & 8 & & 6 \\
\hline STATUS & & & & & & & & & & & \\
\hline
\end{tabular}




\section{I-Hb. Glazing}

$1-\mathrm{l} \mathrm{b}-1$. Develop a range of polymeric and other non-glass materials resistant to weathering, UV radiation,

1 high temperatures $\left(\sim 300^{\circ} \mathrm{F}\right)$. These materials must be suitable for mass-produced collector glazings and nousings, and they must be low cost (detailed economic studies will be necessary). Identify existing production techniques and products, and evaluate the products for resistance to UV radiation, abrasion, temperature, humidity, etc.

\begin{tabular}{|c|c|c|c|c|c|c|c|c|c|c|c|}
\hline \multirow{2}{*}{ P.ATH } & \multicolumn{3}{|c|}{$\begin{array}{c}\text { SERVICE } \\
\text { HOT WATER } \\
\end{array}$} & \multicolumn{4}{|c|}{ SPACE HEATING } & \multicolumn{5}{c|}{ SPACE COOLING } \\
& W1 & W2 & H1 & H2 & H3 & H4 & C1 & C2 & C3 & C4 & C5 \\
\hline $\begin{array}{c}\text { IMPORTANCE } \\
\text { NO. }\end{array}$ & 7 & 7 & 7 & 8 & 7 & 7 & 8 & 7 & 7 & 8 & \\
\hline STATUS & \multicolumn{3}{|l|}{ FUNDED RFP/PRDA } \\
\hline
\end{tabular}

\begin{tabular}{|c|c|c|c|c|c|c|c|c|c|c|c|}
\hline \multirow[t]{2}{*}{ PATH } & \multicolumn{3}{|c|}{$\begin{array}{l}\text { SHELTER } \\
\text { HEATING }\end{array}$} & \multicolumn{3}{|c|}{ DRYING } & \multicolumn{2}{|c|}{$\begin{array}{l}\text { PROCESS } \\
\text { HOT WATER }\end{array}$} & \multirow{2}{*}{$\begin{array}{c}\text { PROCESS } \\
\text { STEAM } \\
\text { SL }\end{array}$} & \multicolumn{2}{|c|}{$\begin{array}{l}\text { COOLING/ } \\
\text { REFRIG. } \\
\text { ERATION }\end{array}$} \\
\hline & HP & HA & $\mathrm{HL}$ & DD & $\mathrm{DA}$ & $\mathrm{DL}$ & WL & WA & & $\mathrm{CP}$ & $\mathrm{CA}$ \\
\hline IMPORTANCE NO. & 8 & & & 7 & & & & & & & \\
\hline STATUS & & & & & & & & & & & \\
\hline
\end{tabular}

1-Hb-2. Determine the damage history of both glass and non-glass collector glazings, including hail damage and vandalism as well as thermal stress breaks. Determine the significance of such damage for collector performance.

\begin{tabular}{|c|c|c|c|c|c|c|c|c|c|c|c|}
\hline \multirow[t]{2}{*}{ PATH } & \multicolumn{2}{|c|}{$\begin{array}{l}\text { SERVICE } \\
\text { HOT WATER }\end{array}$} & \multicolumn{4}{|c|}{ SPACE HEATING } & \multicolumn{5}{|c|}{ SPACE COOLING } \\
\hline & w1 & W2 & $\mathrm{HI}$ & $\mathrm{H} 2$ & H3 & $\mathrm{H} 4$ & $\mathrm{C} 1$ & $\mathrm{C}_{2}$ & $\mathrm{C} 3$ & $\mathrm{C4}$ & $\mathrm{C5}$ \\
\hline $\begin{array}{c}\text { IMPORTANCE } \\
\text { NO. }\end{array}$ & 5 & 5 & 5 & 5 & 5 & 5 & 5 & 5 & . & & 4 \\
\hline STATUS & $F L$ & D RE & 75 & & & & & & & & . \\
\hline
\end{tabular}


$1-\mathrm{Hb}-3$. Investigate the potential for large volume production of glass tailored for use in solar collectors. Include the transmissivity, reflectance, durability, thickness, and size limitations of the glass.

\begin{tabular}{|c|c|c|c|c|c|c|c|c|c|c|c|}
\hline \multirow{2}{*}{ PATH } & \multicolumn{2}{|c|}{$\begin{array}{l}\text { SERVICE } \\
\text { HOT WATER }\end{array}$} & \multicolumn{4}{|c|}{ SPACE HEATING } & \multicolumn{5}{|c|}{ SPACE COOLING } \\
\hline & w1 & w2 & H1 & $\mathrm{H} 2$ & H3 & $\mathrm{H} 4$ & $\mathrm{Cl}$ & $\mathrm{C} 2$ & c3 & $\mathrm{C4}$ & $\mathrm{C5}$ \\
\hline $\begin{array}{l}\text { IMPORTANCE } \\
\text { NO. }\end{array}$ & 6 & 6 & 6 & 6 & 4 & 6 & 5 & 6 & 7 & & 4 \\
\hline STATUS & & & & & & & & & & & \\
\hline
\end{tabular}

$\mathrm{I}-\mathrm{Hb}-4$. Determine the effect of glass surface conditions on collector performance. Include an evaluation of traditional glass surface figuring and etching, and transmission of cover as a function of direction in the solar baind.

\begin{tabular}{|c|c|c|c|c|c|c|c|c|c|c|c|}
\hline \multirow[t]{2}{*}{ PATH } & \multicolumn{2}{|c|}{$\begin{array}{l}\text { SERVICE } \\
\text { HOT WATER }\end{array}$} & \multicolumn{4}{|c|}{ SPACE HEATING } & \multicolumn{5}{|c|}{ SPACE COOLING } \\
\hline & w1 & w2 & $\mathrm{H1}$ & $\mathrm{H} 2$ & $\mathrm{H3}$ & $\mathrm{H} 4$ & $\mathrm{C} 1$ & $\mathrm{C} 2$ & $\mathrm{C} 3$ & $\mathrm{C} 4$ & $\mathrm{C} 5$ \\
\hline $\begin{array}{c}\text { IMPORTANCE } \\
\text { NO. }\end{array}$ & 4 & 4 & 5 & 6 & 4 & 4 & 5 & 5 & 4 & & 4 \\
\hline STATUS & & & & & & & & & & & \\
\hline
\end{tabular}

1-Hb-5. Develop glazing materials or material combinations with variable transmittance depending on temperature, e.g., a collector glazing which becomes opaque when the collector is subject to no-flow conditions. Such material could also be used as a passive heat flow controller.

\begin{tabular}{|c|c|c|c|c|c|c|c|c|c|c|c|}
\hline PATH & $\begin{array}{r}\text { SE } \\
\text { HOT }\end{array}$ & $\begin{array}{l}\text { ICE } \\
\text { ATER }\end{array}$ & & CEE & ATII & & & & $\mathrm{COO}$ & NG & \\
\hline . & $w_{1}$ & w2 & $\mathrm{H} 1$ & $\mathrm{H} 2$ & $\mathrm{H} 3$ & $\mathrm{H} 4$ & $\mathrm{C} 1$. & $\mathrm{C} 2$ & C3 & $\mathrm{C} 4$ & $\mathrm{C5}$ \\
\hline $\begin{array}{c}\text { IMPORTANCE } \\
\text { NO. }\end{array}$ & 6 & 6 & 6 & 6 & 6 & 6 & & 6 & 6 & & \\
\hline
\end{tabular}


1-Hb-6. Investigatc, test, and support the development of improved glazing materials for use as water bag materials in liquid-heating collectors. Attention must be given to increasing UV stability, increasing tolerance limited duration high temperatures encountered under stagnation conditions, increasing longevity under

rating conditions in polluted atmospheres at high humidity, lowering costs, and compatibility with various working fluids.

\begin{tabular}{|c|c|c|c|c|c|c|c|c|c|c|c|}
\hline \multirow[t]{2}{*}{ PATH } & \multicolumn{3}{|c|}{$\begin{array}{l}\text { SHELTER } \\
\text { HEATING }\end{array}$} & \multicolumn{3}{|c|}{ DRYING } & \multicolumn{2}{|c|}{\begin{tabular}{|l} 
PROCESS \\
HOT WATER
\end{tabular}} & \multirow{2}{*}{$\begin{array}{c}\text { PROCESS } \\
\text { STEAM } \\
\text { SL } \\
\end{array}$} & \multicolumn{2}{|c|}{$\begin{array}{l}\text { COOLING/ } \\
\text { REFRIG- } \\
\text { ERATION }\end{array}$} \\
\hline & HP & HA & $\mathrm{HL}$ & DD & DA & $\mathrm{DL}$ & WL & WA & & $C P$ & CA \\
\hline IMPORTANCE NO. & & & 9 & & & 10 & 9 & & & $"$. & 8 \\
\hline STATUS & & & & & & & & & & & \\
\hline
\end{tabular}

$\mathrm{I}-\mathrm{Hb}-7$. Investigate, test, and support the development of improved polymeric/elastomeric thin 'film materials for use as the inflated outer cylinder or sphere for low-cost concentrating collectors or as collector shields. Important characteristics of the film are high transmissivity, low cost, good weatherability, durability, strength, and ease and reliability of joining.

\begin{tabular}{|c|c|c|c|c|c|c|c|c|c|c|c|}
\hline \multirow[t]{2}{*}{ PATH } & \multicolumn{3}{|c|}{$\begin{array}{l}\text { SHELTER } \\
\text { HEATING }\end{array}$} & \multicolumn{3}{|c|}{ DRYING } & \multicolumn{2}{|c|}{$\begin{array}{l}\text { PROCESS } \\
\text { HOT WATER }\end{array}$} & \multirow{2}{*}{$\begin{array}{c}\text { PROCESS } \\
\text { STEAM } \\
\text { SL }\end{array}$} & \multicolumn{2}{|c|}{$\begin{array}{l}\text { COOLING/ } \\
\text { REFRIG- } \\
\text { ERATION }\end{array}$} \\
\hline & HP & HA & $\mathrm{HL}$ & DD & DA & $\mathrm{DL}$ & WL & WA & & $C P$ & CA \\
\hline IMPORTANCE NO. & & & & & 5 & & 8 & 5 & 8 & & 5 \\
\hline STATUS & & & & & & & & & & & \\
\hline
\end{tabular}

\section{I-Hc. Glazing Surface Coatings}

I-Hc-1. Develop durable coatings for plastic glazings. Compare the cost of applying a coating of polymeric plastic on PVC film to the cost of building the stabilizer into the polymeric material. Include development of durable coatings that are infrared transparent for use with windscreen materials for radiative cooling.

\begin{tabular}{|c|c|c|c|c|c|c|c|c|c|c|c|}
\hline \multirow{2}{*}{ PATH } & \multicolumn{3}{|c|}{$\begin{array}{c}\text { SERVICE } \\
\text { HOT WATER }\end{array}$} & \multicolumn{4}{|c|}{ SPACE HEATING } & \multicolumn{5}{c|}{ SPACE COOLING } \\
& $\begin{array}{c}\text { W1 } \\
\text { W2 }\end{array}$ & H1 & H2 & H3 & H4 & C1 & C2 & C3 & C4 & C5 \\
\hline $\begin{array}{c}\text { IMPORTANCE } \\
\text { NO. }\end{array}$ & 6 & 6 & 6 & 7 & 6 & 6 & 7 & 5 & 6 & 7 & 5 \\
\hline STATUS & \multicolumn{3}{|l|}{ FUNDED RFP/PRDA } \\
\hline
\end{tabular}


I-Hc-2. Continue development of surface etching processes for reducing reflectivity on both glass and plastics. Determine the types of glass or plastic most appropriate for this treatment, their potential for mechanical surface failure, the effect on them of dirt and repeated washing, and their cost effectivent

\begin{tabular}{|c|c|c|c|c|c|c|c|c|c|c|c|}
\hline \multirow[t]{2}{*}{ PATH } & \multicolumn{2}{|c|}{$\begin{array}{l}\text { SERVICE } \\
\text { HOT WATER }\end{array}$} & \multicolumn{4}{|c|}{ SPACE HEATING } & \multicolumn{5}{|c|}{ SPACE COOLING } \\
\hline & $w_{1}$ & W2 & $\mathrm{H1}$ & $\mathrm{H} 2$ & $\mathrm{H} 3$ & $\mathrm{H} 4$ & $\mathrm{C} 1$ & $\mathrm{C} 2$ & $\mathrm{C} 3$ & $\mathrm{C} 4$ & $\mathrm{C5}$ \\
\hline $\begin{array}{l}\text { IMPORTANCE } \\
\text { NO. } \\
\end{array}$ & 5 & 5 & 6 & 6 & 5 & 5 & 5 & 5 & 6 & & 5 \\
\hline STATUS & $\mathrm{RE}$ & AL & INSO & -1 & & & & & & " & \\
\hline
\end{tabular}

1-Hc-3. Investigate means for applying IR or anti-reflection coatings uniformly in large volume production. Consider coatings for glass and plastics, and study the cost implications of the production process.

\begin{tabular}{|c|c|c|c|c|c|c|c|c|c|c|c|}
\hline \multirow[t]{2}{*}{ PATH } & \multicolumn{2}{|c|}{$\begin{array}{l}\text { SERVICE } \\
\text { HOT WATER }\end{array}$} & \multicolumn{4}{|c|}{ SPACE HEATING } & \multicolumn{5}{|c|}{ SPACE COOLING } \\
\hline & W1 & w2 & $\mathrm{H} 1$ & $\mathrm{H} 2$ & H3 & $\mathrm{H} 4$ & $\mathrm{Cl}$ & $\mathrm{C} 2$ & C3 & $\mathrm{C} 4$ & $\mathrm{C} 5$ \\
\hline $\begin{array}{l}\text { IMPORTANCE } \\
\text { NO. }\end{array}$ & 4 & 6 & 5 & 6 & 4 & 4 & 5 & 6 & 5 & 5 & 4 \\
\hline$\therefore$ status & & D & & & & & & & & & \\
\hline
\end{tabular}

I-Hc-4. Develop IR reflection coatings. Emphasize increasing the solar spectrum transmittance of thecoating while retaining the reflection characteristics. Study the effect of IR reflection and solar transmission on collector performance for both flat black absorber and selective absorber surfaces. Evaluate conventional and advanced collectors with honeycomb convection suppression and other advanced collector systems such as evacuated collectors.

\begin{tabular}{|c|c|c|c|c|c|c|c|c|c|c|c|}
\hline \multirow{2}{*}{$\begin{array}{c}\text { PATH } \\
\ldots\end{array}$} & \multicolumn{2}{|c|}{$\begin{array}{l}\text { SERVICE } \\
\text { HOT WATER }\end{array}$} & \multicolumn{4}{|c|}{ SPACE HEATING } & \multicolumn{5}{|c|}{ SPACE COOLING } \\
\hline & $w 1$ & w2 & H1 & $\mathrm{H} 2$ & $\mathrm{H}^{\circ}$ & $\mathrm{H} 4$ & $\mathrm{Cl}$ & C2 & C3 & $\mathrm{C4}$ & C5 \\
\hline $\begin{array}{c}\text { IMPORTANCE } \\
\text { NO. }\end{array}$ & 4 & 6 & 5 & 6 & 4 & 4 & 5 & 6 & 5 & & 4 \\
\hline STATUS & & & & & & & & & & & \\
\hline
\end{tabular}


1-Hc-5. Develop semi-conductor IR reflection coatings such as tin uxide and indium oxide. Pay particular attention to environmental stability, the optimization of the level of doping, and the coating thickness. Main-

$\mathrm{n}$ close monitoring and interfacing with solar photovoltaic developments involving these coatings.

\begin{tabular}{|c|c|c|c|c|c|c|c|c|c|c|c|}
\hline \multirow[t]{2}{*}{ PATH } & \multicolumn{2}{|c|}{$\begin{array}{l}\text { SERVICE } \\
\text { HOT WATER }\end{array}$} & \multicolumn{4}{|c|}{ SPACE HEATING } & \multicolumn{5}{|c|}{ SPACE COOLING } \\
\hline & w1 & w2 & $\mathrm{H} 1$ & $\mathrm{H} 2$ & $\mathrm{H} 3$ & $\mathrm{H4}$ & $\mathrm{C} 1$ & $\mathrm{C} 2$ & C3 & $\mathrm{C} 4$ & $\mathrm{C5}$ \\
\hline $\begin{array}{c}\text { IMPORTANCE } \\
\text { NO. }\end{array}$ & 4 & 6 & 5 & 5 & 4 & 4 & 5 & 5 & 5 & & 4 \\
\hline STATUS & $F$ & $\mathrm{R}$ & PF & & & & & & & & \\
\hline
\end{tabular}

\section{I-Hd. Sealants}

1-Hd-1. Evaluate a large range of sealants for use in solar collectors. Investigate silicons, ethylene terpolymer/hydroxide (rubber) adhesive, polyvinyl butyral, EPDM, organic tars, etc. Study outgassing, high temperature stability, UV degradation, strength characteristics, the matching of thermal coefficients of expansion with collector materials, cost of materials and installation, and durability.

\begin{tabular}{|c|c|c|c|c|c|c|c|c|c|c|c|}
\hline \multirow[t]{2}{*}{ PATH } & \multicolumn{2}{|c|}{$\begin{array}{l}\text { SERVICE } \\
\text { HOT WATER }\end{array}$} & \multicolumn{4}{|c|}{ SPACE HEATING } & \multicolumn{5}{|c|}{ SPACE COOLING } \\
\hline & W1 & W2 & $\mathrm{HI}$ & $\mathrm{H} 2$ & $\mathrm{H3}$ & $\mathrm{H} 4$ & $\mathrm{C} 1$ & $\mathrm{C} 2$ & $\mathrm{C} 3$ & C4 & $\mathrm{C5}$ \\
\hline $\begin{array}{c}\text { IMPORTANCE } \\
\text { NO. }\end{array}$ & 7 & 8 & 6 & 6 & 8 & 7 & 8 & 8 & 8 & & 5 \\
\hline STATUS & FU & $\mathbf{R}$ & & & & & & & & & \\
\hline
\end{tabular}

1-Hd-2. Evaluate methods for controlling breathing in solar collectors. Candidate techniques are vents, solar regenerative desiccants, and pressure relief tubes. Investigate the effects of uncontrolled breathing on collectors which have been in service for many years. Complete a study of the corrosion or failure of cover plate or absorber plate due to water condensation; the effect of condensed water leaking into insulation material; the effect of condensed, then frozen, moisture; and any effects of moisture on absorber surfaces.

\begin{tabular}{|c|c|c|c|c|c|c|c|c|c|c|c|}
\hline \multirow{2}{*}{ PATH } & \multicolumn{3}{|c|}{$\begin{array}{c}\text { SERVICE } \\
\text { HOT WATER } \\
\end{array}$} & \multicolumn{4}{|c|}{ SPACE HEATING } & \multicolumn{5}{c|}{ SPACE COOLING } \\
& W1 & W2 & H1 & H2 & H3 & H4 & C1 & C2 & C3 & C4 & C5 \\
\hline $\begin{array}{c}\text { IMPORTANCE } \\
\text { NO. }\end{array}$ & 6 & 10 & 5 & 5 & 10 & 6 & 6 & 5 & 6 & 6 & 4 \\
\hline STATUS & \multicolumn{4}{|l|}{ FUNDED RFP/PRDA } \\
\hline
\end{tabular}


I-Hd-3. Develop a durable, high temperature, high humidity, glass-to-metal seal that could be used in a hermetically sealed collector for service between 115 and $150^{\circ} \mathrm{C}\left(250-300^{\circ} \mathrm{F}\right)$.

\begin{tabular}{|c|c|c|c|c|c|c|c|c|c|c|c|}
\hline \multirow[t]{2}{*}{ PATH } & \multicolumn{2}{|c|}{$\begin{array}{l}\text { SERVICE } \\
\text { HOT WATER }\end{array}$} & \multicolumn{4}{|c|}{ SPACE HEATING } & \multicolumn{5}{|c|}{ SPACE COOLING } \\
\hline & wi & w2 & $\mathrm{HI}$ & $\mathrm{H} 2$ & $\mathrm{H3}$ & $\mathrm{H} 4$ & $\mathrm{Cl}$ & $\mathrm{C} 2$ & $\mathrm{C3}$ & $\mathrm{C} 4$ & $\mathrm{C} 5$ \\
\hline $\begin{array}{c}\text { IMPORTANCE } \\
\text { NO. }\end{array}$ & & & & & & & 9 & 9 & 2 & & \\
\hline STATUS & \multicolumn{11}{|c|}{ FUNDED RFP/PRDA } \\
\hline
\end{tabular}

1-Hd-4. Develop and evaluate desiccants for use in air-heating collectors. Investigate methods of incorporating the desiccants into the collectors.

\begin{tabular}{|c|c|c|c|c|c|c|c|c|c|c|c|}
\hline \multirow[t]{2}{*}{ PATH } & \multicolumn{2}{|c|}{$\begin{array}{c}\text { SERVICE } \\
\text { HOT WATER }\end{array}$} & \multicolumn{4}{|c|}{ SPACE HEATING } & \multicolumn{5}{|c|}{ SPACE COOLING } \\
\hline & w1 & w2 & $H 1$. & $\mathrm{H} 2$ & H3 & $\mathrm{H4}$ & $\mathrm{C}_{1}$ & $\mathrm{C} 2$ & C3 & $\mathrm{C} 4$ & $\mathrm{C5}$ \\
\hline $\begin{array}{c}\text { IMPORTANCE } \\
\text { NO. }\end{array}$ & & 6 & & & 6 & & & & & & \\
\hline STATUS & & & & & & & & & & & \\
\hline
\end{tabular}

\section{I-He. Coolants}

I-He-1. Evaluate and develop superior liquid coolants [up to $400^{\circ} \mathrm{C}\left(750^{\circ} \mathrm{F}\right)$ ] for solar collectors. Evaluate the coolants for toxicity, freeze protection, boiling protection, heat capacity, viscosity, heat-transfer effectiveness, stability, cost, safety, flammability, sealing, and corrosiveness in metals such as mild-steel, aluminum, and copper. Analyze the following candidate liquids: ethylene or propylene-glycol in water; silicon fluids; paraffinic oils; hydraulic fluids; and pressurized mixtures of ethanol and water. Survey the state of the art for heat-transfer fluids in non-solar areas, and investigate ways in which these applications differ from solar applications.

\begin{tabular}{|c|c|c|c|c|c|c|c|c|c|c|c|}
\hline \multirow[t]{2}{*}{ PATH } & \multicolumn{2}{|c|}{$\begin{array}{c}\text { SERVICE } \\
\text { HOT WATER }\end{array}$} & \multicolumn{4}{|c|}{ SPACE HEATING } & \multicolumn{5}{|c|}{ SPACE COOLING } \\
\hline & $W_{1}$ & w2 & $\mathrm{H} 1$ & $\mathrm{H} 2$ & $\mathrm{H3}$ & $\mathrm{H} 4$ & $\mathrm{C} 1$ & $\mathrm{C2}$ & $\mathrm{C} 3$ & $\mathrm{C4}$ & $\mathrm{C} 5$ \\
\hline $\begin{array}{c}\text { IMPORTANCE } \\
\text { NO. }\end{array}$ & 8 & & 7 & & & 10 & 10 & 10 & & & 7 \\
\hline STATUS & 10 & & $5 / 2$ & $i$ & DN & LAB & & & & & \\
\hline
\end{tabular}


I-He-2. Document and characterize the properties and behavior of currently used collector coolants.

\begin{tabular}{|c|c|c|c|c|c|c|c|c|c|c|c|}
\hline \multirow[t]{2}{*}{ PATH } & \multicolumn{2}{|c|}{$\begin{array}{l}\text { SERVICE } \\
\text { HOT WATER }\end{array}$} & \multicolumn{4}{|c|}{ SPACE HEATING } & \multicolumn{5}{|c|}{ SPÁCE COOLING } \\
\hline & $w_{1}$ & w2 & $\mathrm{H1}$ & $\mathrm{H} 2$ & H3 & $\mathrm{H} 4$ & C1 & $\mathrm{C} 2$ & C3 & C4 & C5 \\
\hline $\begin{array}{l}\text { IMPORTANCE } \\
\text { NO. }\end{array}$ & 10 & & 6 & & & 10 & 10 & 10 & & & 7 \\
\hline
\end{tabular}

1-He-3. Determine and evaluate the interaction between chemical antifreeze additives and the types of water (ionized, tap, distilled, etc.) used as collector coolants. Indicate how the interaction influences mixture properties and corrosive tendencies. Develop suitable corrosion inhibitors for aqueous coolants.

\begin{tabular}{|c|c|c|c|c|c|c|c|c|c|c|c|}
\hline \multirow[t]{2}{*}{ PATH } & \multicolumn{2}{|c|}{$\begin{array}{l}\text { SERVICE } \\
\text { HOT WATER }\end{array}$} & \multicolumn{4}{|c|}{ SPACE HEATING } & \multicolumn{5}{|c|}{ SPACE COOLING } \\
\hline & w1 & w2 & $\mathrm{H1}$ & $\mathrm{H} 2$ & H3 & $-\mathrm{H}_{4}$ & $\mathrm{Cl}$ & $\mathrm{C} 2$ & C3 & $\mathrm{C} 4$ & $\mathrm{C5}$ \\
\hline $\begin{array}{c}\text { IMPORTANCE } \\
\text { NO. }\end{array}$ & 7 & & 6 & & & 6 & 7 & 7 & & 7 & 6 \\
\hline STATUS & \multicolumn{11}{|c|}{ FUNDED RFP/PRDA } \\
\hline
\end{tabular}

1-He-4. Compare the economic benefits of using control systems to avoid freezing and adding chemical antifreeze or non-water base coolants which will increase collector area.

\begin{tabular}{|c|c|c|c|c|c|c|c|c|c|c|c|}
\hline \multirow[t]{2}{*}{ PATH } & \multicolumn{2}{|c|}{$\begin{array}{l}\text { SERVICE } \\
\text { HOT WATER }\end{array}$} & \multicolumn{4}{|c|}{ SPACE HEATING } & \multicolumn{5}{|c|}{ SPACE COOLING } \\
\hline & $w_{1}$ & w2 & H1 & . $\mathrm{H} 2$ & H3 & $\ddot{H} 4$ & C1 & $\mathrm{C} 2$ & C3 & $\mathrm{C} 4$ & C5: \\
\hline $\begin{array}{l}\text { IMPORTANCE } \\
\text { NO. }\end{array}$ & 4 & & 8 & & & 8 & 7 & 7 & & & \\
\hline STATUS & FUN & $D R F$ & 51 & & & & & & & & \\
\hline
\end{tabular}


I-He-5. Develop potable corrosion inhibitors for use in hot water systems.

\begin{tabular}{|c|c|c|c|c|c|c|c|c|c|c|c|}
\hline \multirow[t]{2}{*}{ PATH } & \multicolumn{2}{|c|}{$\begin{array}{l}\text { SERVICE } \\
\text { HOT WATER }\end{array}$} & \multicolumn{4}{|c|}{ SPACE HEATING } & \multicolumn{5}{|c|}{ SPACE COOLING } \\
\hline & w1 & w2 & $\mathrm{H} 1$ & $\mathrm{H} 2$ & H3 & $\mathrm{H} 4$ & $\mathrm{C}_{1}$ & $\mathrm{C} 2$ & $\mathrm{C} 3$ & $\mathrm{C} 4$ & $\mathrm{C5}$ \\
\hline $\begin{array}{l}\text { IMPORTANCE } \\
\text { NO. }\end{array}$ & 10 & & & .. & & 7 & & & & & \\
\hline STATUS & FŨN & $R$ & D & & & & & & & & \\
\hline
\end{tabular}

1-He-6. Study air filtering requirements and air filtering technology for air heaters. Investigate possible air contamination problems arising from disintegration of air system components such as sealants, insulation, etc:

\begin{tabular}{|c|c|c|c|c|c|c|c|c|c|c|c|}
\hline \multirow[t]{2}{*}{ PATH } & \multicolumn{2}{|c|}{$\begin{array}{l}\text { SERVICE } \\
\text { HOT WATER }\end{array}$} & \multicolumn{4}{|c|}{ SPACE HEATING } & \multicolumn{5}{|c|}{ SPACE COOLING } \\
\hline & w1 & $w_{2}$ & $H 1$ & $\mathrm{H} 2$ & H3 & $\mathrm{H} 4$ & $c_{1}$ & $\mathrm{C} 2$ & $\mathrm{C} 3$ & $\mathrm{C} 4$ & C.5 \\
\hline $\begin{array}{l}\text { IMPORTANCE } \\
\text { NO. }\end{array}$ & & 2 & 2 & & 10 & & & & 4 & & \\
\hline STATUS & & & & & & & & & & & \\
\hline
\end{tabular}

1-He-7. Determine the corrosion characteristics and long term effects of collector fluids and multi-metallic systems, indicating which materials are most effective under various given conditions. Emphasize elevated temperature and stagnation conditions. Create a data bank for storing this information. Use accelerated tests if necessary.

\begin{tabular}{|c|c|c|c|c|c|c|c|c|c|c|c|}
\hline \multirow[t]{2}{*}{ PATH } & \multicolumn{2}{|c|}{$\begin{array}{l}\text { SERVICE } \\
\text { HOT WATER }\end{array}$} & \multicolumn{4}{|c|}{ SPACE HEATING } & \multicolumn{5}{|c|}{ SPACE COOLING } \\
\hline & w1 & w2 & H1 & $\mathrm{H} 2$ & $\mathrm{H3}$ & $\mathrm{H} 4$ & $\mathrm{C}_{1}$ & $\mathrm{C2}$ & $\mathrm{C} 3$ & $\mathrm{C} 4$ & $\mathrm{C5}$ \\
\hline $\begin{array}{c}\text { IMPORTANCE } \\
\text { NO. }\end{array}$ & 10 & 10 & 6 & 8 & 5 & 10 & 10 & 10 & 8 & & 5 \\
\hline STATUS & RE & TAL & NSO & $I^{\prime}$ & & & & & & & \\
\hline
\end{tabular}


I-Hf. Insulation

$1-H f-1$. Evaluate the problems of moisture absorption and out-gassing of adhesive binders in fibrous insulation. Continue the investigation of foil facing used as.an out-gassing, moisture, and radiation barrier.

\begin{tabular}{|c|c|c|c|c|c|c|c|c|c|c|c|}
\hline & \multicolumn{3}{|c|}{$\begin{array}{c}\text { SERVICE } \\
\text { POT WATH }\end{array}$} & \multicolumn{4}{|c|}{ SPACE HEATING } & \multicolumn{5}{c|}{ SPACE COOLING } \\
& W1 & W2 & H1 & H2 & H3 & H4 & C1 & C2 & C3 & C4 & C5 \\
\hline $\begin{array}{c}\text { IMPORTANCE } \\
\text { NO. }\end{array}$ & 6 & 6 & 3 & 6 & 6 & 6 & 8 & 8 & 7 & & 3 \\
\hline STATUS & FUNDED & RFP/PRDA \\
\hline
\end{tabular}

1-Hf-2. Support the development of $\mathrm{CO}_{2}$ and air-blown polyurethane foams for use as collector insulation. Determine optimal void volume, thermal stability, lifetime, and insulating properties. Define methods for protecting the foam against fire.

\begin{tabular}{|c|c|c|c|c|c|c|c|c|c|c|c|}
\hline \multirow[t]{2}{*}{ PATH } & \multicolumn{2}{|c|}{$\begin{array}{l}\text { SERVICE } \\
\text { HOT WATER }\end{array}$} & \multicolumn{4}{|c|}{ SPACE HEATING } & \multicolumn{5}{|c|}{ SPACE COOLING } \\
\hline & w1 & w2 & $\mathrm{H} 1$ & $\mathrm{H} 2$ & $\mathrm{H3}$ & $\mathrm{H} 4$ & $\mathrm{C} 1$ & $\mathrm{C} 2$ & C3 & $\mathrm{C} 4$ & C5 \\
\hline $\begin{array}{l}\text { IMPORTANCE } \\
\text { NO. }\end{array}$ & 5 & 5 & 4 & 6 & 6 & 6 & 7 & 5 & 5 & & 3 \\
\hline
\end{tabular}

I-Hf-3. Investigate the use of mineral rock wool for collector insulation:

\begin{tabular}{|c|c|c|c|c|c|c|c|c|c|c|c|}
\hline \multirow{2}{*}{ PATH } & \multicolumn{3}{|c|}{$\begin{array}{c}\text { SERVICE } \\
\text { HOT WATER } \\
\text { W1 }\end{array}$} & \multicolumn{4}{|c|}{ SPACE HEATING } & \multicolumn{6}{c|}{ SPACE COOLING } \\
& $\mathrm{W}$ & $\mathrm{H} 1$ & $\mathrm{H} 2$ & $\mathrm{H} 3$ & $\mathrm{H} 4$ & $\mathrm{C} 1$ & $\mathrm{C} 2$ & $\mathrm{C} 3$ & $\mathrm{C} 4$ & $\mathrm{C5}$ \\
\hline $\begin{array}{c}\text { IMPORTANCE } \\
\text { NO. }\end{array}$ & 4 & 4 & 4 & 5 & 5 & 5 & 7 & 7 & 6 & & 3 \\
\hline STATUS & \multicolumn{3}{|l|}{ FUNDED } \\
\hline
\end{tabular}


I-Hf-4. Investigate and develop foam glass for use as a collector insulation. Consider the following aspects of foam glass: cost effectiveness and cost reduction; water absorption properties; dimensional stability; and high temperature degradation during collector stagnation.

\begin{tabular}{|c|c|c|c|c|c|c|c|c|c|c|c|}
\hline \multirow{2}{*}{ PATH } & \multicolumn{3}{|c|}{$\begin{array}{c}\text { SERVICE } \\
\text { HOT WATER }\end{array}$} & \multicolumn{4}{|c|}{ SPACE HEATING } & \multicolumn{5}{c|}{ SPACE COOLING } \\
& W1 & W2 & H1 & H2 & H3 & H4 & C1 & C2 & C3 & C4 & C5 \\
\hline $\begin{array}{c}\text { IMPORTANCE } \\
\text { NO. }\end{array}$ & 4 & 4 & 3 & 3 & 4 & 4 & 7 & 6 & 4 & & 3 \\
\hline STATUS & \multicolumn{3}{|l|}{ FUNDED } \\
\hline
\end{tabular}

1-Hf-5. Survey and document the properties of known and candidate insulation materials, especially those originally developed for non-solar applications. These properties include out-gassing, moisture absorption, thermal degradation, etc. [for coolants to $400^{\circ} \mathrm{C}\left(750^{\circ} \mathrm{F}\right)$ ]. Identify new, high performance, insulating. materials suitable for use in solar collectors.

\begin{tabular}{|c|c|c|c|c|c|c|c|c|c|c|c|}
\hline \multirow[t]{2}{*}{ PATH } & \multicolumn{2}{|c|}{$\begin{array}{l}\text { SERVICE } \\
\text { HOT WATER }\end{array}$} & \multicolumn{4}{|c|}{ SPACE HEATING } & \multicolumn{5}{|c|}{ SPACE COOLING } \\
\hline & $W_{1}$ & W2 & $H 1$ & $\mathrm{H} 2$ & H3 & $\mathrm{H} 4$ & $\mathrm{C} 1$ & $\mathrm{C} 2$ & C3 & $\mathrm{C} 4$ & $\mathrm{C} 5$ \\
\hline $\begin{array}{c}\text { IMPORTANCE } \\
\text { NO. }\end{array}$ & 6 & 6 & 6 & 6 & 6 & 7 & 6 & 5 & 6 & & 4 \\
\hline STATUS & \multicolumn{11}{|c|}{ FUNDED RFP/PRDA } \\
\hline
\end{tabular}

I-Hf-6. Support the development of polyimide foams for use as collector insulation. Study the following aspects of the foams: dimensional stability, flammability, cost effectiveness and cost reduction, stability at evaluated temperatures, and the thermal conductivity/density relationship.

\begin{tabular}{|c|c|c|c|c|c|c|c|c|c|c|c|}
\hline \multirow[t]{2}{*}{ PATH } & \multicolumn{2}{|c|}{$\begin{array}{l}\text { SERVICE } \\
\text { HOT WATER }\end{array}$} & \multicolumn{4}{|c|}{ SPACE HEATING } & \multicolumn{5}{|c|}{ SPACE COOLING } \\
\hline & W1 & W2 & $\mathrm{H} 1$ & $\mathrm{H} 2$ & H3 & $\mathrm{H} 4$ & $\mathrm{C} 1$ & $\mathrm{C} 2$ & C3. & $\mathrm{C} 4$ & $\mathrm{C5}$ \\
\hline $\begin{array}{c}\text { IMPORTANCE } \\
\text { NO. }\end{array}$ & 4 & 5 & 4 & 5 & 5 & 5 & 8 & 8 & 5 & & 3 \\
\hline STATUS & & & $P$ & & & & & & & & \\
\hline
\end{tabular}


1-Hf-7. Investigate varieties of insulation that can be used in passive solar heating and cooling applications. ^ śsess cost, convenience, safety, lifetime, and thermal performance characteristics.

\begin{tabular}{|c|c|c|c|c|c|c|c|c|c|c|c|}
\hline \multirow[t]{2}{*}{ PATH } & \multicolumn{2}{|c|}{$\begin{array}{l}\text { SERVICE } \\
\text { HOT WATER }\end{array}$} & \multicolumn{4}{|c|}{ SPACE HEATING } & \multicolumn{5}{|c|}{ SPACE COOLING } \\
\hline & $w_{1}$ & w2 & $\mathrm{H} 1$ & $\mathrm{H} 2$ & H3 & $\mathrm{H} 4$ & C1 & $\mathrm{C} 2$ & $\mathrm{C} 3$ & $\mathrm{C4}$ & $\mathrm{C5}$ \\
\hline $\begin{array}{l}\text { IMPORTANCE } \\
\text { NO. }\end{array}$ & & & & 10 & & & & & & 10 & 4 \\
\hline STATUS & \multicolumn{2}{|c|}{ FUNDED } & $P / F$ & & & & & & & & \\
\hline
\end{tabular}

1-Hf-8. Support the development of low cost, water impermeable, insulating materials which could be used in contact with the earth as beds for large area collector systems or as insulating blankets on underground storage reservoirs.

\begin{tabular}{|c|c|c|c|c|c|c|c|c|c|c|c|}
\hline \multirow[t]{2}{*}{ PATH } & \multicolumn{3}{|c|}{$\begin{array}{l}\text { SHELTER } \\
\text { HEATING }\end{array}$} & \multicolumn{3}{|c|}{ DRYING } & \multicolumn{2}{|c|}{$\begin{array}{l}\text { PROCESS } \\
\text { HOT WATER }\end{array}$} & \multirow{2}{*}{$\begin{array}{c}\text { PROCESS } \\
\text { STEAM } \\
\text { SL }\end{array}$} & \multicolumn{2}{|c|}{$\begin{array}{l}\text { COOLINGI } \\
\text { REFRIG- } \\
\text { ERATION }\end{array}$} \\
\hline & HP & HA & $H L$ & DD & DA & $\mathrm{DL}$ & WL & WA & & $\mathrm{CP}$ & $=C A$ \\
\hline IMPORTANCE NO. & & & 7 & & & 7 & 7 & & 6 & & \\
\hline STATUS & . & & & & & & & & & & \\
\hline
\end{tabular}

\section{I-Hg. Absorber Surfaces}

$\mathrm{I}-\mathrm{Hg}-1$. Evaluate the potential of long-life, stable, non-metallic absorber surfaces. Study the problem of low conductivity; consider the development of an integrated, sealed, all-plastic collector module.

\begin{tabular}{|c|c|c|c|c|c|c|c|c|c|c|c|}
\hline \multirow[t]{2}{*}{ PATH } & \multicolumn{2}{|c|}{$\begin{array}{l}\text { SERVICE } \\
\text { HOT WATER }\end{array}$} & \multicolumn{4}{|c|}{ SPACE HEATING } & \multicolumn{5}{|c|}{ SPACE COOLING } \\
\hline & $w 1$ & w2 & $\mathrm{H} 1$ & $\mathrm{H} 2$ & $\mathrm{H} 3$ & $\mathrm{H} 4$ & $\mathrm{C} 1$ & $\mathrm{C} 2$ & $\mathrm{C} 3$ & $\mathrm{C} 4$ & $\mathrm{C5}$ \\
\hline $\begin{array}{l}\text { IMPORTANCE } \\
\text { NO. }\end{array}$ & 7 & 6 & 7 & 5 & 6 & 7 & & & 5 & 7 & 3 \\
\hline STATUS & FU & o & & & & & & & & & \\
\hline
\end{tabular}




\begin{tabular}{|c|c|c|c|c|c|c|c|c|c|c|c|}
\hline \multirow[t]{2}{*}{ PATH } & \multicolumn{3}{|c|}{$\begin{array}{l}\text { SHELTER } \\
\text { HEATING }\end{array}$} & \multicolumn{3}{|c|}{ DRYING } & \multicolumn{2}{|c|}{$\begin{array}{l}\text { PROCESS } \\
\text { HOT WATER }\end{array}$} & \multirow{2}{*}{$\begin{array}{c}\text { PROCESS } \\
\text { STEAM } \\
\text { SL } \\
\end{array}$} & \multicolumn{2}{|c|}{$\begin{array}{l}\text { COOLING/ } \\
\text { REFRIG- } \\
\text { ERATION }\end{array}$} \\
\hline & $\mathrm{HP}$ & HA & $\mathrm{HL}$ & DD & DA & DL & WL & WA & & $C P$ & CA \\
\hline IMPORTANCE NO. & & 7 & 7 & & 8 & 8 & 6 & 5 & & 7 & \\
\hline STATUS. & & & & & & & & & & & \\
\hline
\end{tabular}

\section{I-Hh. Mirror Surfaces}

I-Hh-1. Evaluate and/or develop cost effective mirror materials for use in concentrating collectors. Measure specular and diffuse reflection. Consider longevity problems associated with long periods of stagnation operation.

\begin{tabular}{|c|c|c|c|c|c|c|c|c|c|c|c|}
\hline & \multicolumn{3}{|c|}{$\begin{array}{c}\text { SERVICE } \\
\text { HOT WATER } \\
\text { PATH }\end{array}$} & \multicolumn{4}{|c|}{ SPACE HEATING } & \multicolumn{4}{c|}{ SPACE COOLING } \\
& W1 & W2 & H1 & H2 & H3 & H4 & C1 & C2 & C3 & C4 & C5 \\
\hline $\begin{array}{c}\text { IMPORTANCE } \\
\text { NO. }\end{array}$ & & & & & & & 10 & & & & \\
\hline STATUS & \multicolumn{3}{|l|}{ FEDERAL LAB } \\
\hline
\end{tabular}

\section{I-I. Test Procedures}

I-I-1. Develop new standard test procedures as required for proper evaluation of new or advanced collectors or collector applications. Consider, for example, reflector-augmented collectors, non-tracking concentrating collectors, tracking concentrating collectors, collectors utilizing phase change fluids, all day calorimetric tests, collector heating fluids with sub-ambient inlet temperatures, etc.

\begin{tabular}{|c|c|c|c|c|c|c|c|c|c|c|c|}
\hline \multirow[t]{2}{*}{ PATH } & \multicolumn{2}{|c|}{$\begin{array}{l}\text { SERVICE } \\
\text { HOT WATER }\end{array}$} & \multicolumn{4}{|c|}{ SPACE HEATING } & \multicolumn{5}{|c|}{ SPACE COOLING } \\
\hline & w1 & W2 & H1 & $\mathrm{H} 2$ & H3 & $\mathrm{H} 4$ & $\mathrm{C}_{1}$ & $\mathrm{C} 2$ & C3 & $\mathrm{C4}$ & $\mathrm{C5}$ \\
\hline $\begin{array}{c}\text { IMPORTANCE } \\
\text { NO. }\end{array}$ & 5 & 5 & 5 & 5 & 5 & 5 & 5 & 5 & 5 & & \\
\hline STATUS & $F$ & $A L$ & & & & & & & & & \\
\hline
\end{tabular}




\section{Thermal Energy Storage and Heat Exchange}

\section{OBJECTIVE}

The objective of the tasks in this category is to develop and disseminate the technology for a variety of types and capacities of low cost per unit stored energy thermal energy storage devices, and for highefficiency, low cost heat exchangers for transferring solar thermal energy into and out of these storage devices.

\section{EMPHASIS}

The thermal energy storage and heat exchange program emphasizes the following:

- Dissemination, through design and installation manuals, state-of-the-art technology reviews, and the preparation, standardization and documentation of computer models of information on current, state-of-the-art thermal energy storage and heat exchange equipment and techniques.

- Development of lower cost, higher durability, and reduced corrosion materials for heat exchangers, water tanks, and containers for phase-change and chemical thermal energy storage devices.

- Evaluation and development of innovative designs and construction methods for thermal energy storage and heat exchange devices which offer reduced manufacturing and installation costs and improved performance, in both new and retrofit solar heating and cooling applications.

- Evaluation and development of large capacity, long-term (up to seasonal) thermal energy storage systems.

- Development of low cost, high thermal energy storage density devices based on phase-change materials and reversible chemical reactions

- Establishment of standard test procedures and performance criteria for thermal energy storage and heat exchange devices.

- Development of thermal energy and heat exchange technologies for solar applications related to domestic hot water, solar heating and cooling of buildings, and industrial and agricultural heat processes. Liquid, air, and hybrid liquid-air solar energy systems are included.

\section{TASKS}

\section{II-A. System Studies Related to Storage}

II-A-1. Prepare a handbook on the various means used for collecting energy from a solar collector array and transferring it to a storage medium. Include methods of manifolding collectors and running the thermal collection medium to a central storage point, and methods of heat exchange with the thermal storage material. For each approach, identify materials and installation costs, required building space, and thermal loss characteristics. Describe means of combining or integrating collection and heat exchange processes to reduce costs.

\begin{tabular}{|c|c|c|c|c|c|c|c|c|c|c|c|}
\hline \multirow{2}{*}{ PATH } & \multicolumn{3}{|c|}{$\begin{array}{c}\text { SERVICE } \\
\text { HOT WATER }\end{array}$} & \multicolumn{4}{|c|}{ SPACE HEATING } & \multicolumn{5}{c|}{ SPACE COOLING } \\
& W1 & W2 & H1 & H2 & H3 & H4 & C1 & C2 & C3 & C4 & C5 \\
\hline $\begin{array}{c}\text { IMPORTANCE } \\
\text { NO. }\end{array}$ & 5 & 5 & 8 & & 6 & 8 & 8 & 8 & 8 & 8 & 6 \\
\hline STATUS & \multicolumn{3}{|c|}{ RENEWAL (UNSOLICITED) ; FEDERAL LAB } \\
\hline
\end{tabular}


il-A-2. Study the characteristics of normal building components, materials, and massive walls for passive thermal storage. Examine special media that could be used in buildings. Discuss how all these eleménts cou'd be used to smoothe out temperature variations in buildings.

\begin{tabular}{|c|c|c|c|c|c|c|c|c|c|c|c|}
\hline & \multicolumn{3}{|c|}{$\begin{array}{c}\text { SERVICE } \\
\text { POT WATER } \\
\end{array}$} & \multicolumn{4}{|c|}{ SPACE HEATING } & \multicolumn{4}{c|}{ SPACE COOLING } \\
& W1 & W2 & H1 & H2 & H3 & H4 & C1 & C2 & C3 & C4 & C5 \\
\hline $\begin{array}{c}\text { IMPORTANCE } \\
\text { NO. }\end{array}$ & & & 9 & 9 & & & & & & 7 & 7 \\
\hline STATUS & \multicolumn{3}{|c|}{ FEDERAL LAB } \\
\hline
\end{tabular}

II-A-3. Assemble and standardize existing computer models of various thermal energy. storage and heat transfer and exchange components and subsystems. Prepare a linkage, input-output code to permit utilization of different combinations of thermal energy storage, transport and exchange component and subsystem models in computer analyses of solar energy systems for a variety of applications and conditions, including whole building system analyses. Prepare fully detailed and validated models where possible. Also, develop simplified and streamlined codes validated against the more detailed codes. Prepare documentation and users manuals for all these codes, and distribute for general use.

\begin{tabular}{|c|c|c|c|c|c|c|c|c|c|c|c|}
\hline \multirow{2}{*}{ PATH } & \multicolumn{3}{|c|}{$\begin{array}{c}\text { SERVICE } \\
\text { HOT WATER }\end{array}$} & \multicolumn{4}{|c|}{ SPACE HEATING } & \multicolumn{4}{c|}{ SPACE COOLING } \\
& W1 & W2 & H1 & H2 & H3 & H4 & C1 & C2 & C3 & C4 & C5 \\
\hline $\begin{array}{c}\text { IMPORTANCE } \\
\text { NO. }\end{array}$ & 5 & 5 & 7 & 4 & 7 & 7 & 7 & 7 & 7 & 4 & 7 \\
\hline STATUS & \multicolumn{4}{|c|}{ FUNDED RFP/PRDA } \\
\hline
\end{tabular}

II-A-4. Develop a theoretical model for the characterization of congruent and incongruent phase-change storage media. This model should identify and characterize the phenomena of crystallization and heat transfer within the medium. It should also be useful for characterizing long-term effects such as precipitation and phase separation. The model should be developed to be useful for determining the effect of varying the heat-transfer rate and the effect of varying the geometry of storage containers that use phase-change material. The model should be validated (or calibrated) against experimental data on phase-change materials.

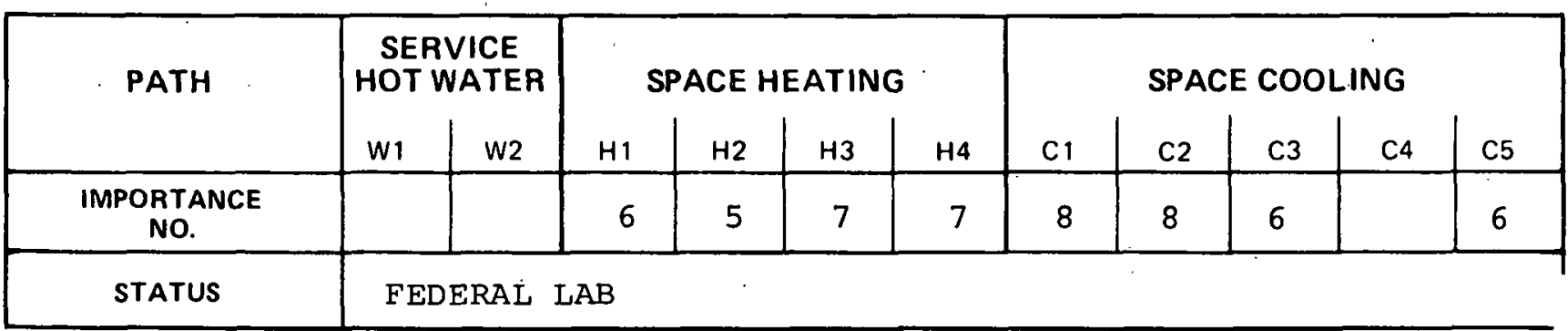


II-A-5. Asscmble a handbook of data on thermal storage media, insulation, containers and subsystem designs, including performance and cost factors. The handbook should be useful for architects and engineers well as manufacturers and installers of solar energy systems. It should incorporate information on thermal rage systems installed in buildings, problems with installing thermal storage systems, and theoretical and actual performance characteristics, and interactions with other solar energy system components.

\begin{tabular}{|c|c|c|c|c|c|c|c|c|c|c|c|}
\hline \multirow[t]{2}{*}{ PATH } & \multicolumn{2}{|c|}{$\begin{array}{l}\text { SERVICE } \\
\text { HOT WATER }\end{array}$} & \multicolumn{4}{|c|}{ SPACE HEATING } & \multicolumn{5}{|c|}{ SPACE COOLING } \\
\hline & w1 & w2 & $\mathrm{H} 1$ & $\mathrm{H} 2$ & $\mathrm{H3}$ & $\mathrm{H} 4$ & $\mathrm{C} 1$ & $\mathrm{C} 2$ & $\mathrm{C} 3$ & $\mathrm{C} 4$ & $\mathrm{C} 5$ \\
\hline $\begin{array}{c}\text { IMPORTANCE } \\
\text { NO. }\end{array}$ & 5 & 5 & 9 & 8 & 9 & 9 & 7 & 7 & 7 & 5 & 7 \\
\hline STATUS & & AL & & & & & & & & & \\
\hline
\end{tabular}

II-A-6. Study the economics and technical feasibility of seasonal storage, both for winter heating and summer cooling. Define the relevant subsystem parameters and climatic variables affecting cost effectiveness.

\begin{tabular}{|c|c|c|c|c|c|c|c|c|c|c|c|}
\hline \multirow{2}{*}{ PATH } & \multicolumn{3}{|c|}{$\begin{array}{c}\text { SERVICE } \\
\text { HOT WATER }\end{array}$} & \multicolumn{4}{|c|}{ SPACE HEATING } & \multicolumn{5}{c|}{ SPACE COOLING } \\
& W1 & W2 & H1 & H2 & H3 & H4 & C1 & C2 & C3 & C4 & C5 \\
\hline $\begin{array}{c}\text { IMPORTANCE } \\
\text { NO. }\end{array}$ & & & 7 & & 5 & 7 & & & & 5 & 7 \\
\hline STATUS & RENEWAL (UNSOLICITED) ; FEDEPAL .LAB \\
\hline
\end{tabular}

II-A-7. Prepare periodic updates of all handbooks on thermal storage subsystems.

\begin{tabular}{|c|c|c|c|c|c|c|c|c|c|c|c|}
\hline \multirow[t]{2}{*}{ PATH } & \multicolumn{2}{|c|}{$\begin{array}{l}\text { SERVICE } \\
\text { HOT WATER }\end{array}$} & \multicolumn{4}{|c|}{ SPACE HEATING } & \multicolumn{5}{|c|}{ SPACE COOLING } \\
\hline & w1 & w2 & $\mathrm{H} 1$ & $\mathrm{H} 2$ & H3 & $\mathrm{H} 4$ & $\mathrm{C}_{1}$ & $\mathrm{C} 2$ & $\mathrm{C} 3$ & $\mathrm{C} 4$ & $\mathrm{C5}$ \\
\hline $\begin{array}{c}\text { IMPORTANCE } \\
\text { NO. }\end{array}$ & 4 & 4 & 7 & 7 & 7 & 7 & 6 & 6 & 6 & 5 & 7 \\
\hline STATUS & $\mathrm{FE}$ & RAL & & . & & & & & & & \\
\hline
\end{tabular}


II-A-8. Conduct a system analysis of advanced thermal energy storage subsystems, emphasizing the physical requirements of various solar energy applications. Define the significant physical parameters, optimum parameter ranges, and boundary conditions for the subsystems when they function in each of sever important solar energy systems. Study input and output requirements for the subsystems (phase-chan' materials, reversible chemical reactions, etc.). The results of this task will be used in setting priorities for additional R\&D activities.

\begin{tabular}{|c|c|c|c|c|c|c|c|c|c|c|c|}
\hline \multirow[t]{2}{*}{ PATH } & \multicolumn{2}{|c|}{$\begin{array}{l}\text { SERVICE } \\
\text { HOT WATER }\end{array}$} & \multicolumn{4}{|c|}{ SPACE HEATING } & \multicolumn{5}{|c|}{ SPACE COOLING } \\
\hline & w1 & W2 & H1 & $\mathrm{H} 2$ & $\mathrm{H3}$ & $-\mathrm{H}_{4}$ & $\mathrm{C} 1$ & $\mathrm{C} 2$ & C3 & C4 & C5 \\
\hline $\begin{array}{c}\text { IMPORTANCE } \\
\text { NO. }\end{array}$ & & & 5 & 4 & 6 & 6 & 10 & 9 & 9 & , & 5 \\
\hline STATUS & \multicolumn{11}{|c|}{ FUNDED RFP/PRDA } \\
\hline
\end{tabular}

II-A-9. Investigate the problems associated with thermal storage in the temperature range from ${ }^{\prime \prime} 90-175^{\circ} \mathrm{C}$ $\left(195-350^{\circ} \mathrm{F}\right)$. Include the use of pressurized hot water, fluids such as paraffinic oils, solid materials such as rock, and phase-change materials. Consider the thermal performance characteristics and the cost characteristics of storage, including container and heat exchangers. Design, construct, and test storage subsystems in this temperature range.

\begin{tabular}{|c|c|c|c|c|c|c|c|c|c|c|c|}
\hline \multirow[t]{2}{*}{ PATH } & \multicolumn{2}{|c|}{$\begin{array}{l}\text { SERVICE } \\
\text { HOT WATER }\end{array}$} & \multicolumn{4}{|c|}{ SPACE HEATING } & \multicolumn{5}{|c|}{ SPACE COOLING } \\
\hline & $w_{1}$ & w2 & $\mathrm{HI}$ & $\mathrm{H} 2$ & H3 & $\mathrm{H} 4$ & $\mathrm{C}_{1}$ & $\mathrm{C} 2$ & C3 & $\mathrm{C4}$ & C5 \\
\hline $\begin{array}{l}\text { IMPORTANCE } \\
\text { NO. }\end{array}$ & & & & & & & 8 & 8 & 8 & & \\
\hline STATUS & FU & & & ; & $\Delta$ & (U) & LIC & D) & & & \\
\hline
\end{tabular}

II-A-10. Investigate and analyze the sensible heat storage of thermal energy at industrial steam temperatures $\left[100-350^{\circ} \mathrm{C}\left(212-660^{\circ} \mathrm{F}\right)\right]$. Examine safety problems. Design, construct, and test à subsystem in this temperature range.

\begin{tabular}{|c|c|c|c|c|c|c|c|c|c|c|c|}
\hline \multirow[t]{2}{*}{ PATH } & \multicolumn{3}{|c|}{$\begin{array}{l}\text { SHELTER } \\
\text { HEATING }\end{array}$} & \multicolumn{3}{|c|}{ DRYING } & \multicolumn{2}{|c|}{$\begin{array}{l}\text { PROCESS } \\
\text { HOT WATER }\end{array}$} & \multirow{2}{*}{$\begin{array}{c}\text { PROCESS } \\
\text { STEAM } \\
\text { SL }\end{array}$} & \multicolumn{2}{|c|}{$\begin{array}{l}\text { COOLING/ } \\
\text { REFRIG- } \\
\text { ERATION }\end{array}$} \\
\hline & HP & HA & $\mathrm{HL}$ & DD & $\mathrm{DA}$ & $\mathrm{DL}$ & $W L$ & WA & & $\mathrm{CP}$ & $\mathrm{CA}$ \\
\hline IMPORTANCE NO. & & & & & & & & & 8 & & \\
\hline STATUS & & & & & & & & & & & \\
\hline
\end{tabular}




\section{II-B. Piping, Ducting, Heat Exchangers}

II-B-1. Develop a fail-safe heat exchanger for use with a domestic hot water system. The heat exchanger ust not leak the primary heat transfer fluid into the domestic hot water system even when the exchanger inalfunctions. Emphasize cost effectiveness. Include investigation of building safety code approval requirements for such a device.

\begin{tabular}{|c|c|c|c|c|c|c|c|c|c|c|c|}
\hline \multirow[t]{2}{*}{ PATH } & \multicolumn{2}{|c|}{$\begin{array}{l}\text { SERVICE } \\
\text { HOT WATER }\end{array}$} & \multicolumn{4}{|c|}{ SPACE HEATING } & \multicolumn{5}{|c|}{ SPACE COOLING } \\
\hline & w1 & w2 & $\mathrm{H} 1$ & $\mathrm{H} 2$ & $\mathrm{H}_{3}$ & $\mathrm{H} 4$ & $\mathrm{Cr}$ & C2 & $\mathrm{c} 3$ & $\mathrm{C} 4$ & C5 \\
\hline $\begin{array}{l}\text { IMPORTANCE } \\
\text { NO. }\end{array}$ & 8 & & & & & & & . & & & \\
\hline STATUS & & & & & & & & & & & \\
\hline
\end{tabular}

II-B-2. Investigate the effects of flow passage size and system layout on the performance of low velocity, natural convection, or pumped air solar heating systems which utilize rock bed thermal storage and either air-heating collectors or direct heating of the space or structure. Analyze the stability of flow through the rock bed and the effect of turns, duct sizes, and obstructions on the overall air flow characteristics of the system.

\begin{tabular}{|c|c|c|c|c|c|c|c|c|c|c|c|}
\hline \multirow[t]{2}{*}{ PATH } & \multicolumn{2}{|c|}{$\begin{array}{c}\text { SERVICE } \\
\text { HOT WATER }\end{array}$} & \multicolumn{4}{|c|}{ SPACE HEATING } & \multicolumn{5}{|c|}{ SPACE COOLING } \\
\hline & w1 & w2 & $\mathrm{H} 1$ & $\mathrm{H} 2$ & $\mathrm{H} 3$ & $\mathrm{H} 4$ & $\mathrm{c1}$ & $\mathrm{C} 2$ & $\mathrm{C} 3$ & $\mathrm{C} 4$ & $\mathrm{C} 5$ \\
\hline $\begin{array}{l}\text { IMPORTANCE } \\
\text { NO. }\end{array}$ & & & 5 & 6 & 6 & & & & & & 5 \\
\hline STATUS & & & & & & & & & & & \\
\hline
\end{tabular}

II-B-3. Investigate the use of direct contact, liquid-to-liquid heat exchangers for use in liquid-heating collector/water tank storage solar energy systems. Study the effects of transfer of liquids from loop to loop through the heat exchanger. Design, construct, and test a prototype device.

\begin{tabular}{|c|c|c|c|c|c|c|c|c|c|c|c|}
\hline \multirow{2}{*}{ PATH } & \multicolumn{2}{|c|}{$\begin{array}{c}\text { SERVICE } \\
\text { HOT WATER }\end{array}$} & \multicolumn{4}{|c|}{ SPACE HEATING } & \multicolumn{5}{c|}{ SPACE COOLING } \\
& $\mathrm{W} 1$ & $\mathrm{~W} 2$ & $\mathrm{H} 1$ & $\mathrm{H} 2$ & $\mathrm{H} 3$ & $\mathrm{H} 4$ & $\mathrm{C} 1$ & $\mathrm{C} 2$ & $\mathrm{C} 3$ & $\mathrm{C} 4$ & $\mathrm{C} .5$ \\
\hline $\begin{array}{c}\text { IMPORTANCE } \\
\text { NO. }\end{array}$ & 2 & & 8 & & & 8 & 2 & 4 & 5 & & \\
\hline STATUS & \multicolumn{3}{|l|}{ RENEWAL (UNSOLICITED) } \\
\hline
\end{tabular}


II-B-4. Investigate the technical and economic feasibility of self-controlling, self-pumping circulation systems, such as heat pipes, for transferring heat between collector and storage system and between storage system and heat load. Identify the most promising heat-transfer methods and compare their cos effectiveness with that of standard pumping systems. .

\begin{tabular}{|c|c|c|c|c|c|c|c|c|c|c|c|}
\hline \multirow[t]{2}{*}{ PATH } & \multicolumn{2}{|c|}{$\begin{array}{l}\text { SERVICE } \\
\text { HOT WATER }\end{array}$} & \multicolumn{4}{|c|}{ SPACE HEATING } & \multicolumn{5}{|c|}{ SPACE COOLING. } \\
\hline & $w 1$ & w2 & H1 & $\mathrm{H} 2$ & - $\mathrm{H3}$ & H4 & $\mathrm{C}_{1}$ : & $\mathrm{C} 2$ & .63 & $\mathrm{C4}$ & $\mathrm{C5}$ \\
\hline $\begin{array}{c}\text { IMPORTANCE } \\
\text { NO. }\end{array}$ & 3 & 3 & 2 & 5 & 5 & 5 & 5 & 5 & 5 & 3 & \\
\hline STATUS & \multicolumn{2}{|c|}{ FUNDED } & $\mathrm{EP}$ & $\mathrm{DA}$ & & & & & & . & \\
\hline
\end{tabular}

II-B-5. Investigate and develop low cost, high temperature insulation suitable for use up to $205^{\circ} \mathrm{C}\left(400^{\circ} \mathrm{F}\right)$.

\begin{tabular}{|c|c|c|c|c|c|c|c|c|c|c|c|}
\hline \multirow[t]{2}{*}{ PATH } & \multicolumn{2}{|c|}{$\begin{array}{l}\text { SERVICE } \\
\text { HOT WATER }\end{array}$} & \multicolumn{4}{|c|}{ SPACE HEATING } & \multicolumn{5}{|c|}{ SPACE COOLING } \\
\hline & $w_{1}$ & w2 & $\mathrm{H1}$ & $\mathrm{H} 2$ & $\mathrm{H} 3$ & $\mathrm{H} 4$ & $\mathrm{C} 1$ & $\mathrm{C}_{2}$ & $\mathrm{C} 3$ & $\mathrm{C} 4$ & $\mathrm{C5}$ \\
\hline $\begin{array}{c}\text { IMPORTANCE } \\
\text { NO. }\end{array}$ & & & 5 & & & 3 & 8 & 8 & 6 & & 5 \\
\hline STATUS & & & & & & & & & & & \\
\hline
\end{tabular}

II-B-6. Develop, improve, and test cost-effective, large capacity, fail-safe heat exchangers and heat pipes, liquid-air and air-liquid. Consider use of polymeric materials.

\begin{tabular}{|c|c|c|c|c|c|c|c|c|c|c|c|}
\hline \multirow[t]{2}{*}{ PATH } & \multicolumn{3}{|c|}{$\begin{array}{l}\text { SHELTER } \\
\text { HEATING }\end{array}$} & \multicolumn{3}{|c|}{ DRYING } & \multicolumn{2}{|c|}{$\begin{array}{l}\text { PROCESS } \\
\text { HOT WATER }\end{array}$} & \multirow{2}{*}{$\begin{array}{c}\text { PROCESS } \\
\text { STEAM } \\
\text { SL } \\
\end{array}$} & \multicolumn{2}{|c|}{$\begin{array}{l}\text { COOLING/ } \\
\text { REFRIG- } \\
\text { ERATION }\end{array}$} \\
\hline & HP & HA & $\mathrm{HL}$ & DD & DA & DL & WL & WA & & $\mathrm{CP}$ & CA \\
\hline IMPORTANCE NO. & & & 6 & & & 6 & & 6 & & & 6 \\
\hline STATUS & & & (Ul & $I$ & D) & & & & & & \\
\hline
\end{tabular}


II-B-7. Develop, improve, and test low cost, large capacity, fail-safe, heat exchangers, liquid-liquid, in the mperature range from $20^{\circ}-120^{\circ} \mathrm{C}\left(68-250^{\circ} \mathrm{F}\right)$. Consider the use of polymeric materials and also of immissle liquids.

\begin{tabular}{|c|c|c|c|c|c|c|c|c|c|c|c|}
\hline \multirow[t]{2}{*}{ PATH } & \multicolumn{3}{|c|}{$\begin{array}{l}\text { SHELTER } \\
\text { HEATING }\end{array}$} & \multicolumn{3}{|c|}{ DRYING } & \multicolumn{2}{|c|}{$\begin{array}{l}\text { PROCESS } \\
\text { HOT WATER }\end{array}$} & \multirow{2}{*}{$\begin{array}{c}\text { PROCESS } \\
\text { STEAM } \\
\text { SL }\end{array}$} & \multicolumn{2}{|c|}{$\begin{array}{l}\text { COOLING/ } \\
\text { REFRIG- } \\
\text { ERATION }\end{array}$} \\
\hline & HP & HA & $\mathrm{HL}$ & DD & $\mathrm{DA}$ & $\mathrm{DL}$ & WL & WA & & $\mathrm{CP}$ & $\mathrm{CA}$ \\
\hline IMPORTANCE NO. & & & 2 & & & 4 & 6 & & & & 6 . \\
\hline STATUS & \multicolumn{11}{|c|}{ RENEWAL (UNSOLICITED) } \\
\hline
\end{tabular}

II-B-8. Develop low cost, well-insulated pipe to transport hot liquids $\left[50-100^{\circ} \mathrm{C}\left(122-212^{\circ} \mathrm{F}\right)\right]$ at moderate flow rates (100-1000 GPM) over distances of a mile or more without excessive heat loss. Consider combinations of common materials such as closed cell foams. Consider surface and buried construction techniques.

\begin{tabular}{|c|c|c|c|c|c|c|c|c|c|c|c|}
\hline \multirow[t]{2}{*}{ PATH } & \multicolumn{3}{|c|}{$\begin{array}{l}\text { SHELTER } \\
\text { HEATING }\end{array}$} & \multicolumn{3}{|c|}{ DRYING } & \multicolumn{2}{|c|}{$\begin{array}{l}\text { PROCESS } \\
\text { HOT WATER }\end{array}$} & \multirow{2}{*}{$\begin{array}{c}\text { PROCESS } \\
\text { STEAM } \\
\text { SL }\end{array}$} & \multicolumn{2}{|c|}{$\begin{array}{l}\text { COOLING/ } \\
\text { REFRIG- } \\
\text { ERATION }\end{array}$} \\
\hline & HP & HA & $\mathrm{HL}$ & DD & DA & DL &.$W L$ & WA & & $\mathrm{CP}$ & CA \\
\hline IMPORTANCE NO. & & . & & & & 7 & 7 & & & & \\
\hline STATUS & & & & & & & & & & & \\
\hline
\end{tabular}

II-B-9. Develop low cost, insulated ducting for transporting hot air over distances of a mile or more. Problems of manifolding a large collector array should be considered as well as the trunk line from collector field to end use.

\begin{tabular}{|c|c|c|c|c|c|c|c|c|c|c|c|}
\hline \multirow[t]{2}{*}{ PATH } & \multicolumn{3}{|c|}{$\begin{array}{l}\text { SHELTER } \\
\text { HEATING }\end{array}$} & \multicolumn{3}{|c|}{ DRYING } & \multicolumn{2}{|c|}{$\begin{array}{c}\text { PROCESS } \\
\text { HOT WATER }\end{array}$} & \multirow{2}{*}{$\begin{array}{c}\text { PROCESS } \\
\text { STEAM } \\
\text { SL } \\
\end{array}$} & \multicolumn{2}{|c|}{$\begin{array}{l}\text { COOLING/ } \\
\text { REFRIG- } \\
\text { ERATION }\end{array}$} \\
\hline & HP & HA & $\mathrm{HL}$ & DD & DA &.$D L$ & WL & WA & & $\mathrm{CP}$ & $\mathrm{CA}$ \\
\hline IMPORTANCE NO. & & & & & 9 & & & 7 & & & \\
\hline - STATUS & - & & & & & & & & & & \\
\hline
\end{tabular}


II-B-10. Investigate and develop low cost, high temperature insulation suitable for solar industrial process system, temperature up to $400^{\circ} \mathrm{C}\left(700^{\circ} \mathrm{F}\right)$. Consider the technical and economic advantage of vacuur jacketed piping.

\begin{tabular}{|c|c|c|c|c|c|c|c|c|c|c|c|}
\hline \multirow[t]{2}{*}{ PATH } & \multicolumn{3}{|c|}{$\begin{array}{l}\text { SHELTER } \\
\text { HEATING }\end{array}$} & \multicolumn{3}{|c|}{ DRYING } & \multicolumn{2}{|c|}{$\begin{array}{l}\text { PROCESS } \\
\text { HOT WATER }\end{array}$} & \multirow{2}{*}{$\begin{array}{c}\text { PROCESS } \\
\text { STEAM } \\
\text { SL } \\
\end{array}$} & \multicolumn{2}{|c|}{$\begin{array}{l}\text { COOLING/ } \\
\text { REFRIG- } \\
\text { ERATION }\end{array}$} \\
\hline & HP & HA & HL & DD & DA & $\mathrm{DL}$ & WL & WA & & $C P$ & CA \\
\hline IMPORTANCE NO. & & & & & & & & & 7 & & \\
\hline STATUS & & & & & & & & & & & \\
\hline
\end{tabular}

II-B-11. Develop techniques for using the ground as a heat source and sink. Investigate heat transfer rates to dry and wet earth and determine optimal configurations for heat extraction and injection systems under different soil and temperature conditions.

\begin{tabular}{|c|c|c|c|c|c|c|c|c|c|c|c|}
\hline \multirow[t]{2}{*}{ PATH } & \multicolumn{2}{|c|}{$\begin{array}{l}\text { SERVICE } \\
\text { HOT WATER }\end{array}$} & \multicolumn{4}{|c|}{ SPACE HEATING } & \multicolumn{5}{|c|}{ SPACE COOLING } \\
\hline & $w_{1}$ & w2 & H1 & $\mathrm{H} 2$ & H3 & $\mathrm{H} 4$ & C1 & $\mathrm{C} 2$ & C3 & $\mathrm{C} 4$ & $\mathrm{C} 5$ \\
\hline $\begin{array}{c}\text { IMPORTANCE } \\
\text { NO. }\end{array}$ & & & & & & & & & & 6 & 10 \\
\hline STATUS & & & & & & & & & & & \\
\hline
\end{tabular}

\section{II-C. Water Tank Storage}

II-C-1. Investigate the heat flow characteristics for water tank thermal storage in a passive solar heating system. Consider transfer of heat into storage during direct sun irradiation and transfer of heat out of storage into the structure. Investigate the effect of color, surface shape, and form on subsystem performance.

\begin{tabular}{|c|c|c|c|c|c|c|c|c|c|c|c|}
\hline \multirow[t]{2}{*}{ PATH } & \multicolumn{2}{|c|}{$\begin{array}{l}\text { SERVICE } \\
\text { HOT WATER }\end{array}$} & \multicolumn{4}{|c|}{ SPACE HEATING } & \multicolumn{5}{|c|}{ SPACE COOLING } \\
\hline & w1 & w2 & $\mathrm{HI}$ & $\mathrm{H} 2$ & $\mathrm{H3}$ & $\mathrm{H}_{4}$ & C1 & $\mathrm{C} 2$ & C3 & $\mathrm{C4}$ & $\mathrm{C5}$ \\
\hline $\begin{array}{c}\text { IMPORTANCE } \\
\text { NO. }\end{array}$ & & & 8 & 8 & & & & & & 8 & 8 \\
\hline STATUS & FU & & $/ F$ & i; & $\mathrm{DE}$ & LA & & & & & \\
\hline
\end{tabular}


II-C-2. Write a handbook for water tank thermal storage. This handbook should identify the ways in which iter has been. used for thermal storage, various means of storing water and insulating the tanks, types of ier for tanks, and the corrosion characteristics of the various approaches. The handbook should also identity the basic cost characteristics of each approach.

\begin{tabular}{|c|c|c|c|c|c|c|c|c|c|c|c|}
\hline \multirow[t]{2}{*}{ PATH } & \multicolumn{2}{|c|}{$\begin{array}{l}\text { SERVICE } \\
\text { HOT WATER }\end{array}$} & \multicolumn{4}{|c|}{ SPACE HEATING } & \multicolumn{5}{|c|}{ SPACE COOLING } \\
\hline & w1 & w2 & $\mathrm{H1}$ & $\mathrm{H} 2$ & H3 & $\mathrm{H} 4$ & $\mathrm{C} 1$ & $\mathrm{C} 2$ & $\mathrm{C} 3$ & $\mathrm{C} 4$ & $\mathrm{C5}$ \\
\hline $\begin{array}{c}\text { IMPORTANCE' } \\
\text { NO. }\end{array}$ & 5 & 3 & 6 & 6 & & 10 & 4 & 4 & 4 & 4 & 4 \\
\hline STATUS & FE & $A L$ & & & & & & & & & \\
\hline
\end{tabular}

II-C-3. Investigate the use of multiple tanks to allow thermal storage at a number of temperature levels. Determine whether this approach is cost beneficial in various system applications.

\begin{tabular}{|c|c|c|c|c|c|c|c|c|c|c|c|}
\hline \multirow[t]{2}{*}{ PATH } & \multicolumn{2}{|c|}{$\begin{array}{l}\text { SERVICE } \\
\text { HOT WATER }\end{array}$} & \multicolumn{4}{|c|}{ SPACE HEATING } & \multicolumn{5}{|c|}{ SPACE COOLING } \\
\hline & W1 & w2 & $\mathrm{H} 1$ & $\mathrm{H} 2$ & $\mathrm{H3}$ & $\mathrm{H} 4$ & $\mathrm{Cl}^{\circ}$ & $\mathrm{C} 2$ & $\mathrm{C3}$ & $\mathrm{C} 4$ & $\mathrm{C} 5$ \\
\hline $\begin{array}{c}\text { IMPORTANCE } \\
\text { NO. }\end{array}$ & 7 & 7 & 8 & 5 & & 8 & 5 & 5 . & 5 & & 7 \\
\hline STATUS & & & & & & & & & & & \\
\hline
\end{tabular}

II-C-4. Investigate the use of unconventional materials, such as light-weight concrete composite structure, for a water thermal storage tank. The material used should be waterproof and low in thermal conductivity so as to be insulating. It might also be capable of service as a structural element of a building. Design, construct, and test storage subsystems utilizing these materials.

\begin{tabular}{|c|c|c|c|c|c|c|c|c|c|c|c|}
\hline \multirow[t]{2}{*}{ PATH } & \multicolumn{2}{|c|}{$\begin{array}{l}\text { SERVICE } \\
\text { HOT WATER }\end{array}$} & \multicolumn{4}{|c|}{ SPACE HEATING } & \multicolumn{5}{|c|}{ SPACE COOLING } \\
\hline & w1 & w2 & H1 & $\mathrm{H} 2$ & H3 & $\mathrm{H} 4$ & C1 & $\mathrm{C} 2$ & c3 & $\mathrm{C} 4$ & C5 \\
\hline $\begin{array}{c}\text { IMPORTANCE } \\
\text { NO. } \\
\end{array}$ & 5 & 5 & 5 & 5 & & 8 & 5 & 5 & 5 & 3 & 5 \\
\hline STATUS & FL & & סי & & זירה & 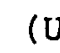 & LI & $\mathrm{ED}$ & & & \\
\hline
\end{tabular}


II-C-5. Identify the cost and performance characteristics of water tanks which have the heat exchanger in the tank wall. Investigate tanks with double walls along the vertical sides and tanks with separate heat $\cdots$ change panels strapped on the outside. In considering cost characteristics, allow for the reduced amount equipment required and for the extra thermal tank manufacturing cost.

\begin{tabular}{|c|c|c|c|c|c|c|c|c|c|c|c|}
\hline \multirow[t]{2}{*}{ PATH } & \multicolumn{2}{|c|}{$\begin{array}{l}\text { SERVICE } \\
\text { HOT WATER }\end{array}$} & \multicolumn{4}{|c|}{ SPACE HEATING } & \multicolumn{5}{|c|}{ SPACE COOLING } \\
\hline & wi & w2 & $\mathrm{HI}$ & $\mathrm{H} 2$ & H3 & $\mathrm{H} 4$ & $\mathrm{C} 1$ & $\mathrm{C2}$ & C3 & $\mathrm{C4}$ & $\mathrm{C5}$ \\
\hline $\begin{array}{c}\text { IMPORTANCE } \\
\text { NO. }\end{array}$ & 6 & 3 & 5 & & & 5 & 5 & 5 & 3 & l & 5 \\
\hline STATUS & RE & AL & $V_{N}$ & 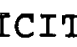 & & & & & & & \\
\hline
\end{tabular}

II-C-6. Investigate the effectiveness of temperature stratification in water storage tanks. This study should be a combination of a system analysis (to determine the effectiveness of stratification in a given application) and an analysis of the means by which stratification can be achieved. Identify theoretical models suitable for predicting the degree of stratification that can be achieved and validate the models. Examine the effects of the placement of heat exchangers and auxiliary heaters on producing and maintaining stratification. Identify the cost characteristics of the various means of achieving stratification.

\begin{tabular}{|c|c|c|c|c|c|c|c|c|c|c|c|}
\hline \multirow[t]{2}{*}{ PATH } & \multicolumn{2}{|c|}{$\begin{array}{l}\text { SERVICE } \\
\text { HOT WATER }\end{array}$} & \multicolumn{4}{|c|}{ SPACE HEATING } & \multicolumn{5}{|c|}{ SPACE COOLING } \\
\hline & w1 & w2 & $H_{1}$ & $\mathrm{H} 2$ & H3 & $\mathrm{H} 4$ & $\mathrm{C}_{1}$ & $\mathrm{C} 2$ & C3. & $\mathrm{C} 4$ & $\hat{\mathrm{C} 5}$ \\
\hline $\begin{array}{l}\text { IMPORTANCE } \\
\text { NO. }\end{array}$ & 8 & 8 & 8 & 5 & & 8 & 8 & 8 & 4 & & 8 \\
\hline STATUS & & & & & I & (U) & $\mathrm{LI}$ & (ED) & EI & L 1 & \\
\hline
\end{tabular}

II-C-7. Investigate the technical and economic feasibility of a hybrid storage system in which a water tank is surrounded by a supporting rock bed or otherwise linked with a second thermal storage media. Identify the heat exchange and thermal storage characteristics of the system. Develop a suitable mathematical model for the hybrid storage systems and validate that model with test data.

\begin{tabular}{|c|c|c|c|c|c|c|c|c|c|c|c|}
\hline \multirow{2}{*}{ PATH } & \multicolumn{3}{|c|}{$\begin{array}{c}\text { SERVICE } \\
\text { HOT WATER } \\
\text { W1 }\end{array}$} & \multicolumn{4}{|c|}{ SPACE HEATING } & \multicolumn{4}{c|}{ SPACE COOLING } \\
& W1 & W2 & H1 & H2 & H3 & H4 & C1 & C2 & C3 & C4 & C5 \\
\hline $\begin{array}{c}\text { IMPORTANCE } \\
\text { NO. }\end{array}$ & 5 & 6 & 5 & & 6 & 5 & & & 4 & & 4 \\
\hline STATUS & \multicolumn{3}{|l|}{ FUNDED RFP/PRDA } \\
\hline
\end{tabular}


II-C-8. Investigate the use of unconventional fabrication methods, both in factory and on site, for the construction of water tank thermal storage units. Include alternate-material-layer buildup, foam spray techiques, incorporation of the tank as a structural element, and retrofit potential. Design, construct, and test torage subsystems utilizing these methods.

\begin{tabular}{|c|c|c|c|c|c|c|c|c|c|c|c|}
\hline \multirow{2}{*}{ PATH } & \multicolumn{2}{|c|}{$\begin{array}{l}\text { SERVICE } \\
\text { HOT WATER }\end{array}$} & \multicolumn{4}{|c|}{ SPACE HEATING } & \multicolumn{5}{|c|}{ SPACE COOLING } \\
\hline & w1 & W2 & $\mathrm{HI}$ & $\mathrm{H} 2$ & H3 & $\mathrm{H} 4$ & $\mathrm{C} 1$ & $\mathrm{C} 2$ & C3 & $\mathrm{C} 4$ & $\mathrm{C} 5$ \\
\hline $\begin{array}{c}\text { IMPORTANCE } \\
\text { NO. }\end{array}$ & 8 & 5 & 7 & 3 & 5 & 8 & 6 & 5 & 5 & 3 & 6 \\
\hline STATUS & FUI & & $\boldsymbol{I}$ & & & ron & +4 & ) & & & \\
\hline
\end{tabular}

II-C-9. Investigate the design requirements, material selection, and cost factors involved in the retrofit of water tank thermal storage in existing buildings, including single and multiple residences and commercial buildings.

\begin{tabular}{|c|c|c|c|c|c|c|c|c|c|c|c|}
\hline \multirow{2}{*}{$\begin{array}{c}\text { PATH } \\
. \\
\end{array}$} & \multicolumn{2}{|c|}{$\begin{array}{l}\text { SERVICE } \\
\text { HOT WATER }\end{array}$} & \multicolumn{4}{|c|}{ SPACE HEATING } & \multicolumn{5}{|c|}{ SPACE COOLING } \\
\hline & w1 & W2 & $\mathrm{HI}$ & $\mathrm{H} 2$ & H3 & $\mathrm{H} 4$ & $\mathrm{Cl}$ & $\mathrm{C}_{2}$ & $\mathrm{C} 3$ & $\mathrm{C} 4$ & $\mathrm{C5}$ \\
\hline $\begin{array}{l}\text { IMPORTANCE } \\
\text { NO. }\end{array}$ & 10 & 10 & 8 & 9 & 5 & 8 & 5 & 4 & 8 & & 7 \\
\hline STATUS & FUND & & & & 7 & (U) & $L I$ & D) & & & \\
\hline
\end{tabular}

11-C-10. Investigate all possible methods for combating aqueous corrosion of the various materials used for water tanks and heat exchangers. Include chemical additives, electrolytic processes, and liners.

\begin{tabular}{|c|c|c|c|c|c|c|c|c|c|c|c|}
\hline \multirow[t]{2}{*}{ PATH } & \multicolumn{2}{|c|}{$\begin{array}{l}\text { SERVICE } \\
\text { HOT WATER }\end{array}$} & \multicolumn{4}{|c|}{ SPACE HEATING } & \multicolumn{5}{|c|}{ SPACE COOLING } \\
\hline & W1 & $w 2$ & $\mathrm{H} 1$ & $\mathrm{H} 2$ & $\mathrm{H3}$ & $\mathrm{H} 4$ & C1 & $\mathrm{C2}$ & $\mathrm{C} 3$ & $\mathrm{C} 4$ & $\mathrm{C5}$ \\
\hline $\begin{array}{l}\text { IMPORTANCE } \\
\text { NO. }\end{array}$ & 10 & 10 & $8^{\circ}$ & 8 & 3 & 8 & 5 & 6 & 3 & & 7 \\
\hline STATUS & & $\mathrm{AL}$ & $\mathrm{N}$ & & & & & & & & \\
\hline
\end{tabular}


II-C-11. Design, construct, and test water tanks with increased temperature stratification. Include the use of fixed or movable baffles, water flow controls, tank shape or orientation, etc. The cost effectiveness of each design should be emphasized. This should be based on results of Task II-C-6.

\begin{tabular}{|c|c|c|c|c|c|c|c|c|c|c|c|}
\hline \multirow[t]{2}{*}{ PATH } & \multicolumn{2}{|c|}{$\begin{array}{c}\text { SERVICE } \\
\text { HOT WATER }\end{array}$} & \multicolumn{4}{|c|}{ SPACE HEATING } & \multicolumn{5}{|c|}{ SPACE COOLING } \\
\hline & w1 & w2 & $\mathrm{H} 1$ & $\mathrm{H} 2$ & H3 & $\mathrm{H} 4$ & C1 & $\mathrm{C2}$ & C3 & $\mathrm{c} 4$ & $\mathrm{C} 5$ \\
\hline $\begin{array}{c}\text { IMPORTANCE } \\
\text { NO. }\end{array}$ & 8 & 8 & 8 & 5 & & 8 & 8 & 8 & 4 & & 8 \\
\hline STATUS & & & & & & & & & & & \\
\hline
\end{tabular}

II-C-12. Design, construct, and test seasonal storage solar energy systems utilizing water as the storage medium. Evaluate the relative cost effectiveness versus shorter term storage systems.

\begin{tabular}{|c|c|c|c|c|c|c|c|c|c|c|c|}
\hline \multirow[t]{2}{*}{ PATH } & \multicolumn{2}{|c|}{$\begin{array}{l}\text { SERVICE } \\
\text { HOT WATER }\end{array}$} & \multicolumn{4}{|c|}{ SPACE HEATING } & \multicolumn{5}{|c|}{ SPACE COOLING } \\
\hline & w1 & w2 & $\mathrm{H1}$ & $\mathrm{H} 2$ & H3 & $\mathrm{H} 4$ & $\mathrm{C} 1$ & $\mathrm{C} 2$ & $\mathrm{C} 3$ & $\mathrm{C} 4$ & $\mathrm{C} 5$ \\
\hline $\begin{array}{l}\text { IMPORTANCE } \\
\text { NO. }\end{array}$ & & & 8 & & 5 & 7 & & & & 2 & 8 \\
\hline STATUS & & AL & JNS & $C I$ & & & & & & & \\
\hline
\end{tabular}

II-C-13. Investigate technical and economic feasibility of a seasonal storage system designed for an agricultural process needing large amounts of heat for short periods (1-2 months) to use small high temperature collectors and collect all year - discharge only at process time.

\begin{tabular}{|c|c|c|c|c|c|c|c|c|c|c|c|}
\hline \multirow[t]{2}{*}{ PATH } & \multicolumn{3}{|c|}{$\begin{array}{l}\text { SHELTER } \\
\text { HEATING }\end{array}$} & \multicolumn{3}{|c|}{ DRYIING } & \multicolumn{2}{|c|}{$\begin{array}{l}\text { PROCESS } \\
\text { HOT WATER }\end{array}$} & \multirow{2}{*}{$\begin{array}{c}\text { PROCESS } \\
\text { STEAM } \\
\text { SL }\end{array}$} & \multicolumn{2}{|c|}{$\begin{array}{l}\text { COOLING } \\
\text { REFRIG- } \\
\text { ERATION }\end{array}$} \\
\hline & $\mathrm{HP}$ & HA & $\mathrm{HL}$ & $\mathrm{DO}$ & $D A$ & $\mathrm{DL}$ & $W L$ & WA & & $\mathrm{CP}$ & $\mathrm{CA}$ \\
\hline IMPORTANCE NO. & & & & 3 & 3 & 3 & 3 & 3 & & & \\
\hline STATUS & & & & & & & & & & & \\
\hline
\end{tabular}


II-C-14. Investigate and develop water-ice storage tanks system for use with heat pump.

\begin{tabular}{|c|c|c|c|c|c|c|c|c|c|c|c|}
\hline \multirow[t]{2}{*}{ PATH. } & \multicolumn{2}{|c|}{$\begin{array}{l}\text { SERVICE } \\
\text { HOT WATER }\end{array}$} & \multicolumn{4}{|c|}{ SPACE HEATING } & \multicolumn{5}{|c|}{ SPACE COOLING } \\
\hline & w1 & w2 & $H 1$ & $\mathrm{H} 2$ & $\mathrm{H3}$ & $\mathrm{H} 4$ & $\mathrm{Cl}$ & $\mathrm{C} 2$ & $\mathrm{C} 3$ & $\mathrm{C}_{4}$ & $\mathrm{C5}$ \\
\hline $\begin{array}{c}\text { IMPORTANCE } \\
\text { NO. }\end{array}$ & & & 5 & & & & & & & & 5 \\
\hline STATUS & & & & & & & & & & & \\
\hline
\end{tabular}

\begin{tabular}{|c|c|c|c|c|c|c|c|c|c|c|c|}
\hline \multirow[t]{2}{*}{ PATH } & \multicolumn{3}{|c|}{$\begin{array}{l}\text { SHELTER } \\
\text { HEATING }\end{array}$} & \multicolumn{3}{|c|}{ DRYING } & \multicolumn{2}{|c|}{$\begin{array}{l}\text { PROCESS } \\
\text { HOT WATER }\end{array}$} & \multirow{2}{*}{$\begin{array}{c}\text { PROCESS } \\
\text { STEAM } \\
\text { SL }\end{array}$} & \multicolumn{2}{|c|}{$\begin{array}{l}\text { COOLING/ } \\
\text { REFRIG- } \\
\text { ERATION }\end{array}$} \\
\hline & $\mathrm{HP}$ & HA & $H L$ & $\mathrm{DD}$ & DA & $D L$ & WL & WA & & $\mathrm{CP}$ & $\mathrm{CA}$ \\
\hline IMPORTANCE NO. & & & & & 8 & 8 & 6 & 6 & & 4 & 5 \\
\hline STATUS & & & & & & & & & & & \\
\hline
\end{tabular}

II-C-15. Investigate and develop thermal energy storage subsystems with improved efficiency in design and placement of auxiliary heat source, specifically tailored to solar heated hot water system.

\begin{tabular}{|c|c|c|c|c|c|c|c|c|c|c|c|}
\hline \multirow[t]{2}{*}{ PATH } & \multicolumn{2}{|c|}{$\begin{array}{l}\text { SERVICE } \\
\text { HOT WATER }\end{array}$} & \multicolumn{4}{|c|}{ SPACE HEATING } & \multicolumn{5}{|c|}{ SPACE COOLING } \\
\hline & W1 & W2 & H1 & $\mathrm{H} 2$ & $\mathrm{H3}$ & $\mathrm{H} 4$ & $\mathrm{C1}_{1}$ & $\mathrm{C} 2$ & c3 & $\mathrm{C} 4$ & $\mathrm{C} 5$ \\
\hline $\begin{array}{c}\text { IMPORTANCE } \\
\text { NO. }\end{array}$ & 8 & 6 & & & & & & & & & \\
\hline STATUS & |. & & & & & & & & & & \\
\hline
\end{tabular}

\begin{tabular}{|c|c|c|c|c|c|c|c|c|c|c|c|}
\hline \multirow[t]{2}{*}{ PATH } & \multicolumn{3}{|c|}{$\begin{array}{l}\text { SHELTER } \\
\text { HEATING }\end{array}$} & \multicolumn{3}{|c|}{ DRYING } & \multicolumn{2}{|c|}{$\begin{array}{l}\text { PROCESS } \\
\text { HOT WATER }\end{array}$} & \multirow{2}{*}{$\begin{array}{c}\text { PROCESS } \\
\text { STEAM } \\
\text { SL }\end{array}$} & \multicolumn{2}{|c|}{$\begin{array}{l}\text { COOLING/ } \\
\text { REFRIG. } \\
\text { ERATION }\end{array}$} \\
\hline & HP & $\mathrm{HA}$ & $\mathrm{HL}$ & $\mathrm{DD}$ & $\mathrm{DA}$ & $\mathrm{DL}$ & WL & WA & & $\mathrm{CP}$ & $\mathrm{CA}$ \\
\hline IMPORTANCE NO. & & & & & & & 6 & 6 & & & \\
\hline STATIUS & & & & & & & & & & & \\
\hline
\end{tabular}


II-C-16. Investigate and evaluate the technical and economic feasibility of thermal storage subsystems which have multiple utility, such as a solar heated swimming pool combined with a heat pump space heating system.

\begin{tabular}{|c|c|c|c|c|c|c|c|c|c|c|c|}
\hline \multirow[t]{2}{*}{ PATH } & \multicolumn{2}{|c|}{$\begin{array}{l}\text { SERVICE } \\
\text { HOT WATER }\end{array}$} & \multicolumn{4}{|c|}{ SPACE HEATING } & \multicolumn{5}{|c|}{ SPACE COOLING } \\
\hline & W1 & w2 & $\mathrm{HI}$ & $\mathrm{H} 2$ & $\mathrm{H} 3$ & $\mathrm{H} 4$ & $\mathrm{C} 1$ & $\mathrm{C} 2$ & $\mathrm{C} 3$ & $\mathrm{C} 4$ & $\mathrm{C} 5$ \\
\hline $\begin{array}{l}\text { IMPORTANCE } \\
\text { NO. }\end{array}$ & 5 & & 5 & & & 5 & & & & & 5 \\
\hline
\end{tabular}

II-C-17. Investigate the technical and economic feasibility and develop thermal energy storage subsystems based on small scale, plastic encapsulated water, for solar air-heated collector systems.

\begin{tabular}{|c|c|c|c|c|c|c|c|c|c|c|c|}
\hline \multirow[t]{2}{*}{ PATH } & \multicolumn{2}{|c|}{$\begin{array}{l}\text { SERVICE } \\
\text { HOT WATER }\end{array}$} & \multicolumn{4}{|c|}{ SPACE HEATING } & \multicolumn{5}{|c|}{ SPACE COOLING } \\
\hline & W1 & W2 & $\mathrm{H} 1$ & $\mathrm{H} 2$ & $\mathrm{H3}$ & $\mathrm{H} 4$ & $\mathrm{C} 1$ & $\mathrm{C2}$ & $\mathrm{C} 3$ & $\mathrm{C4}$ & $\mathrm{C5}$ \\
\hline $\begin{array}{c}\text { IMPORTANCE } \\
\text { NO. }\end{array}$ & & 3 & 3 & & 4 & & & & & & \\
\hline STATUS & & & & & 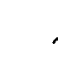 & & & & & & \\
\hline
\end{tabular}

\begin{tabular}{|c|c|c|c|c|c|c|c|c|c|c|c|}
\hline \multirow{2}{*}{$\begin{array}{l}\text { PATH } \\
. \\
\end{array}$} & \multicolumn{3}{|c|}{$\begin{array}{l}\text { SHELTER } \\
\text { HEATING. }\end{array}$} & \multicolumn{3}{|c|}{ DRY்ING } & \multicolumn{2}{|c|}{$\begin{array}{l}\text { PROCESS } \\
\text { HOT WATER }\end{array}$} & \multirow{2}{*}{$\begin{array}{c}\text { PROCESS } \\
\text { STEAM } \\
\text { SL } \\
\end{array}$} & \multicolumn{2}{|c|}{$\begin{array}{l}\text { COOLING/ } \\
\text { REFRIG. } \\
\text { ERATION }\end{array}$} \\
\hline & HP & $\mathrm{HA}$ & $\mathrm{HL}$ & DD & $\mathrm{DA}$ & $D L$ & $\dot{W L}$ & WA & & $\mathrm{CP}$ & $\mathrm{CA}$ \\
\hline IMPORTANCE NO. & & 3 & & & & & & & & & \\
\hline - status & & & & & & & & & & & \\
\hline
\end{tabular}




\section{II-D. Rock Bed Storage}

1-D-1. Investigate the technical and economic feasibility of using rock beds for cooling applications, such is storing cool from night air for daytime applications, or cooling by evaporative chillers during the day or night. The stored coolness can then be used to cool the building. Study problems caused by water condensation in the rock bed, and investigate means of counteracting them.

\begin{tabular}{|c|c|c|c|c|c|c|c|c|c|c|c|}
\hline \multirow[t]{2}{*}{ PATH } & \multicolumn{2}{|c|}{$\begin{array}{l}\text { SERVICE } \\
\text { HOT WATER }\end{array}$} & \multicolumn{4}{|c|}{ SPACE HEATING } & \multicolumn{5}{|c|}{ SPACE COOLING } \\
\hline & w1 & w2 & $\mathrm{Hi}$ & $\mathrm{H} 2$ & $\mathrm{H} 3$ & $\mathrm{H} 4$ & $\mathrm{C} 1$ & C2 & c3 & $\mathrm{C} 4$ & C5 \\
\hline $\begin{array}{l}\text { IMPORTANCE } \\
\text { NO. }\end{array}$ & & & 6 & 6 & & & & & & 9 & 7 \\
\hline STATUS & \multicolumn{11}{|l|}{ FT } \\
\hline
\end{tabular}

II-D-2. Promote an exchange of information with CSIRO of Australia on the performance of rock bed thermal storage systems (commonly called rock bed regenerators in Australia).

\begin{tabular}{|c|c|c|c|c|c|c|c|c|c|c|c|}
\hline \multirow[t]{2}{*}{ PATH } & \multicolumn{2}{|c|}{$\begin{array}{l}\text { SERVICE } \\
\text { HOT WATER }\end{array}$} & \multicolumn{4}{|c|}{ SPACE HEATING } & \multicolumn{5}{|c|}{ SPACE COOLING } \\
\hline & W1 & W2 & $\mathrm{H} 1$ & $\mathrm{H} 2$. & $\mathrm{H3}$ & $\mathrm{H} 4$ & $\mathrm{C} 1$ & $\mathrm{C} 2$ & C3 & $\mathrm{C} 4$ & C! \\
\hline $\begin{array}{l}\text { IMPORTANCE } \\
\text { NO. }\end{array}$ & & & 3 & 3 & 6 & & & & 10 & 7 & 3 \\
\hline STATUS & & c & & & & & & & & & \\
\hline
\end{tabular}

II-D-3. Prepare a handbook on rock bed or gravel bed thermal storage systems. Identify the basic characteristics of rocks commonly used in such beds, including their thermal heat capacity, density, and packing fraction. Use design charts to indicate the effects of bed length, air flow rate, rock size, distribution of rock size, etc: on the heat transfer and pressure drop characteristics of the rock bed. Discuss methods of constructing and supporting rock beds, methods of installing plena at the ends of the beds, the availability of various kinds of rock, rock costs, problems caused by dirt in rock, and areas of the system where problems are likely to occur. Include several examples of typical rock bed installations, and effects of moisture and algae.

\begin{tabular}{|c|c|c|c|c|c|c|c|c|c|c|c|}
\hline \multirow[t]{2}{*}{ PATH } & \multicolumn{2}{|c|}{$\begin{array}{l}\text { SERVICE } \\
\text { HOT WATER }\end{array}$} & \multicolumn{4}{|c|}{ SPACE HEATING } & \multicolumn{5}{|c|}{ SPACE COOLING } \\
\hline & W1 & w2 & $\mathrm{H} 1$ & $\mathrm{H} 2$ & $\mathrm{H} 3$ & $\mathrm{H} 4$ & $\mathrm{C} 1$ & $\mathrm{C} 2$ & C3 & $\mathrm{C} 4$ & CE \\
\hline $\begin{array}{c}\text { IMPORTANCE } \\
\text { NO. }\end{array}$ & & & 6 & 5 & 8 & & & & 6 & 7 & 5 \\
\hline STATUS & \multicolumn{11}{|c|}{ FEDERAL LAB } \\
\hline
\end{tabular}


II-D-4. Investigate the technical and economic feasibility of incorporating the evaporator portion of a heat pump into a rock bin thermal storage device. In computing costs, include the cost of the piping that may be necessary and the heat transfer rates to the piping, both with forced air flow and without air flow. Study th overall problems of building such a subsystem and the optimum performance configuration.

\begin{tabular}{|c|c|c|c|c|c|c|c|c|c|c|c|}
\hline & \multicolumn{2}{|c|}{$\begin{array}{c}\text { SERVICE } \\
\text { HOT WATH }\end{array}$} & \multicolumn{3}{|c|}{ SPACE HEATING } & \multicolumn{5}{c|}{ SPACE COOLING } \\
& W1 & W2 & H1 & H2 & H3 & H4 & C1 & C2 & C3 & C4 & C5 \\
\hline $\begin{array}{c}\text { IMPORTANCE } \\
\text { NO. }\end{array}$ & & & 6 & & & 5 & 5 & 5 & 4 & & 5 \\
\hline STATUS & \multicolumn{2}{|c|}{ FUNDED } & RFP/PRDA & \\
\hline
\end{tabular}

II-D-5. Investigate the technical and economic feasibility of utilizing rock beds for storing heat above $205^{\circ} \mathrm{C}\left(400^{\circ} \mathrm{F}\right)$.

\begin{tabular}{|c|c|c|c|c|c|c|c|c|c|c|c|}
\hline \multirow[t]{2}{*}{ PATH } & \multicolumn{2}{|c|}{$\begin{array}{l}\text { SERVICE } \\
\text { HOT WATER }\end{array}$} & \multicolumn{4}{|c|}{ SPACE HEATING } & \multicolumn{5}{|c|}{ SPACE COOLING } \\
\hline & W1 & w2 & $H 1$ & $\mathrm{H} 2$ & $\mathrm{H3}$ & $\mathrm{H} 4$ & $\mathrm{C} 1$ & $\mathrm{C} 2$ & $\mathrm{C} 3$ & $\mathrm{C4}$ & $\mathrm{C} 5$ \\
\hline $\begin{array}{c}\text { IMPORTANCE } \\
\text { NO. }\end{array}$ & & . & & & & & 5 & 4 & 4 & & . \\
\hline STATUS & & AL & NS & I & & & & & & & - \\
\hline
\end{tabular}

II-D-6. Investigate and develop low cost "synthetic rocks" with higher thermal conductivity and storage capacity than natural rocks, and evaluate use of natural materials (slag clinkers, etc.) other than rocks for "rock beds" (solid cheap industrial waste products).

\begin{tabular}{|c|c|c|c|c|c|c|c|c|c|c|c|}
\hline \multirow[t]{2}{*}{ PATH } & \multicolumn{2}{|c|}{$\begin{array}{l}\text { SERVICE } \\
\text { HOT WATER }\end{array}$} & \multicolumn{4}{|c|}{ SPACE HEATING } & \multicolumn{5}{|c|}{ SPACE COOLING } \\
\hline & - w1 & w2 & $H 1$ & $\mathrm{H} 2$ & H3 & $\mathrm{H} 4$ & $\mathrm{C} 1$ & $\mathrm{C} 2$ & C3 & $\mathrm{C} 4$ & $\mathrm{C5}$ \\
\hline $\begin{array}{c}\text { IMPORTANCE } \\
\text { NO. }\end{array}$ & & 5 & & 3 & 5 & & & & 5 & 5 & \\
\hline STATUS & & & & & & & & & & & \\
\hline
\end{tabular}




\begin{tabular}{|c|c|c|c|c|c|c|c|c|c|c|c|}
\hline \multirow{2}{*}{, PATH } & \multicolumn{3}{|c|}{$\begin{array}{l}\text { SHELTER } \\
\text { HEATING }\end{array}$} & \multicolumn{3}{|c|}{ DRYING } & \multicolumn{2}{|c|}{$\begin{array}{l}\text { PROCESS } \\
\text { HOT WATER }\end{array}$} & \multirow{2}{*}{$\begin{array}{c}\text { PROCESS } \\
\text { STEAM } \\
\text { SL }\end{array}$} & \multicolumn{2}{|c|}{$\begin{array}{l}\text { COOLING/ } \\
\text { REFRIG. } \\
\text { ERATION }\end{array}$} \\
\hline & HP & $\mathrm{HA}$ & $\mathrm{HL}$ & DD & $D A$ & $\mathrm{DL}$ & WL & WA & & $\mathrm{CP}$ & $\mathrm{CA}$ \\
\hline IMPORTANCE NO. & . & 5 & & & 6 & & ' & & & . & \\
\hline STATUS & & & & & & & & & & & \\
\hline
\end{tabular}

\section{II-E. Phase-Change Storage}

II-E-1. Analyze the influence of materials characteristics on the performance of phase-change systems in solar heating applications. Study the use of phase-change storage with air-heating collector systems and with liquid-heating collectors. Identify the phase-change temperatures most suitable for different solar applications and operating conditions. Determine which phase-change materials are most suitable according to the fraction of heat to be supplied by solar energy and according to the characteristics of the solar heating system.

\begin{tabular}{|c|c|c|c|c|c|c|c|c|c|c|c|}
\hline \multirow[t]{2}{*}{ PATH } & \multicolumn{2}{|c|}{$\begin{array}{c}\text { SERVICE } \\
\text { HOT WATER }\end{array}$} & \multicolumn{4}{|c|}{ SPACE HEATING } & \multicolumn{5}{|c|}{ SPACE COOLING } \\
\hline & $W_{1}$ & W2 & $\mathrm{H} 1$ & $\mathrm{H} 2$ & $\mathrm{H3}$ & $\mathrm{H} 4$ & C1 & $\mathrm{C} 2$ & $\mathrm{C} 3$ & $\mathrm{C} 4$ & $\mathrm{C5}$ \\
\hline $\begin{array}{c}\text { IMPORTANCE } \\
\text { NO. }\end{array}$ & & & 6 & 4 & 6 & & 8 & 8 & 8 & & 5 \\
\hline STATUS & & $E D$ & $F$ & $A$; & DE & St & & & & & \\
\hline
\end{tabular}

II-E-2. Identify the cost characteristics of phase-change storage systems. Include the cost of the storage medium itself, the cost of the storage container, the operating penalty of the system due to the additional heat exchange required, and the cost savings from reduced space requirements.

\begin{tabular}{|c|c|c|c|c|c|c|c|c|c|c|c|}
\hline \multirow[t]{2}{*}{ PATH } & \multicolumn{2}{|c|}{$\begin{array}{l}\text { SERVICE } \\
\text { HOT WATER }\end{array}$} & \multicolumn{4}{|c|}{ SPACE HEATING } & \multicolumn{5}{|c|}{ SPACE COOLING } \\
\hline & $w_{1}$ & w2 & $\mathrm{Hi}$ & $\mathrm{H} 2$ & $\mathrm{H3}$ & $\mathrm{H} 4$ & $\mathrm{C}_{1}$ & $\mathrm{C} 2$ & $\mathrm{C} 3$ & $\mathrm{C} 4$ & $\mathrm{C5}$ \\
\hline $\begin{array}{c}\text { IMPORTANCE } \\
\text { NO. }\end{array}$ & & & 3 & 4 & 6 & & 8 & 8 & 8 & 5 & 5 \\
\hline STATUS & & $\mathrm{ED}$ & חי & $D A$ & $E N$ & & r & m & $F$ & AL & $B$ \\
\hline
\end{tabular}


II-E-3. Continue the investigation of congruently and incongruently melting salt hydrate phase-change storage materials. Determine the nucleation heat-transfer and precipitation characteristics of the salt hydrates. Include means of promoting nucleation and preventing precipitation. The study should conce trate on those types of salt hydrates that are most appropriate for solar heating and cooling applicatiol...

\begin{tabular}{|c|c|c|c|c|c|c|c|c|c|c|c|}
\hline \multirow[t]{2}{*}{ PATH } & \multicolumn{2}{|c|}{$\begin{array}{l}\text { SERVICE } \\
\text { HOT WATER }\end{array}$} & \multicolumn{4}{|c|}{ SPACE HEATING } & \multicolumn{5}{|c|}{ SPACE COOLING } \\
\hline & $w 1$ & w2 & $\mathrm{HI}$ & $\mathrm{H} 2$ & $\mathrm{H3}$ & $\mathrm{H} 4$ & $\mathrm{C} 1$ & $\mathrm{C} 2$ & $\mathrm{C} 3$ & $\mathrm{C} 4$ & $\mathrm{C5}$ \\
\hline $\begin{array}{c}\text { IMPORTANCE } \\
\text { NO. }\end{array}$ & & & 2 & 3 & 6 & 5 & 8 & 8 & 3 & 5 & 2 \\
\hline STATUS & & & & $;$ & די & & $\Delta \perp$ & D) & $\mathrm{FE}$ & $L$ & \\
\hline
\end{tabular}

II-E-4. Investigate the potential of phase-change materials for thermal storage in passive solar applications. Include an identification of the desirable temperature and heat-transfer characteristics of the phase-change material. Consider methods of encapsulating or containing the storage material and indicate how these methods might be incorporated into the structure of the building to be conditioned.

\begin{tabular}{|c|c|c|c|c|c|c|c|c|c|c|c|}
\hline \multirow[t]{2}{*}{ PATH } & \multicolumn{2}{|c|}{$\begin{array}{l}\text { SERVICE } \\
\text { HOT WATER }\end{array}$} & \multicolumn{4}{|c|}{ SPACE HEATING } & \multicolumn{5}{|c|}{ SPACE COOLING } \\
\hline & w1 & w2 & $\mathrm{H} 1$ & $\mathrm{H} 2$ & H3 & $\mathrm{H} 4$ & $\mathrm{Cl}$ & $\mathrm{C} 2$ & $\mathrm{C} 3$ & $\mathrm{C} 4$ & $\mathrm{C5}$ \\
\hline $\begin{array}{l}\text { IMPORTANCE } \\
\text { NO. }\end{array}$ & & & 6 & 6 & & & & & & 6 & 6 \\
\hline STATUS & \multicolumn{11}{|c|}{ RENEWAL (UNSOLICITED) ; FEDERAL LAB } \\
\hline
\end{tabular}

II-E-5. Investigate the use of organic materials such as paraffins or waxes for phase-change thermal storage. Study microencapsulated paraffin spheres in packed beds or a water slurry and paraffin in a thermallyconducting honeycomb or other suitable container structure.

\begin{tabular}{|c|c|c|c|c|c|c|c|c|c|c|c|}
\hline \multirow[t]{2}{*}{ PATH } & \multicolumn{2}{|c|}{$\begin{array}{l}\text { SERVICE } \\
\text { HOT WATER }\end{array}$} & \multicolumn{4}{|c|}{ SPACE HEATING } & \multicolumn{5}{|c|}{ SPACE COOLING } \\
\hline & W1 & w2 & $\mathrm{H1}$ & $\mathrm{H} 2$ & H3 & $\mathrm{H} 4$ & $\mathrm{C} 1$ & $\mathrm{C2}$ & c3 & $\mathrm{C} 4$ & $\mathrm{C} 5$ \\
\hline $\begin{array}{c}\text { IMPORTANCE } \\
\text { NO. }\end{array}$ & & & 6 & 3 & 6. & .5 & 8 & 8 & 8 & 6 & 6 \\
\hline STATUS & & $A \dot{A}$ & & $C I$ & & & & & & & \\
\hline
\end{tabular}


II-E-6. Investigate cost-effeclive methods for containerizing phase-change storage materials for thermal storage systems. Container designs must satisfy heat exchange requirements, both from air to water or other "lids and within the material.

\begin{tabular}{|c|c|c|c|c|c|c|c|c|c|c|c|}
\hline \multirow[t]{2}{*}{ PATH } & \multicolumn{2}{|c|}{$\begin{array}{l}\text { SERVICE } \\
\text { HOT WATER }\end{array}$} & \multicolumn{4}{|c|}{ SPACE HEATING } & \multicolumn{5}{|c|}{ SPACE COOLING } \\
\hline & $w_{1}$ & w2 & $\mathrm{HI}$ & $\mathrm{H} 2$ & H3 & $\mathrm{H} 4$ & $\mathrm{Cl}$ & $\mathrm{C} 2$ & c3 & $\mathrm{C} 4^{\circ}$ & $\mathrm{CE}$ \\
\hline $\begin{array}{l}\text { IMPORTANCE } \\
\text { NO. }\end{array}$ & . & & 5 & 3 & 5 & 5 & 8 & 8 & 3 & 6 & 5 \\
\hline STATUS & & & & & D & (C) & $U_{L}$ & [ED) & & & \\
\hline
\end{tabular}

II-E-7. Conduct a search for phase-change materials whose transition occurs at temperatures appropriate for use with absorption chillers, which require inlet fluid temperatures of $90^{\circ} \mathrm{C}\left(195^{\circ} \mathrm{F}\right), 110^{\circ} \mathrm{C}\left(230^{\circ} \mathrm{F}\right)$, and $150^{\circ} \mathrm{C}\left(300^{\circ} \mathrm{F}\right)$. Develop container/heat exchangers for these materials, and design, construct, and test prototype devices.

\begin{tabular}{|c|c|c|c|c|c|c|c|c|c|c|c|}
\hline \multirow[t]{2}{*}{ PATH } & \multicolumn{2}{|c|}{$\begin{array}{l}\text { SERVICE } \\
\text { HOT WATER }\end{array}$} & \multicolumn{4}{|c|}{ SPACE HEATING } & \multicolumn{5}{|c|}{ SPACE COOLING } \\
\hline & WI & W2 & $\mathrm{H1}$ & $\mathrm{H} 2$ & H3 & $\mathrm{H} 4$ & $\mathrm{Cl}$ & $\mathrm{C} 2$ & $\mathrm{C} 3$ & $\mathrm{C4}$ & $\mathrm{CE}$ \\
\hline $\begin{array}{l}\text { IMPORTANCE } \\
\text { NO. }\end{array}$ & & & & & & & 9 & 9 & 9 & & \\
\hline STATUS & FUN & & & $\mathrm{R}$ & We & UN & $1 \mathrm{C}$ & D) & & & \\
\hline
\end{tabular}

II-E-8. Investigate safety hazards connected with the use of phase-change materials. These hazards include large expansion of paraffins and salt hydrates, paraffin flammability, etc. Suggest reliable and cost-effective methods for either avoiding or eliminating these dangers.

\begin{tabular}{|c|c|c|c|c|c|c|c|c|c|c|c|}
\hline & \multicolumn{3}{|c|}{$\begin{array}{c}\text { SERVICE } \\
\text { HOT WATER }\end{array}$} & \multicolumn{4}{|c|}{ SPACE HEATING } & \multicolumn{5}{c|}{ SPACE COOLING } \\
& $\begin{array}{c}\text { POTH } \\
\text { W1 }\end{array}$ & W2 & H1 & H2 & H3 & H4 & C1 & C2 & C3 & C4 & C5 \\
\hline $\begin{array}{c}\text { IMPORTANCE } \\
\text { NO. }\end{array}$ & & & 5 & 5 & 5 & 5 & 8 & 8 & 8 & & \\
\hline STATUS & \multicolumn{4}{|l|}{ FUNDED RFP/PRDA; RENEWAL (UNSOLICITED) } \\
\hline
\end{tabular}


II-E-9. Investigate and test advanced thermal storage systems for heat in the $100-350^{\circ} \mathrm{C}\left(212-660^{\circ} \mathrm{F}\right)$ range, to be compatible with process steam and pressurized hot water systems. Materials considered for latent heat and heat of reaction storage should include elements and solid solutions, congruently melting compounc'and eutectics. Consideration must be given to problems of phase separation, super cooling, heat transferthe solid phase, corrosion, stability, and cost. Survey, analyze, and test possible candidate materials. Consider safety requirements.

\begin{tabular}{|c|c|c|c|c|c|c|c|c|c|c|c|}
\hline \multirow{2}{*}{ PATH } & \multicolumn{3}{|c|}{$\begin{array}{l}\text { SHELTER } \\
\text { HEATING }\end{array}$} & \multicolumn{3}{|c|}{ DRYING } & \multicolumn{2}{|c|}{$\begin{array}{l}\text { PROCESS } \\
\text { HOT WATER }\end{array}$} & \multirow{2}{*}{$\begin{array}{c}\text { PROCESS } \\
\text { STEAM } \\
\text { SL }\end{array}$} & \multicolumn{2}{|c|}{$\begin{array}{l}\text { COOLING/ } \\
\text { REFRIG- } \\
\text { ERATION }\end{array}$} \\
\hline & HP & HA & HL & DD & DA & $\mathrm{DL}$ & WL & WA & & $\mathrm{CP}$ & $\mathrm{CA}$ \\
\hline IMPORTANCE NO. & & & & & & & & & 10 & & \\
\hline STATUS & & & & & & & & & & & \\
\hline
\end{tabular}

II-F-10. Investigate and develop phase change materials for specified temperatures between $10-40^{\circ} \mathrm{C}$ $(50-105 \%)$ for heat pump input. Study heat exchange and other problems with water and air heat exchange media.

\begin{tabular}{|c|c|c|c|c|c|c|c|c|c|c|c|}
\hline \multirow[t]{2}{*}{ PATH } & \multicolumn{2}{|c|}{$\begin{array}{l}\text { SERVICE } \\
\text { HOT WATER }\end{array}$} & \multicolumn{4}{|c|}{ SPACE HEATING } & \multicolumn{5}{|c|}{ SPACE COOLING } \\
\hline & w1 & w2 & H1 & $\mathrm{H} 2$ & H3 & $\mathrm{H} 4$ & $\mathrm{C}_{1}$ & $\mathrm{C} 2$ & $\mathrm{C} 3$ & $\mathrm{C4}$ & C5 \\
\hline $\begin{array}{c}\text { IMPORTANCE } \\
\text { NO. }\end{array}$ & & & 9 & & & & & & & & 9 \\
\hline STATUS & & & & & & & & & & & \\
\hline
\end{tabular}

\begin{tabular}{|c|c|c|c|c|c|c|c|c|c|c|c|}
\hline \multirow[t]{2}{*}{ PATH } & \multicolumn{3}{|c|}{$\begin{array}{l}\text { SHELTER } \\
\text { HEATING }\end{array}$} & \multicolumn{3}{|c|}{ DRYING } & \multicolumn{2}{|c|}{$\begin{array}{l}\text { PROCESS } \\
\text { HOT WATER }\end{array}$} & \multirow{2}{*}{$\begin{array}{c}\text { PROCESS } \\
\text { STEAM } \\
\text { SL }\end{array}$} & \multicolumn{2}{|c|}{$\begin{array}{l}\text { COOLING/ } \\
\text { REFRIG- } \\
\text { ERATION }\end{array}$} \\
\hline & HP & HA & $\mathrm{HL}$ & DD & DA & $\mathrm{DL}$ & WL & WA & & $\mathrm{CP}$ & $\mathrm{CA}$ \\
\hline IMPORTANCE NO. & & & & 9 & 9 & 9 & 9 & 9 & & & 9 \\
\hline STATUS & & & & & & & & & & & \\
\hline
\end{tabular}


II-E-11. Investigate and develop isothermal hcat of fusion or reaction thermal energy storage subsystems with transition temperatures between $150-600^{\circ} \mathrm{C}\left(300-1100^{\circ} \mathrm{F}\right)$ for high temperature solar driven absorption or nkine cycle chillers.

\begin{tabular}{|c|c|c|c|c|c|c|c|c|c|c|c|}
\hline \multirow[t]{2}{*}{ PATH } & \multicolumn{2}{|c|}{$\begin{array}{l}\text { SERVICE } \\
\text { HOT WATER }\end{array}$} & \multicolumn{4}{|c|}{ SPACE HEATING } & \multicolumn{5}{|c|}{ SPACE COOLING } \\
\hline & $w_{1}$ & w2 & $\mathrm{H1}$ & $\mathrm{H} 2$ & H3 & $\mathrm{H4}$ & $\mathrm{Cl}$ & $\mathrm{C} 2$ & $\mathrm{C3}$ & $\mathrm{C4}$ & C5 \\
\hline $\begin{array}{c}\text { IMPORTANCE } \\
\text { NO. }\end{array}$ & & & & & & & 8 & & & & \\
\hline STATUS & & & & & & & & & & & \\
\hline
\end{tabular}

II-E-12. Investigate and develop PCM thermal storage subsystems with transition temperatures below. $0^{\circ} \mathrm{C}$ $\left(32^{\circ} \mathrm{F}\right)$ for industrial refrigeration applications.

\begin{tabular}{|c|c|c|c|c|c|c|c|c|c|c|c|}
\hline \multirow[t]{2}{*}{ PATH } & \multicolumn{3}{|c|}{$\begin{array}{l}\text { SHELTER } \\
\text { HEATING }\end{array}$} & \multicolumn{3}{|c|}{ DRYING } & \multicolumn{2}{|c|}{$\begin{array}{l}\text { PROCESS } \\
\text { HOT WATER }\end{array}$} & \multirow{2}{*}{$\begin{array}{c}\text { PROCESS } \\
\text { STEAM } \\
\text { SL } \\
\end{array}$} & \multicolumn{2}{|c|}{$\begin{array}{l}\text { COOLING/ } \\
\text { REFRIG- } \\
\text { ERATION }\end{array}$} \\
\hline & $\mathrm{HP}$ & $\mathrm{HA}$ & $\mathrm{HL}$ & $\mathrm{DO}$ & DA & $\mathrm{DL}$ & $\dot{W L}$ & WA & & $\mathrm{CP}$ & $\mathrm{CA}$ \\
\hline IMPORTANCE NO. & & & & & & & & & & 4 & 4 \\
\hline STATUS & & & & & & & & & & & \\
\hline
\end{tabular}

II-E-13. Investigate the technical feasibility and optimal configurations and operational procedures for utilizing PCM thermal energy storage with air heating collector systems (i.e., performance of air collector is strongly enhancer by stratification in the storage subsystem).

\begin{tabular}{|c|c|c|c|c|c|c|c|c|c|c|c|}
\hline \multirow[t]{2}{*}{ PATH } & \multicolumn{2}{|c|}{$\begin{array}{c}\text { SERVICE } \\
\text { HOT WATER }\end{array}$} & \multicolumn{4}{|c|}{ SPACE HEATING } & \multicolumn{5}{|c|}{ SPACE COOLING } \\
\hline & w1 & W2 & $\mathrm{H} 1$ & $\mathrm{H} 2$ & H3 & $\mathrm{H4}$ & $\mathrm{C} 1$ & $\mathrm{C2}$ & C3 & $\mathrm{C4}$ & C5 \\
\hline $\begin{array}{c}\text { IMPORTANCE } \\
\text { NO. }\end{array}$ & & 8 & 6 & & 8 & & 5 & 5 & 5 & & 5 \\
\hline STATUS & & & & & & & & & & & \\
\hline
\end{tabular}




\begin{tabular}{|c|c|c|c|c|c|c|c|c|c|c|c|}
\hline \multirow[t]{2}{*}{ PATH } & \multicolumn{3}{|c|}{$\begin{array}{l}\text { SHELTER } \\
\text { HEATING }\end{array}$} & \multicolumn{3}{|c|}{ DRYING } & \multicolumn{2}{|c|}{$\begin{array}{l}\text { PROCESS } \\
\text { HOT WATER }\end{array}$} & \multirow{2}{*}{$\begin{array}{c}\text { PROCESS } \\
\text { STEAM } \\
\text { SL } \\
\end{array}$} & \multicolumn{2}{|c|}{$\begin{array}{c}\text { COOLING/ } \\
\text { REFRIG- } \\
\text { ERATION }\end{array}$} \\
\hline & HP & HA & HL & DD & DA & DL & WL & WA & & $\mathrm{CP}$ & CA \\
\hline IMPORTANCE NO. & & 5 & & & & & & & & & \\
\hline STATUS. & & & & & & & & & & & \\
\hline
\end{tabular}

II-E-14. Investigate and develop isothermal heat of fusion or reaction thermal energy storage subsystems with transition temperatures and thermal properties closely tailored to specific solar air heating collector, agricultural and industrial drying processes (specific temperatures and thermal properties to be identified in a separate system study).

\begin{tabular}{|c|c|c|c|c|c|c|c|c|c|c|c|}
\hline \multirow[t]{2}{*}{ PATH } & \multicolumn{3}{|c|}{$\begin{array}{l}\text { SHELTER } \\
\text { HEATING }\end{array}$} & \multicolumn{3}{|c|}{ DRYING } & \multicolumn{2}{|c|}{$\begin{array}{l}\text { PROCESS } \\
\text { HOT WATER }\end{array}$} & \multirow{2}{*}{$\begin{array}{c}\text { PROCESS } \\
\text { STEAM } \\
\text { SL }\end{array}$} & \multicolumn{2}{|c|}{$\begin{array}{l}\text { COOLING/ } \\
\text { REFRIG- } \\
\text { ERATION }\end{array}$} \\
\hline & HP & HA & HL & DD & DA & DL & WL & WA & & CP & CA \\
\hline IMPORTANCE NO. & & & & & 5 & & & & & & \\
\hline STATUS & & & & & & & & & & & \\
\hline
\end{tabular}

\section{II-F. Chemical Storage}

II-F-1. Continue the investigation of the feasibility of heat storage using LANis and mischmetal-Nis.

\begin{tabular}{|c|c|c|c|c|c|c|c|c|c|c|c|}
\hline \multirow[t]{2}{*}{ PATH } & \multicolumn{2}{|c|}{$\begin{array}{l}\text { SERVICE } \\
\text { HOT WATER }\end{array}$} & \multicolumn{4}{|c|}{ SPACE HEATING } & \multicolumn{5}{|c|}{ SPACE COOLING } \\
\hline & $w_{1}$ & w2 & $\mathrm{HI}$ & $\mathrm{H} 2$ & H3 & $\mathrm{H4}$ & $\mathrm{Cl}_{1}$ & $\mathrm{C}_{2}$ & C3 & C4 & $\mathrm{C5}$ \\
\hline $\begin{array}{c}\text { IMPORTANCE } \\
\text { NO. }\end{array}$ & & & & & & 2 & 2 & 2 & & & \\
\hline STATUS & & AL & & & & & & & & & \\
\hline
\end{tabular}


II-F-2. Initiate a search for inexpensive metal hydrides for use in thermal storage systems. These mètal hvdrides should have reactions which occur in the temperature ranges normally available from solar collec-

s. This study should also include a search for other materials or means of achieving chemical thermal ...urage. Identify reactions which have a high heat of reaction at low reaction temperatures.

\begin{tabular}{|c|c|c|c|c|c|c|c|c|c|c|c|}
\hline \multirow{2}{*}{ PATH } & \multicolumn{2}{|c|}{ SERVICE } & \multicolumn{4}{|c|}{ SOT } & \multicolumn{5}{|c|}{ SPACE COOLING } \\
& $\begin{array}{c}\text { HOT WATER } \\
\text { W1 }\end{array}$ & W2 & H1 & H2 & H3 & H4 & C1 & C2 & C3 & C4 & C5 \\
\hline $\begin{array}{c}\text { IMPORTANCE } \\
\text { NO. }\end{array}$ & & & & & & 2 & 2 & 2 & & & \\
\hline STATUS & \multicolumn{3}{|c|}{ RENEWAL (UNSOLICITED) ; FEDERAL LAB } \\
\hline
\end{tabular}

II-F-3. Initiate a search for chemical storage materials whose reaction temperature is appropriate for the operation of Rankine cycle/vapor compression chillers for solar cooling. A typical temperature might be $200^{\circ} \mathrm{C}\left(400^{\circ} \mathrm{F}\right)$.

\begin{tabular}{|c|c|c|c|c|c|c|c|c|c|c|c|}
\hline \multirow{2}{*}{ PATH } & \multicolumn{2}{|c|}{ SERVICE } & \multicolumn{4}{|c|}{ SPACE HEATING } & \multicolumn{5}{|c|}{ SPACE COOLING } \\
& HOT WATER & \multicolumn{3}{|c|}{ SPACE } \\
& W1 & W2 & H1 & H2 & H3 & H4 & C1 & C2 & C3 & C4 & C5 \\
\hline $\begin{array}{c}\text { IMPORTANCE } \\
\text { NO. }\end{array}$ & & & & & & & 5 & 5 & & & \\
\hline STATUS & \multicolumn{3}{|c|}{ FUNDED RFP/PRDA; RENEWAL (UNSOLICITED) } \\
\hline
\end{tabular}

$\mathrm{II}-\mathrm{F}-4$. Investigate and test chemical storage systems for industrial hot water, up to $120^{\circ} \mathrm{C}\left(250^{\circ} \mathrm{F}\right)$. Both latent heat and heat of reaction storage systems should be considered. Consider one vessel and two vessel schemes. Storage should be compatible in cost and in regard to heat exchange with industrial hot water systems.

\begin{tabular}{|c|c|c|c|c|c|c|c|c|c|c|c|}
\hline \multirow[t]{2}{*}{ PATH } & \multicolumn{3}{|c|}{$\begin{array}{l}\text { SHELTER } \\
\text { HEATING }\end{array}$} & \multicolumn{3}{|c|}{ DRYING } & \multicolumn{2}{|c|}{$\begin{array}{l}\text { PROCESS } \\
\text { HOT WATER }\end{array}$} & \multirow{2}{*}{$\begin{array}{c}\text { PROCESS } \\
\text { STEAM } \\
\text { SL } \\
\end{array}$} & \multicolumn{2}{|c|}{$\begin{array}{l}\text { COOLING/ } \\
\text { REFRIG. } \\
\text { ERATION }\end{array}$} \\
\hline & HP & HA & $\mathrm{HL}$ & $\mathrm{DD}$ & $\mathrm{DA}$ & $\mathrm{DL}$ & $W L$ & WA & & $\mathrm{CP}$ & $\mathrm{CA}$ \\
\hline IMPORTANCE NO. & & & & & 8 & 8 & 6 & 6 & & & \\
\hline STATUS & & & & & & & & & & & \\
\hline
\end{tabular}




\section{II-G. Test Procedures}

II-G-1. Evaluate the ASHRAE Consensus Standard 94-77 thermal storage test technique for water tank, ro bed, and phase-change systems. Examine the procedure, incorporate useful experience and suggestions, ar recommend any necessary modifications.

\begin{tabular}{|c|c|c|c|c|c|c|c|c|c|c|c|}
\hline \multirow{2}{*}{ PATH } & \multicolumn{3}{|c|}{$\begin{array}{c}\text { SERVICE } \\
\text { HOT WATER } \\
\end{array}$} & \multicolumn{4}{|c|}{ SPACE HEATING } & \multicolumn{4}{c|}{ SPACE COOLING } \\
& W1 & W2 & H1 & H2 & H3 & H4 & C1 & C2 & C3 & C4 & C5 \\
\hline $\begin{array}{c}\text { IMPORTANCE } \\
\text { NO. }\end{array}$ & 4 & 4 & 4 & 4 & 6 & 6 & 4 & 4 & 4 & 4 & 4 \\
\hline STATUS & \multicolumn{4}{|l|}{ FEDERAL LAB } \\
\hline
\end{tabular}

II-G-2. Develop criteria in cooperation with ASHRAE Committee 94-P for evaluating the durability of thermal storage devices and for evaluating the cyclability of such devices. The criteria must be incorporated into the thermal storage test and evaluation techniques.

\begin{tabular}{|c|c|c|c|c|c|c|c|c|c|c|c|}
\hline & \multicolumn{3}{|c|}{$\begin{array}{c}\text { SERVICE } \\
\text { POT WATH }\end{array}$} & \multicolumn{4}{|c|}{ SPACE HEATING } & \multicolumn{4}{c|}{ SPACE COOLING } \\
& W1 & W2 & H1 & H2 & H3 & H4 & C1 & C2 & C3 & C4 & C5 \\
\hline $\begin{array}{c}\text { IMPORTANCE } \\
\text { NO. }\end{array}$ & & & & 1 & 6 & & & & 2 & 1 & \\
\hline STATUS & \multicolumn{3}{|l|}{ FEDERAL LAB } \\
\hline
\end{tabular}




\section{Solar Chillers, Air Conditioners, and Heat Pumps}

\section{OBJECTIVE}

The present technology for using solar heat to cool buildings must be advanced. It will be necessary to identify the cost and performance characteristics required for a solar cooling system to be cost effective in various climatic zones. It will also be necessary to define climatic regions where heat pump systems can be used for both heating and cooling.

The basic technology for the use of passive and active solar cooling and refrigeration systems for various agricultural and industrial process applications must be developed.

\section{EMPHASIS}

The program emphasizes the following:

- System analysis of the most effective approaches and configurations for solar cooling, with a separate analysis for each climatic zone.

- Optimization of absorption and heat engine driven chillers for use with medium and high temperature collectors. Cold and hot storage will be considered. Cooling output will be direct expansion or chilled water. Condensers may be air or liquid cooled.

- Development of solar-actuated dehumidification.

- Development of unitary cooling systems in sizes from 3 to 75 tons.

- Determination of climatic zones and operating conditions which allow heat pump systems to be used for heating and cooling.

- System studies of passive and active solar cooling and refrigeration systems in the attempt to provide suitable matches with specific agricultural and industrial requirements.

- Investigation of the applications and cost effectiveness of industrial heat pumps in conjunction with solar collector systems to provide process heating and cooling.

\section{TASKS}

\section{III-A. System Studies Related to Air Conditioning and Heat Pumps}

III-A-1. Analyze cooling and heating requirements for different climatic zones, identifying areas where a system designed for solar heating can be used for cooling when augmented by a heat actuated chiller. Identify also those areas where either direct or indirect evaporative cooling with thermal storage is effective. For areas where a separate solar cooling system is necessary, define collector area requirements for a system that uses a high performance collector producing energy at temperatures between 120 and $150^{\circ} \mathrm{C}\left(250\right.$ and $\left.300^{\circ} \mathrm{F}\right)$., Also, define requirements for a moderate performance system that uses a high performance flat plate collector.

\begin{tabular}{|c|c|c|c|c|c|c|c|c|c|c|c|}
\hline \multirow[t]{2}{*}{ PATH } & \multicolumn{2}{|c|}{$\begin{array}{c}\text { SERVICE } \\
\text { HOT WATER }\end{array}$} & \multicolumn{4}{|c|}{ SPACE HEATING } & \multicolumn{5}{|c|}{ SPACE COOLING } \\
\hline & $w_{1}$ & w2 & $\mathrm{H} 1$ & $\mathrm{H} 2$ & $\mathrm{H} 3$ & $\mathrm{H4}$ & C1 & $\mathrm{C} 2$ & C3 & C4 & $\mathrm{C5}$ \\
\hline $\begin{array}{l}\text { IMPORTANCE } \\
\text { NO. }\end{array}$ & & & & & & 7 & 8 & 8 & 8 & 8 & 8 \\
\hline STATUS & & & & & & & & & & & \\
\hline
\end{tabular}


III-A-2. Identify computer models of chillers that can be used with the major dynamic solar energy system analysis codes. Models should be generated for absorption, Rankine cycle, and desiccant machines. The models should incorporate transient effects in the chillers.

\begin{tabular}{|c|c|c|c|c|c|c|c|c|c|c|c|}
\hline \multirow[t]{2}{*}{ PATH } & \multicolumn{2}{|c|}{$\begin{array}{l}\text { SERVICE } \\
\text { HOT WATER }\end{array}$} & \multicolumn{4}{|c|}{ SPACE HEATING } & \multicolumn{5}{|c|}{ SPACE COOLING } \\
\hline & w1 & w2 & $\mathrm{H1}$ & $\mathrm{H} 2$ & $\mathrm{H3}$ & $\mathrm{H4}$ & $\mathrm{C}_{1}$ & C2 & $\mathrm{C} 3$ & $\mathrm{C} 4$ & $\mathrm{C} 5$ \\
\hline $\begin{array}{c}\text { IMPORTANCE } \\
\text { NO. }\end{array}$ & & & & & & & 9 & 9 & 9 & & \\
\hline STATUS & & & & & & & & & & & \\
\hline
\end{tabular}

III-A-3. Investigate the possibility and implications of varying the air conditioning evaporator temperature in the range from $7^{\circ} \mathrm{C}\left(45^{\circ} \mathrm{F}\right)$ (the ASHRAE standard) to perhaps $15^{\circ} \mathrm{C}\left(60^{\circ} \mathrm{F}\right)$. Other means of controlling the dew-point are to be considered such as solar power dehumidification. Use performance data from the new heat pump now under development and other types of cooling machines.

\begin{tabular}{|c|c|c|c|c|c|c|c|c|c|c|c|}
\hline \multirow[t]{2}{*}{ PATH } & \multicolumn{2}{|c|}{$\begin{array}{l}\text { SERVICE } \\
\text { HOT WATER }\end{array}$} & \multicolumn{4}{|c|}{ SPACE HEATING } & \multicolumn{5}{|c|}{ SPACE COOLING } \\
\hline & $w 1$ & w2 & $H 1$ & $\mathrm{H} 2$ & $\mathrm{H3}$ & $\mathrm{H} 4$ & $\mathrm{C} 1$ & $\mathrm{C} 2$ & $\mathrm{c} 3$ & $\mathrm{C} 4$ & $\mathrm{C} 5$ \\
\hline $\begin{array}{l}\text { IMPORTANCE } \\
\text { NO. }\end{array}$ & & & & & - & & 9 & 9 & & & 8 \\
\hline
\end{tabular}

III-A-4. Prepare a dynamic model of an absorption type of cooling system suitable for studying on-off operation and variable-input-temperature operation in a typical solar installation. Use this model to investigate the effects of on-off operation on overall system performance, and validate the model against results obtained in actual system tests.

\begin{tabular}{|c|c|c|c|c|c|c|c|c|c|c|c|}
\hline \multirow[t]{2}{*}{ PATH } & \multicolumn{2}{|c|}{$\begin{array}{l}\text { SERVICE } \\
\text { HOT WATER }\end{array}$} & \multicolumn{4}{|c|}{ SPACE HEATING } & \multicolumn{5}{|c|}{ SPACE COOLING } \\
\hline & w1 & w2 & H1 & $\mathrm{H} 2$ & H3 & H4 & $\mathrm{C1}$ & $\mathrm{C}_{2}$ & C3 & $\mathrm{C4}$ & $\mathrm{C5}$ \\
\hline $\begin{array}{c}\text { IMPORTANCE } \\
\text { NO: }\end{array}$ & & & & & & & 9 & 9 & & & \\
\hline STATUS & & & & & & & & & & & \\
\hline
\end{tabular}


III-A-5. Identify the utility load profile characteristics of solar cooling systems for various climatic zones and system configurations. Investigate means by which load profiles can be modified to lessen the impact on z electric utilities.

\begin{tabular}{|c|c|c|c|c|c|c|c|c|c|c|c|}
\hline \multirow{2}{*}{ PATH } & \multicolumn{2}{|c|}{$\begin{array}{l}\text { SERVICE } \\
\text { HOT WATER }\end{array}$} & \multicolumn{4}{|c|}{ SPACE HEATING } & \multicolumn{5}{|c|}{ SPACE COOLING } \\
\hline & w1 & w2 & $\mathrm{HI}$ & $\mathrm{H} 2$ & $\mathrm{H} 3$ & $\mathrm{H} 4$ & $\mathrm{C} 1$ & $\mathrm{C} 2$ & $\mathrm{C} 3$ & $\mathrm{C} 4$ & $\mathrm{C} 5$ \\
\hline $\begin{array}{c}\text { IMPORTANCE } \\
\text { NO. }\end{array}$ & & & & & & & 7 & 7 & 7 & 6 & 7 \\
\hline STATUS & & & & & & & & & & & \\
\hline
\end{tabular}

III-A-6. Identify the trade-off between using hot storage and cold storage in solar cooling systems in locations where solar cooling is warranted. Identify the optimum thermal storage characteristics for hot storage, considering the cost of solar heat, the cost of thermal storage, and the cost and COP of energy conversion.

\begin{tabular}{|c|c|c|c|c|c|c|c|c|c|c|c|}
\hline \multirow[t]{2}{*}{ PATH } & \multicolumn{2}{|c|}{$\begin{array}{l}\text { SERVICE } \\
\text { HOT WATER }\end{array}$} & \multicolumn{4}{|c|}{ SPACE HEATING } & \multicolumn{5}{|c|}{ SPACE COOLING } \\
\hline & w1 & w2 & $\mathrm{H1}$ & $\mathrm{H} 2$ & H3 & $\mathrm{H4}$ & $\mathrm{C}_{1}$ & $\mathrm{C} 2$ & $\mathrm{C} 3$ & $\mathrm{C} 4$ & $\mathrm{C} 5$ \\
\hline $\begin{array}{c}\text { IMPORTANCE } \\
\text { NO. }\end{array}$ & & & 4 & & & & 7 & 7 & 7 & & 7 \\
\hline STATUS & & & & & & & & & & & \\
\hline
\end{tabular}

\section{III-B. Absorption Chillers}

III-B-1. Collect and disseminate information on the operation of the currently available 3-ton lithium bromide absorption chiller operated at temperatures of $80^{\circ} \mathrm{C}\left(175^{\circ} \mathrm{F}\right)$ and up. Discuss the effects of modifications to the chiller. For the mòst part, this information can be derived from installations where these chillers are used.

\begin{tabular}{|c|c|c|c|c|c|c|c|c|c|c|c|}
\hline \multirow[t]{2}{*}{ PATH } & \multicolumn{2}{|c|}{$\begin{array}{c}\text { SERVICE } \\
\text { HOT WATER }\end{array}$} & \multicolumn{4}{|c|}{ SPACE HEATING } & \multicolumn{5}{|c|}{ SPACE COOLING } \\
\hline & W1 & W2 & HI & $\mathrm{H} 2$ & H3 & $\mathrm{H} 4$ & C1 & $\mathrm{C} 2$ & C3 & C4 & C5 \\
\hline $\begin{array}{c}\text { IMPORTANCE } \\
\text { NO. }\end{array}$ & & & & & & & 7 & 8 & & & \\
\hline STATUS & & AL & תו & -11 & 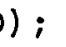 & D & + & & & & \\
\hline
\end{tabular}


III-B-2. Study in detail the following approach to small absorption machines: absorption with evaporative condenser cooling. It has three potential advantages: the economic benefit of combining two components into one; consumption of less electricity; and more evaporative surface, reducing the scaling.problem.

\begin{tabular}{|c|c|c|c|c|c|c|c|c|c|c|c|}
\hline & \multicolumn{3}{|c|}{$\begin{array}{c}\text { SERVICE } \\
\text { POT WATER }\end{array}$} & \multicolumn{4}{|c|}{ SPACE HEATING } & \multicolumn{5}{c|}{ SPACE COOLING } \\
& $\begin{array}{c}\text { POTH } \\
\text { W1 }\end{array}$ & W2 & H1 & H2 & H3 & H4 & C1 & C2 & C3 & C4 & C5 \\
\hline $\begin{array}{c}\text { IMPORTANCE } \\
\text { NO. }\end{array}$ & & & & & & & 7 & 7 & & & \\
\hline STATUS & \multicolumn{3}{|c|}{ RENEWAL (UNSOLICITED) } \\
\hline
\end{tabular}

III-B-3. Investigate the possibility of using additives to lithium bromide and water and ammonia and water or other refrigerant absorber pairs in absorption units. The objective is to permit higher temperatures for air coobling.

\begin{tabular}{|c|c|c|c|c|c|c|c|c|c|c|c|}
\hline & \multicolumn{3}{|c|}{$\begin{array}{c}\text { SERVICE } \\
\text { POT WATH }\end{array}$} & \multicolumn{4}{|c|}{ SPACE HEATING } & \multicolumn{5}{c|}{ SPACE COOLING } \\
& H1 & W2 & H1 & H2 & H3 & H4 & C1 & C2 & C3 & C4 & C5 \\
\hline $\begin{array}{c}\text { IMPORTANCE } \\
\text { NO. }\end{array}$ & & & & & & & 7 & 7 & & & \\
\hline STATUS & \multicolumn{3}{|c|}{ FUNDED RFP/PRDA } \\
\hline
\end{tabular}

III-B-4. Develop an ammonia and water absorption chiller optimized for use with a high temperature solar heat supply $\left[120-150^{\circ} \mathrm{C}\left(250-300^{\circ} \mathrm{F}\right)\right]$ for a residential application with an air heat-rejection system. After settling on the design characteristics of such a system, have the system built and test it. In parallel with this, investigate the use of the system with various solar collector and storage configurations in different climates. Include an investigation of potential market limitations, cost characteristics of the entire system with regard to conventional designs, and the overall operating system COP:

\begin{tabular}{|c|c|c|c|c|c|c|c|c|c|c|c|}
\hline & \multicolumn{2}{|c|}{$\begin{array}{c}\text { SERVICE } \\
\text { POT WATER }\end{array}$} & \multicolumn{4}{|c|}{ SPACE HEATING } & \multicolumn{5}{c|}{ SPACE COOLING } \\
& $\begin{array}{c}\text { HOTH } \\
\text { W1 }\end{array}$ & W2 & H1 & H2 & H3 & H4 & C1 & C2 & C3 & C4 & C5 \\
\hline $\begin{array}{c}\text { IMPORTANCE } \\
\text { NO. }\end{array}$ & & & & & & & 7 & 6 & & & \\
\hline STATUS & \multicolumn{4}{|c|}{} & & & & & & & \\
\hline
\end{tabular}


III-B-5. Develop a lithium bromide absorption chiller optimized for use with a solar flat plate collector svstem for residential applications. The chiller should have a capacity of about three tons and should be opized for use with generator inlet temperatures of approximately $90^{\circ} \mathrm{C}\left(195^{\circ} \mathrm{F}\right)$. Design the machine for use ...th either water or air cooled condenser and absorber.

\begin{tabular}{|c|c|c|c|c|c|c|c|c|c|c|c|}
\hline \multirow[t]{2}{*}{ PATH } & \multicolumn{2}{|c|}{$\begin{array}{l}\text { SERVICE } \\
\text { HOT WATER }\end{array}$} & \multicolumn{4}{|c|}{ SPAC̈E HEATING } & \multicolumn{5}{|c|}{ SPACE COOLING } \\
\hline & w1 & w2 & $\mathrm{H1}$ & $\mathrm{H} 2$ & $\mathrm{H3}$ & $\mathrm{H} 4$ & $\mathrm{C1}$ & $\mathrm{C} 2$ & C3 & $\mathrm{C4}$ & $\mathrm{C5}$ \\
\hline $\begin{array}{c}\text { IMPORTANCE } \\
\text { NO. }\end{array}$ & & & & & & & & 10 & & & \\
\hline STATUS & & $E D$ & 11 & & $|E|$ & $(\tau)$ & LI & ED) & & & \\
\hline
\end{tabular}

1II-B-6. Develop and test absorption chillers that appear to satisfy the performance and cost requirements of various cooling systems.

\begin{tabular}{|c|c|c|c|c|c|c|c|c|c|c|c|}
\hline \multirow[t]{2}{*}{ PATH } & \multicolumn{2}{|c|}{$\begin{array}{l}\text { SERVICE } \\
\text { HOT WATER }\end{array}$} & \multicolumn{4}{|c|}{ SPACE HEATING } & \multicolumn{5}{|c|}{ SPACE COOLING } \\
\hline & W1 & w2 & $\mathrm{HI}$ & $\mathrm{H} 2$ & $\mathrm{H} 3$ & $\mathrm{H} 4$ & $\mathrm{C} 1$ & $\mathrm{C} 2$ & C3 & $\mathrm{C} 4$ & $\mathrm{C5}$ \\
\hline $\begin{array}{l}\text { IMPORTANCE } \\
\text { NO. }\end{array}$ & & & & & & & 10 & 10 & & & \\
\hline STATUS & FU & & & & & & & & & & \\
\hline
\end{tabular}

III-B-7. Test and evaluate the performance of solar-powered absorption cooling unit at off-design conditions. Understanding of the performance of the absorption cooling unit at off-design conditions is of vital importance, particularly in solar applications where a wide variety of operating conditions exists. The results of the part-load performance tests will be particularly useful in designing absorption cooling systems.

\begin{tabular}{|c|c|c|c|c|c|c|c|c|c|c|c|}
\hline \multirow[t]{2}{*}{ PATH } & \multicolumn{2}{|c|}{$\begin{array}{l}\text { SERVICE } \\
\text { HOT WATER }\end{array}$} & \multicolumn{4}{|c|}{ SPACE HEATING } & \multicolumn{5}{|c|}{ SPACE COOLING } \\
\hline & W1 & w2 & $H 1$ & $\mathrm{H} 2$ & H3 & $\mathrm{H} 4$ & $\mathrm{Cl}$ & $\mathrm{C} 2$ & C3 & $\mathrm{C} 4$ & $\mathrm{C5}$ \\
\hline $\begin{array}{c}\text { IMPORTANCE } \\
\text { NO. }\end{array}$ & & & & & & & 10 & 10 & & & \\
\hline STATUS & & $A L$ & סדי & CII & ; & & LA & & & & \\
\hline
\end{tabular}


III-B-8. Investigate and develop advanced absorption cycles or cycle modifications that can potentially improve the performance or reduce the cost of the absorption chiller in both residential and light commercial applications.

\begin{tabular}{|c|c|c|c|c|c|c|c|c|c|c|c|}
\hline \multirow[t]{2}{*}{ PATH } & \multicolumn{2}{|c|}{$\begin{array}{l}\text { SERVICE } \\
\text { HOT WATER }\end{array}$} & \multicolumn{4}{|c|}{ SPACE HEATING } & \multicolumn{5}{|c|}{ SPACE COOLING } \\
\hline & W1 & W2 & $\mathrm{H} 1$ & $\mathrm{H} 2$ & $\mathrm{H3}$ & $\mathrm{H4}$ & $\mathrm{C} 1$ & $\mathrm{C} 2$ & $\mathrm{C} 3$ & $\mathrm{C} 4$ & $\mathrm{C5}$ \\
\hline $\begin{array}{c}\text { IMPORTANCE } \\
\text { NO. }\end{array}$ & & & & & & & 10 & 10 & & & \\
\hline STATUS & FUI & 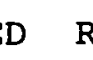 & $/ F$ & & & & & & & & \\
\hline
\end{tabular}

III-B-9. Develop a double-effect lithium bromide-water absorption chiller optimized for use with a solar concentrating collector system for multi-residential or commercial applications. The chiller should have a capacity over 15 tons and should be optimized for use with generator inlet temperatures of $135^{\circ} \mathrm{C}\left(280^{\circ} \mathrm{F}\right)$ or more. Design the unit for use with a water or air cooled condenser and absorber.

\begin{tabular}{|c|c|c|c|c|c|c|c|c|c|c|c|}
\hline \multirow[t]{2}{*}{ PATH } & \multicolumn{2}{|c|}{$\begin{array}{l}\text { SERVICE } \\
\text { HOT WATER }\end{array}$} & \multicolumn{4}{|c|}{ SPACE HEATING } & \multicolumn{5}{|c|}{ SPACE COOLING } \\
\hline & w1 & W2 & H1 & $\mathrm{H} 2$ & H3 & $\mathrm{H4}$ & $\mathrm{Cl}_{1}$ & $\mathrm{C}_{2}$ & $\mathrm{C3}$ & $\mathrm{C} 4$ & $\mathrm{C5}$ \\
\hline $\begin{array}{c}\text { IMPORTANCE } \\
\text { NO. }\end{array}$ & & & & & & & 10 & & & & \\
\hline STATUS & & & & & & & & & & & \\
\hline
\end{tabular}

\section{III-C. Heat Engine/Vapor Compression Chillers}

III-C-1. Investigate the potential of Rankine cycle chillers for use in solar cooling installations that use high temperature advanced collectors producing temperatures in excess of $120^{\circ} \mathrm{C}\left(250^{\circ} \mathrm{F}\right)$.

\begin{tabular}{|c|c|c|c|c|c|c|c|c|c|c|c|}
\hline \multirow[t]{2}{*}{ PATH } & \multicolumn{2}{|c|}{$\begin{array}{l}\text { SERVICE } \\
\text { HOT WATER }\end{array}$} & \multicolumn{4}{|c|}{ SPACE HEATING } & \multicolumn{5}{|c|}{ SPACE COOLING } \\
\hline & W1 & w2 & H1 & $\mathrm{H} 2$ & H3 & $\mathrm{H} 4$ & $\mathrm{Cl}$ & $\mathrm{C} 2$ & c3 & C4 & C5 \\
\hline $\begin{array}{c}\text { IMPORTANCE } \\
\text { NO. }\end{array}$ & & & & & & . & 8 & 7 & & & \\
\hline STATUS & & & & & & & & & & & \\
\hline
\end{tabular}


III-C-2. Compare absorption, adsorption, Rankine cycle, photo-voltaic, and passive solar cooling of varying size ( 3 tons, 100 tons, etc.), considering the solar heat energy, the electrical energy, and other elements reuired for the operation of these machines. Compare the effects of transient operation for both systems. -lefine the advantages of the Rankine cycle units, considering the opcrating range of both types of systems, the climatic zones in which they are effective, and the potential of the Rankine unit for mixed cycle operation. Discuss reliability, cost, and performance of both systems. Both the basic Rankine cycles and Rankine cycles with high super heat should be considered.

\begin{tabular}{|c|c|c|c|c|c|c|c|c|c|c|c|}
\hline \multirow[t]{2}{*}{ PATH } & \multicolumn{2}{|c|}{$\begin{array}{l}\text { SERVICE } \\
\text { HOT WATER }\end{array}$} & \multicolumn{4}{|c|}{ SPACE HEATING } & \multicolumn{5}{|c|}{ SPACE COOLING } \\
\hline & W1 & W2 & $\mathrm{H1}$ & $\mathrm{H} 2$ & $\mathrm{H} 3$ & $\mathrm{H} 4$ & $\mathrm{Cl}$ & $\mathrm{C} 2$ & $\mathrm{C} 3$ & $\mathrm{C} 4$ & $\mathrm{C} 5$ \\
\hline $\begin{array}{c}\text { IMPORTANCE } \\
\text { NO. }\end{array}$ & & & & & & 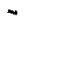 & 7 & 7 & & & \\
\hline STATUS & & & & & & & & & & & \\
\hline
\end{tabular}

III-C-3. Develop a Rankine cycle vapor compression chiller optimized for multi-family residential applications. Study the potential for driving the Rankine cycle by a solar heat source with an electric motor as an auxiliary system component. Identify the most attractive system configurations that use this principle.

\begin{tabular}{|c|c|c|c|c|c|c|c|c|c|c|c|}
\hline & \multicolumn{3}{|c|}{$\begin{array}{c}\text { SERVICE } \\
\text { HOT WATER }\end{array}$} & \multicolumn{3}{|c|}{ SPACE HEATING } & \multicolumn{5}{c|}{ SPACE COOLING } \\
& $\begin{array}{c}\text { P1 } \\
\text { PATH }\end{array}$ & W2 & H1 & H2 & H3 & H4 & C1 & C2 & C3 & C4 & C5 \\
\hline $\begin{array}{c}\text { IMPORTANCE } \\
\text { NO. }\end{array}$ & & & & & & & 7 & 7 & & & \\
\hline STATUS & \multicolumn{3}{|l|}{ RENEWAL (UNSOLICITED) } \\
\hline
\end{tabular}

III-C-4. Investigate the potential for using solar collectors as the generator or the boiler in a Rankine cycle system. Consider the performance, cost, reliability, and leak-tightness requirements of the system. Linear and point source concentrators should be considered.

\begin{tabular}{|c|c|c|c|c|c|c|c|c|c|c|c|}
\hline \multirow[t]{2}{*}{ PATH } & \multicolumn{2}{|c|}{$\begin{array}{l}\text { SERVICE } \\
\text { HOT WATER }\end{array}$} & \multicolumn{4}{|c|}{ SPACE HEATING } & \multicolumn{5}{|c|}{ SPACE COOLING } \\
\hline & w1 & W2 & $\mathrm{H1}$ & $\mathrm{H} 2$ & $\mathrm{H3}$ & $\mathrm{H} 4$ & C1 & $\mathrm{C2}$ & $\mathrm{C} 3$ & $\mathrm{C} 4$ & $\mathrm{C5}$ \\
\hline $\begin{array}{c}\text { IMPORTANCE } \\
\text { NO. }\end{array}$ & & & & & & & 7 & & & & \\
\hline STATUS & & & & & & & & & & & \\
\hline
\end{tabular}


III-C-5. Develop heat engine using $120-150^{\circ} \mathrm{C}\left(250-300^{\circ} \mathrm{F}\right)$ solar energy for evaporation of the working fluid and either fossil fuel or a concentrating collector for super heating the vapor to $550^{\circ} \mathrm{C}\left(1000^{\circ} \mathrm{F}\right)$. Rankine. Stirling, or other cycles should be considered.

\begin{tabular}{|c|c|c|c|c|c|c|c|c|c|c|c|}
\hline \multirow[t]{2}{*}{ PATH } & \multicolumn{2}{|c|}{$\begin{array}{l}\text { SERVICE } \\
\text { HOT WATER }\end{array}$} & \multicolumn{4}{|c|}{ SPACE HEATING } & \multicolumn{5}{|c|}{ SPACE COOLING } \\
\hline & w1 & W2 & $\mathrm{H} 1$ & $\mathrm{H} 2$ & $\mathrm{H3}$ & $\mathrm{H} 4$ & c1 & $\mathrm{C} 2$ & C3 & $\mathrm{C} 4$ & $\mathrm{C5}$ \\
\hline $\begin{array}{c}\text { IMPORTANCE } \\
\text { NO. }\end{array}$ & & & & & & & 10 & 10 & & & \\
\hline STATUS & \multicolumn{11}{|c|}{ FUNDED RFP/PRDA } \\
\hline
\end{tabular}

\section{III-D. Passive and Hybrid Cooling Components}

III-D-1. Investigate the viability and cost effectiveness of using various forms of nocturnal energy dissipation (night sky, fan coil, etc.) in either active or passive systems to achieve a net cooling effect. Determine ways in which thermal storage can augment the performance of such systems. Identify climates in the U.S. where such methods might be effective.

\begin{tabular}{|c|c|c|c|c|c|c|c|c|c|c|c|}
\hline \multirow[t]{2}{*}{ PATH } & \multicolumn{2}{|c|}{$\begin{array}{l}\text { SERVICE } \\
\text { HOT WATER }\end{array}$} & \multicolumn{4}{|c|}{ SPACE HEATING } & \multicolumn{5}{|c|}{ SPACE COOLING } \\
\hline & w1 & w2 & H1 & $\mathrm{H} 2$ & $\mathrm{H3}$ & $\mathrm{H} 4$ & $\mathrm{C} 1$ & $\mathrm{C} 2$ & $\mathrm{C} 3$ & $\mathrm{C} 4$ & $\mathrm{C} 5$ \\
\hline $\begin{array}{c}\text { IMPORTANCE } \\
\text { NO. }\end{array}$ & & & & & & & & & & 10 & 10 \\
\hline
\end{tabular}

III-D-2. Prepare a handbook summarizing the results of Task III-D-1 (nocturnal radiation cooling).

\begin{tabular}{|c|c|c|c|c|c|c|c|c|c|c|c|}
\hline \multirow[t]{2}{*}{ PATH } & \multicolumn{2}{|c|}{$\begin{array}{l}\text { SERVICE } \\
\text { HOT WATER }\end{array}$} & \multicolumn{4}{|c|}{ SPACE HEATING } & \multicolumn{5}{|c|}{ SPACE COOLING } \\
\hline & w1 & w2 & H1 & $\mathrm{H} 2$ & H3 & $\mathrm{H} 4$ & $\mathrm{C}_{1}$ & $\mathrm{C} 2$ & C3 & C4 & $\mathrm{C} 5$ \\
\hline $\begin{array}{c}\text { IMPORTANCE } \\
\text { NO. }\end{array}$ & & & & & & & & & & 9 & 9 \\
\hline STATUS & & & & & & & & & & & \\
\hline
\end{tabular}


III-D-3. Investigate the potential application of passive cooling systems to various agricultural and industrial applications. Various schemes are to be examined, including night cooling, heat exchange to the arth or to a body of water as a heat sink, evaporative cooling, including the use of a desiccant, couling ronds, and the use of ice. Specific applications should be studied in an attempt to match the cooling requirement with the most appropriate passive cooling approaches.

\begin{tabular}{|c|c|c|c|c|c|c|c|c|c|c|c|}
\hline \multirow[t]{2}{*}{ PATH } & \multicolumn{3}{|c|}{$\begin{array}{l}\text { SHELTER } \\
\text { HEATING }\end{array}$} & \multicolumn{3}{|c|}{ DRYING } & \multicolumn{2}{|c|}{$\begin{array}{l}\text { PROCESS } \\
\text { HOT WATER }\end{array}$} & \multirow{2}{*}{$\begin{array}{c}\text { PRÒCESS } \\
\text { STEAM } \\
\text { SL }\end{array}$} & \multicolumn{2}{|c|}{$\begin{array}{l}\text { COOLING/ } \\
\text { REFRIG. } \\
\text { ERATION }\end{array}$} \\
\hline & HP & HA & $\mathrm{HL}$ & DD & $D A$ & $\mathrm{DL}$ & WL & WA & & $\mathrm{CP}$ & CA \\
\hline IMPORTANCE NO. & & & & & & & & & & 10 & \\
\hline status & & & & & & & - & & & & \\
\hline
\end{tabular}

\section{III-E. Desiccant Chillers/Dehumidifiers}

III-E-1. Develop desiccant cooling subsystems of the molecular sieve and silica gel types, emphasizing dehumidification as an aid to other cooling methods. Identify the theoretical and experimental characteristics of these subsystems.

\begin{tabular}{|c|c|c|c|c|c|c|c|c|c|c|c|}
\hline \multirow[t]{2}{*}{ PATH } & \multicolumn{2}{|c|}{$\begin{array}{l}\text { SERVICE } \\
\text { HOT WATER }\end{array}$} & \multicolumn{4}{|c|}{ SPACE HEATING } & \multicolumn{5}{|c|}{ SPACE COOLING } \\
\hline & w1 & w2 & $H 1$ & $\mathrm{H} 2$ & $\mathrm{H} 3$ & $\mathrm{H} 4$ & $\mathrm{C} 1$ & $\mathrm{C}_{2}$ & C3 & $\mathrm{C} 4$ & $\mathrm{C5}$ \\
\hline $\begin{array}{c}\text { IMPORTANCE } \\
\text { NO. }\end{array}$ & & & & & & & & & 10 & & \\
\hline STATUS & & $E D$ & P/ & A; & $\mathrm{NE}$ & 7 & OLI & TED & & & \\
\hline
\end{tabular}

III-E-2. Using system analysis results, develop desiccants suitable for solar cooling and dehumidification systems. Identify useful materials and determine and catalog their appropriate thermodynamic and physical properties. The toxicity of the desiccants must be considered.

\begin{tabular}{|c|c|c|c|c|c|c|c|c|c|c|c|}
\hline \multirow{2}{*}{ PATH } & \multicolumn{3}{|c|}{$\begin{array}{c}\text { SERVICE } \\
\text { HOT WATER }\end{array}$} & \multicolumn{4}{|c|}{ SPACE HEATING } & \multicolumn{5}{c|}{ SPACE COOLING } \\
& W1 & W2 & H1 & H2 & H3 & H4 & C1 & C2 & C3 & C4 & C5 \\
\hline $\begin{array}{c}\text { IMPORTANCE } \\
\text { NO. }\end{array}$ & & & & & & & & & 10 & & \\
\hline STATUS & & & & & & & & & & & \\
\hline
\end{tabular}


III-E-3. Develop wheel support structures compatible with the most promising desiccant combinations found in Task III-E-2. These supports must be simple to construct and durable, and they must provide maximum air-surface contact area and minimum pressure drop.

\begin{tabular}{|c|c|c|c|c|c|c|c|c|c|c|c|}
\hline \multirow[t]{2}{*}{ PATH } & \multicolumn{2}{|c|}{$\begin{array}{l}\text { SERVICE } \\
\text { HOT WATER }\end{array}$} & \multicolumn{4}{|c|}{ SPACE HEATING } & \multicolumn{5}{|c|}{ SPACE COOLING } \\
\hline & $w_{1}$ & W2 & $\mathrm{H} 1$ & $\mathrm{H} 2$ & H3 & $\mathrm{H} 4$ & $\mathrm{Cl}$ & $\mathrm{C} 2$ & $\mathrm{C} 3$ & $\mathrm{C4}$ & $\mathrm{C} 5$ \\
\hline $\begin{array}{l}\text { IMPORTANCE } \\
\text { NO. }\end{array}$ & & & & & - & & & & 10 & & \\
\hline STATUS & & & & & & & & & & & \\
\hline
\end{tabular}

III-E-4. Investigate ways in which desiccants can be used to produce net cooling or dehumidifying effects in solar energy systems. Identify the desiccant characteristics desirable for use in such systems and compare them with the characteristics of known desiccant combinations. Include system requirements for air pumping, desiccant heat exchange, and mass exchange; and analyze the net effect on the overall system COP of the requirement for electrical fan energy. Explore any gains achieved by raising the temperature of the solar heat.

\begin{tabular}{|c|c|c|c|c|c|c|c|c|c|c|c|}
\hline \multirow[t]{2}{*}{ PATH } & \multicolumn{2}{|c|}{$\begin{array}{l}\text { SERVICE } \\
\text { HOT WATER }\end{array}$} & \multicolumn{4}{|c|}{ SPACE HEATING } & \multicolumn{5}{|c|}{ SPACE COOLING } \\
\hline & wi & w2 & $\mathrm{HI}$ & $\mathrm{H} 2$ & H3 & $\mathrm{H} 4$ & $\mathrm{C}_{1}$ & $\mathrm{C} 2$ & $\mathrm{C} 3$ & $\mathrm{C} 4$ & C5 \\
\hline $\begin{array}{c}\text { IMPORTANCE } \\
\text { NO. }\end{array}$ & & & & & & & & & 8 & & \\
\hline STATUS & & & & & & & & & & & \\
\hline
\end{tabular}

III-E-5. Support the construction, testing, and simulation validation of the second generation desiccant systems that evolve from the preceding tasks. Several such systems should be built to satisfy the heating and cooling loads of a selection of basic national climatic/solar zones.

\begin{tabular}{|c|c|c|c|c|c|c|c|c|c|c|c|}
\hline \multirow[t]{2}{*}{ PATH } & \multicolumn{2}{|c|}{$\begin{array}{l}\text { SERVICE } \\
\text { HOT WATER }\end{array}$} & \multicolumn{4}{|c|}{ SPACE HEATING } & \multicolumn{5}{|c|}{ SPACE COOLING } \\
\hline & $w_{1}$ & W2 & $\mathrm{H1}$ & $\mathrm{H} 2$ & $\mathrm{H3}$ & $\mathrm{H} 4$ & $\mathrm{C}_{1}$ & C2 & $\mathrm{C3}$ & $\mathrm{C} 4$ & $\mathrm{C5}$ \\
\hline $\begin{array}{l}\text { IMPORTANCE } \\
\text { NO. }\end{array}$ & & & & & & & & & 3 & & \\
\hline STATUS & & & & & & & & & & & \\
\hline
\end{tabular}


III-E-6. Prepare appropriate preliminary or final handbooks for extending the use of viable desiccant cooling/heating systems.

\begin{tabular}{|c|c|c|c|c|c|c|c|c|c|c|c|}
\hline \multirow[t]{2}{*}{ PATH } & \multicolumn{2}{|c|}{$\begin{array}{l}\text { SERVICE } \\
\text { HOT WATER }\end{array}$} & \multicolumn{4}{|c|}{ SPACE HEATING } & \multicolumn{5}{|c|}{ SPACE COOLING } \\
\hline & W1 & w2 & $\mathrm{H1}$ & $\mathrm{H} 2$ & $\mathrm{H3}$ & $\mathrm{H4}$ & $\mathrm{C} 1$ & $\mathrm{C} 2$ & $\mathrm{C} 3$ & $\mathrm{C4}$ & $\mathrm{C} 5$ \\
\hline $\begin{array}{l}\text { IMPORTANCE } \\
\quad \text { NO. } \\
\end{array}$ & & & & & & & & & 3 & & \\
\hline STATUS & & & & & & & & & & & \\
\hline
\end{tabular}

III-E-7. Investigate the possibilities of the closed cycle zeolite desiccant system for cooling applications.

\begin{tabular}{|c|c|c|c|c|c|c|c|c|c|c|c|}
\hline \multirow[t]{2}{*}{ PATH } & \multicolumn{2}{|c|}{$\begin{array}{c}\text { SERVICE } \\
\text { HOT WATER }\end{array}$} & \multicolumn{4}{|c|}{ SPACE HEATING } & \multicolumn{5}{|c|}{ SPACE COOLING } \\
\hline & $w_{1}$ & w2 & $\mathrm{HI}$ & $\mathrm{H} 2$ & H3 & $\mathrm{H4}$ & $\mathrm{C} 1$ & $\mathrm{C} 2$ & $\mathrm{c} 3$ & $\mathrm{C4}$ & $\mathrm{C} 5$ \\
\hline $\begin{array}{c}\text { IMPORTANCE } \\
\text { NO. }\end{array}$ & & & . & & & & & . & 5 & & \\
\hline STATUS & & & & & & & & & & & \\
\hline
\end{tabular}

\section{III-F. Other Chillers}

III-F-1. Investigate the potential of the jet compression technique for air conditioning.

\begin{tabular}{|c|c|c|c|c|c|c|c|c|c|c|c|}
\hline \multirow{2}{*}{ PATH } & \multicolumn{2}{|c|}{$\begin{array}{l}\text { SERVICE } \\
\text { HOT WATER }\end{array}$} & \multicolumn{4}{|c|}{ SPACE HEATING } & \multicolumn{5}{|c|}{ SPACE COOLING } \\
\hline & w1 & w2 & H1 & $\mathrm{H} 2$ & H3 & $\mathrm{H} 4$ & $\mathrm{C}_{1}$ & $\mathrm{C} 2$ & C3 & $\mathrm{C} 4$ & $\mathrm{C5}$ \\
\hline $\begin{array}{l}\text { IMPORTANCE } \\
\text { NO. }\end{array}$ & & & & & & & 5 & 5 & & & \\
\hline STATUS & & & & & & & . & & & & \\
\hline
\end{tabular}


III-F-2. Investigate the potential of the metal-hydride heat pump, in which hydrogen is used as the energy transport medium, for use in solar cooling installations.

\begin{tabular}{|c|c|c|c|c|c|c|c|c|c|c|c|}
\hline \multirow[t]{2}{*}{ PATH } & \multicolumn{2}{|c|}{$\begin{array}{l}\text { SERVICE } \\
\text { HOT WATER }\end{array}$} & \multicolumn{4}{|c|}{ SPACE HEATING } & \multicolumn{5}{|c|}{ SPACE COOLING } \\
\hline & $w_{1}$ & w2 & $\mathrm{H} 1$ & $\mathrm{H} 2$ & $\mathrm{H} 3$ & $\mathrm{H} 4$ & $\mathrm{Cl}_{1}$ & $\mathrm{C} 2$ & $\mathrm{C} 3$ & $\mathrm{C} 4$ & C5 \\
\hline $\begin{array}{l}\text { IMPORTANCE } \\
\text { NO. }\end{array}$ & & & & & & & 5 & 5 & & & \\
\hline STATUS & & & & & & & & & & & \\
\hline
\end{tabular}

III-F-3. Investigate the potential of a hybrid photovoltaic-thermal heat pump for solar heating and cooling

\begin{tabular}{|c|c|c|c|c|c|c|c|c|c|c|c|}
\hline \multirow[t]{2}{*}{ PATH } & \multicolumn{2}{|c|}{$\begin{array}{l}\text { SERVICE } \\
\text { HOT WATER }\end{array}$} & \multicolumn{4}{|c|}{ SPACE HEATING } & \multicolumn{5}{|c|}{ SPACE COOLING } \\
\hline & w1 & W2 & H1 & $\mathrm{H} 2$ & H3 & . 14 & $\mathrm{Cl}$ & $\mathrm{C} 2$ & C3 & $\mathrm{C} 4$ & $\mathrm{C} 5$ \\
\hline $\begin{array}{c}\text { IMPORTANCE } \\
\text { NO. }\end{array}$ & & & 6 & & & & & & & & 5 \\
\hline STATUS & & & & & & & & & & & \\
\hline
\end{tabular}

III-F-4. Investigate optimum system configurations for hybrid photovoltaic-thermal solar heating and cooling.

\begin{tabular}{|c|c|c|c|c|c|c|c|c|c|c|c|}
\hline \multirow{2}{*}{$\begin{array}{c}\text { PATH } \\
:\end{array}$} & \multicolumn{2}{|c|}{$\begin{array}{l}\text { SERVICE } \\
\text { HOT WATER }\end{array}$} & \multicolumn{4}{|c|}{ SPACE HEATING } & \multicolumn{5}{|c|}{ SPACE COOLING } \\
\hline & $w_{1}$ & w2 & $\mathrm{HI}$ & $\mathrm{H} 2$ & $\mathrm{H} 3$ & $\mathrm{H} 4$. & $\mathrm{C}_{1}$ & $\mathrm{C} 2$ & C3 & $\mathrm{C} 4$ & $\mathrm{C5}$ \\
\hline $\begin{array}{l}\text { IMPORTANCE } \\
\text { NO. }\end{array}$ & & & 6 & & & & & & & . & 5 \\
\hline STATUS & & & & & & & & & & & \\
\hline
\end{tabular}


III-F-5. Encourage the development of innovative ideas in solar-activated cooling. Support those which, after technical evaluation, appear to show promise.

\begin{tabular}{|c|c|c|c|c|c|c|c|c|c|c|c|}
\hline \multirow[t]{2}{*}{ PATH } & \multicolumn{2}{|c|}{$\begin{array}{c}\text { SERVICE } \\
\text { HOT WATER }\end{array}$} & \multicolumn{4}{|c|}{ SPACE HEATING } & \multicolumn{5}{|c|}{ SPACE COOLING } \\
\hline & W1 & w2 & $\mathrm{H} 1$ & $\mathrm{H} 2$ & $\mathrm{H} 3$ & $\mathrm{H} 4$ & $\mathrm{C} 1$ & $\mathrm{C} 2$ & $\mathrm{C} 3$ & $\mathrm{C} 4$ & C5 \\
\hline $\begin{array}{c}\text { IMPORTANCE } \\
\text { NO. }\end{array}$ & & & & & & & 8 & 8 & & & \\
\hline STATUS & & & & & & & & & & & \\
\hline
\end{tabular}

\section{III-G. Heat Pumps}

III-G-1. Evaluate the relative merit of using either natural or otherwise available elements for thermal storage in a combined solar and heat pump system. These elements might be ponds or swimming pools. Identify the cost characteristics of these systems and any adverse effects which they may cause. Evaluate the benefits to be derived from incorporating waste heat recovery in combined systems.

\begin{tabular}{|c|c|c|c|c|c|c|c|c|c|c|c|}
\hline \multirow{2}{*}{ PATH } & \multicolumn{2}{|c|}{ SERVICE } & \multicolumn{4}{|c|}{} & \multicolumn{4}{|c|}{ SPACE COOLING } \\
& HOT WATER & \multicolumn{3}{|c|}{ SPACE HEATING } & \multicolumn{4}{|c|}{} \\
& W1 & W2 & H1 & H2 & H3 & H4 & C1 & C2 & C3 & C4 & C5 \\
\hline $\begin{array}{c}\text { IMPORTANCE } \\
\text { NO. }\end{array}$ & & & 10 & & & & & & & & 9 \\
\hline STATUS & \multicolumn{3}{|l|}{ FUNDED RFP/PRDA } \\
\hline
\end{tabular}

III-G-2. Identify the electrical utility load characteristics of combined solar and heat pump systems. Investigate means of using thermal storage for load leveling in combined systems. List both the positive and negative effects of adding solar energy and/or storage to heat pump systems, including benefits of using thermal storage on the high- and low-temperature sides of the heat pump system.

\begin{tabular}{|c|c|c|c|c|c|c|c|c|c|c|c|}
\hline \multirow[t]{2}{*}{ PATH } & \multicolumn{2}{|c|}{$\begin{array}{l}\text { SERVICE } \\
\text { HOT WATER }\end{array}$} & \multicolumn{4}{|c|}{ SPACE HEATING } & \multicolumn{5}{|c|}{ SPACE COOLING } \\
\hline & $w_{1}$ & w2 & HI & $\mathrm{H} 2$ & H3 & $\mathrm{H} 4$ & $\mathrm{C}_{1}$ & $\mathrm{C} 2$ & $\mathrm{C} 3$ & $\mathrm{C} 4$ & $\mathrm{C5}$ \\
\hline $\begin{array}{c}\text { IMPORTANCE } \\
\text { NO. }\end{array}$ & & & 10 & & & & & & & & 9 \\
\hline STATUS & & & & & & & & & & & \\
\hline
\end{tabular}


III-G-3. Perform configuration studies for various combinations of heat pumps (both water source and air source), collectors, and storage units. Determine the characteristics of the best combinations and the sensifivity of each combination to changes in component performance.

\begin{tabular}{|c|c|c|c|c|c|c|c|c|c|c|c|}
\hline \multirow[t]{2}{*}{ PATH } & \multicolumn{2}{|c|}{$\begin{array}{l}\text { SERVICE } \\
\text { HOT WATER }\end{array}$} & \multicolumn{4}{|c|}{ SPACE HEATING } & \multicolumn{5}{|c|}{ SPACE COOLING } \\
\hline & $w 1$ & w2 & $\mathrm{HI}$. & $\mathrm{H} 2$ & $\mathrm{H3}$ & $\mathrm{H} 4$ & $\mathrm{Cl}$ & $\mathrm{C} 2$ & C3 & $\mathrm{C4}$ & $\mathrm{C5}$ \\
\hline $\begin{array}{c}\text { IMPORTANCE } \\
\text { NO. }\end{array}$ & & & 10 & & & & & & & & 9 \\
\hline STATUS & & & 1 & & & & & & & & \\
\hline
\end{tabular}

III-G-4. Investigate various modifications to improve the performance of piston compressors for heat pumps combined with solar energy systems. Consider the use of better electric motors and heat exchangers. Investigate the use of speed modulation to vary the capacity of the machine. This modulation significantly improves the net COP of the machine and better matches capacity to load requirements.

\begin{tabular}{|c|c|c|c|c|c|c|c|c|c|c|c|}
\hline \multirow[t]{2}{*}{ PATH } & \multicolumn{2}{|c|}{$\begin{array}{l}\text { SERVICE } \\
\text { HOT WATER }\end{array}$} & \multicolumn{4}{|c|}{ SPACE HEATING } & \multicolumn{5}{|c|}{ SPACE COOLING } \\
\hline & W1 & W2 & H1 & $\mathrm{H} 2$ & H3 & $\mathrm{H} 4$ & c1 & $\mathrm{C}_{2}$ & C3 & $\mathrm{C4}$ & $\mathrm{C5}$ \\
\hline $\begin{array}{l}\text { IMPORTANCE } \\
\text { NO. }\end{array}$ & & & 10 & & & & 8 & 8 & & & 9 \\
\hline STATUS & \multicolumn{11}{|c|}{ FUNDED RFP/PRDA } \\
\hline
\end{tabular}

III-G-5. Prepare and validate transient models of heat pumps used in combined solar and heat pump systems and evaluate their accuracy. for part load transient and overall system performance. Prepare test and evaluation procedures.

\begin{tabular}{|c|c|c|c|c|c|c|c|c|c|c|c|}
\hline \multirow[t]{2}{*}{ PATH } & \multicolumn{2}{|c|}{$\begin{array}{l}\text { SERVICE } \\
\text { HOT WATER }\end{array}$} & \multicolumn{4}{|c|}{ SPACE HEATING } & \multicolumn{5}{|c|}{ SPACE COOLING } \\
\hline & w1 & w2 & $\mathrm{HI}$ & $\mathrm{H} 2$ & H3 & $\mathrm{H} 4$ & $\mathrm{C}_{1}$ & $\mathrm{C} 2$ & C3 & $\mathrm{C4}$ & $\mathrm{C} 5$ \\
\hline $\begin{array}{c}\text { IMPORTANCE } \\
\text { NO. }\end{array}$ & & & 8 & & & & & & & & 8 \\
\hline STATUS & \multicolumn{11}{|c|}{ FUNDED RFP / PRDA } \\
\hline
\end{tabular}


III-G-6. Perform a side-by-side comparison of two combined solar and hcat purnp systems, one with an imnroved performance heat pump and one with a conventional heat pump. Analyze the performance of the vo systcms in typical cycles and use this information to determine the usefulness of an improved performunce heat pump in a variety of climatic zones.

\begin{tabular}{|c|c|c|c|c|c|c|c|c|c|c|c|}
\hline \multirow[t]{2}{*}{ PATH } & \multicolumn{2}{|c|}{$\begin{array}{c}\text { SERVICE } \\
\text { HOT WATER }\end{array}$} & \multicolumn{4}{|c|}{ SPACE HEATING } & \multicolumn{5}{|c|}{ SPACE COOLING } \\
\hline & w1 & w2 & $\mathrm{Hi}$ & $\mathrm{H} 2$ & H3 & $\mathrm{H} 4$ & $\mathrm{C}_{1}$ & $\mathrm{C} 2$ & $\mathrm{C} 3$ & $\mathrm{C} 4$ & $\mathrm{C5}$ \\
\hline $\begin{array}{l}\text { IMPORTANCE } \\
\text { NO. }\end{array}$ & & & 8 & & & & & & & & 7 \\
\hline$\therefore \quad$ STATUS & FU & & 571 & & & & & & & & . \\
\hline
\end{tabular}

III-G-7. Compare combined solar and heat pump systems, pure solar energy systems, and pure heat pump systems for different climates. Choose the best configuration for each climate for both residential multifamily, and commercial installations and for both new and old buildings. Identify the performance advantages of each system. Evaluate the performance of a combined system optimized without solar input, and evaluate the performance of the same system augmented by a small amount of solar heat. Define the value of the solar heat input for various climates. This will indicate whether even a small solar energy system (e.g., a normal domestic hot water system) might substantially increase total system performance.

\begin{tabular}{|c|c|c|c|c|c|c|c|c|c|c|c|}
\hline \multirow[t]{2}{*}{ PATH } & \multicolumn{2}{|c|}{$\begin{array}{l}\text { SERVICE } \\
\text { HOT WATER }\end{array}$} & \multicolumn{4}{|c|}{ SPACE HEATING } & \multicolumn{5}{|c|}{ SPACE COOLING } \\
\hline & $w_{1}$ & W2 & $\mathrm{H1}$ & $\mathrm{H} 2$ & H3 & $\mathrm{H} 4$ & $\mathrm{Cl}$ & C2 & C3 & C4 & C5 \\
\hline $\begin{array}{c}\text { IMPORTANCE } \\
\text { NO. }\end{array}$ & 3 & & 8 & & & & & & & & 5 \\
\hline STATUS & & & & & & & & & & & \\
\hline
\end{tabular}

III-C-8. Evaluate the use of a variable speed drive system for a centrifugal heat pump. Determine whether this system improves the performance of the combined solar and heat pump system. (Account for extra losses associated with the variable speed drive.)

\begin{tabular}{|c|c|c|c|c|c|c|c|c|c|c|c|}
\hline \multirow[t]{2}{*}{ PATH } & \multicolumn{2}{|c|}{$\begin{array}{l}\text { SERVICE } \\
\text { HOT WATER }\end{array}$} & \multicolumn{4}{|c|}{ SPACE HEATING } & \multicolumn{5}{|c|}{ SPACE COOLING } \\
\hline & w1 & w2 & $\mathrm{H} 1$ & $\mathrm{H} 2$ & $\mathrm{H3}$ & $\mathrm{H} 4$ & $\mathrm{Cl}$ & $\mathrm{C} 2$ & $\mathrm{C} 3$ & $\mathrm{C} 4$ & $\mathrm{C5}$ \\
\hline $\begin{array}{c}\text { IMPORTANCE } \\
\text { NO. }\end{array}$ & & & 7 & & & & & & & & 6 \\
\hline STATUS & & & & & & : & & & & & \\
\hline
\end{tabular}


III-G-9. Use system analysis results to develop heat pumps optimized to work effectively with solar input for heating and cooling applications. Heat pumps usable in combined heating and cooling systems are required because of their cost-effective potential.

\begin{tabular}{|c|c|c|c|c|c|c|c|c|c|c|c|}
\hline \multirow{2}{*}{ PATH } & \multicolumn{3}{|c|}{$\begin{array}{c}\text { SERVICE } \\
\text { HOT WATER }\end{array}$} & \multicolumn{3}{|c|}{ SPACE HEATING } & \multicolumn{5}{c|}{ SPACE COOLING } \\
& W1 & W2 & H1 & H2 & H3 & H4 & C1 & C2 & C3 & C4 & C5 \\
\hline $\begin{array}{c}\text { IMPORTANCE } \\
\text { NO. }\end{array}$ & & & 7 & & & & 7 & 7 & & & 7 \\
\hline STATUS & \multicolumn{3}{|l|}{ FUNDED RFP/PRDA } \\
\hline
\end{tabular}

III-G-10. Evaluate the potential of a combined solar and heat pump system using a solarium or atrium as a collector. Rock bed thermal storage could be used. The rork bed could be the heat source for space heating during periods without sunshine, and the heat source or sink for the heat pump.

\begin{tabular}{|c|c|c|c|c|c|c|c|c|c|c|c|}
\hline \multirow[t]{2}{*}{ PATH } & \multicolumn{2}{|c|}{$\begin{array}{l}\text { SERVICE } \\
\text { HOT WATER }\end{array}$} & \multicolumn{4}{|c|}{ SPACE HEATING } & \multicolumn{5}{|c|}{ SPACE COOLING } \\
\hline & w1 & w2 & $\mathrm{H} 1$ & $\mathrm{H} 2$ & $\mathrm{H3}$ & $\mathrm{H} 4$ & $\mathrm{C}_{1}$ & $\mathrm{C} 2$ & C3 & $\mathrm{C} 4$ & $\mathrm{C5}$ \\
\hline $\begin{array}{l}\text { IMPORTANCE } \\
\text { NO. }\end{array}$ & & & 9 & & & & & & & & 8 \\
\hline STATUS & \multicolumn{11}{|c|}{ FUNDED RFP/PRDA } \\
\hline
\end{tabular}

III-G-11. Sponsor a design competition and test marketing for combined solar and heat pump systems. The competition should be based on a standard set of weather and solar data.

\begin{tabular}{|c|c|c|c|c|c|c|c|c|c|c|c|}
\hline \multirow{2}{*}{ PATH } & \multicolumn{2}{|c|}{$\begin{array}{l}\text { SERVICE } \\
\text { HOT WATER }\end{array}$} & \multicolumn{4}{|c|}{ SPACE HEATING } & \multicolumn{5}{|c|}{ SPACE COOLING } \\
\hline & w1 & w2 & $\mathrm{H1}$ & $\mathrm{H} 2$. & H3 & $\mathrm{H4}$ & $\mathrm{C}_{1}$ & $\mathrm{C} 2$ & $\mathrm{C} 3$ & $\mathrm{C} 4$ & $\mathrm{C5}$ \\
\hline $\begin{array}{c}\text { IMPORTANCE } \\
\text { NO. }\end{array}$ & & & 10 & & & & & & & & 9 \\
\hline STATUS & & & & & & & & & & & \\
\hline
\end{tabular}


III-G-12. Evaluate the potential of using a solar collector as the evaporator/condenser in a combined solar and heat pump system. Identify the problems and costs associated with sealing leaks in such a system.

\begin{tabular}{|c|c|c|c|c|c|c|c|c|c|c|c|}
\hline \multirow[t]{2}{*}{ PATH } & \multicolumn{2}{|c|}{$\begin{array}{l}\text { SERVICE } \\
\text { HOT WATER }\end{array}$} & \multicolumn{4}{|c|}{ SPACE HEATING } & \multicolumn{5}{|c|}{ SPACE COOLING } \\
\hline & w1 & w2 & $\mathrm{H} 1$ & $\mathrm{H} 2$ & H3 & $\mathrm{H4}$ & $\mathrm{C}_{1}$ & $\mathrm{C} 2$ & C3 & $\mathrm{C4}$ & C5 \\
\hline $\begin{array}{c}\text { IMPORTANCE } \\
\text { NO. }\end{array}$ & & & 7 & & . & & & & & & 6 \\
\hline STATUS & & & & & & & & & & & \\
\hline
\end{tabular}

III-G-13. Evaluate industrial sized heat pumps for possible application with solar collectors to provide process hot water, hot air, or steam. Compare overall economic feasibility with the direct use of solar energy systems to provide these temperatures. (Work should be coordinated with DOE industrial conservation office.)

\begin{tabular}{|c|c|c|c|c|c|c|c|c|c|c|c|}
\hline \multirow{2}{*}{ PATH } & \multicolumn{3}{|c|}{$\begin{array}{l}\text { SHELTER } \\
\text { HEATING }\end{array}$} & \multicolumn{3}{|c|}{ DRYING } & \multicolumn{2}{|c|}{$\begin{array}{l}\text { PROCESS } \\
\text { HOT WATER }\end{array}$} & \multirow{2}{*}{$\begin{array}{c}\text { PROCESS } \\
\text { STEAM } \\
\text { SL }\end{array}$} & \multicolumn{2}{|c|}{$\begin{array}{l}\text { COOLING/ } \\
\text { REFRIG- } \\
\text { ERATION }\end{array}$} \\
\hline & HP & HA & $\mathrm{HL}$ & DD & DA & $\mathrm{DL}$ & WL & WA & & $\mathrm{CP}$ & $C A$ \\
\hline IMPORTANCE NO. & & 8 & 8 & & 8 & 8 & 8 & 8 & 8 & 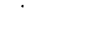 & 6 \\
\hline STATUS & & & & & & & & & & & \\
\hline
\end{tabular}

III-G-14. Prepare design procedure and guidance/handbooks for marketable system configurations.

\begin{tabular}{|c|c|c|c|c|c|c|c|c|c|c|c|}
\hline \multirow[t]{2}{*}{ PATH } & \multicolumn{2}{|c|}{$\begin{array}{l}\text { SERVICE } \\
\text { HOT WATER }\end{array}$} & \multicolumn{4}{|c|}{ SPACE HEATING } & \multicolumn{5}{|c|}{ SPACE COOLING } \\
\hline & W1 & W2 & H1 & $\mathrm{H}_{2}$ & H3 & $\mathrm{H} 4$ & C1 & $\mathrm{C} 2$ & C3 & $\mathrm{C} 4$ & $\mathrm{C} 5$ \\
\hline $\begin{array}{l}\text { IMPORTANCE } \\
\text { NO. }\end{array}$ & & & 10 & & & & & & & & 10 \\
\hline STATUS & & & & & & & & & & & \\
\hline
\end{tabular}

\begin{tabular}{|c|c|c|c|c|c|c|c|c|c|c|c|}
\hline \multirow[t]{2}{*}{ PATH } & \multicolumn{3}{|c|}{$\begin{array}{l}\text { SHELTER } \\
\text { HEATING }\end{array}$} & \multicolumn{3}{|c|}{ DRYING } & \multicolumn{2}{|c|}{$\begin{array}{l}\text { PROCESS } \\
\text { HOT WATER }\end{array}$} & \multirow{2}{*}{$\begin{array}{c}\text { PROCESS } \\
\text { STEAM } \\
\text { SL } \\
\end{array}$} & \multicolumn{2}{|c|}{$\begin{array}{l}\text { COOLING/ } \\
\text { REFRIG- } \\
\text { ERATION }\end{array}$} \\
\hline & HP & HA & $\mathrm{HL}$ & DD & DA & $\mathrm{DL}$ & WL & WA & & $\mathrm{CP}$ & CA \\
\hline IMPORTANCE NO. & & & & & & & & & & 10 & 10 \\
\hline STATUS & & & & & & & & & & & \\
\hline
\end{tabular}




\section{III-H. Agricultural/Industrial Cooling/Refrigeration}

III-H-1. Investigate the possibilities for development of solar cooling and refrigeration by means of absor tion chillers, heat engine/vapor compression chillers or other means. The focus of this task should be on lark industrial units which will operate over the range of temperatures required for the various agricultural and industrial applications.

\begin{tabular}{|c|c|c|c|c|c|c|c|c|c|c|c|}
\hline \multirow[t]{2}{*}{ PATH } & \multicolumn{3}{|c|}{$\begin{array}{l}\text { SHELTER } \\
\text { HEATING }\end{array}$} & \multicolumn{3}{|c|}{ DRYING } & \multicolumn{2}{|c|}{$\begin{array}{l}\text { PROCESS } \\
\text { HOT WATER }\end{array}$} & \multirow{2}{*}{$\begin{array}{c}\text { PROCESS } \\
\text { STEAM } \\
\text { SL }\end{array}$} & \multicolumn{2}{|c|}{$\begin{array}{l}\text { COOLING/ } \\
\text { REFRIG- } \\
\text { ERATION }\end{array}$} \\
\hline & HP & HA & $\mathrm{HL}$ & $\mathrm{DD}$ & DA & $\mathrm{DL}$ & WL & WA & & $C P$ & CA \\
\hline IMPORTANCE NO. & & & & & & & & & & & 10 \\
\hline STATUS & & & & & & & & & & & \\
\hline
\end{tabular}

$\mathrm{III}-\mathrm{H}-2$. Evaluate industrial cooling and refrigeration market, including temperature ranges and unit sizes. Identify cooling and refrigeration components to be developed.

\begin{tabular}{|c|c|c|c|c|c|c|c|c|c|c|c|}
\hline \multirow[t]{2}{*}{ PATH } & \multicolumn{3}{|c|}{$\begin{array}{l}\text { SHELTER } \\
\text { HEATING }\end{array}$} & \multicolumn{3}{|c|}{ DRYING } & \multicolumn{2}{|c|}{$\begin{array}{l}\text { PROCESS } \\
\text { HOT WATER }\end{array}$} & \multirow{2}{*}{$\begin{array}{c}\text { PROCESS } \\
\text { STEAM } \\
\text { SL. } \\
\end{array}$} & \multicolumn{2}{|c|}{$\begin{array}{l}\text { COOLING/ } \\
\text { REFRIG- } \\
\text { ERATION }\end{array}$} \\
\hline & HP & HA & $\mathrm{HL}$ & DD & DA & $\mathrm{DL}$ & WL & WA & & $C P$ & $C A$ \\
\hline IMPORTANCE NO. & & & & & & & & & & & 10 \\
\hline STATUS & & & & & & & & & & & \\
\hline
\end{tabular}

\section{III-I. Test Procedures}

III-1-1. Develop a standardized terminology and a set of standard test methods for rating solar-activated absorption chillers.

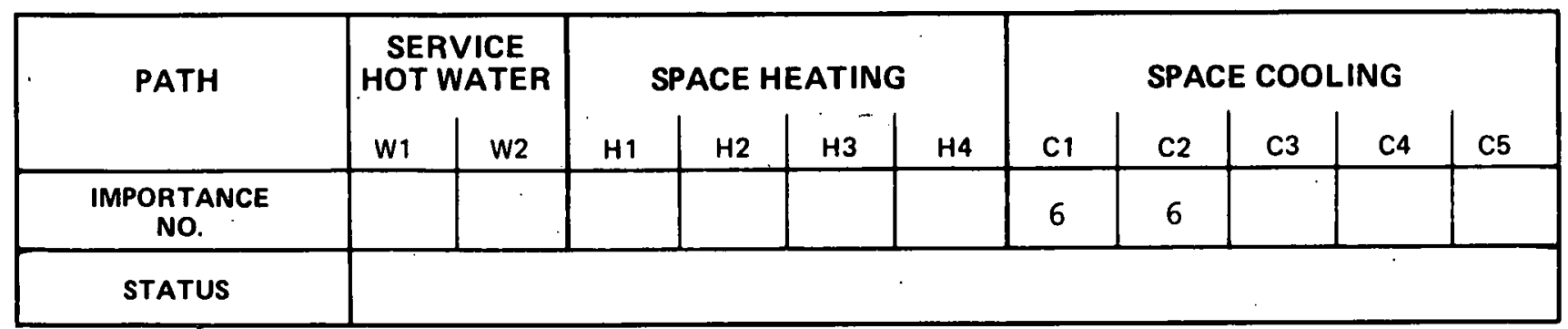


III-1-2. Develop a standardized terminology and a set of standard test methods for rating solar-activated heat engine/vapor compression chillers.

\begin{tabular}{|c|c|c|c|c|c|c|c|c|c|c|c|}
\hline \multirow[t]{2}{*}{ PATH } & \multicolumn{2}{|c|}{$\begin{array}{l}\text { SERVICE } \\
\text { HOT WATER }\end{array}$} & \multicolumn{4}{|c|}{ SPACE HEATING } & \multicolumn{5}{|c|}{ SPACE COOLING } \\
\hline & $w_{1}$ & w2 & $\mathrm{H1}$ & $\mathrm{H} 2$ & H3 & $\mathrm{H} 4$ & $\mathrm{Cl}$ & $\mathrm{C} 2$ & C3 & $\mathrm{C} 4$ & $\mathrm{C5}$ \\
\hline $\begin{array}{c}\text { IMPORTANCE } \\
\text { NO. }\end{array}$ & & & & & & & 6 & 6 & & & \\
\hline STATUS & & & & & & & & & & & \\
\hline
\end{tabular}

III-1-3. Develop a standardized terminology and a set of standard test methods for rating solar-activated desiccant chillers/dehumidifiers.

\begin{tabular}{|c|c|c|c|c|c|c|c|c|c|c|c|}
\hline \multirow{2}{*}{ PATH } & \multicolumn{2}{|c|}{$\begin{array}{l}\text { SERVICE } \\
\text { HOT WATER }\end{array}$} & \multicolumn{4}{|c|}{ SPACE HEATING } & \multicolumn{5}{|c|}{ SPACE COOLING } \\
\hline & w! & w2 & $\mathrm{HI}$ & $\mathrm{H} 2$ & H3 & $\mathrm{H} 4$ & $\mathrm{C} 1$ & $\mathrm{C} 2$ & C3 & $\mathrm{C} 4$ & C5 \\
\hline $\begin{array}{c}\text { IMPORTANCE } \\
\text { NO. }\end{array}$ & & . & & & & & & & 5 & & \\
\hline STATUS & & & & & & & & & & & \\
\hline
\end{tabular}

III-I-4. Develop a standardized terminology and a set of standard test methods for rating electrically drivẹn, solar-assisted heat pumps.

\begin{tabular}{|c|c|c|c|c|c|c|c|c|c|c|c|}
\hline \multirow[t]{2}{*}{ PATH } & \multicolumn{2}{|c|}{$\begin{array}{l}\text { SERVICE } \\
\text { HOT WATER }\end{array}$} & \multicolumn{4}{|c|}{ SPACE HEATING } & \multicolumn{5}{|c|}{ SPACE COOLING } \\
\hline & w1 & W2 & $\mathrm{HI}$ & $\mathrm{H} 2$ & $\mathrm{H3}$ & $\cdot \mathrm{H4}$ & $\mathrm{C} 1$ & $\mathrm{C} 2$ & C3 & $\mathrm{C} 4$ & $\mathrm{C5}$ \\
\hline $\begin{array}{c}\text { IMPORTANCE } \\
\text { NO. }\end{array}$ & & & 12 & $\because$ & & & & & & ? & 9 \\
\hline STATUS & & & & & & & & & & & \\
\hline
\end{tabular}




\section{APPENDIX A \\ R\&D PROGRAM TASKS}

This appendix describes the tasks that make up the R\&D program. Both engineering and non-engineering tasks are included. Task descriptions are detailed enough to define the work required but broad enough to make the program flexible and responsive to changes in technology. All engineering tasks are identified according to major category and sub-category. The paths on which the tasks occur develop in parallel, and particular tasks may occur on more than one path. All paths on which each task occurs are listed, and importance of the task to each path is indicated.

The following is an example of a listing of priorities for an engineering task:

\begin{tabular}{|c|c|c|c|c|c|c|c|c|c|c|c|}
\hline \multirow[t]{2}{*}{ PATH } & \multicolumn{2}{|c|}{$\begin{array}{l}\text { SERVICE } \\
\text { HOT WATER }\end{array}$} & \multicolumn{4}{|c|}{ SPACE HEATING } & \multicolumn{5}{|c|}{ SPACE COOLING } \\
\hline & $w_{1}$ & w2 & H1 & $\mathrm{H} 2$ & H3 & $\mathrm{H} 4$ & $\mathrm{C}_{1}$ & $\mathrm{C} 2$ & C3 & $\mathrm{C} 4$ & .05 \\
\hline $\begin{array}{c}\text { IMPORTANCE } \\
\text { NO. }\end{array}$ & 1 & 1 & 6 & & 5 & 6 & 6 & 8 & 8 & 3 & \\
\hline STATUS & & & & & & & & , & & & \\
\hline
\end{tabular}

In this example, the importance numbers indicate the importance of the task to the paths under which the numbers appear. A 1 to 10 scale is used, with a blank indicating no importance, 1 indicating the lowest importance, and 10 indicating the highest importance.

Those tasks which are of particular significance to agricultural and industrial process heat applications are identified separately. However, there are many general tasks which are of equal importance to heating/cooling and agricultural/industrial paths. In some of these cases, only the heating/cooling importance numbers are given; priorities for agricultural/industrial paths can be considered to be comparable.

The status designation indicates whether a task is being conducted on the basis of a solicited (RFP/PRDA) or unsolicited proposal or at one of the Federal laboratories (FEDERAL LAB). The fact that a task is currently being funded does not imply that the work being done is applicable to all paths to which that task is important. RFP/PRDA solicitations may be issued to cover those tasks or aspects of tasks which are not presently being funded. 


\section{Systems and Controls}

\section{OBJECTIVES}

The systems and controls tasks are divided into three main categories: systems and controls; system analysis; and advanced systems testing.

The objective of the first task category includes research and development of solar heating and cooling systems and controls. Various system configurations are analyzed and experimentally tested to determine system and subsystem performance. Advanced prototype components (collectors, storage, air conditioning, etc.) are combined in an integrated system to provide the full range of data essential to advancing the state of the art of solar heating and cooling. These data also provide guidance for future research and development.

System analysis involves the development and validation of models, design methods, and analysis techniques required by a variety of users to assess the cost, performance, and benefits of solar energy systems.

The objective of advanced system testing is to conduct controlled experimental tests of a wide range of solar energy systems under different operating conditions: The combination of prototype and pre-prototype solar components into integrated system tests provides data for the development and validation of models, the development of advanced systems and components, and feedback to manufacturers.

\section{EMPHASIS}

Emphasis of the systems and controls category is on the development of active, passive, and hybrid solar heating and cooling systems for a variety of applications, including the paths described in this plan. Research and development of innovative controls and control strategies aid in the marketing of new hardware and software for various system configurations. These tasks also stress improvement of retrofit systems to enhance market penetration. Program plans for passive and retrofit systems will describe these activities in more detail.'

System analysis tasks emphasize the provision of data and design methods for predicting the performance of solar encrgy systems in various climates and applications. Design methods, handbooks, and computer programs are used to conduct system studies and market analysis to determine effects of changes in design parameters, economic factors, etc. This area also emphasizes the validation of techniques used or developed by comparing simulated system performance to actual data.

Emphasis in advanced systems testing is on the timely reporting of data to assist in the development of advanced cost-effective solar energy systems and the validation of -mathematical models. Data from test facilities, including residential and commercial buildings, supplement the results of highly controlled experiments. An Advanced Systems Testing Plan will describe the tests which are to be conducted. ${ }^{2}$

in' ans in preparation.

in in preparation. 


\section{TASKS}

\section{IV-A. Integrated Active Solar Energy Systems}

IV-A-1. Establish the capability for dynamic testing at current and future test facilities. Dynamic testing $n$ be used to determine the transient response characteristics of solar energy system comporients and subsystems in various modes of operation.

\begin{tabular}{|c|c|c|c|c|c|c|c|c|c|c|c|}
\hline & \multicolumn{3}{|c|}{$\begin{array}{c}\text { SERVICE } \\
\text { POTH }\end{array}$} & \multicolumn{4}{|c|}{} & \multicolumn{5}{c|}{ SPACE COOLING } \\
& W1 & W2 & H1 & H2 & H3 & H4 & C1 & C2 & C3 & C4 & C5 \\
\hline $\begin{array}{c}\text { IMPORTANCE } \\
\text { NO. }\end{array}$ & 4 & 4 & 9 & 9 & 9 & 9 & 9 & 9 & 9 & 9 & 9 \\
\hline STATUS & \multicolumn{3}{|c|}{ FUNDED } & RFP/PRDA & \\
\hline
\end{tabular}

IV-A-2. Establish a system and subsystem test facility in which the collector output and building load can both be simulated (programmed as a function of both time and observed system parameters). This facility will be used to provide operating data validation on all components and subsystems except the collectors and the building.

\begin{tabular}{|c|c|c|c|c|c|c|c|c|c|c|c|}
\hline \multirow[t]{2}{*}{ PATH } & \multicolumn{2}{|c|}{$\begin{array}{l}\text { SERVICE } \\
\text { HOT WATER }\end{array}$} & \multicolumn{4}{|c|}{ SPACE HEATING } & \multicolumn{5}{|c|}{ SPACE COOLING } \\
\hline & W1 & W2 & $\mathrm{H1}$ & $\mathrm{H} 2$ & H3 & $\mathrm{H} 4$ & $\mathrm{C}_{1}$ & $\mathrm{C} 2$ & C3 & $\mathrm{C} 4$ & C5. \\
\hline $\begin{array}{c}\text { IMPORTANCE } \\
\text { NO. }\end{array}$ & 1 & 1 & 10 & & 10 & 10 & 10 & 10 & 8 & 5 & 10 \\
\hline STATUS & FED & RAL & & & & & & - & & & \\
\hline
\end{tabular}

IV-A-3. Define a standardized method for reporting solar heating and cooling system performance, emphasizing the content of such reports rather than the format. Provide for inclusion of meaningful system performance parameters and variables and for data on mechanical design and degradation (such as corrosion). This will make information on the operation of the existing system more useful to practicing engineers and researchers.

\begin{tabular}{|c|c|c|c|c|c|c|c|c|c|c|c|}
\hline \multirow[t]{2}{*}{ PATH } & \multicolumn{2}{|c|}{$\begin{array}{l}\text { SERVICE } \\
\text { HOT WATER }\end{array}$} & \multicolumn{4}{|c|}{ SPACE HEATING } & \multicolumn{5}{|c|}{ SPACE COOLING } \\
\hline & $w_{1}$ & w2 & $\mathrm{H}_{1}$ & $\mathrm{H}_{2}$ & H3 & $\mathrm{H} 4$ & $\mathrm{Cl}_{1}$ & $\mathrm{C}_{2}$ & c3 & $\mathrm{C} 4_{4}$ & C5 \\
\hline $\begin{array}{l}\text { IMPORTANCE } \\
\text { NO. }\end{array}$ & 10 & 10 & .10 & 10 & 10 & 10 & 10 & 10 & 10 & 10 & 10 \\
\hline STATUS & FED & AL & & & & & & & & & \\
\hline
\end{tabular}




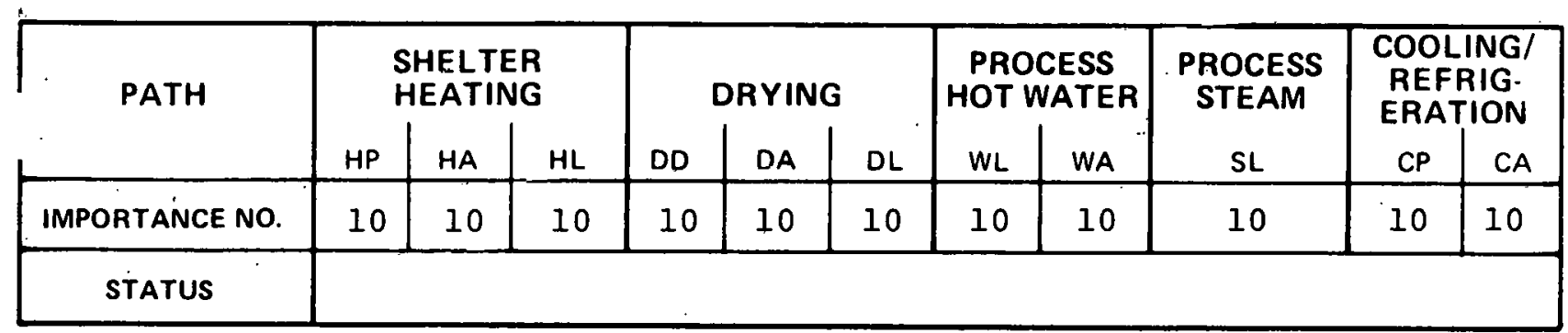

IV-A-4. Develop and standardize a method for evaluating the performance of solar energy.systems that accounts for all solar and non-solar inputs. The method should identify an overall. COP on various bases such as instantaneous, daily, annual, heating, cooling for the total energy input.

\begin{tabular}{|c|c|c|c|c|c|c|c|c|c|c|c|}
\hline \multirow[t]{2}{*}{ PATH } & \multicolumn{2}{|c|}{$\begin{array}{l}\text { SERVICE } \\
\text { HOT WATER }\end{array}$} & \multicolumn{4}{|c|}{ ȘPACE HEATING } & \multicolumn{5}{|c|}{ SPACE COOLING } \\
\hline & $w 1$ & w2 & H1 & $\mathrm{H} 2$ & H3 & $\mathrm{H} 4$ & $\mathrm{Cl}$ & $\mathrm{C} 2$ & $\mathrm{C} 3$ & $\mathrm{C} 4$ & C5 \\
\hline $\begin{array}{l}\text { IMPORTANCE } \\
\text { NO. }\end{array}$ & 10 & 10 & 10 & 10 & 10 & 10 & 10 & 10 & 10 & 10 & 10 \\
\hline STATUS & & D & $I$ & & & & & & & & \\
\hline
\end{tabular}

IV-A-5. Define minimum data requirements for evaluating the performance of active/passive solar heated and solar cooled buildings. Data required includes energy calculations and information on major operating and maintenance characteristics based on observation of operating systems.

\begin{tabular}{|c|c|c|c|c|c|c|c|c|c|c|c|}
\hline \multirow[t]{2}{*}{ PATH } & \multicolumn{2}{|c|}{$\begin{array}{l}\text { SERVICE } \\
\text { HOT WATER }\end{array}$} & \multicolumn{4}{|c|}{ SPACE HEATING } & \multicolumn{5}{|c|}{ SPACE COOLING } \\
\hline & W1 & W2 & $\mathrm{H1}$ & $\mathrm{H} 2$ & $\mathrm{H3}$ & $\mathrm{H} 4$ & $\mathrm{C} 1$ & $\mathrm{C} 2$ & $\mathrm{C} 3$ & $\mathrm{C} 4$ & $\mathrm{C5}$ \\
\hline $\begin{array}{l}\text { IMPORTANCE } \\
\text { NO. }\end{array}$ & & & 4 & 4 & 4 & 4 & 6 & 6 & 6 & 4 & 4 \\
\hline STATUS & \multicolumn{11}{|c|}{ RENEWAL (UNSOLICITED); FEDERAL LAB } \\
\hline
\end{tabular}


IV-A-6. Define a standardized rating procedure for solar heating and cooling systems. The procedure must relate total thermal output (for a defined solar input and a defined load) to the required energy input (from fans, pumps, auxiliary units, etc.). An overall, seasonal COP might be a good approach. Test the rating syste to see that it provides satisfactory performance and economic analyses.

\begin{tabular}{|c|c|c|c|c|c|c|c|c|c|c|c|}
\hline \multirow{2}{*}{ PATH } & \multicolumn{3}{|c|}{$\begin{array}{c}\text { SERVICE } \\
\text { HOT WATER } \\
\end{array}$} & \multicolumn{4}{|c|}{ SPACE HEATING } & \multicolumn{4}{c|}{ SPACE COOLING } \\
& W1 & W2 & H1 & $H 2$ & $H 3$ & $H 4$ & C1 & C2 & C3 & C4 & C5 \\
\hline $\begin{array}{c}\text { IMPORTANCE } \\
\text { NO. }\end{array}$ & 3 & 3 & 3 & 3 & 3 & 3 & 4 & 4 & 4 & 2 & 3 \\
\hline STATUS & \multicolumn{3}{|l|}{ FUNDED RFP/PRDA } \\
\hline
\end{tabular}

IV-A-7. Conduct system studies for a wide range of retrofit situations. Consider a variety of building types and locations, and assess first costs, life cycle costs, and auxiliary energy use.

\begin{tabular}{|c|c|c|c|c|c|c|c|c|c|c|c|}
\hline \multirow[t]{2}{*}{ PATH } & \multicolumn{2}{|c|}{$\begin{array}{l}\text { SERVICE } \\
\text { HOT WATER }\end{array}$} & \multicolumn{4}{|c|}{ SPACE HEATING } & \multicolumn{5}{|c|}{ SPACE COOLING } \\
\hline & W1 & w2 & $\mathrm{HI}$ & $\mathrm{H} 2$ & H3 & $\mathrm{H4}$ & $\mathrm{C}_{1}$ & $\mathrm{C}_{2}$ & C3 & $\mathrm{C} 4$ & $\mathrm{C5}$ \\
\hline $\begin{array}{c}\text { IMPORTANCE } \\
\text { NO. }\end{array}$ & & & 10 & 10 & 10 & 10 & 10 & 10 & 10 & 10 & 10 \\
\hline STATUS & & & & & & & & & & & \\
\hline
\end{tabular}

IV-A-8. Make a detailed analysis of failures in solar energy systems. Identify failures in past and present systems, methods that were used to avoid probable failure, and methods that might be used to avoid future failures. The methods should be cost effective in initial and operating costs and in the use of auxiliary energy units.

\begin{tabular}{|c|c|c|c|c|c|c|c|c|c|c|c|}
\hline \multirow[t]{2}{*}{ PATH } & \multicolumn{2}{|c|}{$\begin{array}{l}\text { SERVICE } \\
\text { HOT WATER }\end{array}$} & \multicolumn{4}{|c|}{ SPACE HEATING } & \multicolumn{5}{|c|}{ SPACE COOLING } \\
\hline & wi & w2 & $\mathrm{HI}$ & $\mathrm{H} 2$ & H3 & $\mathrm{H4}$ & $\mathrm{Cl}$ & $\mathrm{C} 2$ & $\mathrm{C} 3$ & $\mathrm{C} 4$ & $\mathrm{C5}$ \\
\hline $\begin{array}{c}\text { IMPORTANCE } \\
\text { NO. }\end{array}$ & 8 & 8 & 8 & 6 & 4 & 4 & 8 & 8 & 8 & 6 & 6 \\
\hline STATTUS & & & & & & & & & & & \\
\hline
\end{tabular}


IV-A-9. Perform a system study comparing various methods of configuring a solar domestic hot water heating system for various climates, use patterns, number of tanks, collector characteristics, etc.

\begin{tabular}{|c|c|c|c|c|c|c|c|c|c|c|c|}
\hline \multirow[t]{2}{*}{ PATH } & \multicolumn{2}{|c|}{$\begin{array}{l}\text { SERVICE } \\
\text { HOT WATER }\end{array}$} & \multicolumn{4}{|c|}{ SPACE HEATING } & \multicolumn{5}{|c|}{ SPACE COOLING } \\
\hline & W1 & w2 & $\mathrm{H1}$ & $\mathrm{H} 2$ & H3 & $\mathrm{H4}$ & $\mathrm{C}_{1}$ & $\mathrm{C} 2$ & C3 & $\mathrm{C4}$ & $\mathrm{C} 5$ \\
\hline $\begin{array}{c}\text { IMPORTANCE } \\
\text { NO. }\end{array}$ & 8 & 8 & & & & & & & & & \\
\hline STATUS & & & & & & & & & & & \\
\hline
\end{tabular}

IV-A-10. Define minimum data requirements for evaluating performance of active and passive solar energy systems for agricultural and industrial process heat applications. Data required includes energy calculations and information on major operating and maintenance characteristics based on observation of operating systems.

\begin{tabular}{|c|c|c|c|c|c|c|c|c|c|c|c|}
\hline \multirow[t]{2}{*}{ PATH } & \multicolumn{3}{|c|}{$\begin{array}{l}\text { SHELTER } \\
\text { HEATING }\end{array}$} & \multicolumn{3}{|c|}{ DRYING } & \multicolumn{2}{|c|}{$\begin{array}{l}\text { PROCESS } \\
\text { HOT WATER }\end{array}$} & \multirow{2}{*}{$\begin{array}{c}\text { PROCESS } \\
\text { STEAM } \\
\text { SL } \\
\end{array}$} & \multicolumn{2}{|c|}{$\begin{array}{l}\text { COOLING/ } \\
\text { REFRIG- } \\
\text { ERATION }\end{array}$} \\
\hline & HP & HA & $\mathrm{HL}$ & DD & DA & $\mathrm{DL}$ & WL & WA & & $\mathrm{CP}$ & $\mathrm{CA}$ \\
\hline IMPORTANCE NO. & 5 & 5 & 5 & 5 & 5 & 5 & 5 & 5 & 5 & 5 & 5 \\
\hline STATUS & & & & & & & & & & & \\
\hline
\end{tabular}

\section{IV-B. System Design Methods}

IV-B-1. Develcp and/or identify, document, and disseminate computer codes, and simplified design techniques for the performance simulation of solar heating and solar heating and cooling systems. The codes should be of several levels of sophistication, including hand calculation simplifications.

\begin{tabular}{|c|c|c|c|c|c|c|c|c|c|c|c|}
\hline \multirow[t]{2}{*}{ PATH } & \multicolumn{2}{|c|}{$\begin{array}{l}\text { SERVICE } \\
\text { HOT WATER }\end{array}$} & \multicolumn{4}{|c|}{ SPACE HEATING } & \multicolumn{5}{|c|}{ SPACE COOLING } \\
\hline & wi & w2 & $\mathrm{H} 1$ & $\mathrm{H} 2$ & H3 & $\mathrm{H} 4$ & $\mathrm{Cl}$ & $\mathrm{C} 2$ & $\mathrm{C3}$ & $\mathrm{C} 4$ & $\mathrm{C} 5$ \\
\hline $\begin{array}{c}\text { IMPORTANCE } \\
\text { NO. }\end{array}$ & 10 & 10 & 10 & 10 & 10 & 10 & 10 & 10 & 10 & 10 & 10 \\
\hline STATUS & & & & $\mathrm{A}$; & N & I & OL & TED & $\mathrm{FE}$ & RAL & $A B$ \\
\hline
\end{tabular}


IV-B-2. Establish a means of validating computer simulation codes. This will require defining methods of code validation, assembling the data, making the validation tests, and providing a central place for the cer-: tification of analysis tools (computer code algorithms). Determine whether any of the complex load mode adequately predict building energy loads for solar heating and solar heating and cooling systems.

\begin{tabular}{|c|c|c|c|c|c|c|c|c|c|c|c|}
\hline & \multicolumn{3}{|c|}{$\begin{array}{c}\text { SERVICE } \\
\text { HOTWATER }\end{array}$} & \multicolumn{4}{|c|}{ SPACE HEATING } & \multicolumn{5}{c|}{ SPACE COOLING } \\
& $\begin{array}{c}\mathrm{W} 1 \\
\text { PATH }\end{array}$ & $\mathrm{W} 2$ & $\mathrm{H} 1$ & $\mathrm{H} 2$ & $\mathrm{H} 3$ & $\mathrm{H} 4$ & $\mathrm{C} 1$ & $\mathrm{C} 2$ & $\mathrm{C} 3$ & $\mathrm{C} 4$ & $\mathrm{C} 5$ \\
\hline $\begin{array}{c}\text { IMPORTANCE } \\
\text { NO. }\end{array}$ & 10 & 10 & 10 & 10 & 10 & 10 & 10 & 10 & 10 & 10 & 10 \\
\hline STATUS & \multicolumn{3}{|c|}{ FUNDED RFP/PRDA } \\
\hline
\end{tabular}

IV-B-3. Prepare standardized format for data for use in computer simulation analysis. Include solar radiation and climatic information from several cities for representative (standard) years. This format must contain all parameters required by researchers (wind direction as well as speed, for example).

\begin{tabular}{|c|c|c|c|c|c|c|c|c|c|c|c|}
\hline \multirow{2}{*}{ PATH } & \multicolumn{3}{|c|}{$\begin{array}{c}\text { SERVICE } \\
\text { HOT WATER } \\
\text { W1 }\end{array}$} & \multicolumn{4}{|c|}{ SPACE HEATING } & \multicolumn{4}{c|}{ SPACE COOLING } \\
& W1 & W2 & H1 & H2 & H3 & H4 & C1 & C2 & C3 & C4 & C5 \\
\hline $\begin{array}{c}\text { IMPORTANCE } \\
\text { NO. }\end{array}$ & 7 & 7 & 8 & 7 & 7 & 8 & 7 & 7 & 7 & 7 & 7 \\
\hline STATUS & \multicolumn{3}{|l|}{ FUNDED RFP/PRDA } \\
\hline
\end{tabular}

IV-B-4. Analyze the costs for installing, operating, and maintaining current solar heating and heating and cooling systems. Develop a statistical data base for these costs and set realistic guidelines for them. Distribute the guidelines to appropriate industries, along with recommendations for meeting the guidelines.

\begin{tabular}{|c|c|c|c|c|c|c|c|c|c|c|c|}
\hline \multirow[t]{2}{*}{ PATH } & \multicolumn{2}{|c|}{$\begin{array}{l}\text { SERVICE } \\
\text { HOT WATER }\end{array}$} & \multicolumn{4}{|c|}{ SPACE HEATING } & \multicolumn{5}{|c|}{ SPACE COOLING } \\
\hline & w1 & w2 & $\mathrm{H} 1$ & $\mathrm{H} 2$ & H3 & $\mathrm{H} 4$ & $\mathrm{Cl}$ & $\mathrm{C} 2$ & $\mathrm{C} 3$ & $\mathrm{C} 4$ & $\mathrm{C5}$ \\
\hline $\begin{array}{c}\text { IMPORTANCE } \\
\text { NO. }\end{array}$ & 9 & 7 & 8 & 8 & 8 & 9 & 7 & 7 & 7 & 7 & 7 \\
\hline STATUS & FU & & & & & & & & & & \\
\hline
\end{tabular}


IV-B-5. Develop reference year data or typical-year solar plus weather radiation that can be used in solar energy analysis for various localities. Use localities where hourly readings have been taken.

s".

\begin{tabular}{|c|c|c|c|c|c|c|c|c|c|c|c|}
\hline \multirow[t]{2}{*}{ PATH } & \multicolumn{2}{|c|}{$\begin{array}{l}\text { SERVICE } \\
\text { HOT WATER }\end{array}$} & \multicolumn{4}{|c|}{ SPACE HEATING } & \multicolumn{5}{|c|}{ SPACE COOLING } \\
\hline & $w 1$ & w2 & $\mathrm{HI}$ & $\mathrm{H} 2$ & $\mathrm{H3}$ & $\mathrm{H} 4$ & $c_{1}$ & $\mathrm{C} 2$ & $\mathrm{C} 3$ & $\mathrm{C} 4$ & $\mathrm{C5}$ \\
\hline $\begin{array}{l}\text { IMPORTANCE } \\
\text { NO. }\end{array}$ & 9 & 9 & 9 & 9 & 9 & 9 & 9 & 9 & 9 & 9 & 9 \\
\hline STATUS & . & & & & & & & & & & \\
\hline
\end{tabular}

IV-B-6. Coordinate the efforts of DOE and other groups to accumulate and organize solar radiation and climatic data, including additional hourly solar radiation stations with particular emphasis on Beam radiation.

\begin{tabular}{|c|c|c|c|c|c|c|c|c|c|c|c|}
\hline \multirow{2}{*}{ PATH } & \multicolumn{3}{|c|}{ SERVICE } & \multicolumn{4}{|c|}{} & \multicolumn{5}{c|}{ SPACE COOLING } \\
& HOT WATER & \multicolumn{3}{|c|}{ SPACE HEATING } \\
& W1 & W2 & H1 & H2 & H3 & H4 & C1 & C2 & C3 & C4 & C5 \\
\hline $\begin{array}{c}\text { IMPORTANCE } \\
\text { NO. }\end{array}$ & 5 & 5 & 6 & 7 & 6 & 5 & 8 & 8 & 7 & 2 & \\
\hline STATUS & \multicolumn{3}{|c|}{ FEDERAL LAB } \\
\hline
\end{tabular}

IV-B-7. Prepare, validate, and standardize a method for separating measurements of direct and diffuse solar radiation. The method should make possible the derivation of direct radiation values from total horizontal radiation readings.

\begin{tabular}{|c|c|c|c|c|c|c|c|c|c|c|c|}
\hline \multirow{2}{*}{ PATH } & \multicolumn{3}{|c|}{ SERVICE } & \multicolumn{4}{|c|}{} & \multicolumn{5}{c|}{ SPACE COOLING } \\
& HOT WATER & \multicolumn{3}{|c|}{ SPACE HEATING } \\
& W1 & W2 & H1 & H2 & H3 & H4 & C1 & C2 & C3 & 'C4 & C5 \\
\hline $\begin{array}{c}\text { IMPORTANCE } \\
\text { NO. }\end{array}$ & 6 & 3 & 5 & 8 & 3 & 3 & 8 & 3 & 3 & & \\
\hline STATUS & \multicolumn{3}{|c|}{ FEDERAL LAB } \\
\hline
\end{tabular}


IV-B-8. Set up a Federal center for computer based solar and climatic data. The data base should include fundamental data and reduced or summary data derived during other tasks.

\begin{tabular}{|c|c|c|c|c|c|c|c|c|c|c|c|}
\hline & \multicolumn{3}{|c|}{$\begin{array}{c}\text { SERVICE } \\
\text { POT WATH }\end{array}$} & \multicolumn{4}{|c|}{ SPACE HEATING } & \multicolumn{5}{c|}{ SPACE COOLING } \\
& W1 & W2 & H1 & H2 & H3 & H4 & C1 & C2 & C3 & C4 & C5 \\
\hline $\begin{array}{c}\text { IMPORTANCE } \\
\text { NO. }\end{array}$ & 5 & 5 & 5 & 4 & 3 & 3 & 5 & 5 & 5 & 6 &. \\
\hline STATUS & \multicolumn{3}{|c|}{ COMPLETED } \\
\hline
\end{tabular}

IV-B-9. Determine and validate a method for deriving the daily horizontal solar radiation from other commonly recorded weather phenomena (cloud cover, wind, relative humidity, etc.). The method must be accurate for measurements over extended periods rather than for any given day. Use the method with data from as many stations as possible to arrive at estimates of monthly radiation: Merge the corresponding degree day heating and cooling data with the radiation value. Prepare maps of this information with fine resolution (approximately 20 miles) for the U.S.

\begin{tabular}{|c|c|c|c|c|c|c|c|c|c|c|c|}
\hline \multirow{2}{*}{ PATH } & \multicolumn{3}{|c|}{$\begin{array}{c}\text { SERVICE } \\
\text { HOT WATER } \\
\end{array}$} & \multicolumn{4}{|c|}{ SPACE HEATING } & \multicolumn{4}{c|}{ SPACE COOLING } \\
& W1 & W2 & H1 & H2 & H3 & H4 & C1 & C2 & C3 & C4 & C5 \\
\hline $\begin{array}{c}\text { IMPORTANCE } \\
\text { NO. }\end{array}$ & 6 & 6 & 6 & 6 & 6 & 7 & 2 & 6 & 6 & 2 & \\
\hline STATUS & \multicolumn{3}{|c|}{ RENEWAL (UNSOLICTTED) } \\
\hline
\end{tabular}

IV-B-10. Determine the relative importance of diffuse and direct-beam solar radiation for various solar heating and solar heating and cooling applications and climatic regions.

\begin{tabular}{|c|c|c|c|c|c|c|c|c|c|c|c|}
\hline \multirow[t]{2}{*}{ PATH } & \multicolumn{2}{|c|}{$\begin{array}{l}\text { SERVICE } \\
\text { HOT WATER }\end{array}$} & \multicolumn{4}{|c|}{ SPACE HEATING } & \multicolumn{5}{|c|}{ SPACE COOLING } \\
\hline & w1 & w2 & $\mathrm{HI}$ & $\mathrm{H} 2$ & $\mathrm{H3}$ & $\mathrm{H} 4$ & $\mathrm{C}_{1}$ & $\mathrm{C} 2$ & $\mathrm{C} 3$ & $\mathrm{C} 4$ & $\mathrm{C} 5$ \\
\hline $\begin{array}{c}\text { IMPORTANCE } \\
\text { NO. }\end{array}$ & 2 & 2 & 2 & 7 & 2 & 2 & 8 & 8 & 8 & & \\
\hline STATUS & & & & & & & & & & & \\
\hline
\end{tabular}


IV-B-11. Prepare handbooks identifying the cost and performance characteristics of solar domestic hot water, space hcating and cooling systems, and agricultural/industrial process heat applications.

\begin{tabular}{|c|c|c|c|c|c|c|c|c|c|c|c|}
\hline \multirow[t]{2}{*}{ PATH } & \multicolumn{2}{|c|}{$\begin{array}{l}\text { SERVICE } \\
\text { HOT WATER }\end{array}$} & \multicolumn{4}{|c|}{ SPACE HEATING } & \multicolumn{5}{|c|}{ SPACE COOLING } \\
\hline & w1 & w2 & $\mathrm{H} 1$ & $\mathrm{H} 2$ & $\mathrm{H3}$ & $\mathrm{H} 4$ & $\mathrm{Cl}$ & $\mathrm{C} 2$ & $\mathrm{C} 3$ & $\mathrm{C} 4$ & $\mathrm{C} 5$ \\
\hline $\begin{array}{c}\text { IMPORTANCE } \\
\text { NO. }\end{array}$ & 10 & 10 & 10 & 10 & 10 & 10 & 10 & 10 & 10 & 10 & 10 \\
\hline STATUS & & & & & & & & & & & \\
\hline
\end{tabular}

\begin{tabular}{|c|c|c|c|c|c|c|c|c|c|c|c|}
\hline \multirow[t]{2}{*}{ PATH } & \multicolumn{3}{|c|}{$\begin{array}{l}\text { SHELTER } \\
\text { HEATING }\end{array}$} & \multicolumn{3}{|c|}{ DRYING } & \multicolumn{2}{|c|}{$\begin{array}{l}\text { PROCESS } \\
\text { HOT WATER }\end{array}$} & \multirow{2}{*}{$\begin{array}{c}\text { PROCESS } \\
\text { STEAM } \\
\text { SL }\end{array}$} & \multicolumn{2}{|c|}{$\begin{array}{l}\text { COOLING } \\
\text { REFRIG- } \\
\text { ERATION }\end{array}$} \\
\hline & $H P$ & HA & HL & DD & DA & DL & WL & WA & & $\mathrm{CP}$ & CA \\
\hline IMPORTANCE NO. & .10 & 10 & 10 & 10 & 10 & 10 & 10 & 10 & 10 & 10 & 1.0 \\
\hline STATUS & & & & & & & & & & & \\
\hline
\end{tabular}

IV-B-12. Identify, on a regional basis, achievable cost goals for solar heating and cooling systems that result in economic viability for retrofit and new solar heating and cooling systems.

\begin{tabular}{|c|c|c|c|c|c|c|c|c|c|c|c|}
\hline \multirow[t]{2}{*}{ PATH } & \multicolumn{2}{|c|}{$\begin{array}{c}\text { SERVICE } \\
\text { HOT WATER }\end{array}$} & \multicolumn{4}{|c|}{ SPACE HEATING } & \multicolumn{5}{|c|}{ SPACE COOLING } \\
\hline & W1 & W2 & $\mathrm{HI}$ & $\mathrm{H} 2$ & $\mathrm{H3}$ & $\mathrm{H} 4$ & $\mathrm{Cl}$ & $\mathrm{C}_{2}$ & $\mathrm{C} 3$ & $\mathrm{C} 4$ & $\mathrm{C5}$ \\
\hline $\begin{array}{c}\text { IMPORTANCE } \\
\text { NO. }\end{array}$ & 7 & 7 & 7 & 7 & 7 & 7 & 7 & 7 & 7 & 7 & 7 \\
\hline STATUS & & ED & ' & DA & & & & & & & \\
\hline
\end{tabular}




\section{IV-C. Controllers, Valves, and Actuator Components}

IV $-\mathrm{C}-1$. Evaluate the purchase of more sophisticated control logic and additional sensors and control $\bar{c}$ tuators for residential and small commercial solar energy systems. Study the trade-off between first costs a। the savings resulting from use of these components. Develop control algorithms for heating and cooling systems; the algorithms should control the time of day that auxiliary electrical energy is used. Check the algorithms against existing computer simulation programs. Investigate the possible use of systems that anticipate the next day's energy requirements and store energy accordingly. (These "smart" systems avoid the creation of peak demand loads.) Test the sensitivity of the system to storage size when the system is operated in the mode for avoiding peak loads.

\begin{tabular}{|c|c|c|c|c|c|c|c|c|c|c|c|}
\hline \multirow[t]{2}{*}{ PATH } & \multicolumn{2}{|c|}{$\begin{array}{l}\text { SERVICE } \\
\text { HOT WATER }\end{array}$} & \multicolumn{4}{|c|}{ SPACE HEATING } & \multicolumn{5}{|c|}{ SPACE COOLING } \\
\hline & $w_{1}$ & w2 & $\mathrm{H1}$ & $\mathrm{H} 2$ & H3 & $\mathrm{H} 4$ & c1 & $\mathrm{C} 2$ & c3 & $\mathrm{C4}$ & $\mathrm{C5}$ \\
\hline $\begin{array}{c}\text { IMPORTANCE } \\
\text { NO. }\end{array}$ & 5 & 5 & 7 & 3 & 8 & 8 & 5 & 5 & 5 & 5 & 8 \\
\hline STATUS & $\mathrm{FU}$ & & & & NEV & 15 & OLI & TED & FEI & AI. & $\mathrm{B}$ \\
\hline
\end{tabular}

IV-C-2. Identify special control logic and control actuator requirements for passive solar energy systems.

\begin{tabular}{|c|c|c|c|c|c|c|c|c|c|c|c|}
\hline \multirow[t]{2}{*}{ PATH } & \multicolumn{2}{|c|}{$\begin{array}{l}\text { SERVICE } \\
\text { HOT WATER }\end{array}$} & \multicolumn{4}{|c|}{ SPACE HEATING } & \multicolumn{5}{|c|}{ SPACE COOLING } \\
\hline & $w_{1}$ & w2 & $\mathrm{H1}$ & $\mathrm{H} 2$ & H3 & $\mathrm{H} 4$ & $\mathrm{c} 1$ & $\mathrm{C} 2$ & C3 & $\mathrm{C}^{\prime}$ & $\mathrm{C5}$ \\
\hline $\begin{array}{c}\text { IMPORTANCE } \\
\text { NO. }\end{array}$ & & & 6 & 8 & & & & & & 8 & \\
\hline STATUS & & $E D$ & 5 & & & & & & & & \\
\hline
\end{tabular}

IV-C-3. Investigate control strategies for agricultural and industrial process heat applications.

\begin{tabular}{|c|c|c|c|c|c|c|c|c|c|c|c|}
\hline \multirow[t]{2}{*}{ PATH } & \multicolumn{3}{|c|}{$\begin{array}{l}\text { SHELTER } \\
\text { HEATING }\end{array}$} & \multicolumn{3}{|c|}{ DRYING } & \multicolumn{2}{|c|}{$\begin{array}{l}\text { PŔOCESS } \\
\text { HOT WATER }\end{array}$} & \multirow{2}{*}{$\begin{array}{c}\text { PROCESS } \\
\text { STEAM } \\
\text { SL } \\
\end{array}$} & \multicolumn{2}{|c|}{$\begin{array}{l}\text { COOLING/ } \\
\text { REFRIG- } \\
\text { ERATION }\end{array}$} \\
\hline & HP & HA & $\mathrm{HL}$. & DD & DA & $\mathrm{DL}$ & $W L$ & WA & & $\mathrm{CP}$ & CA \\
\hline IMPORTANCE NO. & 5 & 5 & 5 & 5 & 5 & 5 & 5 & 5 & 5 & 5 & 5 \\
\hline . STATUS & & & & & & & & & & & \\
\hline
\end{tabular}


IV-C-4. Determine from the suppliers and installers of all sizes of solar energy systems whether new controls are necessary for these systems.

\begin{tabular}{|c|c|c|c|c|c|c|c|c|c|c|c|}
\hline \multirow[t]{2}{*}{ PATH } & \multicolumn{2}{|c|}{$\begin{array}{c}\text { SERVICE } \\
\text { HOT WATER }\end{array}$} & \multicolumn{4}{|c|}{ SPACE HEATING } & \multicolumn{5}{|c|}{ SPACE COOLING } \\
\hline & w1 & w2 & $\mathrm{H1}$ & $\mathrm{H} 2$ & H3 & H4 & C1 & $\mathrm{C} 2$ & C3 & $\mathrm{C} 4$ & $\mathrm{C5}$ \\
\hline $\begin{array}{c}\text { IMPORTANCE } \\
\text { NO. }\end{array}$ & & & 6 & & 4 & 3 & 5 & 5 & 4 & . & 6 \\
\hline STATUS & \multicolumn{2}{|c|}{ EUNDED } & RFP/ & & & & & & & & \\
\hline
\end{tabular}

IV-C-5. Develop control concepts for heating and cooling systems (using electricity as backup) that can reduce the peak loading problem for electric utilities.

\begin{tabular}{|c|c|c|c|c|c|c|c|c|c|c|c|}
\hline \multirow[t]{2}{*}{ PATH } & \multicolumn{2}{|c|}{$\begin{array}{l}\text { SERVICE } \\
\text { HOT WATER }\end{array}$} & \multicolumn{4}{|c|}{ SPACE HEATING } & \multicolumn{5}{|c|}{ SPACE COOLING } \\
\hline & w1 & w2 & $\mathrm{H1}$ & $\mathrm{H} 2$ & H3 & $\mathrm{H4}$ & $\mathrm{Cl}$ & $\mathrm{C} 2$ & $\mathrm{C3}$ & $\mathrm{C} 4$ & $\mathrm{C} 5$ \\
\hline $\begin{array}{l}\text { IMPORTANCE } \\
\text { NO. }\end{array}$ & 5 & 5 & 6 & & 6 & 6 & 7 & 7 & 7 & & 7 \\
\hline STATUS & \multicolumn{2}{|c|}{ FUNDED } & RFP/ & $\mathrm{DA}$ & & & & & & & \\
\hline
\end{tabular}

IV-C-6. Design and develop novel and innovative controllers that represent significant advances in the state of the art. The measures of such advances are improved performance (lower operating costs) of the system being controlled, increased cost effectiveness, and/or reduced controller cost.

\begin{tabular}{|c|c|c|c|c|c|c|c|c|c|c|c|}
\hline \multirow{2}{*}{ PATH } & \multicolumn{3}{|c|}{$\begin{array}{c}\text { SERVICE } \\
\text { HOT WATER }\end{array}$} & \multicolumn{4}{|c|}{ SPACE HEATING } & \multicolumn{4}{c|}{ SPACE COOLING } \\
& W1 & W2 & H1 & H2 & H3 & H4 & C1 & C2 & C3 & C4 & C5 \\
\hline $\begin{array}{c}\text { IMPORTANCE } \\
\text { NO. }\end{array}$ & 7 & 7 & 7 & 7 & 7 & 7 & 7 & 7 & 7 & 7 & 7 \\
\hline STATUS & \multicolumn{2}{|c|}{ FUNDED } & RFP/PRDA & & & & \\
\hline
\end{tabular}




\section{IV-D. Instrumentation and Data Acquisition}

IV-D-1. Develop a low cost instrumentation and data acquisition system for monitoring the performance 0 advanced solar heated and solar heated and cooled buildings. This system should emphasize the measure ment of the total integrated energy collected by the solar energy system and the total energy used by the building.

\begin{tabular}{|c|c|c|c|c|c|c|c|c|c|c|c|}
\hline \multirow[t]{2}{*}{ PATH } & \multicolumn{2}{|c|}{$\begin{array}{c}\text { SERVICE } \\
\text { HOT WATER }\end{array}$} & \multicolumn{4}{|c|}{ SPACE HEATING } & \multicolumn{5}{|c|}{ SPACE COOLING } \\
\hline & w1 & w2 & H1 & $\mathrm{H} 2$ & H3 & $\mathrm{H} 4$ & $\mathrm{C1}$ & $\mathrm{C} 2$ & $\mathrm{C3}$ & $\mathrm{C} 4$ & $\mathrm{C5}$ \\
\hline $\begin{array}{c}\text { IMPORTANCE } \\
\text { NO. }\end{array}$ & 8 & 8 & 8 & 8 & 8 & 8 & 8 & 8 & 8 & 8 & 8 \\
\hline STATUS & & & & & & & & & & & \\
\hline
\end{tabular}

IV-D-2. Investigate methods of compressing systems data by pre-processing. This will reduce the quantity of data which must be stored and provide a condensed output that will be more easily understood.

\begin{tabular}{|c|c|c|c|c|c|c|c|c|c|c|c|}
\hline \multirow[t]{2}{*}{ PATH } & \multicolumn{2}{|c|}{$\begin{array}{l}\text { SERVICE } \\
\text { HOT WATER }\end{array}$} & \multicolumn{4}{|c|}{ SPACE HEATING } & \multicolumn{5}{|c|}{ SPACE COOLING } \\
\hline & W1 & w2 & $\mathrm{H} 1$ & $\mathrm{H} 2$ & H3. & $\mathrm{H} 4$ & C1 & $\mathrm{C} 2$ & $\mathrm{C} 3$ & $\mathrm{C}_{4}$ & $\mathrm{C} 5$ \\
\hline $\begin{array}{c}\text { IMPORTANCE } \\
\text { NO. }\end{array}$ & 3 & 3 & 4 & 4 & 4 & 4 & 4 & 4 & 4 & 4 & 4 \\
\hline STATUS & & & & & & & & & & & \\
\hline
\end{tabular}

IV-D-3. Determine instrumentation requirements for the detailed evaluation of advanced passive and active solar energy systems, and agricultural and process heat applications.

\begin{tabular}{|c|c|c|c|c|c|c|c|c|c|c|c|}
\hline \multirow[t]{2}{*}{ PATH } & \multicolumn{2}{|c|}{$\begin{array}{l}\text { SERVICE } \\
\text { HOT WATER }\end{array}$} & \multicolumn{4}{|c|}{ SPACE HEATING } & \multicolumn{5}{|c|}{ SPACE COOLING } \\
\hline & W1 & w2 & $\mathrm{H1}$ & $\mathrm{H} 2$ & H3 & $\mathrm{H} 4$ & C1 & $\mathrm{C}_{2}$ & $\mathrm{C3}$ & $\mathrm{C} 4$ & $\mathrm{C5}$ \\
\hline $\begin{array}{l}\text { IMPORTANCE } \\
\text { NO. }\end{array}$ & 8 & 8 & 8 & 8 & 8 & 8 & 8 & 8 & 8 & 8 & 7 \\
\hline STATUS & & & & & & & & & & & \\
\hline
\end{tabular}




\begin{tabular}{|c|c|c|c|c|c|c|c|c|c|c|c|}
\hline \multirow[t]{2}{*}{ PATH } & \multicolumn{3}{|c|}{$\begin{array}{l}\text { SHELTER } \\
\text { HEATING }\end{array}$} & \multicolumn{3}{|c|}{ DRYING } & \multicolumn{2}{|c|}{$\begin{array}{l}\text { PROCESS } \\
\text { HOT WATER }\end{array}$} & \multirow{2}{*}{ 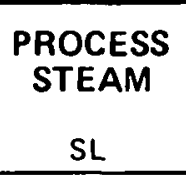 } & \multicolumn{2}{|c|}{$\begin{array}{l}\text { COOLING/ } \\
\text { REFRIG- } \\
\text { ERATION }\end{array}$} \\
\hline & $\mathrm{HP}$ & HA & $\mathrm{HL}$ & $\mathrm{DD}$ & DA & $\mathrm{DL}$ & WL & WA & & $\mathrm{CP}$ & $\mathrm{CA}$ \\
\hline IMPORTANCE NO. & 8 & 8 & 8 & 8 & 8 & 8 & 8 & 8 & 8 & 8 & 8 \\
\hline STATUS & & & & & & & & & & & \\
\hline
\end{tabular}

IV-D-4. Measure infrared spectral characteristics of atmospheric radiation in several diverse climatic regions where summer cooling is required. Attempt to establish correlation between this data and commonly measured meteorological parameters.

\begin{tabular}{|c|c|c|c|c|c|c|c|c|c|c|c|}
\hline \multirow[t]{2}{*}{ PATH } & \multicolumn{2}{|c|}{$\begin{array}{l}\text { SERVICE } \\
\text { HOT WATER }\end{array}$} & \multicolumn{4}{|c|}{ SPACE HEATING } & \multicolumn{5}{|c|}{ SPACE COOLING } \\
\hline & w1 & w2 & $\mathrm{H} 1$ & $\mathrm{H} 2$ & H3 & $\mathrm{H} 4$ & $\mathrm{C}_{1}$ & $\mathrm{C} 2$ & $\mathrm{C} 3$ & $\mathrm{C4}$ & $\mathrm{C5}$ \\
\hline $\begin{array}{l}\text { IMPORTANCE } \\
\text { NO. }\end{array}$ & & & & 5 & & & & & & 5 & \\
\hline STATUS & & & & & & & & & & & \\
\hline
\end{tabular}

IV-D-5. Develop microprocessor-based plug-in diagnostic systems to analyze system performance and to detect system failures. The diagnostic systems will be used in large, complex solar energy installations."

\begin{tabular}{|c|c|c|c|c|c|c|c|c|c|c|c|}
\hline & \multicolumn{2}{|c|}{$\begin{array}{c}\text { SERVICE } \\
\text { POT WATH }\end{array}$} & \multicolumn{4}{|c|}{ SPACE HEATING } & \multicolumn{5}{c|}{ SPACE COOLING } \\
& W1 & W2 & H1 & H2 & H3 & H4 & C1 & C2 & C3 & C4 & C5 \\
\hline $\begin{array}{c}\text { IMPORTANCE } \\
\text { NO. }\end{array}$ & & & & & & & & & & 5 & \\
\hline STATUS & & & & & & & & & & & \\
\hline
\end{tabular}




\section{IV-E. Passive and Hybrid Solar Energy Systems}

IV-E-1. Identify effective ways to control energy flow in passive solar energy systems. Include methods $f_{i}$ controlling both the intake and the release of solar energy, and investigate how the methods selected i. fluence the timing and effectiveness of the overall system, including solar-activated devices.

\begin{tabular}{|c|c|c|c|c|c|c|c|c|c|c|c|}
\hline \multirow[t]{2}{*}{ PATH } & \multicolumn{2}{|c|}{$\begin{array}{l}\text { SERVICE } \\
\text { HOT WATER }\end{array}$} & \multicolumn{4}{|c|}{ SPACE HEATING } & \multicolumn{5}{|c|}{ SPACE COOLING } \\
\hline & $w 1$ & W2 & $\mathrm{H1}$ & $\mathrm{H} 2$ & H3 & $\mathrm{H4}$ & $\mathrm{Cl}$ & C2 & $\mathrm{C} 3$ & $\mathrm{C} 4$ & $\mathrm{C} 5$ \\
\hline $\begin{array}{l}\text { IMPORTANCE } \\
\text { NO. }\end{array}$ & & & 6 & 10 & & & & & & 8 & \\
\hline STATUS & & & & & & & & & & & $\cdot$ \\
\hline
\end{tabular}

IV-E-2. Investigate and tabulate the add-on cost characteristics of the various passive solar energy systems by reviewing existing passive solar energy system installations and costs, using standard cost-estimating procedures for buildings.

\begin{tabular}{|c|c|c|c|c|c|c|c|c|c|c|c|}
\hline \multirow[t]{2}{*}{ PATH } & \multicolumn{2}{|c|}{$\begin{array}{l}\text { SERVICE } \\
\text { HOT WATER }\end{array}$} & \multicolumn{4}{|c|}{ SPACE HEATING } & \multicolumn{5}{|c|}{ SPACE COOLING } \\
\hline & $w 1$ & w2 & $\mathrm{H1}$ & $\mathrm{H} 2$ & H3 & $\mathrm{H} 4$ & $\mathrm{Cl}$ & $\mathrm{C}_{2}$ & $\mathrm{C} 3$ & $\mathrm{C} 4$ & $\mathrm{C5}$ \\
\hline $\begin{array}{c}\text { IMPORTANCE } \\
\text { NO. }\end{array}$ & & & 6 & 9 & & & & & & 9 & \\
\hline STATUS & & & & & & & & & & & \\
\hline
\end{tabular}

IV-E-3. Set up computer simulation models for the modeling of passive solar energy heating and cooling systems. Validate the models by comparing them with existing systems and test systems. Use the models to determine passive system life cycle costs and performance characteristics for different climatic zones.

\begin{tabular}{|c|c|c|c|c|c|c|c|c|c|c|c|}
\hline \multirow{2}{*}{ PATH } & \multicolumn{2}{|c|}{$\begin{array}{l}\text { SERVICE } \\
\text { HOT WATER }\end{array}$} & \multicolumn{4}{|c|}{ SPACE HEATING } & \multicolumn{5}{|c|}{ SPACE COOLING } \\
\hline & w1 & w2 & $\mathrm{H1}$ & $\mathrm{H} 2$ & $\mathrm{H} 3$ & $\mathrm{H} 4$ & C1 & $\mathrm{C} 2$ & $\mathrm{C} 3$ & $\mathrm{C} 4$ & $\mathrm{C5}$ \\
\hline $\begin{array}{l}\text { IMPORTANCE } \\
\text { NO. }\end{array}$ & & & 6 & 9 & & & & & & 9 & \\
\hline STATUS & & AL & & & & & & & & & \\
\hline
\end{tabular}


IV-E-4. Extend the evaluation of the passive roof pond collccting concept to better determine nighttime losses to the sky by radiation and to the air by convection and evaporation. Study the concept for different imates and correlate the results with observable weather parameters such as dew point, dry-bulb mperature, cloud cover, and wind velocity

\begin{tabular}{|c|c|c|c|c|c|c|c|c|c|c|c|}
\hline \multirow[t]{2}{*}{ PATH } & \multicolumn{2}{|c|}{$\begin{array}{l}\text { SERVICE } \\
\text { HOT WATER }\end{array}$} & \multicolumn{4}{|c|}{ SPACE HEATING } & \multicolumn{5}{|c|}{ SPACE COOLING } \\
\hline & $w_{1}$ & w2 & $\mathrm{Ht}$ & $\mathrm{H} 2$ & $\mathrm{H} 3$ & $\mathrm{H} 4$ & $\mathrm{C} 1$ & $\mathrm{C} 2$ & C3 & $\mathrm{C} 4$ & $\mathrm{C5}$ \\
\hline $\begin{array}{l}\text { IMPORTANCE } \\
\text { NO. }\end{array}$ & & & 9 & 9 & & & 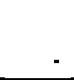 & & & 10 & 9 \\
\hline STATUS & & AL & & & & & & & & & \\
\hline
\end{tabular}

IV-E-5. Analyze air motion effects in various passive and hybrid system configurations. Determine whether or not air motion in these systems is sufficient to satisfy customary comfort conditions within the building.

\begin{tabular}{|c|c|c|c|c|c|c|c|c|c|c|c|}
\hline \multirow[t]{2}{*}{ PATH } & \multicolumn{2}{|c|}{$\begin{array}{l}\text { SERVICE } \\
\text { HOT WATER }\end{array}$} & \multicolumn{4}{|c|}{ SPACE HEATING } & \multicolumn{5}{|c|}{ SPACE COOLING } \\
\hline & $w_{1}$ & W2 & $\mathrm{H} 1$ & $\mathrm{H} 2$ & $\mathrm{H} 3^{\circ}$ & $\mathrm{H} 4$ & $\mathrm{C} 1$ & $\mathrm{C} 2$ & C3 & $\mathrm{C} 4$ & $\mathrm{C5}$ \\
\hline $\begin{array}{c}\text { IMPORTANCE } \\
\text { NO. }\end{array}$ & . & & 4 & 8 & & & & & & 8 & \\
\hline STATUS & & & & & & & & & & & \\
\hline
\end{tabular}

IV-E-6. Define the dynamic characteristics of passive solar heating systems when they are coupled to conventional, active, fossil energy systems. Determine whether the comfort characteristics of passive solar heated buildings are different from those of typical non-passive buildings.

\begin{tabular}{|c|c|c|c|c|c|c|c|c|c|c|c|}
\hline \multirow[t]{2}{*}{ PATH } & \multicolumn{2}{|c|}{$\begin{array}{l}\text { SERVICE } \\
\text { HOT WATER }\end{array}$} & \multicolumn{4}{|c|}{ SPACE HEATING } & \multicolumn{5}{|c|}{ SPACE COOLING } \\
\hline & w1 & w2 & $\mathrm{HI}$ &. $\mathrm{H} 2$ & H3 & $\mathrm{H} 4$ & C1 & $\mathrm{C}_{2}$ & $\mathrm{C3}$ & $\mathrm{C} 4$ & $\mathrm{C5}$ \\
\hline $\begin{array}{c}\text { IMPORTANCE } \\
\text { NO. }\end{array}$ & & & 4 & 6 & & & & & & 6 & \\
\hline STATUS & & & & & & & & & & $*$ & \\
\hline
\end{tabular}


IV-E-7. Devise a way to determine vertical surface solar data from other available solar data.

\begin{tabular}{|c|c|c|c|c|c|c|c|c|c|c|c|}
\hline \multirow[t]{2}{*}{ PATH } & \multicolumn{2}{|c|}{$\begin{array}{l}\text { SERVICE } \\
\text { HOT WATER }\end{array}$} & \multicolumn{4}{|c|}{ SPACE HEATING } & \multicolumn{5}{|c|}{ SPACE COOLING } \\
\hline & w1 & w2 & $\mathrm{H} 1$ & $\mathrm{H} 2$ & $\mathrm{H} 3$ & $\mathrm{H} 4$ & $\mathrm{C} 1$ & $\mathrm{C} 2$ & $\mathrm{C} 3$ & $\mathrm{C} 4$ & $\mathrm{C} 5$ \\
\hline $\begin{array}{c}\text { IMPORTANCE } \\
\text { NO. }\end{array}$ & & & & 8 & 8 & 8 & & & & 8 & \\
\hline STATUS & & & & & & & & & & & \\
\hline
\end{tabular}

IV-E-8. Study applications of thermic diodes to typical buildings.

\begin{tabular}{|c|c|c|c|c|c|c|c|c|c|c|c|}
\hline \multirow{2}{*}{ PATH } & \multicolumn{3}{|c|}{$\begin{array}{c}\text { SERVICE } \\
\text { HOT WATER }\end{array}$} & \multicolumn{4}{|c|}{ SPACE HEATING } & \multicolumn{4}{c|}{ SPACE COOLING } \\
& W1 & W2 & H1 & H2 & H3 & H4 & C1 & C2 & C3 & C4 & C5 \\
\hline $\begin{array}{c}\text { IMPORTANCE } \\
\text { NO. }\end{array}$ & & & 4 & 8 & & & & & & 8 & \\
\hline STATUS & \multicolumn{3}{|c|}{ RENEWAL (UNSOLICITED) } \\
\hline
\end{tabular}

IV-E-9. Study applications of inexpensive heat pipes to passive huildings.

\begin{tabular}{|c|c|c|c|c|c|c|c|c|c|c|c|}
\hline \multirow{2}{*}{ PATH } & \multicolumn{3}{|c|}{$\begin{array}{c}\text { SERVICE } \\
\text { HOT WATER } \\
\end{array}$} & \multicolumn{4}{|c|}{ SPACE HEATING } & \multicolumn{4}{c|}{ SPACE COOLING } \\
& W1 & W2 & H1 & H2 & H3 & H4 & C1 & C2 & C3 & C4 & C5 \\
\hline $\begin{array}{c}\text { IMPORTANCE } \\
\text { NO. }\end{array}$ & & & 3 & 5 & 3 & 3 & & & & & \\
\hline STATUS & \multicolumn{4}{|c|}{ RENEWAL (UNSOLICITED) } \\
\hline
\end{tabular}


IV-E-10. Investigate the possibilities for passive wall heating by thermosiphon from flat plate liquid collectors.

\begin{tabular}{|c|c|c|c|c|c|c|c|c|c|c|c|}
\hline \multirow[t]{2}{*}{ PATH } & \multicolumn{2}{|c|}{$\begin{array}{l}\text { SERVICE } \\
\text { HOT WATER }\end{array}$} & \multicolumn{4}{|c|}{ SPACE HEATING } & \multicolumn{5}{|c|}{ SPACE COOLING } \\
\hline & $w_{1}$ & w2 & $\mathrm{H} 1$ & $\mathrm{H} 2$ & $\mathrm{H3}$ & $\mathrm{H}_{4}$ & $\mathrm{C}_{1}$ & $\mathrm{C} 2$ & $\mathrm{C} 3$ & $\mathrm{C} 4$ & $\mathrm{C} 5$ \\
\hline $\begin{array}{c}\text { IMPORTANCE } \\
\text { NO. }\end{array}$ & & & & 8 & & 8 & & & . & & \\
\hline STATUS & & $A L$ & 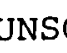 & $T_{T}$ & & & & & & & \\
\hline
\end{tabular}

IV-E-11. Examine the possibility of using an air thermosiphon to heat or cool a rock bed in a passive system.

\begin{tabular}{|c|c|c|c|c|c|c|c|c|c|c|c|}
\hline \multirow[t]{2}{*}{ PATH } & \multicolumn{2}{|c|}{$\begin{array}{l}\text { SERVICE } \\
\text { HOT WATER }\end{array}$} & \multicolumn{4}{|c|}{ SPACE HEATING } & \multicolumn{5}{|c|}{ SPACE COOLING } \\
\hline & W1 & W2 & $\mathrm{H} 1$ & $\mathrm{H} 2$ & $\mathrm{H} 3$ & $\mathrm{H} 4$ & $\mathrm{C} 1$ & $\mathrm{C} 2$ & C3 & $\mathrm{C} 4$ & $\mathrm{C} 5$ \\
\hline $\begin{array}{c}\text { IMPORTANCE } \\
\text { NO. }\end{array}$ & & & & 8 & 7 & 7 & & & & 8 & \\
\hline STATUS & & IAL & JNS & CITE & i & $\mathrm{EF}$ & 7 & & & & \\
\hline
\end{tabular}

IV-E-12. Investigate heat transport fluids that expand on cooling to provide the possibility of a reverse thermosiphon.

\begin{tabular}{|c|c|c|c|c|c|c|c|c|c|c|c|}
\hline & \multicolumn{3}{|c|}{$\begin{array}{c}\text { SERVICE } \\
\text { POT WATER } \\
\text { POTH }\end{array}$} & \multicolumn{4}{|c|}{ SPACE HEATING } & \multicolumn{5}{c|}{ SPACE COOLING } \\
& W1 & W2 & H1 & H2 & H3 & H4 & C1 & C2 & C3 & C4 & C5 \\
\hline $\begin{array}{c}\text { IMPORTANCE } \\
\text { NO. }\end{array}$ & & & & 7 & & & & & & & \\
\hline STATUS & \multicolumn{3}{|c|}{ RENEWAL (UNSOLICITED). } \\
\hline
\end{tabular}


IV-E-13: Identify optimized passive and hybrid heating and cooling systems and predict performance of such systems.

\begin{tabular}{|c|c|c|c|c|c|c|c|c|c|c|c|}
\hline \multirow[t]{2}{*}{ PATH } & \multicolumn{2}{|c|}{$\begin{array}{l}\text { SERVICEE } \\
\text { HOT WATER }\end{array}$} & \multicolumn{4}{|c|}{ SPACE HEATING } & \multicolumn{5}{|c|}{ SPACE COOLING } \\
\hline & W1 & w2 & $\mathrm{HI}$ & $\mathrm{H} 2$ & H3 & $\mathrm{H} 4$ & $\mathrm{Cl}$ & $\mathrm{C} 2$ & $\mathrm{C} 3$ & $\mathrm{C} 4$ & C5 \\
\hline $\begin{array}{c}\text { IMPORTANCE } \\
\text { NO. }\end{array}$ & & & 6 & 10 & & & & & & 5 & 6 \\
\hline STATUS & & & & & & & & & & & \\
\hline
\end{tabular}

IV-E-14. Design and construct buildings that incorporate innovative concepts for passive hybrid solar heating and/or cooling systems. Monitor and evaluate building performance and choose the designs that arc most effective for various climatic regions.

\begin{tabular}{|c|c|c|c|c|c|c|c|c|c|c|c|}
\hline \multirow[t]{2}{*}{ PAT.H } & \multicolumn{2}{|c|}{$\begin{array}{l}\text { SERVICE } \\
\text { HOT WATER }\end{array}$} & \multicolumn{4}{|c|}{ SPACE HEATING } & \multicolumn{5}{|c|}{ SPACE COOLING } \\
\hline & W1 & W2 & $\mathrm{H} 1$ & $\mathrm{H} 2$ & $\mathrm{H} 3$ & $\mathrm{H} 4$ & $\mathrm{Cl}$ & $\mathrm{C} 2$ & $\mathrm{C3}$ & $\mathrm{C} 4$ & $\mathrm{C} 5$ \\
\hline $\begin{array}{c}\text { IMPORTANCE } \\
\text { NO. }\end{array}$ & & & 6 & 8 & & & & & & 8 & 6 \\
\hline STATUS & & DED & RFP & $\mathrm{RDA}$ & & & & & & & 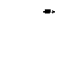 \\
\hline
\end{tabular}

IV-E-15. Develop architectural concepts that use passive or hybrid solar heating and/or cooling techniques. Select techniques for development from among those found most promising in preliminary studies.

\begin{tabular}{|c|c|c|c|c|c|c|c|c|c|c|c|}
\hline \multirow[t]{2}{*}{ PATH } & \multicolumn{2}{|c|}{$\begin{array}{l}\text { SERVICE } \\
\text { HOT WATER }\end{array}$} & \multicolumn{4}{|c|}{ SPACE HEATING } & \multicolumn{5}{|c|}{ SPACE COOLING } \\
\hline & W1 & w2 & $\mathrm{H} 1$ & $\mathrm{H} 2$ & $\mathrm{H} 3$ & $\mathrm{H} 4$ & $\mathrm{C} 1$ & $\mathrm{C} 2$ & $\mathrm{C} 3$ & $\mathrm{C4}$ & $\mathrm{C} 5$ \\
\hline $\begin{array}{l}\text { IMPORTANCE } \\
\text { NO. }\end{array}$ & & & 6 & 6 & & & & & . & 6 & 6 \\
\hline STATUS' & & 1 & & & & & & & & & \\
\hline
\end{tabular}


IV-E-16. Study the potential of passive/hybrid systems for greenhouses/rural residences and animal shelters in various regions of the country.

\begin{tabular}{|c|c|c|c|c|c|c|c|c|c|c|c|}
\hline \multirow[t]{2}{*}{ PATH } & \multicolumn{3}{|c|}{$\begin{array}{l}\text { SHELTER } \\
\text { HEATING }\end{array}$} & \multicolumn{3}{|c|}{ DRYING } & \multicolumn{2}{|c|}{$\begin{array}{l}\text { PROCESS } \\
\text { HOT WATER }\end{array}$} & \multirow{2}{*}{$\begin{array}{c}\text { PROCESS } \\
\text { STEAM } \\
\text { SL } \\
\end{array}$} & \multicolumn{2}{|c|}{$\begin{array}{l}\text { COOLING/ } \\
\text { REFRIG- } \\
\text { ERATION }\end{array}$} \\
\hline & HP & HA & $H L$ & $\mathrm{DD}$ & DA & $\mathrm{DL}$ & WL & WA & & $\mathrm{CP}$ & CA \\
\hline IMPORTANCE NO. & 9 & 4 & 4 & & 4 & 4 & 4 & 4 & & 10 & \\
\hline STATUS & & דת & (UN & $T \Omega$ & & & & & & & \\
\hline
\end{tabular}

IV-E-17. Provide a detailed breakdown of the incremental costs associated with passive techniques for heating and cooling. The study should analyze cost items that are dependent upon building class or geographical region. The study should also identify cost goals for passive systems and establish a methodology and schedule for achieving these goals.

\begin{tabular}{|c|c|c|c|c|c|c|c|c|c|c|c|}
\hline \multirow[t]{2}{*}{ PATH } & \multicolumn{2}{|c|}{$\begin{array}{l}\text { SERVICE } \\
\text { HOT WATER }\end{array}$} & \multicolumn{4}{|c|}{ SPACE HEATING } & \multicolumn{5}{|c|}{ SPACE COOLING } \\
\hline & W1 & W2 & H1 & $\mathrm{H} 2$ & H3 & $\mathrm{H} 4$ & $\mathrm{Cl}$ & $\mathrm{C} 2$ & $\mathrm{C} 3$ & $\mathrm{C} 4$ & $\mathrm{C5}$ \\
\hline $\begin{array}{c}\text { IMPORTANCE } \\
\text { NO. } \\
\end{array}$ & & & & 10 & & & & & & 10 & \\
\hline STATUS & \multicolumn{11}{|c|}{ FUNDED . RFP/PRDA } \\
\hline
\end{tabular}

\section{IV-F. System Studies}

Analyze solar heating and combined solar heating and cooling systems. Identify performance and cost characteristics for variations in system configuration, climatic zone, building type, auxiliary and back-up energy type cost structure, and control strategy. Determine the best system configurations for each climatic zone and calculate the sensitivity of system cost and performance to changes in system parameters or design. These studies should be performed for each path.

Each path will require an initial system study based on the best available mathematical model and a second study based on the final, validated simulation. Twenty tasks, then, will be required, the first ten for the initial studies of each path (IV-F-1 to IV-F-10) and the second ten for the final studies (IV-F-11 to IV-F-20).

The system studies will provide all of the following:

- A definition of system requirements;

- Identification of desirable components and component characteristics;

- A calculation of the percentage of energy supplied by the sun for heating and cooling in various climatic zones;

- The sensitivity of solar load to various system parameters;

- A comparison of life cycle costs and savings for solar energy and conventional systems;

- Summaries of all of these results in appropriate forms (reports, charts, handbooks, etc.); and

- Identification of important components. 
These tasks have been funded in FY77 covered by RFP EG-77-R-04-0023.

Tasks IV-F-21 to IV-F-26 are systems studies for agricultural and industrial process heat. For each . these tasks, computer simulation models will be developed incorporating the essential component ar climatic parameters characterizing these systems. These models will be tested and validated by comparing their performance prediction with available experimental data. Life-cycle cost parameters and cost optimization will be incorporated.

IV-F-21. Conduct a thermal modeling/simulation system study of greenhouse and animal shelter heating. Define requirements and support the development for situations where there is likelihood that solar energy can contribute appreciably to heat requirements.

\begin{tabular}{|c|c|c|c|c|c|c|c|c|c|c|c|}
\hline \multirow[t]{2}{*}{ PATH } & \multicolumn{3}{|c|}{$\begin{array}{l}\text { SHELTER } \\
\text { HEATING }\end{array}$} & \multicolumn{3}{|c|}{ DRYING } & \multicolumn{2}{|c|}{$\begin{array}{l}\text { PROCESS } \\
\text { HOT WATER }\end{array}$} & \multirow{2}{*}{$\begin{array}{c}\text { PROCESS } \\
\text { STEAM } \\
\text { SL }\end{array}$} & \multicolumn{2}{|c|}{$\begin{array}{l}\text { COOLINGI } \\
\text { REFRIG- } \\
\text { ERATION }\end{array}$} \\
\hline & HP & $\mathrm{HA}$ & HL & $\mathrm{DD}$ & DA & $\mathrm{DL}$ & WL & WA & & $\mathrm{CP}$ & $\mathrm{CA}$ \\
\hline IMPORTANCE NO. & 8 & 6 & 6 & & & & & & & & \\
\hline STATUS & & & & & & & & & & & \\
\hline
\end{tabular}

IV-F-22. Conduct a system study for applications of solar drying and concentrating techniques to food processing and preservation. Review and develop unconventional product or process changes to adapt food processes to more effectively use solar energy sources. Develop creative and innovative approaches to using direct solar energy in food processes and on food products for drying or concentrating. Determine temperature-humidity-time requirements for drying or concentrating food products as a function of type of product, geographic location, seasonal climatic conditions, and effects on product nutrients, flavor, texture, and consumer acceptability. Evaluate availability and contribution to operating costs of electricity for auxiliary fan power in solar energy systems. Study optional or alternative functions for solar heat and analyze reliability requirements and augmentation potential from more conventional energy sources.

\begin{tabular}{|c|c|c|c|c|c|c|c|c|c|c|c|}
\hline \multirow[t]{2}{*}{ PATH } & \multicolumn{3}{|c|}{$\begin{array}{l}\text { SHELTER } \\
\text { HEATING }\end{array}$} & \multicolumn{3}{|c|}{ DRYING } & \multicolumn{2}{|c|}{$\begin{array}{l}\text { PROCESS } \\
\text { HOT WATER }\end{array}$} & \multirow{2}{*}{$\begin{array}{c}\text { PROCESS } \\
\text { STEAM } \\
\text { SL }\end{array}$} & \multicolumn{2}{|c|}{$\begin{array}{l}\text { COOLING/ } \\
\text { REFRIG- } \\
\text { ERATION }\end{array}$} \\
\hline & $H P$ & HA & $H L$ & DD & DA & DL & WL & WA & & $\mathrm{CP}$ & $\mathrm{CA}$ \\
\hline IMPORTANCE NO. & & & & 10 & 10 & 10 & & & & & \\
\hline STATUS & & & & & & & & & & & \\
\hline
\end{tabular}


IV-F-23. Conduct system studies for agricultural and industrial hot water up to $120^{\circ} \mathrm{C}\left(250^{\circ} \mathrm{F}\right)$. Identify users, requirements, and cost constraints. Support the development of system components. Consider series vs. arallel vs. series/parallel or parallel/series connections of collectors. Examine piping, plumbing, insulation, alves, and control strategy optimization.

\begin{tabular}{|c|c|c|c|c|c|c|c|c|c|c|c|}
\hline \multirow[t]{2}{*}{ PATH } & \multicolumn{3}{|c|}{$\begin{array}{l}\text { SHELTER } \\
\text { HEATING }\end{array}$} & \multicolumn{3}{|c|}{ DRYING } & \multicolumn{2}{|c|}{$\begin{array}{l}\text { PROCESS } \\
\text { HOT WATER }\end{array}$} & \multirow{2}{*}{$\begin{array}{c}\text { PROCESS } \\
\text { STEAM } \\
\text { SL } \\
\end{array}$} & \multicolumn{2}{|c|}{$\begin{array}{l}\text { COOLING/ } \\
\text { REFRIG- } \\
\text { ERATION }\end{array}$} \\
\hline & HP & HA & $H L$ & DD & DA & DL & WL & WA & & $\mathrm{CP}$ & CA \\
\hline IMPORTANCE NO. & & & 7 & & & 6 & 9 & & & & 6 \\
\hline STATUS & & & & & & & & & & & \\
\hline
\end{tabular}

IV-F-24. Conduct a system study for agricultural and industrial process steam. Identify users, requirements, cost constraints. Isolate possible applications for solar process steam which appear particularly promising in terms of overall demand, steam temperatures required, geographical location, product worth relative to energy consumption, and ease of integrating a solar collector system into the already existing steam system.

\begin{tabular}{|c|c|c|c|c|c|c|c|c|c|c|c|}
\hline \multirow[t]{2}{*}{ PATH } & \multicolumn{3}{|c|}{$\begin{array}{l}\text { SHELTER } \\
\text { HEATING }\end{array}$} & \multicolumn{3}{|c|}{ DRYING } & \multicolumn{2}{|c|}{$\begin{array}{l}\text { PROCESS } \\
\text { HOT WATER }\end{array}$} & \multirow{2}{*}{$\begin{array}{c}\text { PROCESS } \\
\text { STEAM } \\
\text { SL } \\
\end{array}$} & \multicolumn{2}{|c|}{$\begin{array}{l}\text { COOLING/ } \\
\text { REFRIG- } \\
\text { ERATION }\end{array}$} \\
\hline & HP & HA & $\mathrm{HL}$ & DD & DA & $\mathrm{DL}$ & WL & WA & & $\mathrm{CP}$ & $\mathrm{CA}$ \\
\hline IMPORTANCE NO. & & & & & & & & & 9 & & \\
\hline STATUS & \multicolumn{11}{|c|}{ FEDERAL LAB } \\
\hline
\end{tabular}

IV-F-25. Conduct a system study for agricultural and industrial cooling and refrigeration. Establish requirements and economic worth for various products and various climate zones. Isolate possible applications for solar cooling which appear promising in terms of demand, temperature range and tolerances, geographical location, and ease of integrating into an already existing structure.

\begin{tabular}{|c|c|c|c|c|c|c|c|c|c|c|c|}
\hline \multirow[t]{2}{*}{ PATH } & \multicolumn{3}{|c|}{$\begin{array}{l}\text { SHELTER } \\
\text { HEATING }\end{array}$} & \multicolumn{3}{|c|}{ DRYING } & \multicolumn{2}{|c|}{$\begin{array}{l}\text { PROCESS } \\
\text { HOT WATER }\end{array}$} & \multirow{2}{*}{$\begin{array}{c}\text { PROCESS } \\
\text { STEAM } \\
\text { SL } \\
\end{array}$} & \multicolumn{2}{|c|}{$\begin{array}{l}\text { COOLING/ } \\
\text { REFRIG- } \\
\text { ERATION }\end{array}$} \\
\hline & HP & HA & HL & DD & DA & DL & WL & WA & & $\mathrm{CP}$ & CA \\
\hline IMPORTANCE NO. & & & & & & & & & & 10 & 10 \\
\hline STATUS & & & & & & & & & & & \\
\hline
\end{tabular}


IV-F-26. Conductan engineering study of the structural components of large scale solar agricultural or industrial process heat systems. Examine ways of reducing the mass and cost of the structural components. Consider the requirements placed on ground-based and also on roof-based structures. Design cost-effectiv structures for the mounting of the more conventional types of flat plate and concentrating collectors. Ex . amine possible low cost materials which can be used for those structures.

\begin{tabular}{|c|c|c|c|c|c|c|c|c|c|c|c|}
\hline \multirow[t]{2}{*}{ PATH } & \multicolumn{3}{|c|}{$\begin{array}{l}\text { SHELTER } \\
\text { HEATING }\end{array}$} & \multicolumn{3}{|c|}{ DRYING } & \multicolumn{2}{|c|}{$\begin{array}{l}\text { PROCESS } \\
\text { HOT WATER }\end{array}$} & \multirow{2}{*}{$\begin{array}{c}\text { PROCESS } \\
\text { STEAM } \\
\text { SL. } \\
\end{array}$} & \multicolumn{2}{|c|}{$\begin{array}{l}\text { COOLING/ } \\
\text { REFRIG- } \\
\text { ERATION }\end{array}$} \\
\hline & HP & HA & $\mathrm{HL}$ & DD & DA & DL & WL & WA & & $\mathrm{CP}$ & CA \\
\hline IMPORTANCE NO. & & 10 & 10 & 10 & 10 & 10 & 10 & 10 & 10 & 10 & 10 \\
\hline STATUS & & & & & & & & & & & \\
\hline
\end{tabular}

IV-F-27. Develop agricultural and industrial process heat modeling and simulation capabilities comparable to those available for buildings.

\begin{tabular}{|c|c|c|c|c|c|c|c|c|c|c|c|}
\hline \multirow[t]{2}{*}{ PATH } & \multicolumn{3}{|c|}{$\begin{array}{l}\text { SHELTER } \\
\text { HEATING }\end{array}$} & \multicolumn{3}{|c|}{ DRYING } & \multicolumn{2}{|c|}{$\begin{array}{l}\text { PROCESS } \\
\text { HOT WATER }\end{array}$} & \multirow{2}{*}{$\begin{array}{c}\text { PROCESS } \\
\text { STEAM } \\
\text { SL }\end{array}$} & \multicolumn{2}{|c|}{$\begin{array}{l}\text { COOLINGI } \\
\text { REFRIG- } \\
\text { ERATION }\end{array}$} \\
\hline & $\mathrm{HP}$ & HA & $\mathrm{HL}$ & DD & DA & $\mathrm{DL}$ & WL & WA & & $\mathrm{CP}$ & CA \\
\hline IMPORTANCE NO. & 10 & 10 & 10 & 10 & 10 & 10 & $10^{\circ}$ & 10 & 10 & 10 & 10 \\
\hline STATUS & & & & & . & & & & & & \\
\hline
\end{tabular}

\section{IV-G. Test Procedures}

IV-G-1. Conduct an advanced systems testing program for all 11 heating and cooling paths to collect performance data and data for model validation.

\begin{tabular}{|c|c|c|c|c|c|c|c|c|c|c|c|}
\hline \multirow[t]{2}{*}{ PATH } & \multicolumn{2}{|c|}{$\begin{array}{l}\text { SERVICE } \\
\text { HOT WATER }\end{array}$} & \multicolumn{4}{|c|}{ SPACE HEATING } & \multicolumn{5}{|c|}{ SPACE COOLING } \\
\hline & $w_{1}$ & w2 & $\mathrm{H} 1$ & $\mathrm{H} 2$ & $\mathrm{H3}$ & $\mathrm{H} 4$ & C1 & $\mathrm{C} 2$ & $\mathrm{C} 3$ & $\mathrm{C4}$ & $\mathrm{C5}$ \\
\hline $\begin{array}{c}\text { IMPORTANCE } \\
\text { NO. }\end{array}$ & 9 & 9 & 9 & 9 & 9 & 9 & 9. & 9 & 9 & 9 & 9 \\
\hline
\end{tabular}


IV-C-2. Identify cost-effective generic system types to be tested in an advanced system testing program.

\begin{tabular}{|c|c|c|c|c|c|c|c|c|c|c|c|}
\hline \multirow[t]{2}{*}{ PATH } & \multicolumn{2}{|c|}{$\begin{array}{c}\text { SERVICE } \\
\text { HOT WATER }\end{array}$} & \multicolumn{4}{|c|}{ SPACE HEATING } & \multicolumn{5}{|c|}{ SPACE COOLING } \\
\hline & $w_{1}$ & W2 & $H 1$ & $\mathrm{H} 2$ & $\mathrm{H3}$ & $\mathrm{H} 4$ & $\mathrm{C1}$ & $\mathrm{C} 2$ & $\mathrm{C} 3$ & $\mathrm{C} 4$ & $\mathrm{C5}$ \\
\hline $\begin{array}{c}\text { IMPORTANCE } \\
\text { NO. }\end{array}$ & 10 & 10 & $\ddot{10}$ & 10 & 10 & 10 & 10 & 10 & 10 & 10 & 10 \\
\hline STATUS & & & & & & & & & & & \\
\hline
\end{tabular}

IV-G-3. Condúct an advanced systems testing program for all 11 agricultural and industrial process heat paths to collect performance data and data for model validation.

\begin{tabular}{|c|c|c|c|c|c|c|c|c|c|c|c|}
\hline \multirow[t]{2}{*}{ PATH } & \multicolumn{3}{|c|}{$\begin{array}{l}\text { SHELTER } \\
\text { HEATING }\end{array}$} & \multicolumn{3}{|c|}{ DRYING } & \multicolumn{2}{|c|}{$\begin{array}{l}\text { PROCESS } \\
\text { HOT WATER }\end{array}$} & \multirow{2}{*}{$\begin{array}{c}\text { PROCESS } \\
\text { STEAM } \\
\text { SL } \\
\end{array}$} & \multicolumn{2}{|c|}{$\begin{array}{l}\text { COOLING/ } \\
\text { REFRIG- } \\
\text { ERATION }\end{array}$} \\
\hline & HP & HA & HL & $D D$ & DA & $\mathrm{DL}$ & WL & WA & & $\mathrm{CP}$ & $\mathrm{CA}$ \\
\hline IMPORTANCE NO. & 9 & 9 & 9 & 9 & 9 & 9 & 9 & 9 & 9 & 9 & 9 \\
\hline
\end{tabular}

IV-G-4. Identify cost-effective generic system types to be tested in an advanced system testing program for all paths.

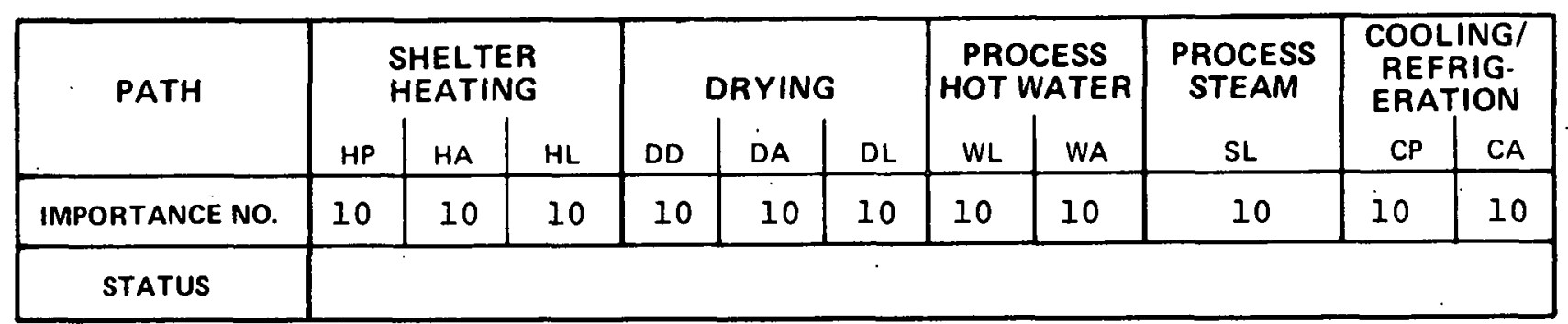


IV-G-5. Develop advanced system testing procedures and reporting format for testing systems and subsystems for detailed performance evaluation and validation of models.

\begin{tabular}{|c|c|c|c|c|c|c|c|c|c|c|c|}
\hline \multirow[t]{2}{*}{ PATH } & \multicolumn{2}{|c|}{$\begin{array}{l}\text { SERVICE } \\
\text { HOT WATER }\end{array}$} & \multicolumn{4}{|c|}{ SPACE HEATING } & \multicolumn{5}{|c|}{ SPACE COOLING } \\
\hline & w1 & W2 & H1 & $\mathrm{H}_{2}$ & H3 & $\mathrm{H} 4$ & $\mathrm{C} 1$ & $\mathrm{C} 2$ & C3 & $\mathrm{C4}$ & $\mathrm{C5}$ \\
\hline $\begin{array}{l}\text { IMPORTANCE } \\
\text { NO. }\end{array}$ & 9 & 9 & 9 & 9 & 9 & 9 & 9 & 9 & 9 & 9 & 9 \\
\hline STATUS & $F$ & $D$ & & & & & & & & & \\
\hline
\end{tabular}

\begin{tabular}{|c|c|c|c|c|c|c|c|c|c|c|c|}
\hline \multirow[t]{2}{*}{ PATH } & \multicolumn{3}{|c|}{$\begin{array}{l}\text { SHELTER } \\
\text { HEATING }\end{array}$} & \multicolumn{3}{|c|}{ DRYING } & \multicolumn{2}{|c|}{$\begin{array}{l}\text { PROCESS } \\
\text { HOT WATER }\end{array}$} & \multirow{2}{*}{$\begin{array}{c}\text { PROCESS } \\
\text { STEAM } \\
\text { SL } \\
\end{array}$} & \multicolumn{2}{|c|}{$\begin{array}{c}\text { COOLING/ } \\
\text { REFRIG- } \\
\text { ERATION }\end{array}$} \\
\hline & HP & HA & $\mathrm{H}^{\prime}$ & $\mathrm{DD}$ & DA & $\mathrm{DL}$ & WL & WA & & $\mathrm{CP}$ & $\mathrm{CA}$ \\
\hline IMPORTANCE NO. & 9 & 9 & 9 & 9 & 9 & 9 & 9 & 9 & 9 & 9 & 9 \\
\hline STATÚS & & & & & & & & & & & \\
\hline
\end{tabular}




\section{Non-Engineering Aspects}

\section{OBJECTIVE}

The objective of the non-engineering tasks is the analysis of the economic, institutional, and social environments in which solar heating and cooling technology will be used. This includes a study of consumer behavior and a definition of the infrastructure for delivering solar technology. Providing this information will help make possible the more rapid development and commercialization of that technology.

\section{EMPHASIS}

The program emphăsizes the following points:

- The collection and dissemination of information on economics, legislation, market structures, etc.

- An analysis of DOE actions and policies to determine the impact on the commercialization of solar technology.

- Research on factors affecting consumer acceptance of solar energy systems and on means of increasing that acceptance.

\section{TASKS}

\section{V-A. Economic and Financial Analysis}

V-A-1. Collect, analyze, adjust if necessary, and distribute data on costs of production, installation, maintenance, depreciation, repair, and replacement of solar heating and cooling systems. Compare actual costs with cost estimates. Cooperate with FEA, FPC, and other agencies in determining auxiliary energy costs. Study the resale value to homes having solar energy systems; include interest rates and taxes paid by owners. Identify high cost items as targets for R\&D efforts.

V-A-2. Develop a standard method for analyzing life cycle costs for solar heating and cooling systems and provide a manual based on that method. Develop separate models for residential and commercial/industrial applications. Include treatment of variable electricity rate structures and property resale values. Prepare economic analysis models that are flexible enough to accommodate varying assumptions on fuel price escalation, inflation, interest rates, etc.

V-A-3. Develop a simplified user's version of the life cycle cost manual called for in Task V-A-2. Manuals should be written for at least three levels of expertise: building owner (consumer), builder/contractor, and architect/engineer. These manuals should enable a potential user to calculate life cycle costs for the solar energy system being considered and to compare those costs with costs for standard gas, oil, or electric systems.

$\mathrm{V}-\mathrm{A}-4$. Study the effect on costs to the consumer of various rate schedules for auxiliary energy (electricity, gas, fuel oil, or LPG). Calculate savings to consumer for systems controlled to use only off-peak electricity under various pricing schemes (time of day pricing, marginal cost pricing, etc.).

V-A-5. Collect data on skilled manpower and material requirements for production, installation, maintenance, and replacement of solar energy systems; and identify current and potential resources for meeting each type of requirement. Identify possible labor or materials shortages that might slow the rate of adoption of solar energy systems. Estimate the total impact of such shortages. Compare current supplies of - - ch with demand, allowing for competing uses of the same resources. Estimate direct and indirect capital 
requirements for solar and conventional energy systems, and indicate how these will be likely to change during the next ten years.

V-A-6. Develop models for evaluating the effect of various incentive policies on market penetration, foss.. fuel savings, etc. Use the models to determine the combinations of incentives that are most effective.

V-A-7. Study the economic incentives that have been granted to the fossil fuel and nuclear energy industries. Both industries have benefitted from subsidies for production and distribution, and recommendations for solar energy incentives should be based in part on an analysis of the support provided to these competing energy programs.

V-A-8. Investigate the capital budgeting requirements of agricultural and industrial process heat systems. Compare overall cost effectiveness of various types of solar energy systems: liquid systems vs. air systems, solar ponds vs. conventional flat-plate collectors, concentrating collectors vs. advanced non-concentrating collectors. Consider minimum required rate of return on solar investment, payback period, effect of different possible government economic incentives, etc. Perform a sensitivity analysis, varying all important system economic factors. Take into account whenever possible such intangible factors as social and environmental impact.

\section{V-B. Consumer Attitudes and Behavior}

V-B-1. Identify the considerations that influence decisions to purchase or lease a solar energy system. Study the importance of first cost, life cycle cost, lease or lease/purchase contracts, and expected increases in fuel costs. Determine the factors that particularly influence home owners, home buyers, contractors, and builders.

V-B-2. Analyze consumer incentive programs, either actual or planned, to determine their effect on consumer decisions to purchase. Evaluate the cost of such programs to governments (Federal, state, and local). Determine whether the incentive programs have a progressive or regressive effect on the redistribution of benefits.

V-B-3. Study the purchase of solar heating and cooling systems in the commercial sector, including the factors that govern purchase decisions. Determine the pay-back period required in various markets and identify other relevant accounting practices, including the effect of tax regulations. Describe changes in accounting procedures that would encourage life cycle costing in industry.

V-B-4. Evaluate consumer attitudes to passive direct solar energy systems, including devices that require active intervention by the resident (moving insulating panels at night, etc.). Assess consumer willingness to accept temperature swings. Compare consumer attitudes in this area with consumer reaction to other energy conservation measures.

V-B-5. Synthesize information on environmental parameters that affect human comfort-e.g., IR flux - and present it in a useful form. The information will be required for the design of structures that employ passive heating and cooling techniques. The information should include data on the comfort provided by cooling and air movement without dehumidification.

\section{V-C. Marketing, Architecture, and Construction}

$\mathrm{V}-\mathrm{C}-1$. Synthesize information on building industry experience with data on technology transfer, commercialization, and market diffusion. Identify factors that have slowed or prevented building technology innovations as well as factors that have accelerated the adoption of such innovations.

$\mathrm{V}-\mathrm{C}-2$. Define promising markets and marketing techniques for solar energy systems for buildings. Compare centralized mass production with local production and determine if economies of scale are likely. Compare the do-it-yourself and turn-key markets and recommend R\&D priorities.

V-C-3. Develop models of alternative ownership arrangements for solar heating and cooling systems (such as co-ops, municipalities, or corporations). Assess the economics of such arrangements, especially the cost of 
delivered energy to the consumer. Investigate the regulatory and legal (especially anti-trust) aspects of such arrangements.

-C-4. Sponsor competitions for the design of passive solar energy systems and for the integration of active systems into building structures. Competitions should be held for a variety of climates and building types, including single- and multi-family, residences, schools, and commercial and office buildings. Publish the winning designs.

$\mathrm{V}-\mathrm{C}-5$. Hold meetings for distributing information to producers and distributors of solar energy and other HVAC equipment, architects, and contractors. Examine the possibility of establishing centers for distributing this information.

$\mathrm{V}-\mathrm{C}-6$. Prepare background material for defining performance rating and warranty criteria for solar heating and cooling equipment. Evaluate public and private methods for providing protection to users and determine the effects of such methods on the industry.

$\mathrm{V}-\mathrm{C}-7$. Investigate the relationships and trade-offs between solar energy systems and energy conservation practices. Determine how changes in the energy conservation features of buildings will affect energy system design, cost, marketability, etc.

$\mathrm{V}-\mathrm{C}-8$. Determine the proper role of DOE and other Federal agencies in advancing the marketability and commercial use of solar energy systems. Evaluate the past efforts of the Federal Government in this area (e.g., Project Breakthrough).

\section{V-D. Utility Interface}

V-D-1. Predict the impact of solar energy systems on electric utility load curves. Make evaluations with and without controls on the time of day that the auxiliary energy is used. Assess the impact on distribution systems of peak load conditions in a highly solar community.

V-D-2. Determine the effect of various rate schedules (including time of day pricing) on the accourits of utility customers, both those having solar energy systems and those without such systems: Evaluate the impact of utility rate structures (marginal cost, actual cost, two-part tariff, etc.) on market penetration.

V-D-3. Examine the legality of ownership by utilities of solar energy heating and cooling equipment. Include the question of exclusive franchise. Survey the policies and trends in policy of state utility regulatory commissions.

V-D-4. Assess the effect on utility accounts of ownership by the utilities of solar energy equipment. Discuss the option of the utility including the solar equipment in its rate base. Examine various depreciation allowances and the feasibility of climate maintenance agreements.

V-D-5. Investigate possible incentives for utility involvement, including utility ownership of solar energy equipment. Consider the cost to governments of incentive programs (for example, through lost tax revenue), and the probable impact on the market for solar heating and cooling.

V-D-6. Examine the desirability of home controlled, auxiliary storage of domestic heated/cooled water, and compare its advantages with utility controlled storage. Analyze the impact of interruptible power contracts on market penetration.

\section{V-E. Legal, Regulatory, and Legislative Considerations}

V-E-1. Determine whether the uses proposed for solar energy systems conflict with standard building, health, and safety codes. Consult with building inspectors if code interpretations become necessary. Where conflicts exist, suggest code modifications that allow the systems to be used while protecting builders and consumers. Consider both active and passive systems and various auxiliary energy sources. 
$\mathrm{V}-\mathrm{E}-2$. Analyze the doctrine of regulated monopoly and equal protection arguments as they pertain to utility rate structures for solar and non-solar consumers of energy.

V-E-3. Develop a model definition of the term "solar" for use in legislation pertaining to the application . solar energy in buildings. The definition must provide for passive energy systems and other innovative approaches.

V-E-4. Prepare model laws for the allocation of sun rights. Include options for allocation by first use (as in western water law) and for purchase of adjacent development rights.

V-E-5. Investigate Federal anti-trust laws for their impact on solar energy applications. Emphasize potential problem areas, including the following: typing agreements (a utility leasing solar equipment only to those who use it as a backup system), joint research by corporations on solar equipment, restraint of trade, resale restrictions, refusal to deal, and requirement contracts.

V-E-6. Analyze the impact of land use planning on solar energy development. Determine whether Federal legislation regarding planned unit development is desirable. Study zoning requirements for setbacks, landscaping, height limitations, etc.

\section{V-F. Education and Training}

V-F-1. Develop a comprehensive vocational training program, including seminars for training instructors and preparing courses. Various successful teaching techniques should be examined. The courses offered should be directed to craftsmen, building inspectors, etc.; and they should be given at existing schools or by existing trade associations whenever possible.

V-F-2. Evaluate current programs for training architects and HVAC engineers. Prepare resource material for the programs, including data on active and passive systems and on new and retrofit situations.

\section{V-G. Social and Environmental Considerations}

V-C-1. Investigate city and regional planning practices for their impact on solar energy heating and cooling. Define requirements for special zoning or limitations on development.

V-G-2. Evaluate community attitudes toward solar energy installations, placing emphasis on design aesthetics, impact on land values, and influences on future development of neighborhoods.

$\mathrm{V}-\mathrm{G}-3$. Collect information on materials and components under development in the heating and cooling R\&D program. Determine whether problems exist in the areas of environmental impact and occupational and consumer hazards. Report the existence of such problems to administrators of the R\&D program and help to solve the problems where possible. 
APPENDIX B

Priorities of Non-Engineering Tasks 


\section{THIS PAGE}

\section{WAS INTENTIONALLY LEFT BLANK}


TABLE B-1

PRIORITIES FOR NON-ENGINEERING TASKS

\begin{tabular}{|c|c|c|}
\hline TASK CLASSIFICATION & $:$ & PRIORITY \\
\hline $\begin{array}{l}\text { A. Economic and } \\
\text { Financial Analysis }\end{array}$ & $\begin{array}{l}\text { 1. Economic Data } \\
\text { 2. Cost Analysis } \\
\text { 3. Layman's Costing Manual } \\
\text { 4. Rate Schedule Costs } \\
\text { 5. Resource Limits } \\
\text { 6. Incentive Assessment Modeling } \\
\text { 7. Incentives for Conventional Energy Sources }\end{array}$ & $\begin{array}{l}\text { High } \\
\text { High } \\
\text { High } \\
\text { High } \\
\text { Medium } \\
\text { High } \\
\text { High }\end{array}$ \\
\hline $\begin{array}{l}\text { B. Consumer Attitudes } \\
\text { and Behavior }\end{array}$ & $\begin{array}{l}\text { 1. Residential Decision Factors } \\
\text { 2. Incentive Programs } \\
\text { 3. Commercial Decision Factors } \\
\text { 4. Attitudes toward Passive Systems } \\
\text { 5. Comfort Parameters }\end{array}$ & $\begin{array}{l}\text { High } \\
\text { High } \\
\text { High } \\
\text { Medium } \\
\text { Low }\end{array}$ \\
\hline $\begin{array}{l}\text { C. Marketing, Architecture, } \\
\text { and Construction }\end{array}$ & $\begin{array}{l}\text { 1. Experience in Industry } \\
\text { 2. Promising Markets } \\
\text { 3. Alternative Ownership } \\
\text { 4. Design Competitions } \\
\text { 5. Information Meetings } \\
\text { 6. Performance Warranties } \\
\text { 7. Solar-Conservation Trade-offs } \\
\text { 8. DOE Marketing Role }\end{array}$ & $\begin{array}{l}\text { Medium } \\
\text { High } \\
\text { High } \\
\text { Medium } \\
\text { Medium } \\
\text { High } \\
\text { Medium } \\
\text { Medium }\end{array}$ \\
\hline D. Utility Interface & $\begin{array}{l}\text { 1. Load Curves } \\
\text { 2. Rate Schedules } \\
\text { 3. Legality of Utility Ownership } \\
\text { 4. Economics of Utility Ownership } \\
\text { 5. Incentives to Utilities } \\
\text { 6. Ownership of Auxiliary Storage }\end{array}$ & $\begin{array}{l}\text { High } \\
\text { High } \\
\text { Medium } \\
\text { High } \\
\text { High } \\
\text { Medium }\end{array}$ \\
\hline $\begin{array}{l}\text { E. Legal, Regulatory, } \\
\text { and Legislative } \\
\text { Considerations }\end{array}$ & $\begin{array}{l}\text { 1. Codes and Standards } \\
\text { 2. Legality of Rate Structures } \\
\text { 3. Definition of "Solar" } \\
\text { 4. Sun Rights } \\
\text { 5. Anti-Trust Legislation } \\
\text { 6. Impact of Land Use Planning }\end{array}$ & $\begin{array}{l}\text { High } \\
\text { Low } \\
\text { Medium } \\
\text { High } \\
\text { Medium } \\
\text { Medium }\end{array}$ \\
\hline $\begin{array}{l}\text { F. Education and } \\
\text { Training }\end{array}$ & $\begin{array}{l}\text { 1. Vocational Training Program } \\
\text { 2. Professional Resource Materials }\end{array}$ & $\begin{array}{l}\text { High } \\
\text { Medium }\end{array}$ \\
\hline $\begin{array}{l}\text { G. Social and } \\
\text { Environmental } \\
\text { Considerations }\end{array}$ & $\begin{array}{l}\text { 1. City and Regional Planning } \\
\text { 2. Attitudes and Aesthetics } \\
\text { 3. Hazards }\end{array}$ & $\begin{array}{l}\text { Low } \\
\text { Medium } \\
\text { Low }\end{array}$ \\
\hline
\end{tabular}

